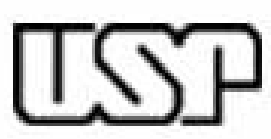

UNIVERSIDADE DE SÃO PAULO

FACULDADE DE CIÊNCIAS FARMACÊUTICAS

Programa de Pós-Graduação em Fármaco e Medicamentos

Área de Insumos Farmacêuticos

\title{
CARBOIDRATOS COMO MATÉRIA-PRIMA PARA A PREPARAÇÃO DE SUBSTRATOS QUIRAIS: APLICAÇÕES EM CATÁLISE ENANTIOSSELETIVA E PROCESSOS DIASTEREOSSELETIVOS
}

Ana Dionéia Wouters

Tese para a obtenção do grau de DOUTOR

Orientador: Prof. Dr. Diogo Seibert Lüdtke

São Paulo, 2013. 
Ficha Catalográfica

Elaborada pela Divisão de Biblioteca e

Documentação do Conjunto das Químicas da USP.

Wouters, Ana Dionéia
Carboidratos como matéria-prima para a preparação de substratos
quirais : aplicações em catálise enantiosseletiva e processos
diastereosseletivos / Ana Dionéia Wouters. -- São Paulo, 2013.
180p.
Tese (doutorado) - Faculdade de Ciências Farmacêuticas da
Universidade de São Paulo. Departamento de Farmácia.
Orientador: Lüdtke, Diogo Seibert
1. Química farmacêutica 2. Fármaco : Síntese : Química
farmacêutica 3. Carboidrato 4. Sintese : Química orgânica I. T. II.
Lüdtke, Diogo Seibert orientador.




\section{ANA DIONÉIA WOUTERS \\ CARBOIDRATOS COMO MATÉRIA-PRIMA PARA A PREPARAÇÃO DE SUBSTRATOS QUIRAIS: APLICAÇÕES EM CATÁLISE ENANTIOSSELETIVA E PROCESSOS DIASTEREOSSELETIVOS}

Comissão julgadora da

Tese para obtenção do grau de Doutor

Prof. Dr.Diogo Seibert Lüdtke

(orientador/presidente)

10. Examinador

2․ Examinador

3․ Examinador

4\%. Examinador

São Paulo, de 
“Os filhos não precisam de pais gigantes, mas de seres humanos que falem a sua linguagem e sejam capazes de penetrar-lhes o coração."

Aos meus pais, Dionei e Olga, e a toda minha grande e fantástica família, os meus mais sinceros agradecimentos por todo amor, carinho e compreensão. A vocês eu dedico esta Tese.

À família Tonin, agradeço pelo imenso carinho e amor com o qual sempre me receberam em sua casa. O sucesso deste trabalho também pertence a vocês.

"A ausência diminui as paixões medíocres, mas aumenta as grandes. Assim como o vento que apaga as velas, mas atiça as fogueiras."

Um agradecimento mais que especial ao querido Jonatan, que compartilha comigo este sentimento tão precioso que é o amor. 


\section{Agradecimentos}

$\grave{A}$ Deus por sempre iluminar o meu caminho e permitir que pessoas maravilhosas cruzem por ele.

Ao Professor Diogo minha sincera gratidão pela acolhida em seu recémformado grupo na FCF-USP. Obrigada pela confiança depositada em mim e por oferecer muitas oportunidades de crescimento profissional, além de permitir que eu conduzisse o trabalho com muita liberdade. Enfim, gostaria de lhe agradecer imensamente pela amizade, orientação competente, valiosa colaboração na elaboração deste trabalho e crescimento pessoal. À você e à Angélica, sempre tão atenciosos comigo, eu desejo muito sucesso!!!

Ao Professor Ludger Wessjohann e a toda sua equipe do Institut für Pflanzenbiochemie pela acolhida, amizade e orientação. Aos meus queridos amigos Ricardo, Cecília, André, Karina, Martin, Ulrik, Tula, Gustavo, Rafael, Camila, Fernando, Eduard, Daniela e Samuel pela super parceria durante a minha estadia em Halle na Alemanha.

Um agradecimento especial ao Professor Hélio Stefani que em inúmeras ocasiões cedeu espaço em seu laboratório e também seus equipamentos para que eu pudesse conduzir meus experimentos.

Ao Professor Gustavo Trossini pela amizade e pela grande contribuição na elaboração deste trabalho, principalmente no auxílio com os cálculos PM3.

À Professora Sandra Farsky e à Carine pelas contribuições com os ensaios biológicos . 
Aos queridos amigos e colegas de laboratório, agradeço pela ótima convivência e coleguismo: Hugo, Adrieli, Lucas, Felipe, Renato, Camila, Marcela e Ellen. Aos amigos dos laboratórios do Professor Hélio Stefani, da Professora Elisabeth Ferreira, do Professor Leandro Helgueira de Andrade e do Professor João Valdir Comasseto, pelas trocas de conhecimentos, empréstimos de reagentes e materiais $e$ pelos maravilhosos momentos de descontração.

À Dri, sempre muito extrovertida, companheira para altos papos e aprendiz super esforçada do gauchês. Aluna de iniciação científica exemplar, dedicada e muito estudiosa, agradeço imensamente pela sua preciosa amizade e pela contribuição valorosa para o desenvolvimento deste trabalho. Ao Hugo que além de excelente amigo e colega de laboratório, sempre super parceria para um happy hour por aí. $A$ vocês eu desejo todo sucesso e felicidades!!!

À Maria Inês pelo excelente trabalho no laboratório de Ressonância Magnética Nuclear. À Elaine e Jorge da secretaria de pós-graduação da FCF, e à Elisabete e David da secretaria de pós-graduação em fármaco e medicamentos, pela disponibilidade e excelente trabalho.

Aos queridos amigos Patrícia, Bernardo e Joel pela excelente convivência, companheirismo e momentos de descontração inesquecíveis.

Às minhas queridas parceiras para todas as horas: Minéia e Marselle.

Enfim, agradeço a todos que de alguma forma ou de outra contribuíram para a elaboração deste trabalho.

Às entidades financiadoras: CAPES, CNPq e Fapesp. Agradecimento especial a CAPES pela concessão das bolsas do Programa Demanda Social e do Programa de Doutorado com Estágio no Exterior (Fevereiro-setembro/2011). 
(...) Moléculas são moléculas. Os químicos e os engenheiros fazem moléculas novas e transformam as velhas. Outros ainda na cadeia econômica as vendem, e todos nós as queremos e as usamos. Cada um de nós tem um papel no uso e no abuso dos produtos químicos. Eis o que vejo como nossa responsabilidade social de cientistas perante nossos companheiros seres humanos.

Vejo os cientistas como atores em uma tragédia clássica. Eles (nós) são (ou somos) obrigados pela natureza a criar. Não há como evitar a investigação do que está ao nosso redor. Não há como fechar os olhos à criação ou à descoberta. Se você não encontrar essa molécula, algum outro o fará. Ao mesmo tempo, creio que os cientistas têm responsabilidade absoluta de pensar sobre os usos de sua criação, e mesmo nos abusos perpetrados por outros. E devem fazer todo o possível para expor esses perigos e abusos ao público. Se não eu, então quem? Correndo o risco de perder seu meio de vida, de se humilhar, devem viver com as consequências de seus atos. É esse dever que os torna atores de uma tragédia e não heróis cômicos sobre um pedestal. É essa responsabilidade perante a humanidade que os torna humanos. (...)

\section{Roald Hoffmann}

(Prêmio Nobel em Química de 1981) 


\section{Resumo}

O presente trabalho descreve o uso de carboidratos como materiais de partida para a preparação de catalisadores quirais e também de substratos quirais.

Primeiramente estudos envolvendo a aplicação de amino álcoois derivados de carboidratos na arilação assimétrica de aldeídos, usando ácidos arilborônicos como fontes de grupos arila transferíveis, revelaram que um ligante preparado a partir da D-xilose mostrou-se bastante eficiente e conduziu aos produtos em excelentes rendimentos e altos excessos enantioméricos.

Posteriormente a arilação de aldeídos derivados de carboidratos é descrita. Em alguns casos diastereosseletividades maiores que 20:1 foram observadas e a metodologia foi aplicada a síntese total da 7-epi-goniofufurona e análogos. 


\begin{abstract}
The work described herein is centered on the use of carbohydrates as starting materials for the synthesis of chiral ligands and chiral sugar-derivatives.

Initially, chiral amino alcohols were studied as ligands for the asymmetric arylation of aldehydes using aryl boronic acids as the source of transferable aryl groups. We found that a chiral ligand derived from D-xylose was very efficient and the desired products were obtained in excellent yields and enantiomeric excesses.

In addition, the arylation of sugar-based aldehydes was also studied. In many cases, excellent diastereoselectivities of $>20: 1$ were achieved and the methodology was employed in the total synthesis of 7-epi-goniofufurone and analogues
\end{abstract}




\section{SUMÁRIO}

RESUMO vii

ABSTRACT viii

LISTA DE FIGURAS xi

LISTA DE ESQUEMAS $\quad$ XV

LISTA DE TABELAS Xvi

LISTA DE ABREVIATURAS E SIGLAS Xvii

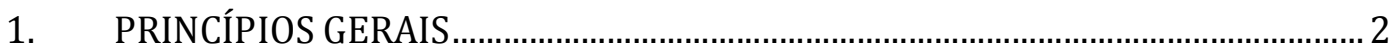

1.1. Sobre a importância da quiralidade..................................................................... 2

1.2. A importância de carboidratos neste contexto ....................................................... 4

1.3. Adição estereosseletiva de reagentes organozinco ............................................ 6

CAPÍTULO 1. Arilação assimétrica de aldeídos catalisada por amino álcoois

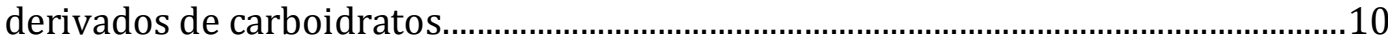

3.1. Preparação dos ligantes derivados da $D$-Glucosamina ........................................16

3.2. Arilação assimétrica na presença dos ligantes 4a-c............................................18

3.3. Preparação dos ligantes derivados da $D$-Xilose ................................................20

3.4. Arilação assimétrica na presença dos ligantes 10a-c ...........................................23

CAPÍTULO 2. Carboidratos como substratos quirais em adições de reagentes

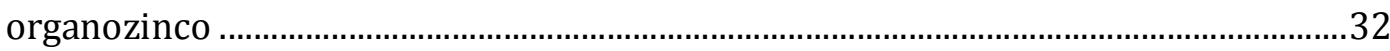

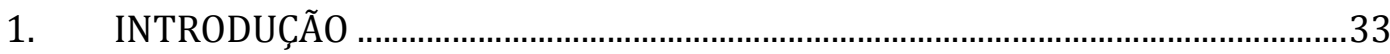

1.1. Goniofufurona, 7-Epi-Goniofufurona e derivados .................................................35

2. JUSTIFICATIVA E OBJETIVOS PROPOSTOS ...........................................................43

3. APRESENTAÇÃO E DISCUSSÃO DOS RESULTADOS OBTIDOS...........................44

3.1. Síntese dos aldeídos derivados de carboidratos....................................................44

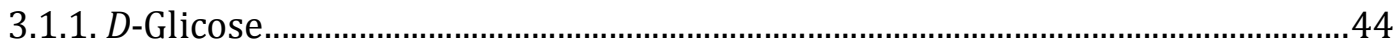

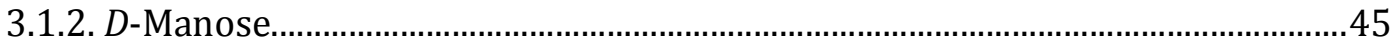

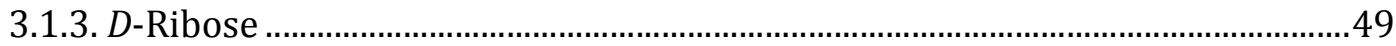

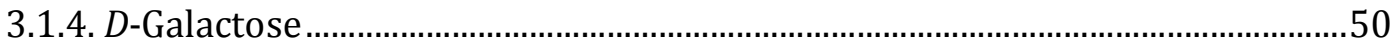

3.2. Adição de reagentes arilzinco a aldeídos derivados de carboidratos...............51

3.2.1. Adição de reagentes arilzinco ao aldeído derivado da $D$-Glicose: ......................51

3.2.2. Adição de reagentes arilzinco ao aldeído derivado da $D$-Manose.......................56

3.2.3. Adição de reagentes arilzinco ao aldeído derivado da $D$-Ribose .......................62 
3.2.4. Adição de reagentes arilzinco ao aldeído derivado da $D$-galactose...................65

3.2.5. Síntese da Epi-Goniofufurona e derivados a partir dos intermediários $31 \ldots . . .67$

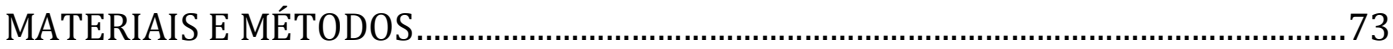

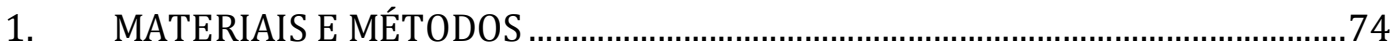

1.1. Métodos de Identificação e Determinação de Pureza..........................................74

1.1.1. Espectroscopia de Ressonância Magnética Nuclear (RMN) ……………........74

1.1.2. Cromatografia Líquida de Alta Eficiência................................................................ 74

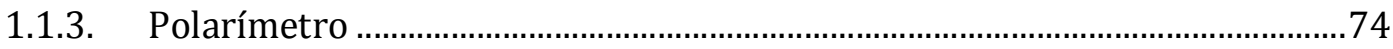

1.1.4. Espectrometria de Massas de Alta Resolução.........................................................75

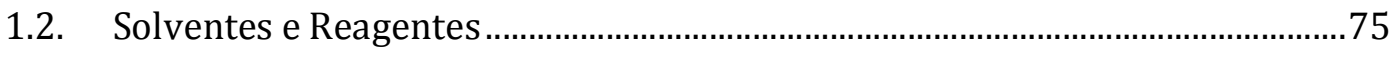

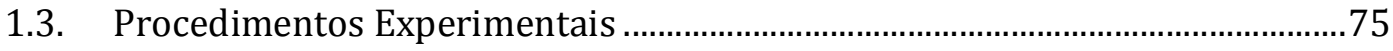

1.3.3. Procedimento geral para a síntese dos diarilmetanois 6:................................81

1.3.4. Procedimento geral para a síntese do aldeído 30 : ..........................................84

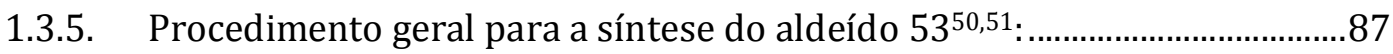

1.3.6. Procedimento geral para a síntese do aldeído $55^{50}$.........................................88

1.3.7. Procedimento geral para a síntese do aldeído 57: ...........................................89

1.3.8. Procedimento geral para a síntese os álcoois 31, 58, 59 e 60:.......................91

1.3.9. Procedimento geral para a síntese da (+)-7-epi-goniofufurona.....................98

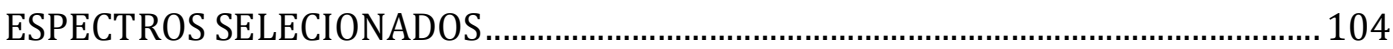




\section{LISTA DE FIGURAS}

Figura 1. Alguns exemplos clássicos da importância da quiralidade............................ 2

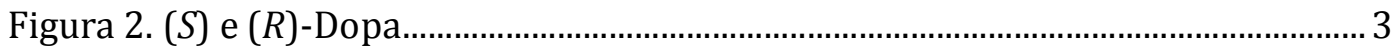

Figura 3. Darvon e Novrad. ….................................................................................... 3

Figura 4. Versatilidade sintética de carboidratos............................................................... 8

Figura 5. Derivados de diarilmetanóis com atividade biológica...................................13

Figura 6. Possibilidade de preparação de ambos enantiômeros. ...................................14

Figura 7. Geometria do estado de transição. 0 orbital preenchido do ânion localizado entre o átomo de zinco e o carbono carbonílico. ..........................................15

Figura 8. Amino álcoois derivados da $D$-Xilose e $D$-Glucosamina selecionados. .......16 Figura 9. Estruturas dos estados de transição determinadas por PM3 para o ligante 10c.

Figura 10. Derivados preparados a partir da $D$-xilose e $D$-Glucosamina. ....................30

Figura 11. Aldeídos derivados dos carboidratos $D$-ribose, $D$-manose, $D$-galactose e

$D$-glicose.

Figura 12. Análise retrossintética da goniofufurona e epi-goniofufurona a partir de aldeído derivado da $D$-Glicose. .35

Figura 13. Alguns compostos identificados a partir de extratos alcoólicos da casca

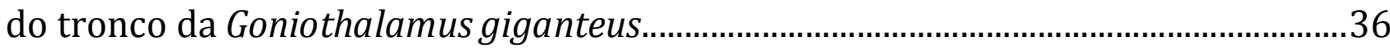

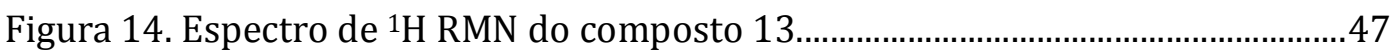

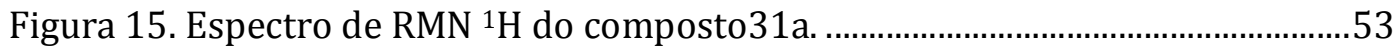

Figura 16. Modelos de adição nucleofílica ao aldeído 30. Modelo quelato 1,2- (A) e

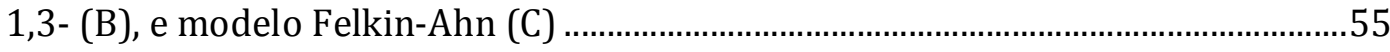

Figura 17. Espectro de $\mathrm{RMN}^{1} \mathrm{H}$ representativo dos derivados obtidos na adição de

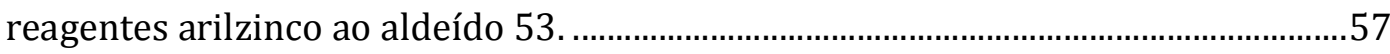

Figura 18. Modelos de adição nucleofílica ao aldeído 53. Modelo quelato 1,2- (A) e

1,3- (B) e respectivos produtos formados.....................................................................58

Figura 19. Ligante 10c utilizado para avaliar variações na diastereosseletividade do

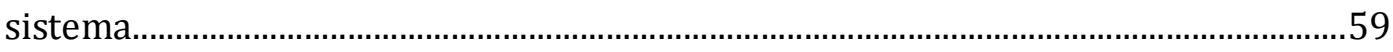

Figura 20. Efeito observado com uso de $20 \mathrm{~mol} \%$ do ligante $5 \mathrm{c}$ na adição de reagentes arilzinco ao aldeído 53.

Figura 21. Efeito observado na adição de quantidade estequiométrica do ligante $5 c$.

Figura 22. Espectro de $\mathrm{RMN}^{1} \mathrm{H}$ do composto 59a. 61

Figura 24. Mecanismo proposto para a formação dos compostos 60 ...........................66

Figura 25. Espectro de ${ }^{1} \mathrm{H}$ RMN do composto 60a. ..........................................................67

Figura 26. Espectro de $\mathrm{RMN}^{13} \mathrm{C}$ da mistura de anômeros do composto 33c. ............68

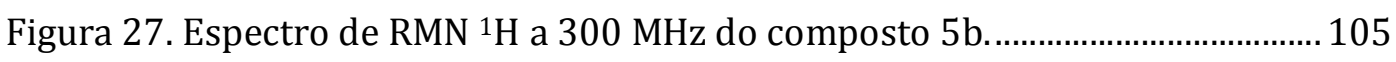

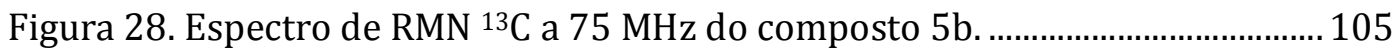

Figura 29. Espectro de $\mathrm{RMN}{ }^{1} \mathrm{H}$ a $300 \mathrm{MHz}$ do composto $5 \mathrm{c}$....................................... 106

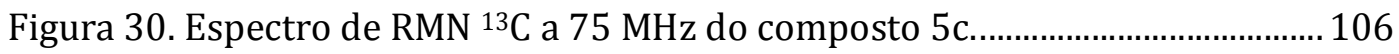


Figura 31. Espectro RMN ${ }^{1} \mathrm{H}$ a $300 \mathrm{MHz}$ do composto10a........................................ 107

Figura 32. Espectro RMN ${ }^{13} \mathrm{C}$ a $75 \mathrm{MHz}$ do composto10a.......................................... 107

Figura 33. Espectro RMN ${ }^{1} \mathrm{H}$ a $300 \mathrm{MHz}$ do composto 10b....................................... 108

Figura 34. Espectro RMN ${ }^{13} \mathrm{Ca} 75 \mathrm{MHz}$ do composto 10b......................................... 108

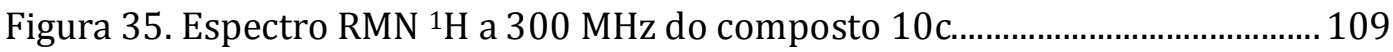

Figura 36. Espectro RMN ${ }^{13} \mathrm{C}$ a $75 \mathrm{MHz}$ do composto $10 \mathrm{c}$..........................................109

Figura 37. Espectro de $\mathrm{RMN}^{1} \mathrm{H}$ a $300 \mathrm{MHz}$ do composto 6 a.......................................... 110

Figura 38. Espectro de RMN ${ }^{13} \mathrm{C}$ a $75 \mathrm{MHz}$ do composto 6a........................................ 110

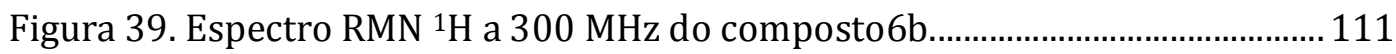

Figura 40. Espectro RMN ${ }^{13} \mathrm{C}$ a $75 \mathrm{MHz}$ do composto6b............................................. 111

Figura 41. Espectro de RMN ${ }^{1} \mathrm{H}$ a $300 \mathrm{MHz}$ do composto $6 \mathrm{c}$.......................................112

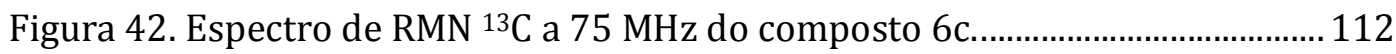

Figura 43. Espectro de RMN ${ }^{1} \mathrm{H}$ a $300 \mathrm{MHz}$ do composto6d....................................... 113

Figura 44. Espectro de $\mathrm{RMN}{ }^{13} \mathrm{C}$ a $75 \mathrm{MHz}$ do composto6d......................................... 113

Figura 45. Espectro de $\mathrm{RMN}^{1} \mathrm{H}$ a $300 \mathrm{MHz}$ do composto 6e.....................................114

Figura 46. Espectro de RMN ${ }^{13} \mathrm{C}$ a $75 \mathrm{MHz}$ do composto 6e...................................... 114

Figura 47. Espectro RMN ${ }^{1} \mathrm{H}$ a $300 \mathrm{MHz}$ do composto 6f......................................... 115

Figura 48. Espectro RMN ${ }^{13} \mathrm{C}$ a $75 \mathrm{MHz}$ do composto $6 \mathrm{f}$.............................................. 115

Figura 49. Espectro de $\mathrm{RMN}^{1} \mathrm{H}$ a $300 \mathrm{MHz}$ do composto $6 \mathrm{~g}$.......................................116

Figura 50. Espectro de $\mathrm{RMN}{ }^{13} \mathrm{C}$ a $75 \mathrm{MHz}$ do composto 6g........................................ 116

Figura 51. Espectro de RMN ${ }^{1} \mathrm{Ha} 300 \mathrm{MHz}$ do composto 6h....................................... 117

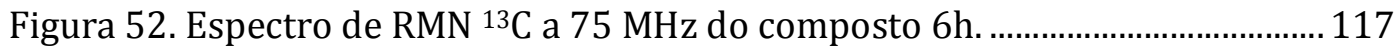

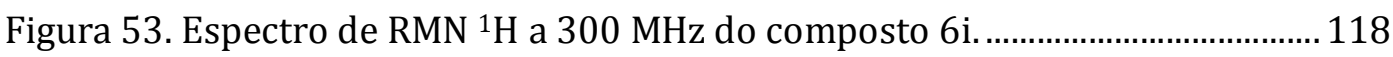

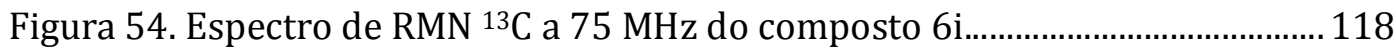

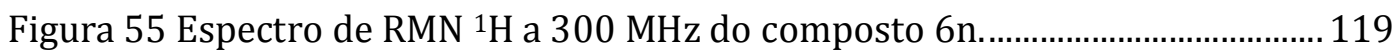

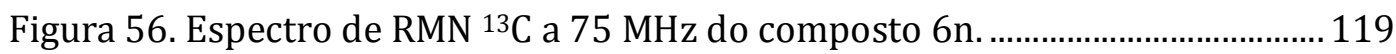

Figura 57. Espectro de RMN ${ }^{1} \mathrm{Ha} 300 \mathrm{MHz}$ do composto $6 \mathrm{~m}$....................................... 120

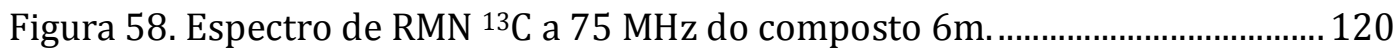

Figura 59. Espectro de $\mathrm{RMN}^{1} \mathrm{H}$ a $300 \mathrm{MHz}$ do composto 48..................................... 121

Figura 60. Espectro de $\mathrm{RMN}{ }^{13} \mathrm{C}$ a $75 \mathrm{MHz}$ do composto 48 ....................................... 121

Figura 61. Espectro de $\mathrm{RMN}^{1} \mathrm{H}$ a $300 \mathrm{MHz}$ do composto 49....................................... 122

Figura 62. Espectro de $\mathrm{RMN}{ }^{13} \mathrm{C}$ a $75 \mathrm{MHz}$ do composto49....................................... 122

Figura 63. Espectro de $\mathrm{RMN}^{1} \mathrm{H}$ a $300 \mathrm{MHz}$ do composto $50 . . . \ldots \ldots \ldots . . . . . . . . . . . . . . . . . . . . . . . .123$

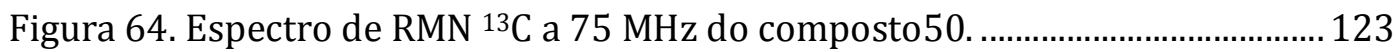

Figura 65. Espectro de $\mathrm{RMN}^{1} \mathrm{H}$ a $300 \mathrm{MHz}$ do composto30..................................... 124

Figura 66. Espectrode RMN ${ }^{13} \mathrm{C}$ a $75 \mathrm{MHz}$ do composto 30.................................... 124

Figura 67. Espectro de RMN ${ }^{1} \mathrm{H}$ a $300 \mathrm{MHz}$ do composto31a..................................... 125

Figura 68. Espectro de RMN ${ }^{13} \mathrm{C}$ a $75 \mathrm{MHz}$ do composto31a.................................... 125

Figura 69. Espectro de $\mathrm{RMN}^{1} \mathrm{H}$ a $300 \mathrm{MHz}$ do composto $31 \mathrm{~b}$................................... 126

Figura 70. Espectro de RMN ${ }^{13} \mathrm{C}$ a 75MHz do composto 31b................................... 126

Figura 71. Espectro de $\mathrm{RMN}^{1} \mathrm{H}$ a $300 \mathrm{MHz}$ do composto 31c.................................... 127

Figura 72. Espectro de $\mathrm{RMN}{ }^{13} \mathrm{C}$ a $75 \mathrm{MHz}$ do composto $31 \mathrm{c}$...................................... 127

Figura 73. Espectro de $\mathrm{RMN}^{1} \mathrm{H}$ a $300 \mathrm{MHz}$ do composto $31 \mathrm{~d}$.................................. 128 
Figura 74. Espectro de $\mathrm{RMN}{ }^{13} \mathrm{C}$ a $75 \mathrm{MHz}$ do composto $31 \mathrm{~d}$...................................... 128

Figura 75. Espectro de $\mathrm{RMN}^{1} \mathrm{H}$ a $300 \mathrm{MHz}$ do composto 31e....................................129

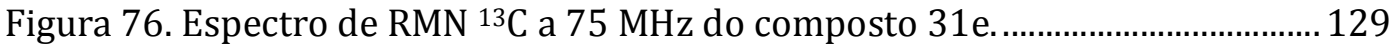

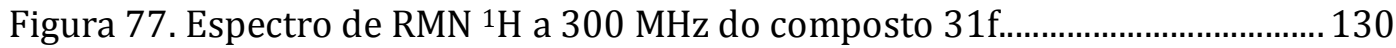

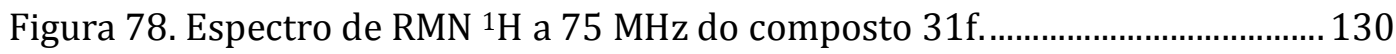

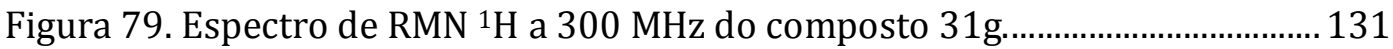

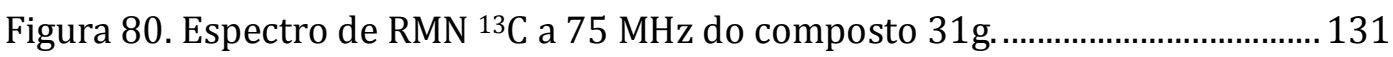

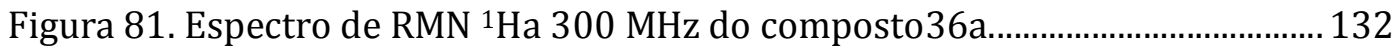

Figura 82. Espectro de $\mathrm{RMN}{ }^{13} \mathrm{C}$ a $75 \mathrm{MHz}$ do composto36a..................................... 132

Figura 83. Espectro de $\mathrm{RMN}{ }^{1} \mathrm{H}$ a $300 \mathrm{MHz}$ do composto 36b................................... 133

Figura 84. Espectro de RMN ${ }^{13} \mathrm{C}$ a $75 \mathrm{MHz}$ do composto 36b..................................... 133

Figura 85. Espectro de $\mathrm{RMN}^{1} \mathrm{H}$ a $300 \mathrm{MHz}$ do composto 36c................................... 134

Figura 86. Espectro de RMN ${ }^{13} \mathrm{C}$ a $75 \mathrm{MHz}$ do composto $36 \mathrm{c}$.................................... 134

Figura 87. Espectro de RMN ${ }^{1} \mathrm{H}$ a $300 \mathrm{MHz}$ do composto36d .................................... 135

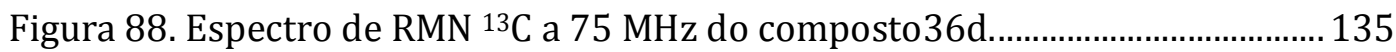

Figura 89. Espectro de $\mathrm{RMN}^{1} \mathrm{H}$ a $300 \mathrm{MHz}$ do composto 36e.................................... 136

Figura 90. Espectro de RMN ${ }^{13} \mathrm{C}$ a $75 \mathrm{MHz}$ do composto 36e................................... 136

Figura 91. Espectro de $\mathrm{RMN}^{1} \mathrm{H}$ a $300 \mathrm{MHz}$ do composto $36 \mathrm{f}$....................................... 137

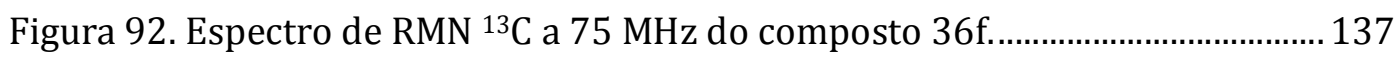

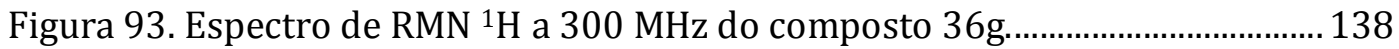

Figura 94. Espectro de $\mathrm{RMN}{ }^{13} \mathrm{C}$ a $75 \mathrm{MHz}$ do composto $36 \mathrm{~g}$.....................................138

Figura 95. Espectro de $\mathrm{RMN}{ }^{1} \mathrm{H}$ a $300 \mathrm{MHz}$ do composto17a..................................... 139

Figura 96. Espectro de $\mathrm{RMN}{ }^{13} \mathrm{C}$ a $75 \mathrm{MHz}$ do composto17a...................................... 139

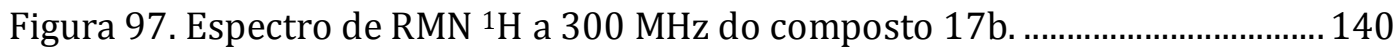

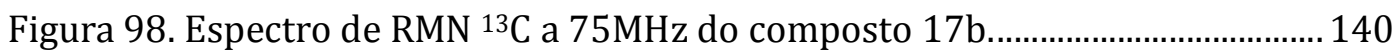

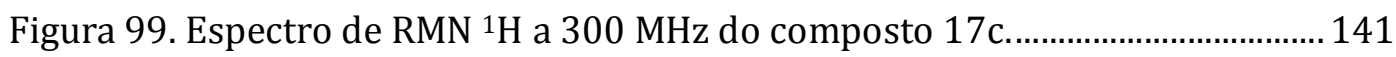

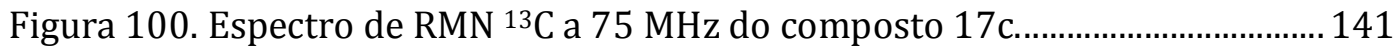

Figura 101. Espectro de $\mathrm{RMN}^{1} \mathrm{H}$ a $300 \mathrm{MHz}$ do composto17d................................. 142

Figura 102. Espectro de RMN ${ }^{13} \mathrm{C}$ a $75 \mathrm{MHz}$ do composto17d.................................. 142

Figura 103. Espectro de $\mathrm{RMN}^{1} \mathrm{H}$ a $300 \mathrm{MHz}$ do composto $17 \mathrm{e}$................................... 143

Figura 104. Espectro de RMN ${ }^{13} \mathrm{C}$ a $75 \mathrm{MHz}$ do composto $17 \mathrm{e}$.................................... 143

Figura 105. Espectro de $\mathrm{RMN}^{1} \mathrm{H}$ a $300 \mathrm{MHz}$ do composto 53................................ 144

Figura 106. Espectro de RMN ${ }^{13} \mathrm{C}$ a $75 \mathrm{MHz}$ do composto 53.................................... 144

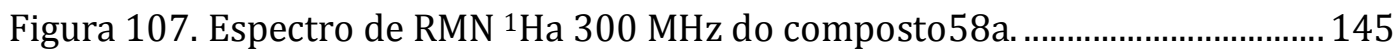

Figura 108. Espectro de RMN ${ }^{13} \mathrm{C}$ a $75 \mathrm{MHz}$ do composto58a................................... 145

Figura 109. Espectro de RMN ${ }^{1} \mathrm{H}$ a $300 \mathrm{MHz}$ do composto 58b................................ 146

Figura 110. Espectro de RMN ${ }^{13} \mathrm{C}$ a $75 \mathrm{MHz}$ do composto 58b.................................. 146

Figura 111. Espectro de RMN ${ }^{1} \mathrm{H}$ a $300 \mathrm{MHz}$ do composto 58c. ................................. 147

Figura 112. Espectro de RMN ${ }^{13} \mathrm{C}$ a $75 \mathrm{MHz}$ do composto 58c................................... 147

Figura 113. Espectro de RMN ${ }^{1} \mathrm{H}$ a $300 \mathrm{MHz}$ do composto58d.................................. 148

Figura 114. Espectro de RMN ${ }^{13} \mathrm{C}$ a $75 \mathrm{MHz}$ do composto58d.................................. 148

Figura 115. Espectro de $\mathrm{RMN}^{1} \mathrm{H}$ a $300 \mathrm{MHz}$ do composto $58 \mathrm{e} . . . . . . . . . . . . . . . . . . . . . . . . . . . . . .149$

Figura 116. Espectro de $\mathrm{RMN}^{1} \mathrm{H}$ a $75 \mathrm{MHz}$ do composto 58e.................................. 149 
Figura 117. Espectro RMN ${ }^{1} \mathrm{H}$ a $300 \mathrm{MHz}$ do composto54....................................... 150

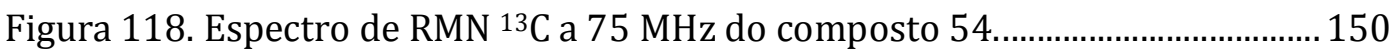

Figura 119. Espectro de RMN ${ }^{1} \mathrm{Ha} 300 \mathrm{MHz}$ do composto55.................................... 151

Figura 120. Espectro RMN ${ }^{1} \mathrm{Ha} 300 \mathrm{MHz}$ do composto59a....................................... 152

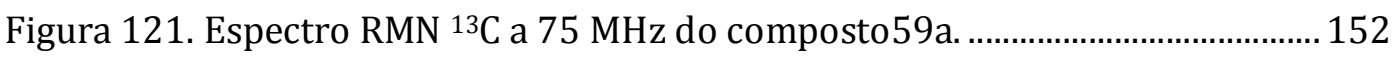

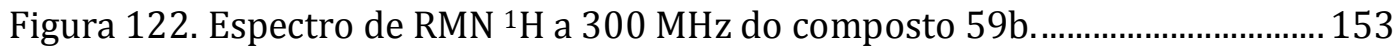

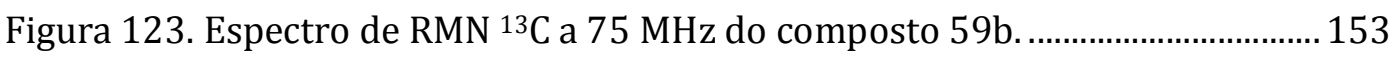

Figura 124. Espectro de RMN ${ }^{1} \mathrm{H}$ a $300 \mathrm{MHz}$ do composto 59c. ................................ 154

Figura 125. Espectro de $\mathrm{RMN}^{13} \mathrm{C}$ a $75 \mathrm{MHz}$ do composto 59c................................... 154

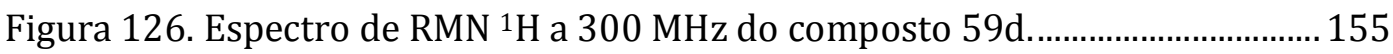

Figura 127. Espectro de RMN ${ }^{13} \mathrm{C}$ a $75 \mathrm{MHz}$ do composto59d.................................. 155

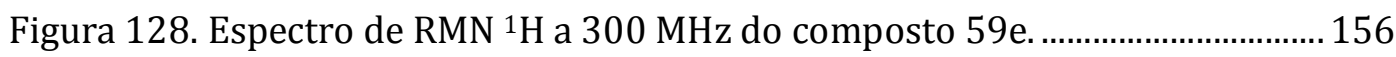

Figura 129. Espectro de $\mathrm{RMN}{ }^{13} \mathrm{C}$ a $75 \mathrm{MHz}$ do composto 59e.................................... 156

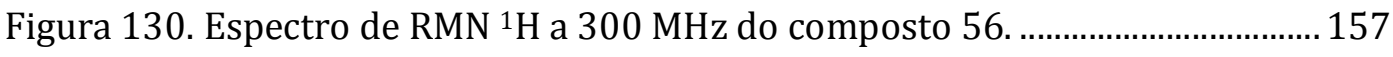

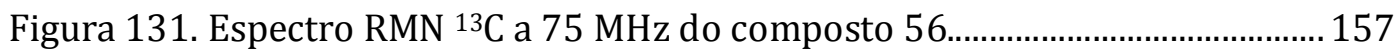

Figura 132. Espectro RMN ${ }^{1} \mathrm{H}$ a $300 \mathrm{MHz}$ do composto 57...................................... 158

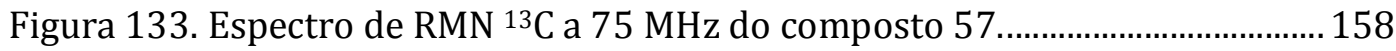

Figura 134. Espectro RMN ${ }^{1} \mathrm{H}$ a $300 \mathrm{MHzd}$ o composto $60 \mathrm{a}$....................................... 159

Figura 135. Espectro RMN ${ }^{13} \mathrm{C}$ a $75 \mathrm{MHz}$ do composto60a......................................... 159

Figura 136. Espectro de RMN ${ }^{1} \mathrm{H}$ a $300 \mathrm{MHz}$ do composto 60b.................................. 160

Figura 137. Espectro de $\mathrm{RMN}^{13} \mathrm{C}$ a $75 \mathrm{MHz}$ do composto $60 \mathrm{~b}$.................................... 160

Figura 138. Espectro de RMN ${ }^{1} \mathrm{H}$ a $300 \mathrm{MHz}$ do composto $60 \mathrm{c} . . . \ldots \ldots \ldots \ldots \ldots . . . . . . . . . . . . . . . . .161$

Figura 139. Espectro de $\mathrm{RMN}^{13} \mathrm{C}$ a $75 \mathrm{MHz}$ do composto $60 \mathrm{c} . . . . . . . . . . . . . . . . . . . . . . . . . . . . . . .161$ 


\section{LISTA DE ESQUEMAS}

Esquema 1. Mecanismo proposto para a troca B-Zn.

Esquema 2. Amino álcoois quirais derivados de carboidratos em arilação assimétrica de aldeídos.

Esquema 3. Preparação de um sistema tipo trans-decalínico. ......................................17

Esquema 4. Etapa inicial para preparação dos derivados da $D$-Glucosamina. ...........18

Esquema 5. Síntese dos derivados 4a-c..........................................................................18

Esquema 6. Análise Retrossintética para obtenção dos aminoálcoois 10.................20

Esquema 7. Preparação bis-acetonídeo 7. ........................................................................20

Esquema 8. Proposta mecanística para a formação do bis-acetonídeo 7......................21

Esquema 9.Preparação do tosilato 9..................................................................................22

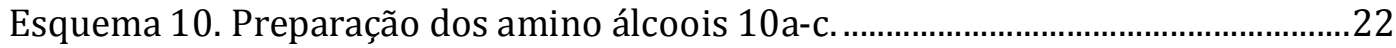

Esquema 11. Proposta para o mecanismo de arilação......................................................28

Esquema 12. Síntese da (-)-goniofufurona 18 por Shing e col.......................................37

Esquema 13. Síntese da (-)-epi-goniofufurona 23 por Shing e col...............................38

Esquema 14. Síntese da (-)-goniofufurona 18 por Gracza e col.....................................38

Esquema 15. Primeira síntese total da (+)-goniofufurona 13 por Shing e Col..........39

Esquema 16. Síntese da (+)-epi-goniofufurona 17 por Prakash e Rao. ........................40

Esquema 17. Síntese da (+)-goniofufurona 13 por Prakash e Rao.................................41

Esquema 18. Síntese da (+)-goniofufurona 13 por Murphy e Dennison......................42

Esquema 19. Síntese da (+)-goniofufurona 13 e (+)-epi-goniofufurona 17 por Köll e

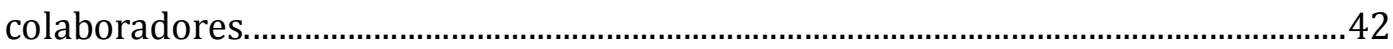

Esquema 20. Síntese da (+)-goniofufurona 13 e (+)-epi-goniofufurona 17 por

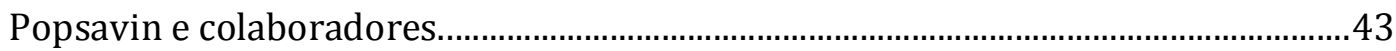

Esquema 21. Síntese do aldeído 30 derivado da $D$-Glicose.........................................45

Esquema 22. Rota sintética para a obtenção do aldeído 53........................................46

Esquema 23. Mecanismo proposto para a formação do bis-acetonídeo51...............47

Esquema 24. Conformações para aneis de cinco membros contendo um íon oxônio

e conformações dos produtos formados.........................................................................48

Esquema 25. Mecanismo proposto para a formação do anômero $\alpha$...............................49

Esquema 26. Preparação do aldeído 55 derivado da $D$-ribose. .....................................50

Esquema 27. Preparação do aldeído 57 derivados da $D$-galactose................................51

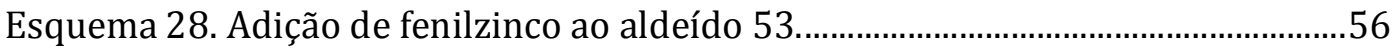

Esquema 29. Mecanismo de reação para a formação do biciclo furanofurona 36...71 


\section{LISTA DE TABELAS}

Tabela 1. Arilação de aldeídos na presença dos ligantes 4a-c.

Tabela 2.Arilação assimétrica do $p$-tolualdeído na presença dos ligantes $10 \mathrm{a}$-c. ....24

Tabela 3. Ampliação do escopo e avaliação das partes constituintes. .........................26

Tabela 4. Estudo das condições reacionais na adição de fenilzinco ao aldeído 30..52

Tabela 5. Adição de reagentes arilzinco ao aldeído 30.................................................54

Tabela 6. Estudo das condições reacionais para adição de fenilzinco ao aldeído 53.

Tabela 7. Adição de reagentes arilzinco ao aldeído 53..................................................62

Tabela 8. Adição de reagentes arilzinco ao aldeído 55 derivado da $D$-ribose............63

Tabela 9. Adição de reagentes arilzinco ao aldeíd o 57...................................................65

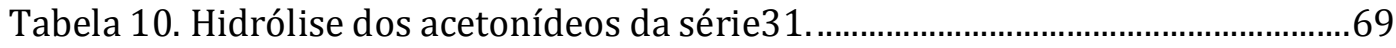

Tabela 11. Preparação do biciclo furanofurona 36..........................................................70

Tabela 12. Hidrogenólise do composto 36 conduz a epi-gioniofufurona.....................71 


\section{LISTA DE ABREVIATURAS E SIGLAS}

\begin{tabular}{|c|c|}
\hline $\mathrm{AcOH}$ & Ácido acético \\
\hline $\mathrm{Bn}$ & benzila \\
\hline $\mathrm{CDCl}_{3}$ & Clorofórmio deuterado \\
\hline $\mathrm{CD}_{3} \mathrm{OD}$ & Metanol deuterado \\
\hline CCD & Cromatografia em camada delgada \\
\hline $\mathrm{CG}$ & Cromatografia gasosa \\
\hline $\mathrm{d}$ & Dubleto \\
\hline dd & Dubleto de dubletos \\
\hline DiMPEG & dimetoxipolietilenoglicol \\
\hline DCM & Diclorometano \\
\hline $\mathrm{DMF}$ & Dimetilformamida \\
\hline DBU & 1,8-diazabicicloundec-7-ene \\
\hline$e e$ & Excesso enantiomérico \\
\hline HRMS & $\begin{array}{c}\text { Espectrometria de massas de alta } \\
\text { resolução }\end{array}$ \\
\hline HPLC & Cromatografia liquida de alta eficiência \\
\hline $\mathrm{Hz}$ & Hertz \\
\hline IBX & Ácido iodoxibenzoico \\
\hline$J$ & Constante de acoplamento \\
\hline
\end{tabular}




\begin{tabular}{|c|c|}
\hline $\mathrm{L}^{*}$ & Ligante quiral \\
\hline Ms & Grupo mesil \\
\hline $\mathrm{MeCN}$ & acetonitrila \\
\hline PCC & Cloro cromato de piridínio \\
\hline pt & Pseudo-tripleto \\
\hline Py & piridina \\
\hline ppm & Parte por milhão \\
\hline PhCHO & benzaldeído \\
\hline qua & Quarteto \\
\hline $\mathrm{RMN}^{1} \mathrm{H}$ & $\begin{array}{l}\text { Ressonância magnética nuclear de } \\
\text { hidrogênio }\end{array}$ \\
\hline $\mathrm{RMN}{ }^{13} \mathrm{C}$ & $\begin{array}{c}\text { Ressonância magnética nuclear de } \\
\text { carbono }\end{array}$ \\
\hline$r d$ & Razão diastereoisomérica \\
\hline sl & Singleto largo \\
\hline Ts & Grupo Tosil \\
\hline TMS & Tetrametilsilano \\
\hline $\mathrm{t}$ & Tripleto \\
\hline TMAB & Brometo de tetrametilamônio \\
\hline TFA & Ácido trifluoracético \\
\hline$\delta$ & Deslocamento químico \\
\hline$[\alpha]_{\mathrm{D}}$ & Rotação ótica \\
\hline
\end{tabular}




\section{PRINCÍPIOS GERAIS}




\section{PRINCÍPIOS GERAIS}

\subsection{Sobre a importância da quiralidade}

A quiralidade é sem sombra de dúvida um dos fenômenos químicos mais fascinantes e de relações mais intrigantes que se tem evidência. Efeitos da quiralidade nos sentidos humanos são conhecidos há mais de 100 anos. Ainda no final do século XIX, Pasteur percebeu que a $(S)$-asparagina era um composto insípido enquanto a $(R)$-asparagina apresentava sabor doce. A quiralidade também desempenha papel importante na percepção de odores. Um bom exemplo é a distinção de aromas entre os dois enantiômeros do terpeno carvona. A $(R)$-carvona é encontrada no óleo de hortelã e a $(S)$-carvona é o principal constituinte do óleo de sementes de cominho. Para um fabricante de sabores, perfumes e fragrâncias, certamente a distinção entre enantiômeros de uma mesma molécula é de grande importância, pois com certeza muitos estranhariam ao provar um creme dental sabor cominho!

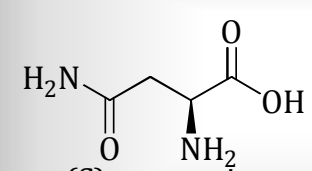

(S)-asparagina

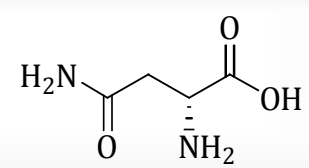

(R)-asparagina

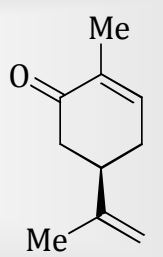

(R)-carvona

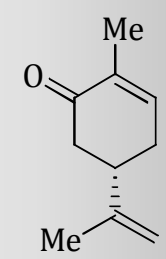

(S)-carvona

Figura 1. Alguns exemplos clássicos da importância da quiralidade.

Já quando se trata de fármacos, o uso do enantiômero correto pode ser caso de vida ou morte. Pacientes com Mal de Parkinson são tratados com o aminoácido dopa. Dopa é um composto quiral e somente o $(S)$-Dopa, conhecido como $L$-Dopa é efetivo no tratamento. $0(R)$-Dopa não é apenas ineficiente, o composto é na 
verdade muito tóxico. Desta forma o fármaco deve ser administrado como um único enantiômero.

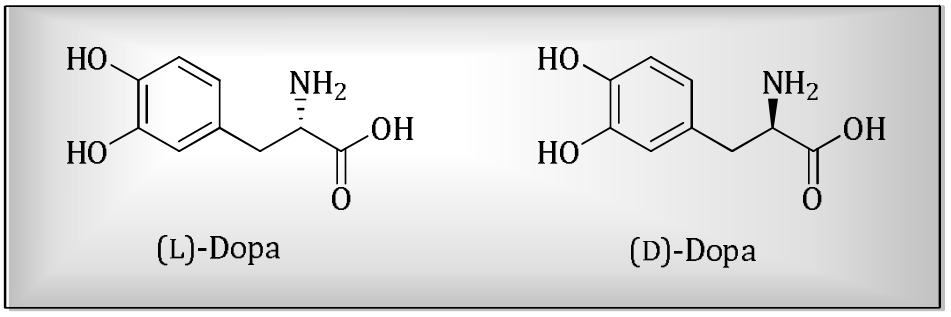

Figura 2. $(S)$ e $(R)$-Dopa

Em outros casos, estereoisômeros de uma droga podem ter propriedades terapêuticas completamente diferentes. É o caso do Darvon, enquanto este é um potente analgésico, seu enantiômero, conhecido como Novrad, é um eficiente agente antitussígeno.

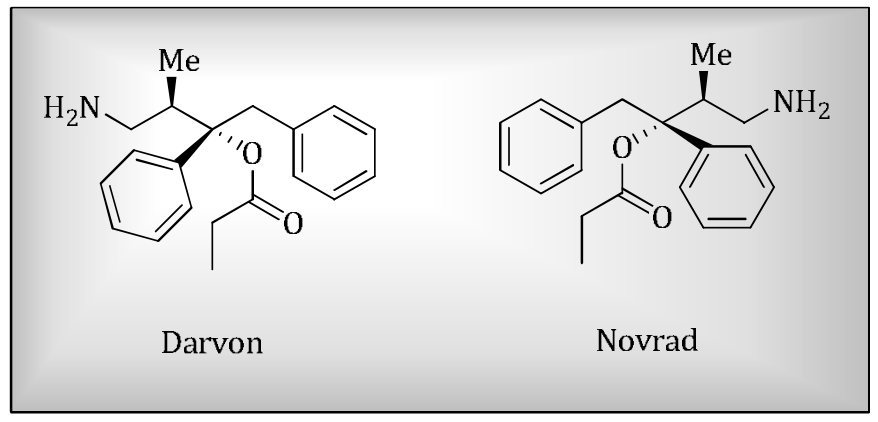

Figura 3. Darvon e Novrad.

Portanto, a quiralidade é um aspecto fundamental na química biológica e de importância vital em todos seus setores, uma vez que os processos bioquímicos que ocorrem em organismos vivos são baseados em reconhecimento molecular, que é definido como um processo onde uma estrutura molecular, geralmente chamada de receptor, reconhece ou interage com uma ou mais moléculas, ou seja, 
processos biológicos são baseados na capacidade de moléculas reconhecerem umas as outras de maneira seletiva e formarem complexos robustos.

\subsection{A importância de carboidratos neste contexto}

“(..) the abundance of substances of which animals and plants are composed, the remarkable processes whereby they are formed and then broken down again have claimed the attention of mankind of old, and hence from the early days they also persistently captivated the interest of chemists. (...)Carbohydrates, not only are these the first organic products formed in plants from the carbon dioxide in the air but in abundance, too, they surpass all substances that are current in the living world.(...)"

Emil Fischer, Nobel Lecture, December 12, 1902.

A química de carboidratos tem sido parte importante e vital da química orgânica desde as pioneiras descobertas de Emil Fischer, em meados de 1890, com a síntese total da glicose. Do ponto de vista histórico, nenhuma classe individual de compostos compartilhou o mesmo impacto que os açúcares na evolução da química orgânica como um todo. A elucidação de aspectos estereoquímicos, características conformacionais e princípios estereoeletrônicos em açúcares, têm servido como base para muitas outras classes de compostos. Além disso, ao longo dos anos a química de carboidratos tornou-se uma importante conexão entre a química orgânica, a química medicinal e a biologia. ${ }^{1}$

Recentemente, a química e bioquímica de carboidratos têm apreciado popularidade sem precedentes. Uma clara indicação do ressurgimento do interesse

\footnotetext{
${ }^{1}$ (a)Levy, D. E.; Fügedi, P.The Organic Chemistry of Sugars, Boca Raton, Taylor and Francis Group, 2006. (b)Hanessian, S. Preparative Carbohydrate Chemistry, Nova Iorque, Marcel Dekker, INC, 1997.
} 
é o grande contingente de químicos em formação que tem se aplicado a área com novas ideias e aplicações. Isto, acoplado ao papel cada vez mais importante que açúcares têm apresentado em glicobiologia: na terapia anti-infectiva como componentes de antibióticos, agentes antitumorais e antivirais e em áreas biomédicas relacionadas, faz desta química uma área vibrante para 0 desenvolvimento de novas metodologias. ${ }^{2}$

Carboidratos podem ser considerados um dos melhores presentes da natureza à química orgânica sintética, pois são naturalmente abundantes, facilmente disponíveis, são altamente funcionalizados e apresentam vários centros estereogênicos. Estas características conferem aos açúcares alta versatilidade sintética, apresentando muitas vantagens, principalmente em síntese assimétrica e síntese total de moléculas com variados graus de complexidade.

Desde a síntese da ureia em 1828 por Friedrich Wöhler, a síntese total tem sido uma área desafiadora. Açúcares foram sintetizados por Emil Fischer já em meados de 1890, estabelecendo também o conceito de síntese assimétrica. Maiores avanços na síntese de moléculas complexas foram publicados a partir de 1950, incluindo a síntese de alcalóides complexos como a reserpina ${ }^{3}$ e a síntese da vitamina B124. Uma tarefa mais desafiadora foi então tornar a síntese total capaz de produzir compostos opticamente ativos idênticos aos alvos naturais. Neste contexto de síntese de compostos enantiomericamente puros, o uso de materiais propícios para adequar-se como blocos construtores quirais tornou-se uma ideia muito interessante. Carboidratos são proeminentes dentre os materiais quirais

\footnotetext{
2 (a)Varki, A., Cummings, R. D.; Esko, J. D. Essentials of Glycobiology.2nd edition.Cold Spring Harbor Laboratory Press(NY), 2009. (b) http://www.ncbi.nlm.nih.gov/books/NBK1895/

3 Woodward, R. B.; Bader, F. E.; Bickel, H.; Frey, A. J.; Kierstead, R. W. Tetrahedron, 1958, 2, 1-57.

4 Woodward, R. B. Pure Appl. Chem., 1973, 33, 1, 145-178.
} 
disponíveis de fontes naturais. Isto devido a muitos fatores, tais como pureza enantiomérica e ao número de centros quirais disponíveis, permitindo que em manipulações posteriores não ocorra nenhuma epimerização indesejável, podendo considerar os produtos finais como enantiomericamente puros, senão diasteroisomericamente enriquecidos.

Por último, mas não menos importante, a existência de ambas as formas enantioméricas do mesmo carboidrato a preços acessíveis é uma das maiores vantagens. Isto é verdadeiro para a maioria dos açúcares, tais como arabinose, xilose, lixose e mesmo a ribose. Dada à alta estereodiversidade dos carboidratos é fácil encontrar o açúcar de partida adequado para garantir um bom ajuste entre o material de partida e a molécula alvo.

\subsection{Adição estereosseletiva de reagentes organozinco}

A troca Boro-Zinco apresenta grande importância para diversas aplicações em síntese orgânica uma vez que permite a formação de novas ligações CarbonoCarbono entre reagentes organometálicos e espécies eletrofílicas. Atualmente aparece como um dos métodos mais interessantes para a geração de grupos arila transferíveis já que um grande número de compostos arilboro estão comercialmente disponíveis ou são facilmente preparados. Dentre os diversos compostos organoboro, ácidos arilborônicos tem recebido atenção especial, uma vez que sua reação com dietilzinco produz como intermediário aril-zinco-etil [ArZnEt], que na presença de ambiente quiral pode ser seletivamente transferido a 
uma ampla variedade de aldeídos, e mais raramente cetonas, conduzindo a álcoois secundários ou terciários quirais, respectivamente. ${ }^{5}$

Baseados em estudos teóricos e experimentais, Maseras e Pericàs ${ }^{6}$ em 2008 propuseram um mecanismo para a troca Boro-Zinco. A etapa chave envolve basicamente uma troca $\mathrm{Zn}-\mathrm{B}$ seguida de uma troca B-Zn, conforme pode ser observado no Esquema 1.

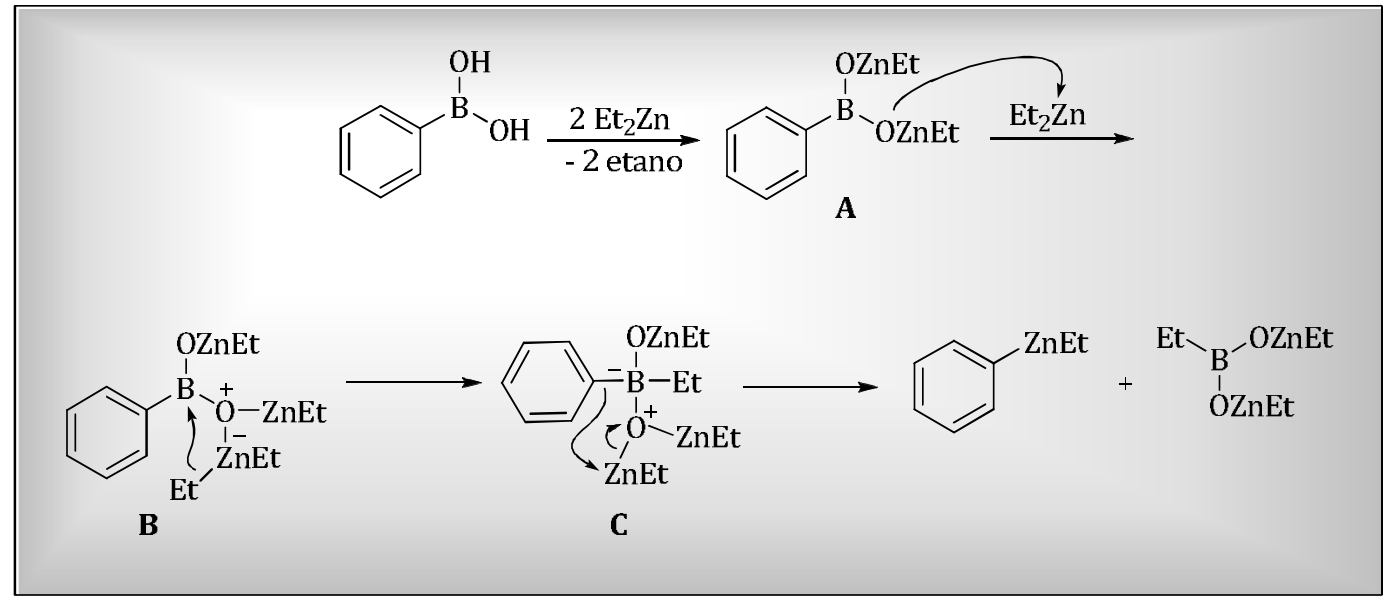

Esquema 1. Mecanismo proposto para a troca B-Zn.

Em um primeiro momento, quando dietilzinco é adicionado ao ácido borônico, os dois prótons ácidos são abstraídos, conduzindo a formação do intermediário A, que atua sobre uma terceira molécula de dietilzinco levando ao intermediário B. É o intermediário B que sofre a troca Zn-B, ou seja, um grupo etil é transferido do zinco para o boro conduzindo ao intermediário $\mathbf{C}$, no qual ocorre nova troca, desta vez B-Zn, onde o grupo fenil ligado ao boro é transferido para o zinco, dando origem a espécie ativa PhZnEt.

\footnotetext{
${ }^{5}$ Para uma revisão recente sobre a aplicação da troca B-Zn em arilações assimétricas de aldeídos, consulte: Paixão, M. W.; Braga, A. L.; Lüdtke, D. S. J. Braz. Chem. Soc. 2008, 19, 813-830.

${ }^{6}$ Jimeno, C.; Sayalero, S.; Fjermestad, T.; Colet, G.; Maseras, F.; Pericàs, M. A. Angew. Chem. In.

Ed.2008, 47, 1098-1101.
} 


\section{OJETIVOS GERAIS}

Como a preparação de compostos enantiomericamente puros é essencial na síntese de produtos naturais bem como para síntese de derivados sintéticos, esforços intensos tem sido realizados no desenvolvimento de auxiliares quirais, reagentes quirais e catalisadores quirais, que possam conduzir a altos níveis de eficiência. Muitas dessas ferramentas sintéticas estão baseadas em amino ácidos, alcalóides e terpenos, enquanto que carboidratos, a classe de compostos quirais naturalmente mais abundante, tem consideravelmente recebido menos atenção. Carboidratos, que estão disponíveis nas mais diferentes arquiteturas e sua alta densidade de grupamentos funcionais oferecem muitas oportunidades para derivatização e aplicação dos mesmos em síntese estereosseletiva. ${ }^{7}$

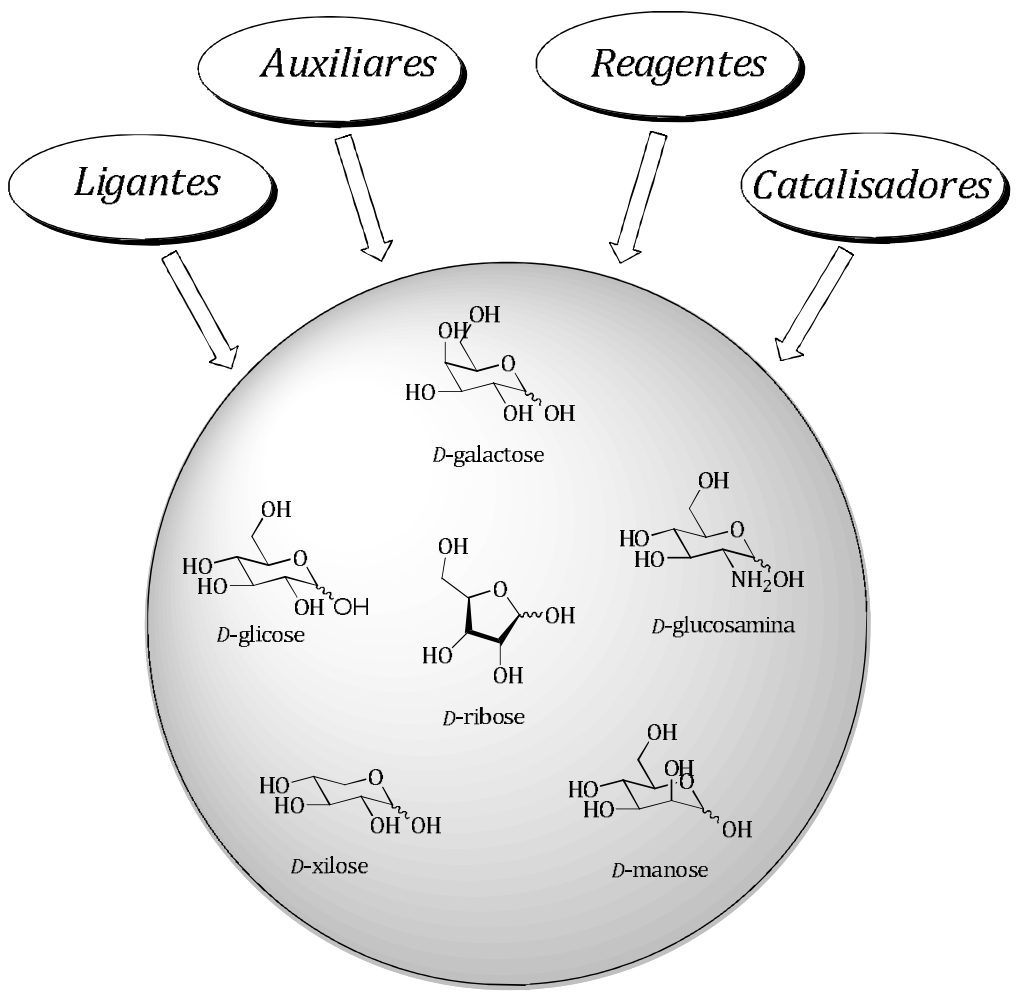

Figura 4. Versatilidade sintética de carboidratos.

\footnotetext{
${ }^{7}$ Boysen, M. M. K. Chem. Eur. J. 2007, 13, 8649-8659.
} 
Tendo em vista a grande importância que o desenvolvimento de novas metodologias para a preparação de compostos quirais via síntese assimétrica ou estereosseletiva, aliados ao uso de blocos quirais de origem natural e a metodologias já bem estabelecidas, o projeto para esta tese teve como ideia geral o uso de carboidratos como matéria prima para a construção de substratos quirais, podendo estes ser usados como indutores de quiralidade ou até mesmo como materiais de partida pró-quirais. 
CAPÍTULO 1. Arilação assimétrica de aldeídos catalisada por amino álcoois derivados de carboidratos 


\section{INTRODUÇÃ̃o}

0 descobrimento de metodologias eficientes que deem acesso à preparação de compostos enantiomericamente puros, principalmente no desenvolvimento de fármacos, agroquímicos e flavorizantes, tem sido um grande desafio para muitos pesquisadores nas últimas décadas. Das várias metodologias disponíveis atualmente para a preparação de compostos enantiopuros, a catálise assimétrica ocupa papel de destaque. Um fato que vem a reforçar a crescente importância dessa área para a química como um todo é o vasto número de publicações neste campo e o reconhecimento da Academia Real de Ciências da Suécia, que agraciou com o Prêmio Nobel de Química de 2001 os pesquisadores William S. Knowles, Ryoji Noyori e K. Barry Sharpless pelas suas notáveis contribuições para o desenvolvimento de métodos catalíticos para a preparação de substâncias opticamente ativas.

Uma das principais vantagens da catálise assimétrica em relação a outros métodos usados em síntese assimétrica é que os produtos podem ser seletivamente sintetizados a partir de materiais de partida pró-quirais baratos e comercialmente disponíveis sem que produtos indesejáveis sejam formados. Geralmente com esta estratégia, um complexo metálico contendo o ligante quiral catalisa a transformação de um substrato pró-quiral em uma molécula enantiomericamente pura ou enriquecida como produto majoritário.

Para que altos níveis de reatividade e seletividade sejam alcançados em reações de catálise enantiosseletiva, muitos parâmetros reacionais devem ser explorados e ajustados. Neste processo de otimização, a seleção cuidadosa e o planejamento do ligante quiral talvez seja a etapa mais importante, já que a 
eficiência do ligante depende de cada reação particular. Uma das maneiras mais simples de obter ligantes quirais é transformar ou derivatizar compostos naturais quirais, sendo assim desnecessário procedimentos de resolução.

Nos últimos anos, resultados impressionantes têm sido obtidos usando ligantes derivados de carboidratos e aminoácidos em um amplo escopo de reações catalíticas assimétricas. Carboidratos apresentam muitas vantagens: são facilmente disponíveis, são altamente funcionalizados e apresentam vários centros estereogênicos. Essas características permitem que uma série de ligantes seja sintetizada e tenham seu desempenho avaliado em busca de altas seletividades para um grande número de reações enantiosseletivas. ${ }^{7,8}$ Aliado a isso, a versatilidade dos carboidratos confere aos ligantes deles derivados, um caráter altamente modular, permitindo o ajuste fino da estrutura do catalisador de modo a se obter informações valiosas sobre a origem da seletividade.

Neste contexto, grande progresso tem sido alcançado na adição de reagentes organozinco a aldeídos com o uso de amino álcoois quirais como ligantes e produtos com altos excessos enantioméricos vêm sendo obtidos. ${ }^{9}$

Recentemente, a arilação enantiosseletiva de aldeídos, na presença de um ligante quiral, tem recebido atenção especial, uma vez que permite o acesso a diarilmetanóis quirais, que são precursores de compostos biológica e farmacologicamente importantes, ${ }^{10}$ como, por exemplo, a orfenadrina e a

8Para revisões recentes sobre ligantes derivados de carboidratos em catálise assimétrica: (a) Diéguez, M.; Pàmies, O.; Claver, C. Chem. Rev. 2004, 104, 3189-3215. (b) Pàmies, O.; Ruiz, A.; Díaz, Y.; Castillón, S.; Claver, C. Coord. Chem. Rev. 2004, 248, 2165-2192. (c) Diéguez, M.; Claver, C.; Pàmies, O. Eur. J. Org. Chem. 2007, 4621-4634.

${ }^{9}$ (a) Noyori, R.; Kitamura, M. Angew. Chem., Int. Ed. Engl.1991, 30, 49-69. (b) Soai, K.; Niwa, S. Chem. Rev. 1992, 92, 833-856. (c) Noyori, R. Asymmetric Catalysis in Organic Synthesis; Wiley: New York, 1994; Chapter 5. (d) Pu, L.; Yu, H. -B. Chem. Rev. 2001, 101, 757-824.

10 (a) Meguro, K.; Aizawa, M.; Sohda, T.; Kawamatsu, Y.; Nagaoka, A. Chem. Pharm. Bull. 1985, 33, 3787-3797. (b) Toda, F.; Tanaka, K.; Koshiro, K. Tetrahedron: Asymmetry 1991, 2, 873-874. (c) 
neobenodina, que apresentam atividade anti-colinérgica e anti-histamínica. ${ }^{11}$ Já a carbinoxamina $^{12}$ é um antagonista histamínico $\mathrm{H}_{1}$, usado no tratamento de doenças alérgicas, bem como o hidrocloreto da cetirizina ${ }^{13}$ que é extremamente seletivo para receptores do tipo $\mathrm{H}_{1}$ e é comercializado na sua forma enantiomericamente pura (enantiômero $S)^{14}$ desde 2002 (Figura 5).

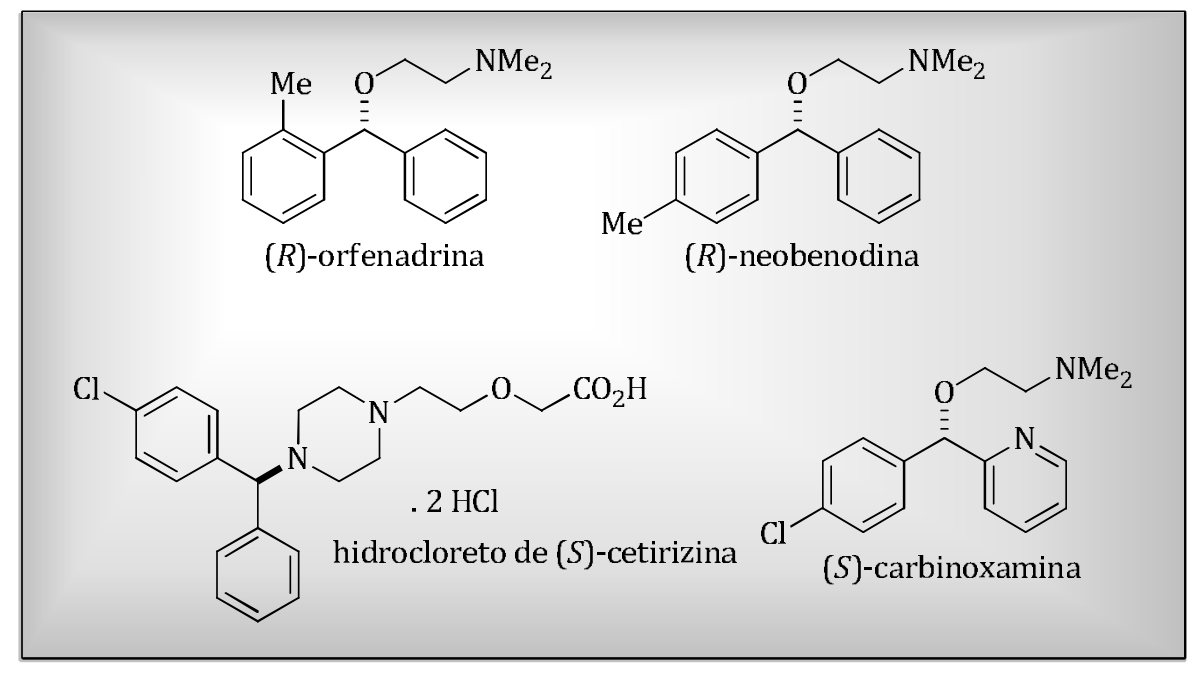

Figura 5. Derivados de diarilmetanóis com atividade biológica.

A abordagem inicialmente descrita para a preparação de diarilmetanóis enantiomericamente enriquecidos envolvia a adição do reagente altamente reativo, difenilzinco ou de um reagente mais brando, oriundo de uma mistura de difenilzinco/dietilzinco. Entretanto o escopo do grupo arila a ser transferido está limitado ao grupo fenil, uma vez que o único reagente diarilzinco disponível comercialmente é o difenilzinco. Portanto, existia a necessidade de desenvolverem-se métodos que permitissem a transferência assimétrica de um

Stanchev, S.; Rakovska, R.; Berova, N.; Snatzke, G. Tetrahedron: Asymmetry 1995, 6, 183-198. (d) Botta, M.; Summa, V.; Corelli, F.; Di Pietro, G.; Lombardi, P. Tetrahedron: Asymmetry 1996, 7, 12631266. (e) Bolm, C.; Hildebrand, J. P.; Muñiz, K.; Hermanns, N. Angew. Chem. Int. Ed. 2001, 40, 32843308. (f) Schmidt, F.; Stemmler, R. T.; Rudolph, J.; Bolm, C. Chem. Soc. Rev. 2006, 35, 454-470.

11 Rekker, R. F.; Timmerman, H.; Harms, A. F.; Nauta, W. T. Arzneim.-Forsch. 1971, 21, 688.

12 Barouth, V.; Dall, H.; Hite, G. J. Med. Chem. 1971, 14, 834-836.

${ }^{13}$ Corey, E. J.; Helal, C. Tetrahedron Lett.1996, 37, 4837-4840.

14 Devalia, J. L.; De Vos, C.; Hanotte, F.; Baltes, E. Allergy 2001, 56, 50-57. 
número maior de grupos arila substituídos, partindo-se de fontes facilmente acessíveis. Nesse contexto, Bolm e colaboradores introduziram um protocolo que utiliza ácidos borônicos como a fonte de espécies aromáticas nucleofílicas, a partir de uma troca boro-zinco, por reação com dietilzinco. 5,15

Esse método permite a exploração de uma variedade mais ampla de grupos arila a serem transferidos, uma vez que uma gama bastante grande de ácidos borônicos é obtida comercialmente ou pode ser facilmente preparada a partir dos haletos correspondentes. Ainda mais interessante é a possibilidade de se preparar ambos os enantiômeros de um dado produto, utilizando-se o mesmo ligante quiral, apenas por escolha apropriada dos dois componentes da reação; ácido borônico e aldeído (Figura 6). ${ }^{16}$

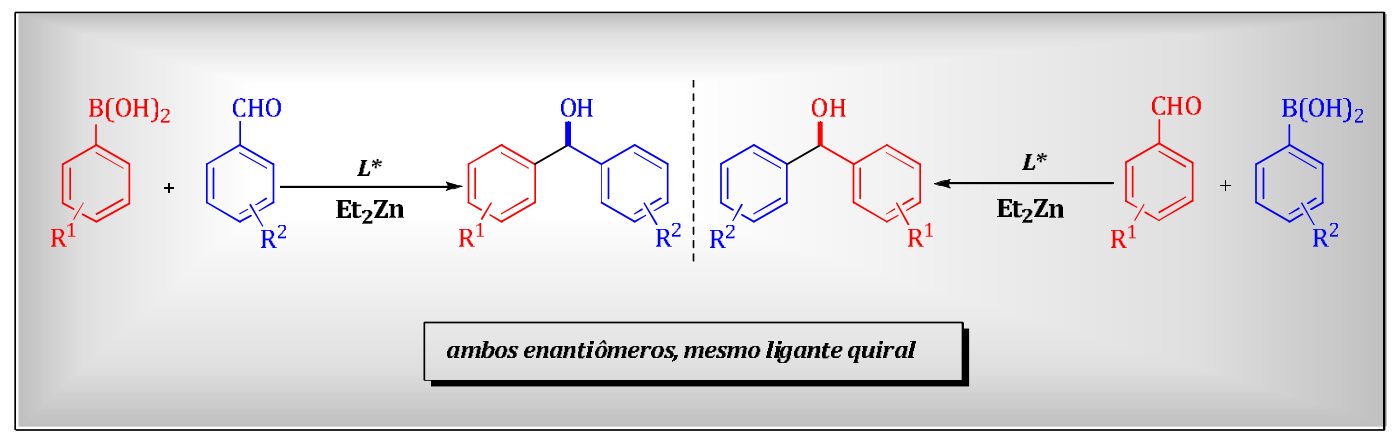

Figura 6. Possibilidade de preparação de ambos enantiômeros.

Muitas características distinguem a reatividade de reagentes arilzinco e dos compostos alquilzinco relacionados. A principal é a velocidade das reações, substancialmente mais altas: $\mathrm{Ph}_{2} \mathrm{Zn}$, por exemplo, se adiciona a aldeídos a temperatura ambiente mesmo na ausência de ligantes. Quando temos um reagente

15 Bolm, C.; Rudolph, J. J. Am. Chem. Soc. 2002, 124, 14850-14851

16 (a) Braga, A. L.; Lüdtke, D. S.; Vargas, F.; Paixão, M. W. Chem. Commun. 2005, 3512-2514. (b) Braga, A. L.; Lüdtke, D. S.; Schneider, P. H.; Vargas, F.; Schneider, A.; Wessjohann, L. A.; Paixão, M. W. Tetrahedron Lett. 2005, 46, 7827-7830. (c) Paixão, M. W.; Godoi, M.; Rhoden, C. R. B.; Westermann, B.; Wessjohann, L. A.; Lüdtke, D. S.; Braga, A. L. J. Mol. Cat. A, Chemical 2007, 261, 120-124. 
do tipo PhZnEt, por exemplo, a geometria do estado de transição está altamente relacionada ao ânion a ser transferido, com o orbital preenchido localizado entre o átomo de zinco e o carbono carbonílico (Figura 7). 0 estado de transição é o ponto de mínima sobreposição do ânion com o aceptor de elétrons. Todavia, para o grupo fenil o orbital $\pi$ aromático sobrepõe-se também ao átomo de zinco, deficiente em elétrons e isto contribui para a maior estabilização do estado de transição. Enquanto que para o grupo etil, a distorção correspondente é um processo altamente energético. Assim, mesmo na presença de grande excesso do reagente $\mathrm{Et}_{2} \mathrm{Zn}$, a transferência do grupo fenil é esperada. ${ }^{17}$

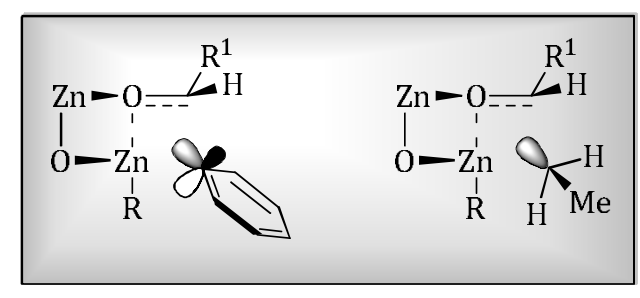

Figura 7. Geometria do estado de transição. 0 orbital preenchido do ânion localizado entre o átomo de zinco e o carbono carbonílico.

\section{OBJETIVOS E JUSTIFICATIVA}

Em vista da importância que a área de síntese assimétrica ocupa atualmente no cenário mundial e da lacuna ainda existente no que diz respeito à utilização de carboidratos como matéria-prima para a confecção de ligantes e catalisadores quirais, o presente plano de trabalho estabeleceu como objetivos:

$\Rightarrow$ a preparação de amino álcoois com o esqueleto quiral, derivados dos açúcares $D$-xilose e $D$-glucosamina (Figura 8)

\footnotetext{
${ }^{17 R u d o l p h, ~ J . ; ~ R a s m u s s e n, ~ T . ; ~ B o l m, ~ C . ; ~ N o r r b y, ~ P .-O . ~ A n g e w . ~ C h e m . ~ I n t . ~ E d .2003, ~ 40, ~ 3002-3005 . ~}$
} 


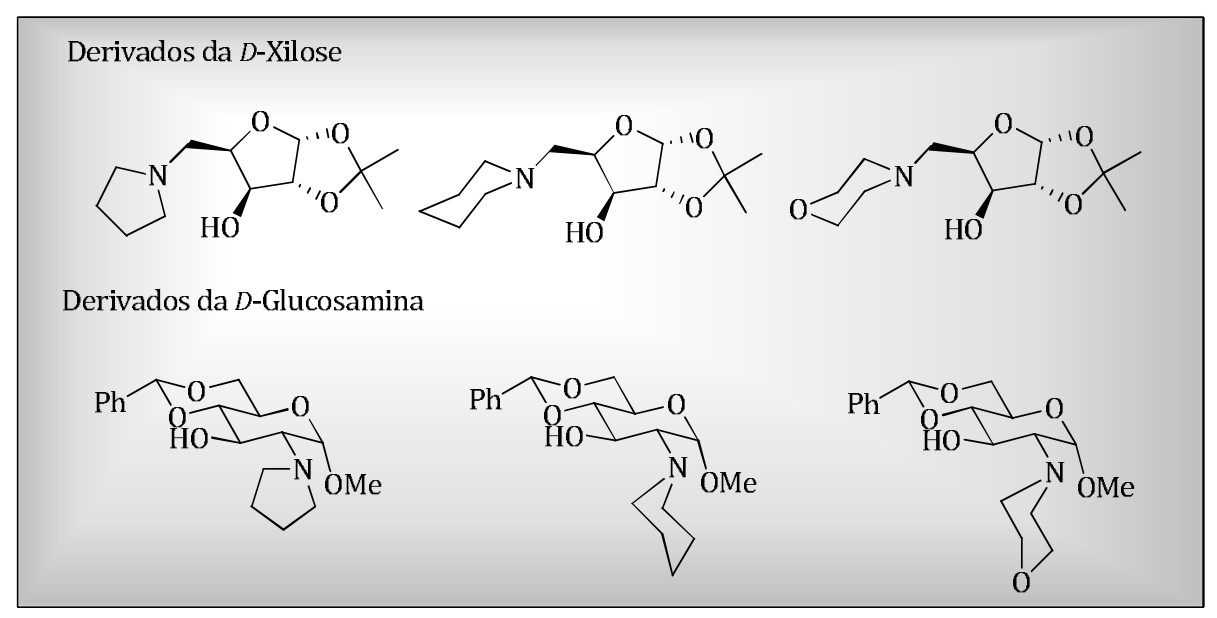

Figura 8. Amino álcoois derivados da $D$-Xilose e $D$-Glucosamina selecionados.

$\Rightarrow$ posterior utilização dos amino álcoois preparados como ligantes quirais na arilação assimétrica de aldeídos (Esquema2).

ligantes quirais:<smiles>[R][Z]1ccc(C(O)c2ccc([R4])cc2)cc1</smiles>

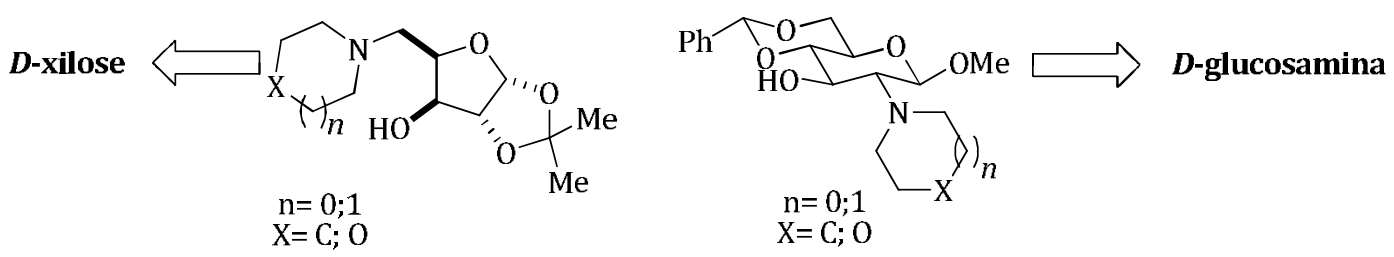

Esquema 2. Amino álcoois quirais derivados de carboidratos em arilação assimétrica de aldeídos.

\section{APRESENTAÇÃO E DISCUSSÃO DOS RESULTADOS OBTIDOS}

\subsection{Preparação dos ligantes derivados da $D$-Glucosamina}


A $D$-glucosamina é um carboidrato que apresenta em sua estrutura um grupo amino, o que confere a ela um grande potencial para utilização como matéria prima no desenvolvimento de novos ligantes quirais. Dentre outras transformações importantes que podem ser realizadas em sua estrutura, pode-se destacar a acetalização das hidroxilas nas posições 4 e 6, levando a formação de um sistema rígido do tipo trans-decalínico, de acordo com precedentes encontrados na literatura(Esquema 3). ${ }^{18}$ Isso é de suma importância, uma vez que permite manipulações posteriores na porção $\beta$-amino álcool, nas posições 2 e 3 .

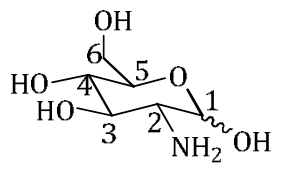

D-glucosamina

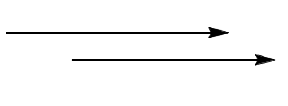

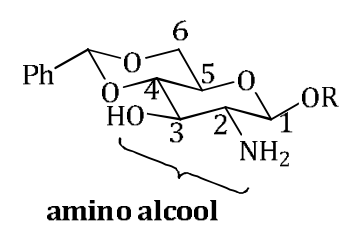

Esquema 3. Preparação de um sistema tipo trans-decalínico.

Dessa forma, diversas manipulações nos grupos amino e hidroxila podem ser feitas, visando modular a reatividade dessas espécies, tornando-as capazes de coordenarem-se eficientemente a diversos metais de transição. Essa coordenação pode resultar em um processo enantiosseletivo, através de um estado de transição organizado, inerente ao esqueleto do açúcar.

Primeiramente, a proteção da posição anomérica se faz necessária e para tanto se tratou a $N$-Ac-Glucosamina 1 com metanol em meio ácido, e posterior tratamento do produto obtido com benzaldeído, na presença de $\mathrm{ZnCl}_{2}$ resultou na acetalização das hidroxilas nas posições 4 e 6, levando ao sistema trans-decalínico, como pode ser observado no Esquema $4 .{ }^{19}$ Cabe salientar que foi obtida uma

18 Inouye, Y.; Onodera, K.; Kitaoka, S.; Hirano, S. J. Am. Chem. Soc. 1956, 78, 4722-4724.

${ }^{19}$ Yonehara, K.; Hashizume, T.; Mori, K.; Ohe, K.; Uemura, S. J. Org. Chem. 1999, 64, 9374-9380. 
mistura de anômeros $\alpha$-2 e $\beta$-2, em $62 \%$ de rendimento, em uma proporção aproximada de 4:1. Os dois anômeros foram facilmente separados por recristalização.
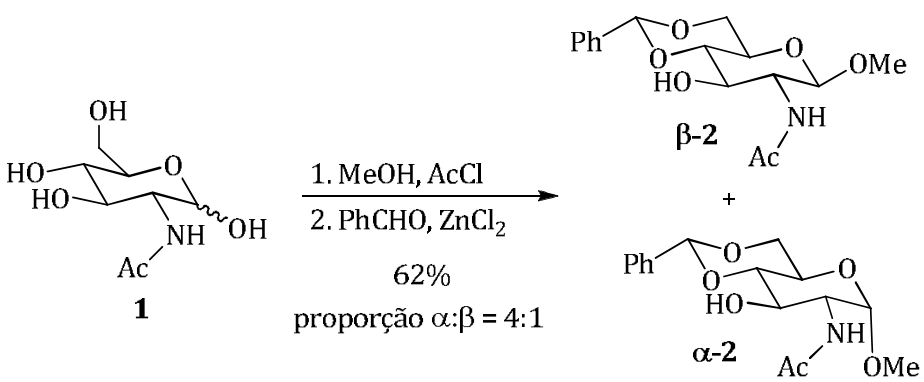

Esquema 4. Etapa inicial para preparação dos derivados da $D$-Glucosamina.

Posteriormente, o grupo acetila de $\alpha$-2 foi removido por reação com KOH $4 \mathrm{~mol} \mathrm{L-19}$ em etanol, fornecendo o amino álcool livre 3 em $76 \%$ de rendimento (Esquema 5). De posse do $\beta$-amino álcool 3, o mesmo foi submetido ao tratamento com di-haletos levando a formação das aminas terciárias cíclicas 4a-c.

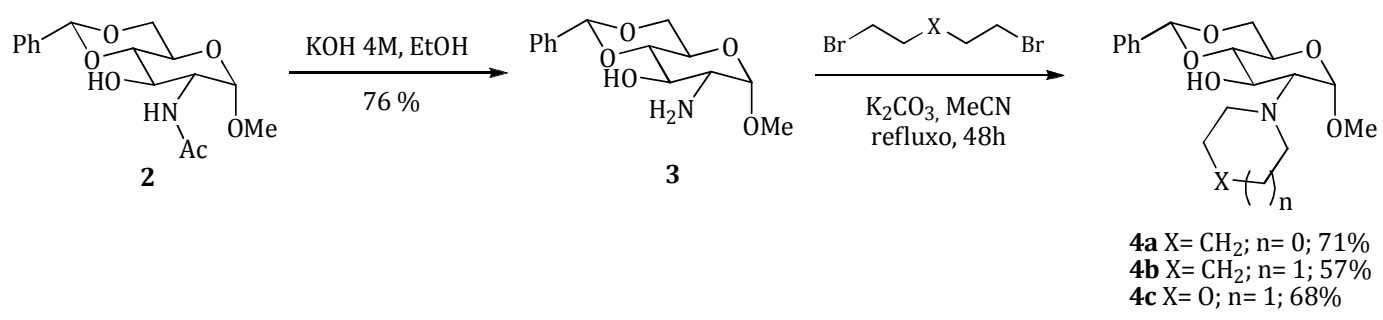

Esquema 5. Síntese dos derivados 4a-c.

\subsection{Arilação assimétrica na presença dos ligantes 4 a-c}

Com os ligantes 4a-c em mãos, estes derivados foram testados frente à arilação assimétrica do $p$-tolualdeído, usando ácido fenilborônico como fonte de grupos fenil. Os derivados contendo pirrolidina $4 \mathbf{a}$ e piperidina $\mathbf{4 b}$ na estrutura conduziram ao produto em bons rendimentos, entretanto a excessos 
enantioméricos muito baixos, conforme pode ser observado na Tabela 1. 0 ligante 4c, contendo o anel morfolínico, mostrou-se um pouco mais eficiente, embora ainda insatisfatório, conduzindo a excessos enantioméricos de apenas 36\%. Para avaliar a reprodutibilidade do sistema a arilação de outros aldeídos foi conduzida e novamente a enantiosseletividade da arilação foi baixa e os diarilmetanóis foram obtidos em excessos de 30-35\%.

Tabela 1. Arilação de aldeídos na presença dos ligantes 4a-c.

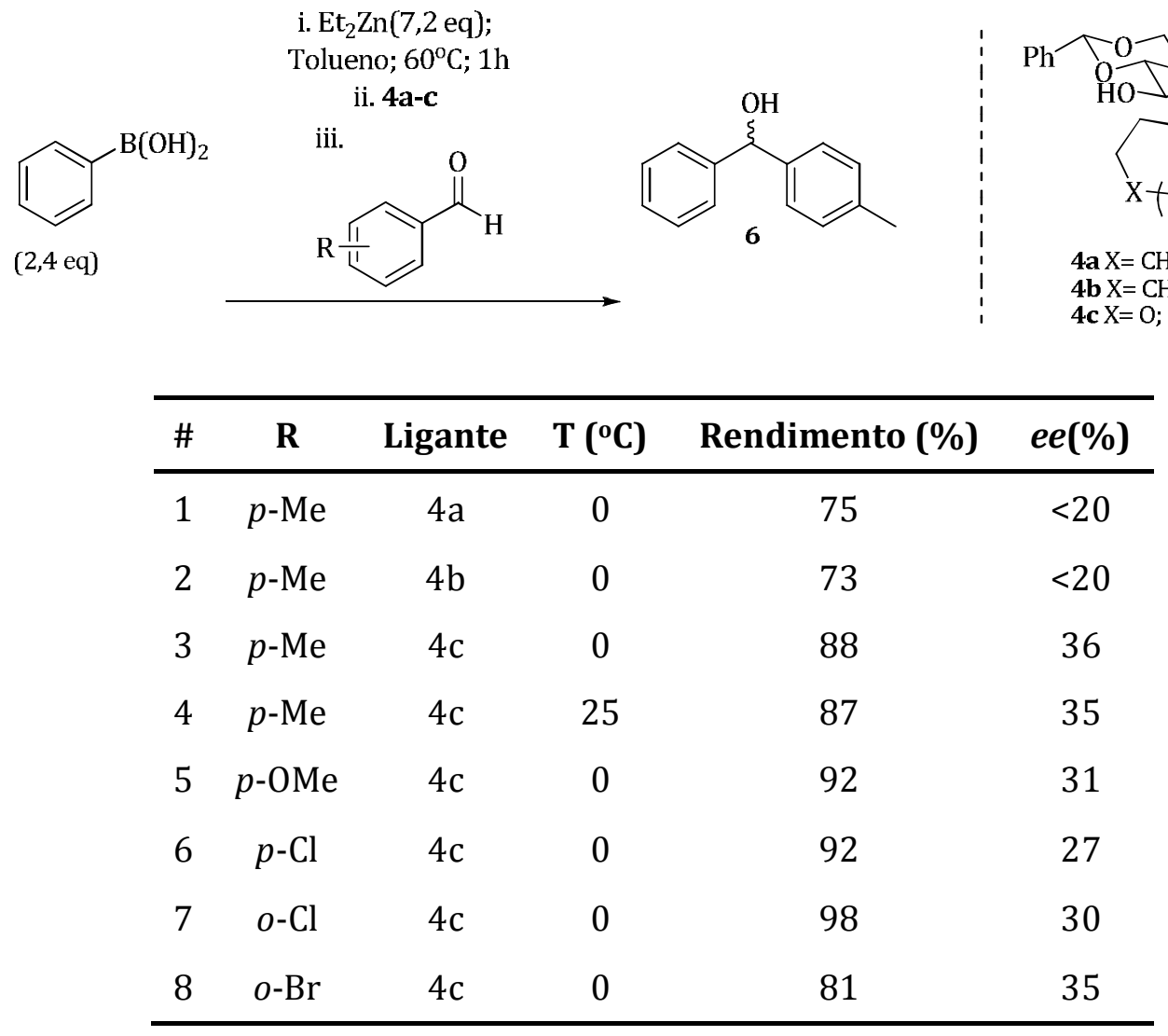

Mesmo após a avaliação de diversas condições reacionais, infelizmente os resultados obtidos continuavam apresentando excessos enantioméricos muito baixos. Optou-se então por focar os esforços na preparação de amino álcoois derivados da $D$-xilose 


\subsection{Preparação dos ligantes derivados da $D$-Xilose}

O planejamento sintético para a síntese dos aminoálcoois $\mathbf{1 0}$, derivados da $D$-Xilose, esteve centrado na substituição nucleofílica de um tosilato por aminas, conforme mostrado na análise retrossintética (Esquema 6). 0 tosilato, por sua vez, seria obtido através de uma tosilação seletiva do diol $\mathbf{8}$, obtido a partir da $D$-xilose.
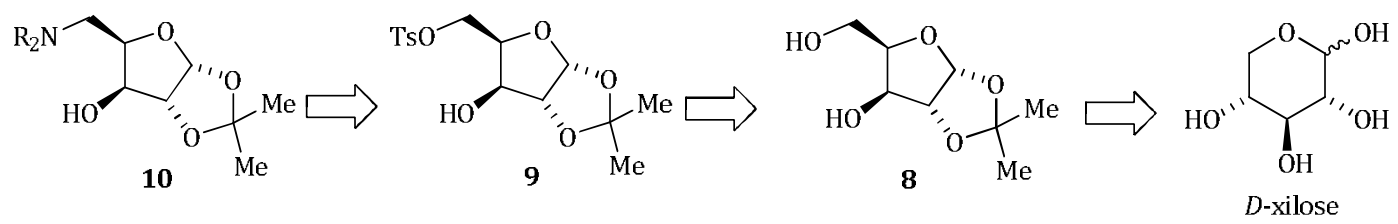

Esquema 6. Análise Retrossintética para obtenção dos aminoálcoois 10.

Como ponto de partida para a síntese dos aminoálcoois 10 desejados, fez-se necessária a preparação do tosilato 9. Para tanto, realizou-se o tratamento da $D$ xilose com acetona, na presença de quantidades catalíticas de $\mathrm{I}_{2}$, fornecendo a diisopropilideno- $D$-xilofuranose $7,20 \mathrm{em}$ 94\% de rendimento (Esquema 7). Esta primeira etapa sintética, onde ocorre a reorganização estrutural e formação do sistema furanosídico, com concomitante bis-acetalização, é catalisada por $\mathrm{I}_{2}$.

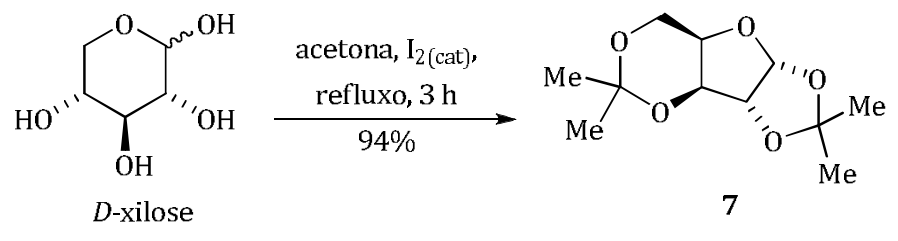

Esquema 7. Preparação bis-acetonídeo 7.

Inicialmente, ocorre a abertura do anel tetraidropirano da xilose (Esquema 8), resultando no açúcar de cadeia aberta. Uma nova reação de ciclização ocorre,

${ }^{20}$ Kartha, K. P. R. Tetrahedron Lett. 1986, 27, 3415-3416. 
desta vez levando ao anel de 5 membros, concomitante com a formação do acetonídeo, por reação das hidroxilas com a acetona. A segunda proteção ocorre por reação das 2 hidroxilas remanescentes com outra molécula de acetona, resultando na formação do bis-acetonídeo 7.

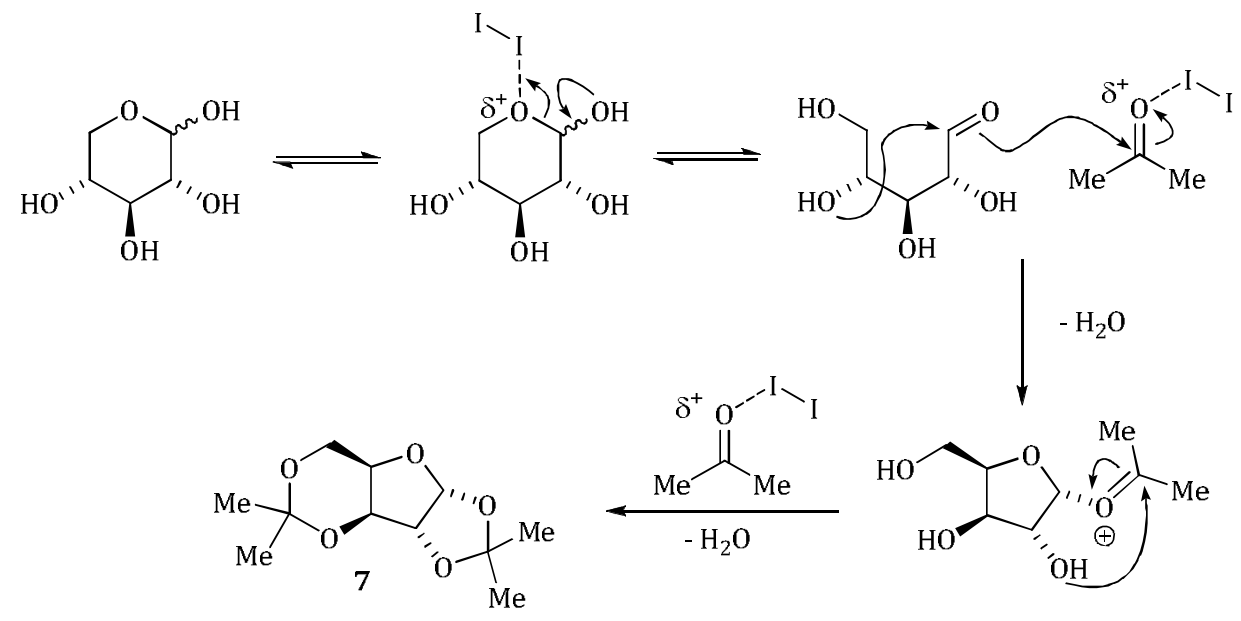

Esquema 8. Proposta mecanística para a formação do bis-acetonídeo 7.

O bis-acetonídeo 7 foi então hidrolisado seletivamente, com $\mathrm{HCl}$ diluído, ao diol correspondente em $86 \%$ de rendimento. Cabe salientar que a concentração da solução de $\mathrm{HCl}$ teve que ser cuidadosamente otimizada, já que soluções muito concentradas resultaram em hidrólise total do bis-acetonídeo, enquanto que soluções muito diluídas não resultaram na formação do produto desejado. Reação de tosilação seletiva da hidroxila primária foi obtida com cloreto de tosila em piridina, resultando no tosilato 9 em $81 \%$ de rendimento (Esquema 9). ${ }^{21}$ Cabe salientar que tempos de reação longos podem conduzir a formação de pequena quantidade de di-tosilato, uma vez que o cloreto de tosila é utilizado em pequeno excesso.

${ }^{21}$ Lu, Y.; Just, G. Tetrahedron 2001, 57, 1677-1687. 


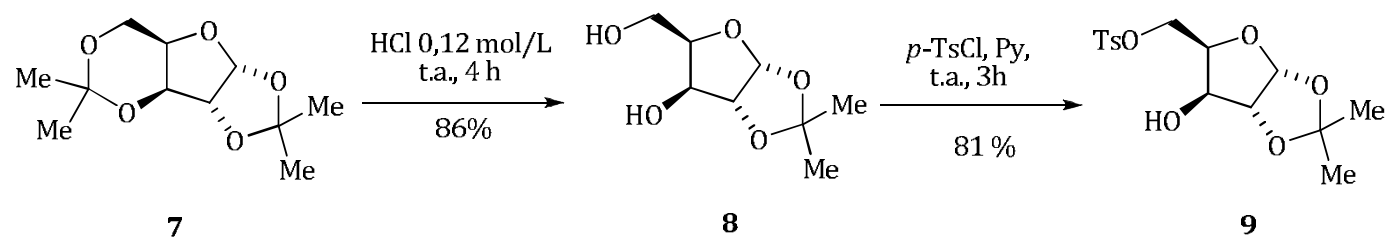

Esquema 9.Preparação do tosilato 9.

Cabe salientar que a otimização desta sequência reacional permite a obtenção do tosilato 9 de maneira eficiente, em $65 \%$ de rendimento global, em escala de gramas, sem a necessidade de purificações cromatográficas.

Posteriormente, o tosilato 9 foi submetido a reação com aminas secundárias pirrolidina, piperidina e morfolina, visando a obtenção dos $3 \gamma$-aminoálcoois 10desejados, correspondendo aos compostos 10a-c. A escolha dessas 3 aminas em particular foi devido as mesmas pertencerem a um sistema cíclico, o que poderia conduzir a estados de transição mais robustos durante o processo de arilação enantiosseletiva. Outro fator que contribuiu para a seleção destas aminas foi que as mesmas resultaram nos amino álcoois correspondentes em condições mais brandas e em melhores rendimentos do que outras aminas testadas. Os resultados obtidos estão apresentados no Esquema 10.
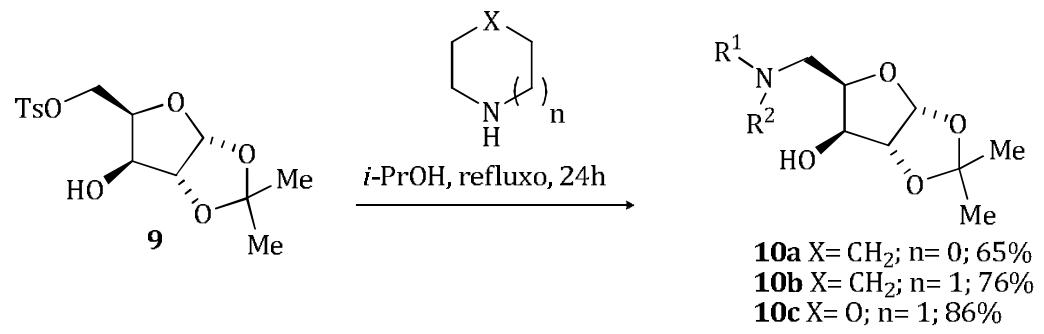

Esquema 10. Preparação dos amino álcoois 10a-c. 


\subsection{Arilação assimétrica na presença dos ligantes $10 \mathrm{a}-\mathrm{c}$}

De posse dos ligantes 10a-c, os mesmos foram avaliados primeiramente na reação de arilação enantiosseletiva do $p$-tolualdeído com ácido fenilborônico. A triagem inicial das condições reacionais envolveu a variação de ligantes e suas proporções, temperatura, tempos reacionais e presença de aditivos. A análise dos resultados descritos na Tabela 2 revela que todos ligantes conduziram ao produto desejado em bons rendimentos. Quando $20 \mathrm{~mol} \%$ do composto 10c foram utilizados, e a reação de arilação conduzida a uma temperatura de $0^{\circ} \mathrm{C}, \mathrm{o}$ diarilmetanol correspondente foi obtido em $93 \%$ de rendimento e com um excesso enantiomérico de $96 \%$ (entrada 3). Aumento da temperatura para ambiente levou a diminuição da enantiosseletividade da reação para $78 \%$ ee (entrada 4). Diminuição da temperatura reacional de $0^{\circ} \mathrm{C}$ para $-20{ }^{\circ} \mathrm{C}$, conduziu a uma diminuição no excesso enantiomérico para $86 \%$ e decréscimo no rendimento também foi observado $90 \%$ (entrada 5). Tentativas de diminuição na quantidade de ligante para 10 mol\% e 15 mol\% também não mostrou-se interessante, uma vez que um decréscimo significativo no excesso enantiomérico foi observado(entradas 6 e 7).0 uso de DiMPEG (di-metoxipolietilenoglicol), um aditivo comumente usado para melhorar a seletividade na adição assimétrica de reagentes organozinco, ${ }^{22}$ também mostrou-se infrutífero, uma vez que conduziu tanto a rendimentos quanto aee menores (entrada8 e 9).

\footnotetext{
22 Rudolph, J.; Hermanns, N.; Bolm, C.J. Org. Chem. 2004, 69, 3997-4000.
} 
Tabela 2.Arilação assimétrica do $p$-tolualdeído na presença dos ligantes 10a-c.

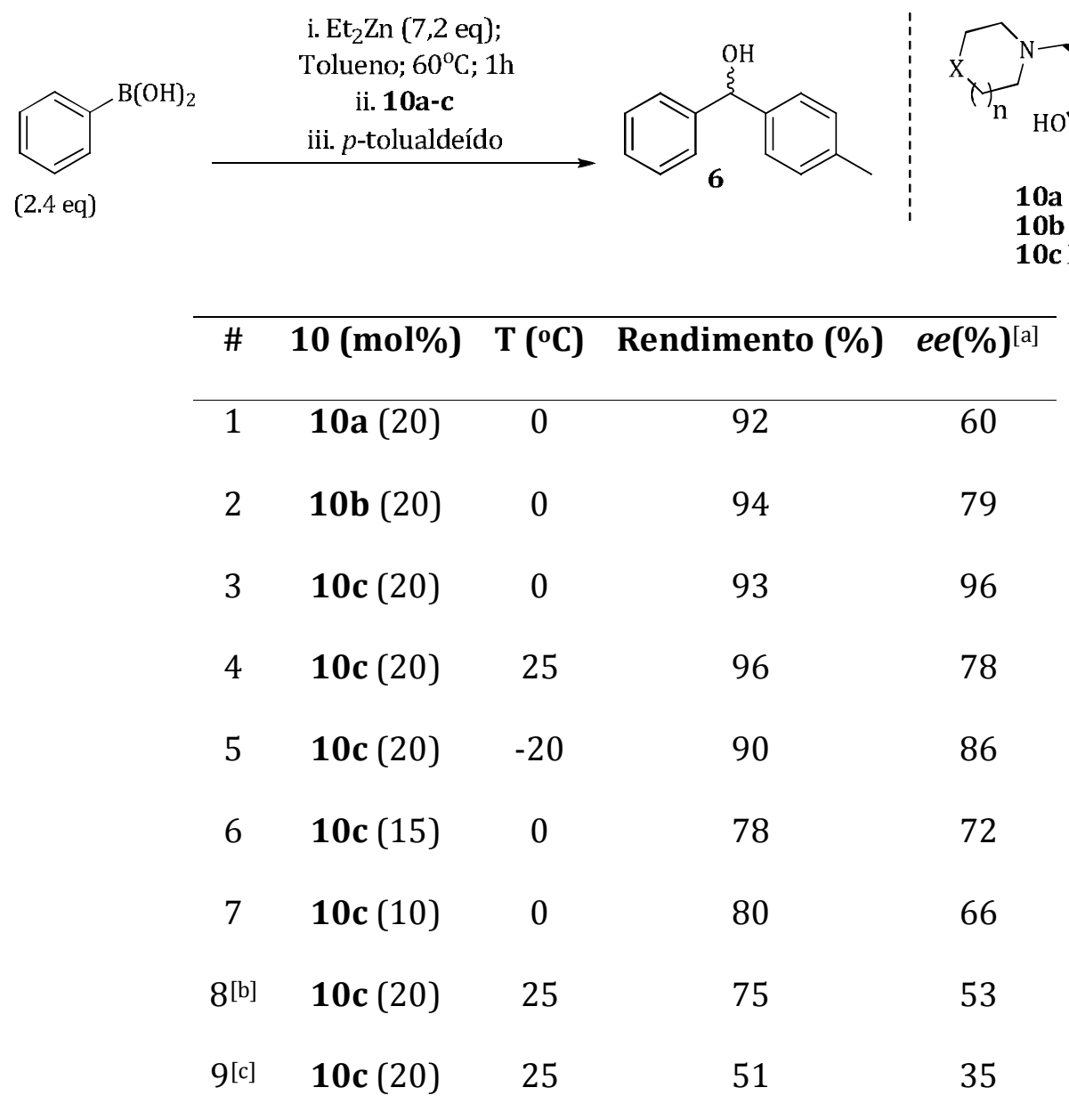

[a] Os excessos enantioméricos foram determinados por HPLC usando fases estacionárias quirais. A configuração absoluta dos compostos foi determinada por comparação com dados da literatura. [b] DiMPEG (20 mol\%) PM 2000 foi usado como aditivo. [c] DiMPEG (10 mol\%) PM 2000 foi usado como aditivo.

Os melhores resultados foram obtidos quando se estabeleceu como objetivo tornar as condições reacionais mais brandas. A reação de arilação enantiosseletiva do $p$-tolualdeído foi conduzida em tempos de reação e temperaturas menores, do que as condições padrões estabelecidas para este tipo de reação. Com satisfação o produto de arilação foi obtido em até $93 \%$ de rendimento e $96 \%$ ee. Estas condições foram usadas como padrão para o restante das reações. 
Com as condições primárias otimizadas, a próxima etapa consistiu na ampliação do escopo das reações de arilação onde ambas as partes constituintes, aldeídos e ácidos borônicos, foram avaliadas (Tabela 3). A reação tolera grande variedade de substituintes e de modo geral, as reações realizadas com aldeídos contendo grupos retiradores de elétrons conduziram a rendimentos e ee maiores. Por exemplo, na arilação do 4-bromobenzaldeído o produto é formado em 95\%de rendimento e 88\%ee (entrada 7), enquanto que a arilação do 4-anisaldeído conduz ao diarilmetanol correspondente em rendimento similar de 94\% mas com decréscimo na enantiosseletividade da reação para $80 \% e e($ entrada 3). Outro dado interessante é a tolerância e similaridade nos resultados obtidos para os derivados com substituintes na posição orto, mostrando que a reação tolera substratos mais impedidos estericamente (p.ex. entradas5 e 6).

A possibilidade de preparar ambos enantiômeros usando o mesmo ligante, através de uma combinação adequada dos constituintes, aldeído e ácido borônicos é uma das características mais atrativas da reação estudada. Nesse particular, a arilação do benzaldeído foi conduzida com ácido $p$-tolilborônico e ácido $p$ cloroborônico levando a excelentes rendimentos e bons excessos enantioméricos dos diarilmetanóis com configuração $S$, oposta àquela obtida utilizando a combinação entre o ácido fenilborônico e o $p$-tolualdeído e o $p$-clorobenzaldeído (compare as entradas 1 e 10 e as entradas 5 e 11).

Adicionalmente, a síntese de diarilmetanois substituídos em ambos os anéis aromáticos em bons rendimentos e ee foi obtida variando-se as substituições nos ácidos borônicos e aldeídos simultaneamente (entradas 12 a 14). Novamente, os dois enantiômeros de um mesmo álcool quiral foram obtidos, em níveis similares de enantiosseletividade, apenas pela variação dos substituintes dos dois reagentes 
utilizados, na presença do mesmo ligante quiral (entradas 12 e 13). Por fim, além da arilação de aldeídos aromáticos, a arilação do cicloexilcarboxaldeído também foi avaliada e o produto foi obtido em bom rendimento, porém com um excesso enantiomérico moderado (entrada 9).

Tabela 3. Ampliação do escopo e avaliação das partes constituintes.

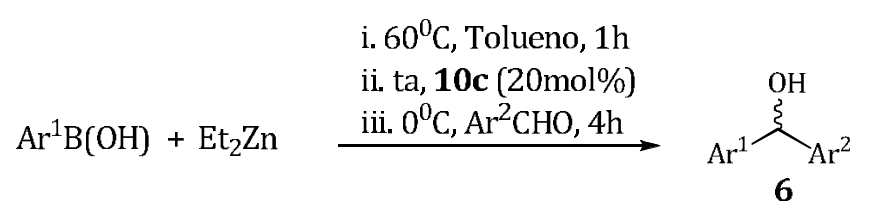

\begin{tabular}{|c|c|c|c|c|}
\hline Entrada & $A r^{1}$ & $A r^{2}$ & Rend. (\%) & $e e(\%)$ \\
\hline $1(a)$ & fenil & 4-metilfenil & 97 & 96 \\
\hline $2(\mathrm{~b})$ & fenil & 2-metilfenil & 96 & 90 \\
\hline $3(c)$ & fenil & 4-metoxifenil & 94 & 80 \\
\hline $4(d)$ & fenil & 2-metoxifenil & 96 & 78 \\
\hline $5(e)$ & fenil & 4-clorofenil & 96 & 83 \\
\hline $6(f)$ & fenil & 2-clorofenil & 91 & 87 \\
\hline $7(\mathrm{~g})$ & fenil & 4-bromofenil & 95 & 88 \\
\hline $8(\mathrm{~h})$ & fenil & 2-bromofenil & 91 & 87 \\
\hline $9(\mathrm{i})$ & fenil & cicloexil & 84 & 67 \\
\hline $10(j)$ & 4-metilfenil & fenil & 95 & 84 \\
\hline $11(\mathrm{k})$ & 4-clorofenil & fenil & 94 & 82 \\
\hline $12(\mathrm{l})$ & 4-metilfenil & 4-clorofenil & 91 & 83 \\
\hline $13(\mathrm{~m})$ & 4-clorofenil & 4-metilfenil & 92 & 88 \\
\hline $14(\mathrm{n})$ & 4-bifenil & 4-metilfenil & 92 & 86 \\
\hline
\end{tabular}


O mecanismo de arilação assimétrica foi proposto independentemente por Pericàs ${ }^{23}$ e Bolm-Norrby ${ }^{24}$. A proposta para o mecanismo reacional está descrita no Esquema11. Primeiramente quando difenilzinco e dietilzinco são misturados em solução, uma troca de grupos ocorre e o equilíbrio é composto predominantemente pela espécie PhZnEt e este reagente misto na presença de um ligante quiral forma preferencialmente um complexo quiral de zinco substituído com o grupo etil, representado pela estrutura A, que é o catalisador propriamente dito para a arilação enantiosseletiva. Desta forma o aldeído interage com o catalisador levando a um estado de transição tricíclico, como descrito originalmente por Noyori. ${ }^{25} \mathrm{O}$ estado de transição representado pela estrutura $\mathbf{C}$, com conformação anti-trans é preferencial a estrutura anti-cis $\mathbf{D}$, pois evita que o grupo arila do aldeído esteja na posição axial, minimizando assim interações estéricas com o grupo etila ligado ao átomo de zinco. De acordo, a transferência do grupo aril pela face $R e$ do aldeído resulta na formação do $(R)$-diarilmetanol como produto majoritário. Esta proposta está de acordo com os resultados observados experimentalmente.

\footnotetext{
${ }^{23}$ Fontes, M.; Verdaguer, X.; Solà, L.; Pericàs, M. A.; Riera, A. J. Org. Chem.;2004; 69; 2532-2543.

24 (a) Rudolph, J.; Bolm, C.; Norrby, P.-O. J. Am. Chem. Soc.; 2005; 127; 1548-1552; (b) Rudolph, J.; Rasmussen, T.; Bolm, C.; Norrby, P.-O.Angew.Chem. Int. Ed.; 2003; 40; 3002-3005.

${ }^{25}$ Noyori, R.; Kitamura, M. Angew. Chem. Int. Ed.1991; 30; 49-69.
} 

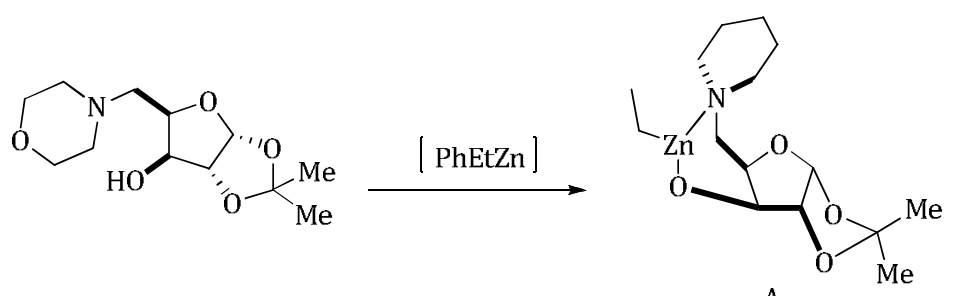

A

Favorecido

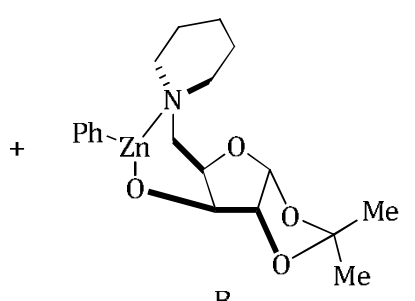

B<smiles>O=Cc1ccccc1</smiles>
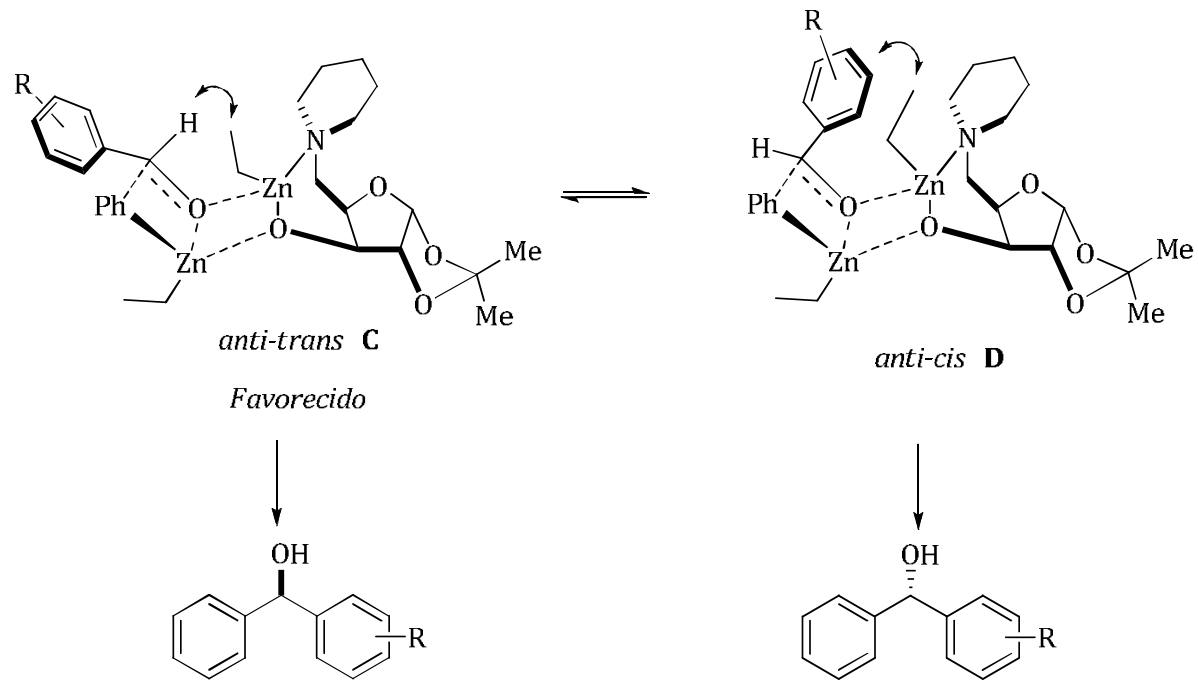

anti-cis D

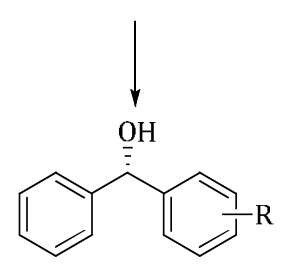

(R)-Produto majoritário

Esquema 11. Proposta para o mecanismo de arilação.

Maiores evidências para validar o estado de transição proposto foram obtidas a partir de cálculos teóricos usando o método PM3. Este método geralmente é eficiente para predizer resultados de reações enantiosseletivas. As estruturas do estado de transição foram calculadas a partir do ligante 10c para a transferência do grupo fenil ao $p$-tolualdeído. Quatro possíveis estruturas para o estado de transição foram consideradas: anti-trans, anti-cis, syn-cis e syn-trans. As formas mais estáveis juntamente com os valores relativos de energia estão descritas na Figura 9. 

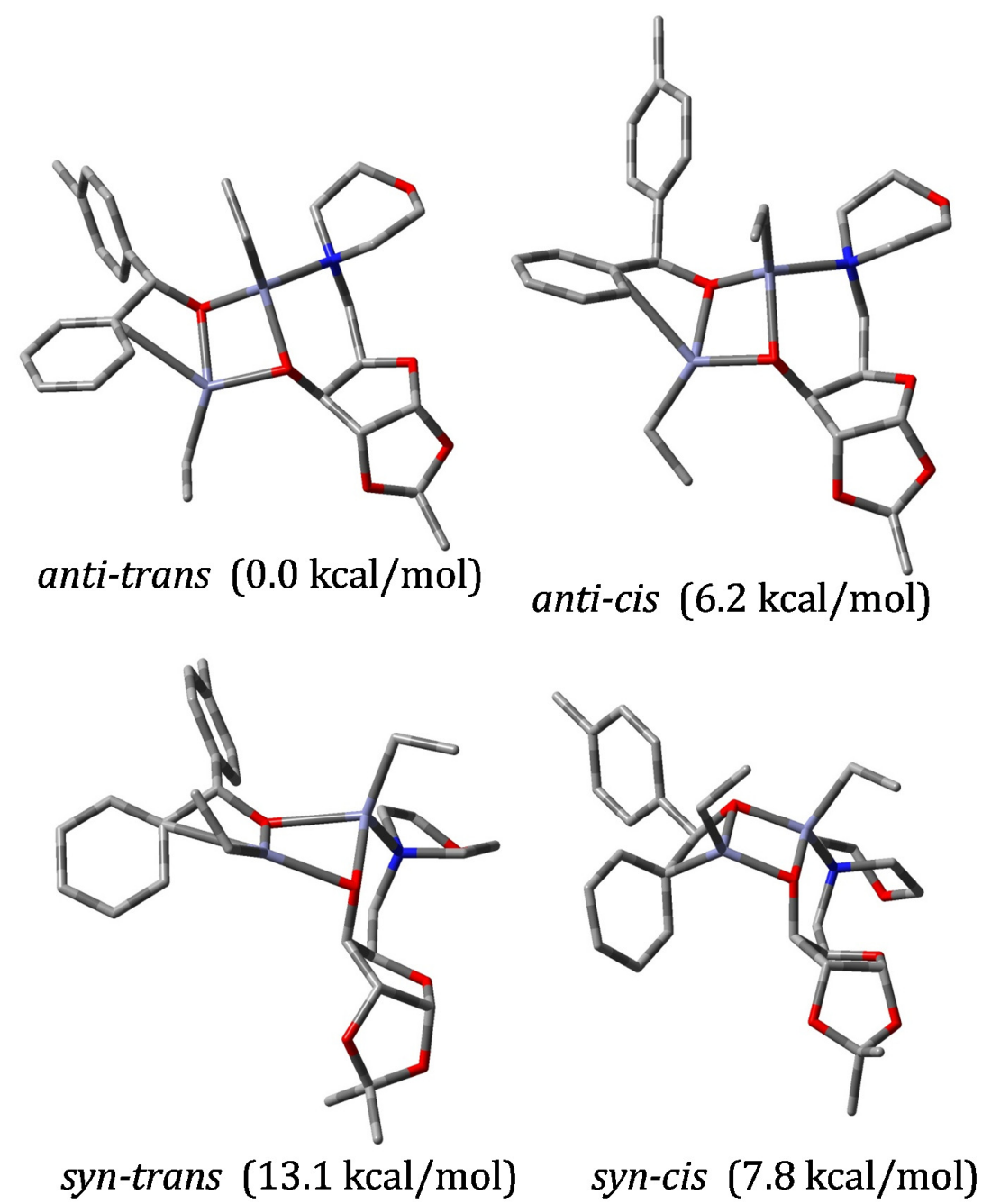

syn-trans $(13.1 \mathrm{kcal} / \mathrm{mol})$

syn-cis $(7.8 \mathrm{kcal} / \mathrm{mol})$

Figura 9. Estruturas dos estados de transição determinadas por PM3 para o ligante 10c.

As estruturas anti-trans e syn-trans levariam ao produto $(R)$, enquanto que as estruturas anti-cis e syn-cis levariam ao enantiomero $(S)$. Dentre elas, a estrutura anti-trans mostrou-se com estado de transição mais estável, seguida pela anti-cis. As estruturas syn-trans e syn-cis apresentaram energias mais altas e de acordo com os cálculos não contribuiriam muito na formação do produto. A diferença de energia entre os estados anti-trans e anti-cis foi de $6.2 \mathrm{kcal} \mathrm{mol}^{-1}$, levando ao produto $(R)$, conforme previsto. Assim, os cálculos realizados no modelo PM3 
foram eficientes para determinar corretamente a estereoquímica observada para a arilação de aldeídos aromáticos usando o ligante 10c derivado da $D$-xilose.

\section{CONSIDERAÇÕES FINAIS E CONCLUSÕES}

A preparação e aplicação de amino álcoois derivados de carboidratos, mais especificamente dos açúcares $D$-xilose e $D$-glucosamina, como ligantes na arilação assimétrica de aldeídos usando ácidos arilborônicos como fontes de grupos arila transferíveis mostrou-se um desafio interessante e com resultados bastante satisfatórios. Os amino álcoois 5a-c e 10a-c, mostrados abaixo, foram facilmente preparados e obtidos em bons rendimentos a partir da $D$-glucosamina e $D$-xilose, respectivamente.

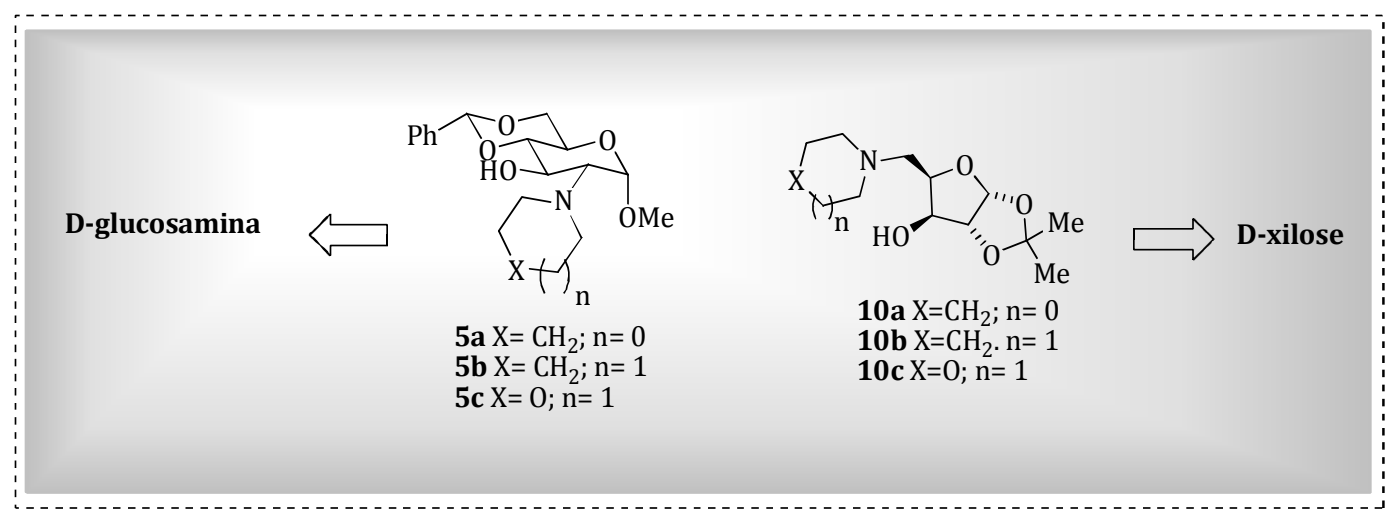

Figura 10. Derivados preparados a partir da $D$-xilose e $D$-Glucosamina.

Os compostos derivados da D-glucosamina, quando usados como ligantes, conduziram aos diarilmetanois em excelentes rendimentos, entretanto a excessos enantioméricos muito baixos. Já os compostos derivados da $D$-xilose se mostraram uma alternativa interessante na arilação assimétrica de aldeídos. No decorrer do trabalho, o composto 10c mostrou-se o ligante mais eficiente, conduzindo a adição 
de uma série de ácidos arilborônicos a vários aldeídos em excelentes rendimentos (84-97\%) e altos excessos enantioméricos (de até 96\%). A discrepância entre os resultados obtidos com os ligantes $\mathbf{1 0 b}$ e 10c, muito similares entre si, leva a crer que o efeito eletrônico exercido pelo oxigênio, presente no anel morfolínico, contribua para o aumento nos excessos enantioméricos.

Ambos enantiômeros de um mesmo diarilmetanol puderam ser preparados, a partir de um mesmo ligante quiral, apenas pela escolha adequada das partes constituintes, o ácido arilborônico e o aldeído. Este é um artifício simples e foi utilizado com sucesso, conduzindo aos produtos desejados em excelentes rendimentos e bons excessos enantioméricos.

O mecanismo de arilação assimétrica proposto por Pericàs e Bolm-Norrby, passando por um estado de transição tricíclico, como proposto originalmente por Noyori, neste trabalho pode ser evidenciado eficientemente por cálculos PM3. Este trabalho foi publicado no European Journal of Organic Chemistry, 2010, 23512356.

Grandes perspectivas estão associadas aos bons resultados obtidos neste trabalho. Carboidratos são compostos naturalmente abundantes e a altamente funcionalizados, características estas que permitem que muitas derivatizações sejam feitas e que os compostos preparados tenham seu desempenho avaliado em busca de altas seletividades para um grande número de reações enantiosseletivas 
CAPÍTULO 2. Carboidratos como substratos quirais em adições de reagentes organozinco 


\section{INTRODUÇÃO}

O controle da estereoquímica absoluta e a introdução estereoespecífica de grupos funcionais permanece um desafio na construção de moléculas quirais, mesmo aquelas apenas moderadamente funcionalizadas. Na verdade, este tem sido um dos maiores problemas para a síntese total ao longo dos anos. 0 planejamento e execução de rotas sintéticas nas quais substratos quirais possam ser produzidos e eficientemente utilizados apresentam vantagens enormes e é indiscutivelmente um dos caminhos mais desejados na busca por compostos opticamente puros. ${ }^{1}$

Durante muitos anos, a maioria das estratégias sintéticas na química de carboidratos foi inspirada por eventos bioquímicos, e o conhecimento ganho nestes estudos tem sido útil no avanço de muitas áreas de fronteiras da bioquímica. Entretanto, vendo os carboidratos de uma perspectiva diferente, são uma fonte barata de compostos quirais, com grande variedade estrutural, com aspectos estereoquímicos, conformacionais e funcionais únicos, sendo assim, fontes ideais para manipulações químicas e exploração de novos métodos sintéticos. A utilização mais conveniente de açúcares em síntese orgânica em geral, em particular na química de produtos naturais, deve ser aquela que enfoque e tire proveito sobre suas inerentes características moleculares transformando-os em intermediários sintéticos quirais eficientes. ${ }^{26}$

No Capítulo 1deste manuscrito está descrita a funcionalização da $D$-xilose e D-glucosamina e seu uso como ligantes quirais na adição de reagentes arilzinco a aldeídos para obtenção de álcoois secundários de forma enantiosseletetiva. Inspirados pela reatividade peculiar dos reagentes arilzinco e o sucesso na

26 (a) Fraser-Reid, B. Acc. Chem. Res., 1975, 8, 192-201. (b) Hanessian, S. Acc. Chem. Res., 1979, 12, 159-165. 
utilização de ligantes derivados de carboidratos nesse processo decidiu-se testar o potencial de aldeídos derivados de açúcares, como substratos quirais, visando o controle da diastereosseletividade sobre a formação do novo centro estereogênico. Considerando-se a hipótese de preparação de aldeídos derivados de carboidratos com diferentes padrões estruturais e estereoquímicos, optou-se pela utilização de $D$-ribose, $D$-manose, $D$-galactose e $D$-glicose, como matérias-primas. As estruturas dos aldeídos planejados podem ser observadas na (Figura11).

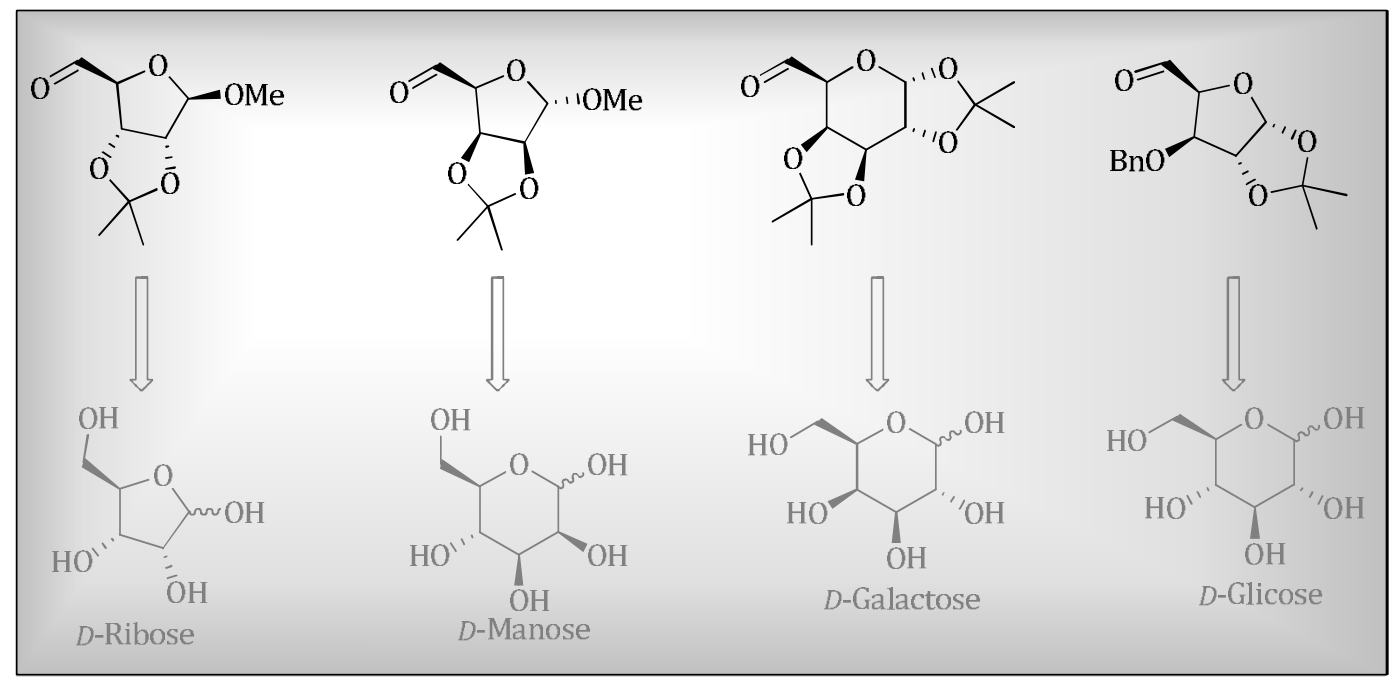

Figura 11. Aldeídos derivados dos carboidratos $D$-ribose, $D$-manose, $D$-galactose e $D$-glicose.

Após breve levantamento de algumas estruturas, observou-se que a adição de fenilzinco ao aldeído derivado da $D$-Glicose, por exemplo, poderia conduzir a um intermediário avançado na síntese total da (+)-goniofufurona, ou de seu epímero, a (+)-epi-goniofufurona (Figura 12). Estes compostos naturais, pertencentes à classe das estiril lactonas, apresentam potencial atividade citotóxica frente a algumas 
linhas de células tumorais e recentemente têm sido alvo de estudo de vários grupos devido a suas interessantes características estruturais e biológicas. ${ }^{27,28}$

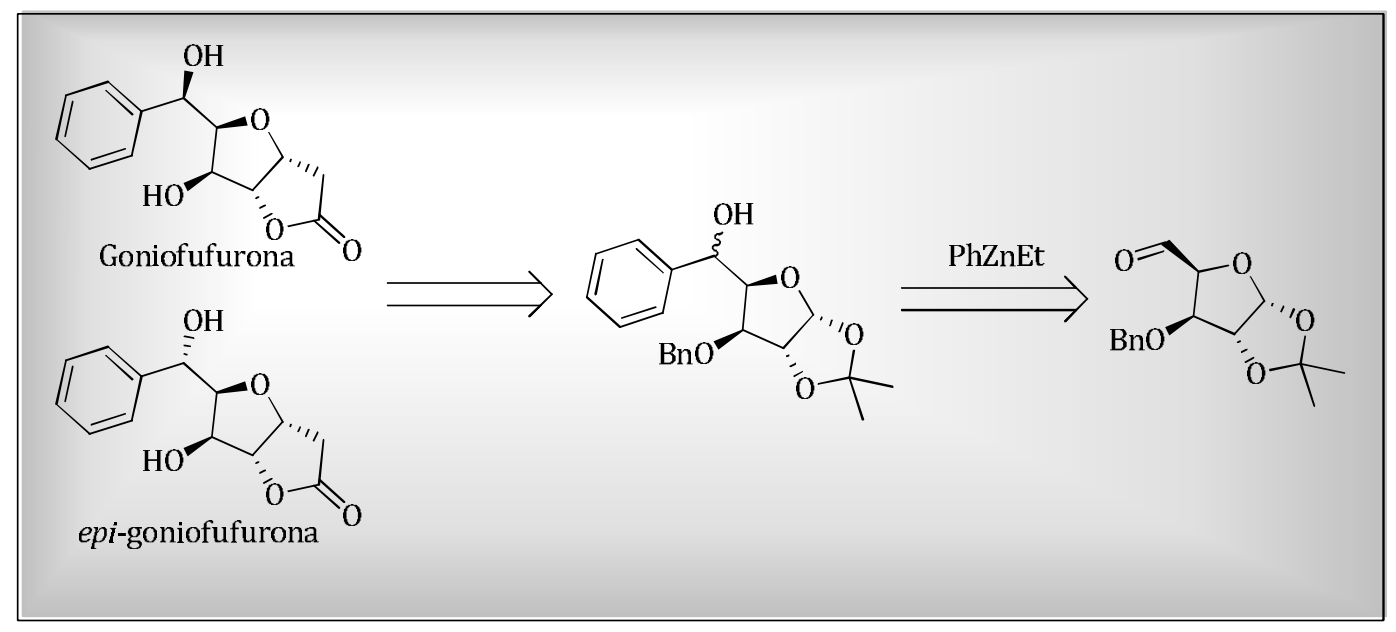

Figura 12. Análise retrossintética da goniofufurona e epi-goniofufurona a partir de aldeído derivado da $D$-Glicose.

\subsection{Goniofufurona, 7-Epi-Goniofufurona e derivados}

As plantas da família Annonaceae, em sua maioria nativas de regiões tropicais, tiveram seu potencial terapêutico reconhecido precocemente, uma vez que extratos e folhas destas plantas são tradicionalmente usados pela medicina popular no tratamento de edemas e reumatismos, bem como analgésicos e repelente de insetos, e também como abortivos. ${ }^{29}$ Este grande potencial despertou o interesse de muitos pesquisadores. A partir de extratos alcoólicos da casca do tronco da Goniothalamus giganteus (Annonaceae) McLaughlin e colaboradoresidentificaram diversos compostos biotativos, dentre eles o

\footnotetext{
${ }^{27}$ Popsavin, V.; Srećo, B.; Benedeković, G.; Francuz, J.; Popsavin, M.; Kojić, V.; Bogdanović, G. Eur. J. Med. Chem.2010, 45, 2876-2883.

${ }^{28}$ Popsavin, V.; Benedeković, G.; Srećo, B.; Popsavin, Francuz, J.; M.; Kojić, V.; Bogdanović, G. Bioorg.Med. Chem. Lett. 2008, 18, 5178-5181.

${ }^{29}$ Bruns, R.; Wernicke, A.; Köll, P. Tetrahedron 1999, 55, 9793.
} 
goniotanelol11, ${ }^{30}$ goniotriol12,31 goniofufurona13, goniopipirona14, acetilgoniotriol15, ${ }^{32}$ 9-deoxigoniopipirona16 e 7 -epi-goniofufurona17 ${ }^{33}$ mostrados na Figura 13.

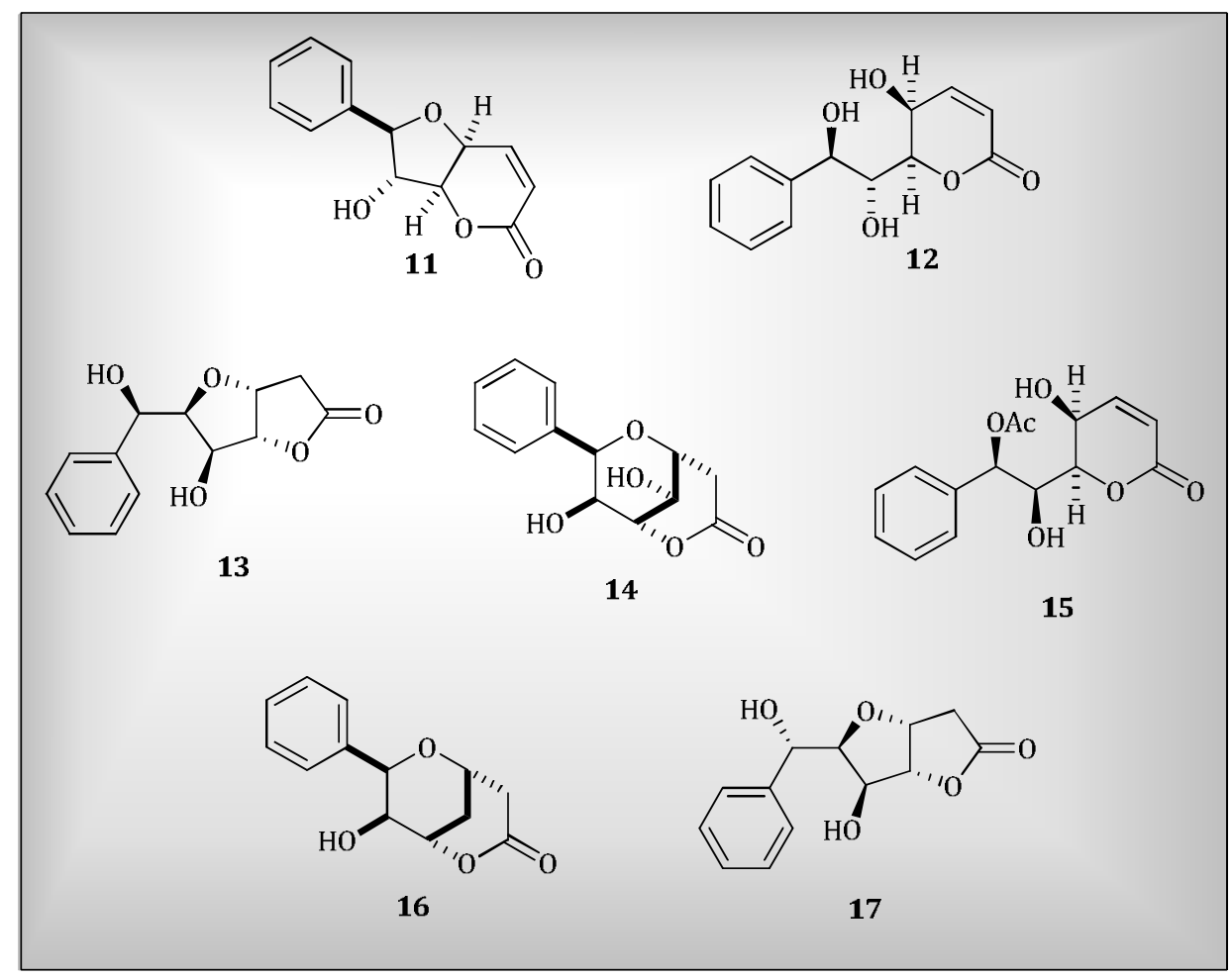

Figura 13. Alguns compostos identificados a partir de extratos alcoólicos da casca do tronco da Goniothalamus giganteus.

Dentre os compostos citados, vale salientar algumas moléculas pertencentes à classe das estiril lactonas, dentre elas pode-se destacar a (+)goniofufurona (13), a (+)-goniopipirona (14) e a (-)-epi-goniofufurona (17). A complexidade estrutural destas estiril lactonas, bem como suas notáveis atividades

\footnotetext{
${ }^{30}$ El-Zayat, A. E.; Ferrigni, N. R.; McCloud, T. G.; McKenzie, A. T.; Byrn, S. R.; Cassady, J. M.; Chang, C.-J.; McLaughlin, J. L. Tetrahedron Lett.1985, 26, 955-956.

${ }^{31}$ Alkofahi, A.; Ma, W.-W.; McKenzie, A. T.; Byrn, S. R.; McLaughlin, J. L. J. Nat. Prod., 1989, 52, 13711373.

${ }^{32}$ Fang, X-F.; Anderson, J. E.; Chang, C-J.; Fanwik, P. E.; McLaughlin, J. L. J. Chem. Soc., Perkin Trans. 1. 1990, 1655-1661.

${ }^{33}$ Fang, X-F.; Anderson, J. E.; Chang, C-J.; McLaughlin, J. L. J. Nat. Prod.,1991, 54, 4, 1034-1043.
} 
citotóxicas frente a certas linhas de células tumorais humanas, de imediato impulsionaram muitos esforços para a síntese destas substâncias e análogos.

Simultaneamente, em 1992, dois grupos de pesquisa determinaram a configuração absoluta da (+)-goniofufurona 13 através da síntese de seu enantiômero, a (-)-goniofufurona 18. Shing e colaboradores ${ }^{34}$ prepararam a (-)goniofufurona a partir da $D$-glicero- $D$-guloheptan- $\gamma$-lactona 19 , como pode ser observado no Esquema 12, a partir de uma sequência de reações clássicas o acetal $\mathbf{2 0}^{35}$ é obtido e posteriormente hidrolisado com simultânea lactonização do sistema. A lactona 21 é então submetida a uma reação tipo Michael intramolecular catalisada por DBU que conduz a (-)-goniofufurona 18. De forma similar ao trabalho previamente descrito, Shing e colaboradores ${ }^{36}$ também divulgaram a síntese do enantiômero da epi-goniofufurona 17 a partir do composto 19 . A estratégia sintética esteve baseada na inversão de configuração no C-7, conforme pode ser observado no Esquema 13.
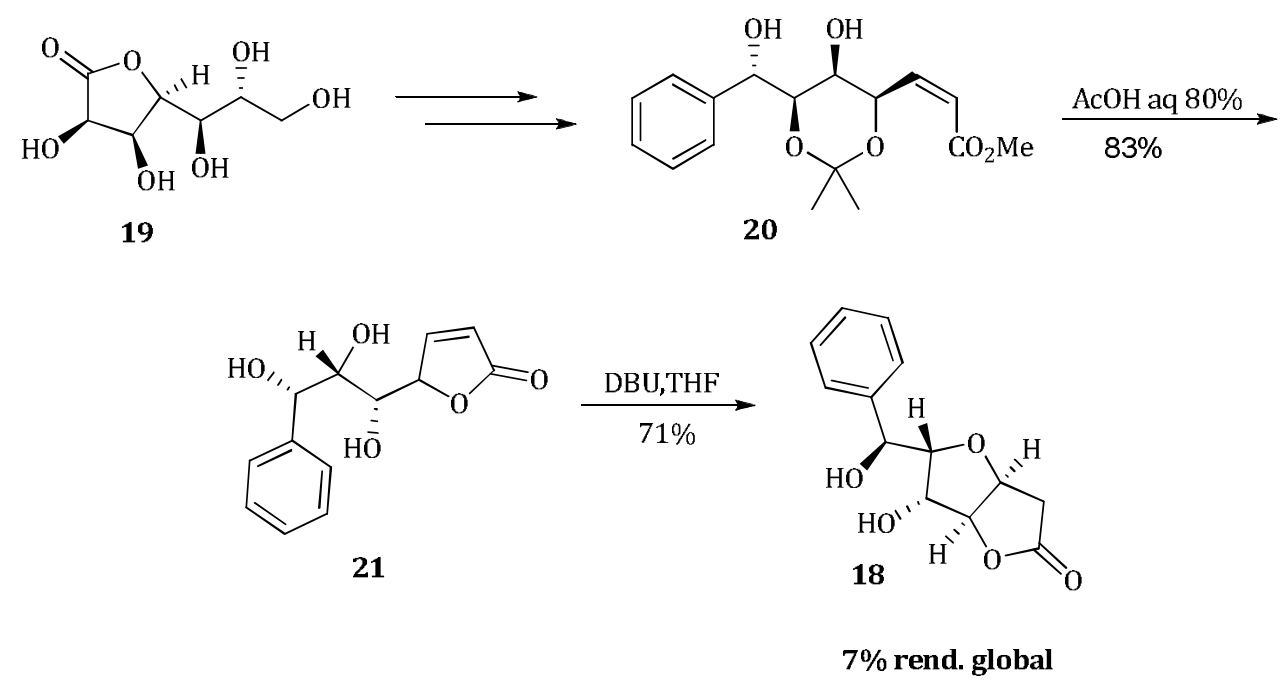

Esquema 12. Síntese da (-)-goniofufurona 18 por Shing e col.

\footnotetext{
${ }^{34}$ Shing, T. K. M.; Tsui, H-C.; J. Chem. Soc., Chem. Commun., 1992, 432.

${ }^{35}$ Shing, T. K. M.; Tsui, H.-C.; Zhou, Z.-H.; Mak, T. C. W. J. Chem. Soc., Perkin Trans. 1, 1992, 887-893.

${ }^{36}$ Shing, T. K. M.; Tsui, H-C.; Zhou, Z-H. Tetrahedron, 1992, 48, 8659-8666.
} 


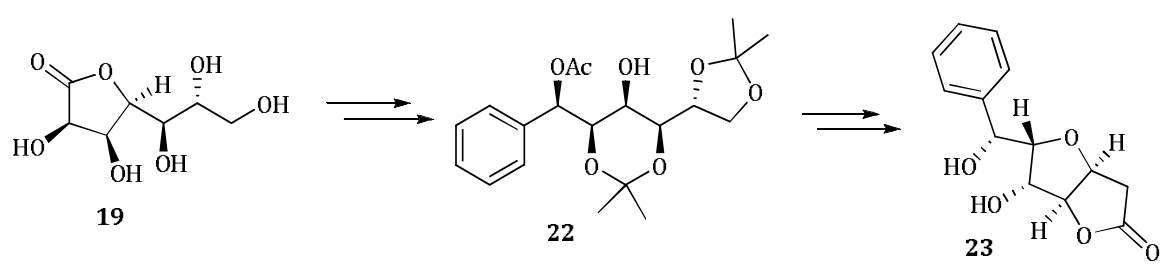

Esquema 13. Síntese da (-)-epi-goniofufurona 23 por Shing e col.

Gracza e colaboradores $^{37}$ em contrapartida prepararam o ene-poliol 24 derivado da D-glicose, conforme Esquema 14, e a formação da furanofurona foi alcançada através de uma ciclização e adição de monóxido de carbono catalisada por cloreto de paládio $\left(\mathrm{PdCl}_{2}\right)$ conduzindo a (-)-goniofufurona 18. Nos trabalhos publicados por Shing e Gracza para a síntese da (-)-goniofufurona, todos dados obtidos foram idênticos aos do produto natural (+)-goniofufurona, exceto a rotação óptica.

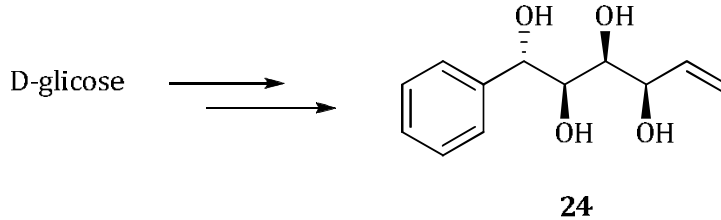

24

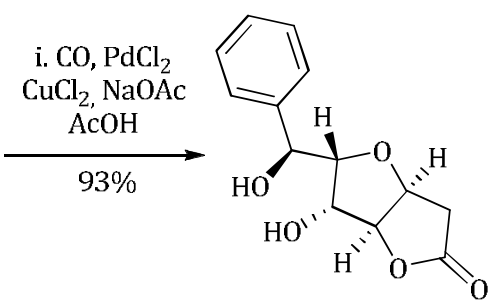

18

$31 \%$ rend. global

Esquema 14. Síntese da (-)-goniofufurona 18 por Gracza e col.

A primeira síntese total do produto natural (+)-goniofufurona 13 também foi descrita por Shing e colaboradores ${ }^{38}$, ainda em 1992, em uma estratégia envolvendo 8 etapas sintéticas, com rendimento global de $12.7 \%$ e utilizando novamente como material de partida o composto 19 de acordo com o Esquema 15. A primeira etapa envolve a bis-acetalização do composto 19 utilizando acetona e

37 Gracza, T.; Jäger, V. Synlett,1992, 191.

${ }^{38}$ Shing, T. K. M.; Tsui, H-C.; Zhou, Z-H.J. Chem. Soc.,Chem. Commun. 1992, 810. 
cloreto de zinco como catalisador, seguida de desproteção seletiva do acetonídeo de 5 membros com solução aquosa de ácido acético. Clivagem oxidativa do diol 26 resultante com subsequente adição de $\mathrm{PhMgBr}$ conduz ao composto 27 que é submetido a nova clivagem oxidativa e sequente reação de Wittig levando ao composto 28. Desproteção do acetonídeo, seguida de adição de Michael intramolecular conduz a (+)-goniofufurona 13.

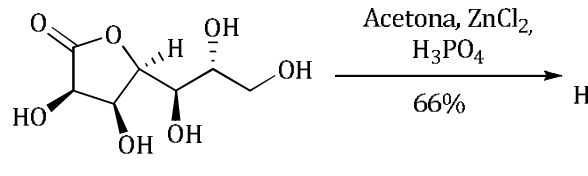

19<smiles>CC1(C)OC2C(O)C(=O)OC2C([C@H]2COC(C)(C)O2)O1</smiles>
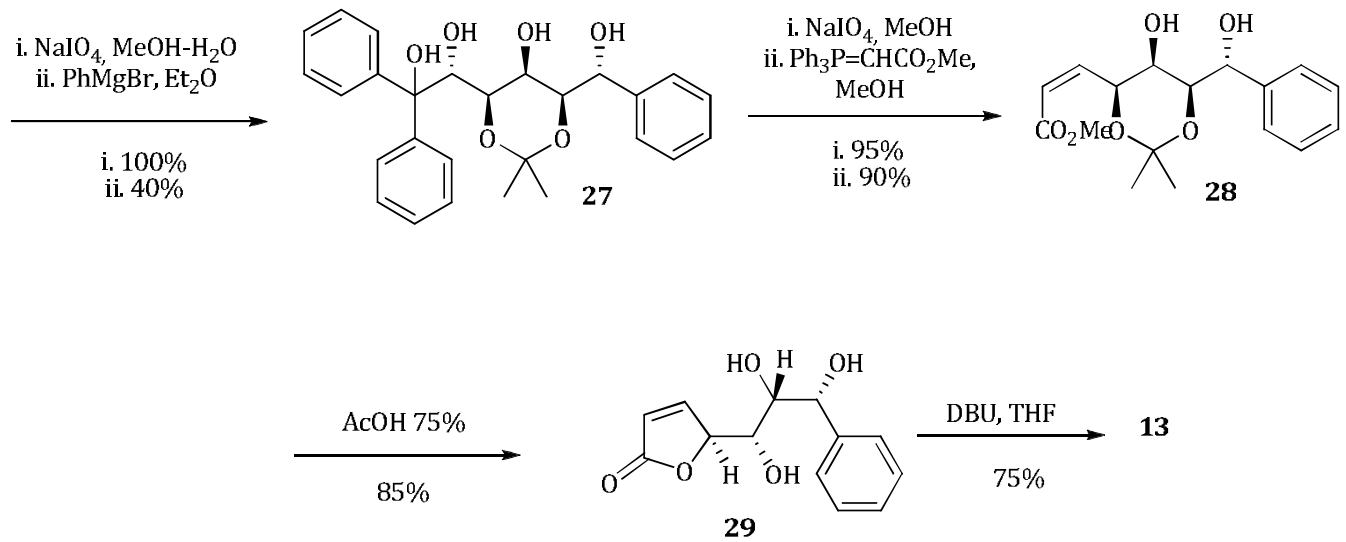

Esquema 15. Primeira síntese total da (+)-goniofufurona 13 por Shing e Col.

A metodologia de Shing e colaboradores, usando como etapa chave a reação de Wittig seguida por lactonização e adição de Michael intramolecular, foi amplamente utilizada em outros trabalhos publicados posteriormente. ${ }^{39} \mathrm{Em} 1993$, por exemplo, Prakash e Rao divulgaram a síntese da (+)-epi-goniofufurona ${ }^{40}$ e da (+)-goniofufurona ${ }^{41}$, ambas a partir da $D$-glicose (Esquema 16). No primeiro caso, a

39 (a) Yang, Z.-C.; Zhou, W.-S. Tetrahedron, 1995,51, 1429-1434; (b) Chen, W.-P.; Roberts, S. M. J. Chem Soc.,Perkin Trans. 1, 1999, 103-105; (c) Su, Y.-L.; Yang, C.-S.; Teng, S.-J.; Zhao, G.; Ding, Y. Tetrahedron, 2001, 57, 2147-2153.

${ }^{40}$ Prakash, K. R. C.; Rao, S. P. Synlett, 1993, 123-124.

41Prakash, K. R. C.; Rao, S. P. Tetrahedron, 1993, 49, 1505-1510. 
síntese da (+)-epi-goniofufurona, adição de brometo de fenilmagnésio a 3-O-benzil1,2-O-isopropilideno- $\alpha$ - $D$-xilopentodialdo-1,4-furanose

conduz preferencialmente ao produto desejado 31 derivado de controle quelante, e ao seu epímero em uma proporção de 12:1. Hidrólise do acetonídeo conduz a um triol como uma mistura $\alpha$ e $\beta$ da furanose32 e da piranose33. Esta mistura de tautômeros foi tratada com etoxicarbonilmetilenotrifenilfosforana para render o composto36 como único produto. As próximas duas etapas consecutivas, lactonização seguida de reação de Michael intramolecular, ocorre sem adição de nenhum catalisador conduzindo ao composto 17.

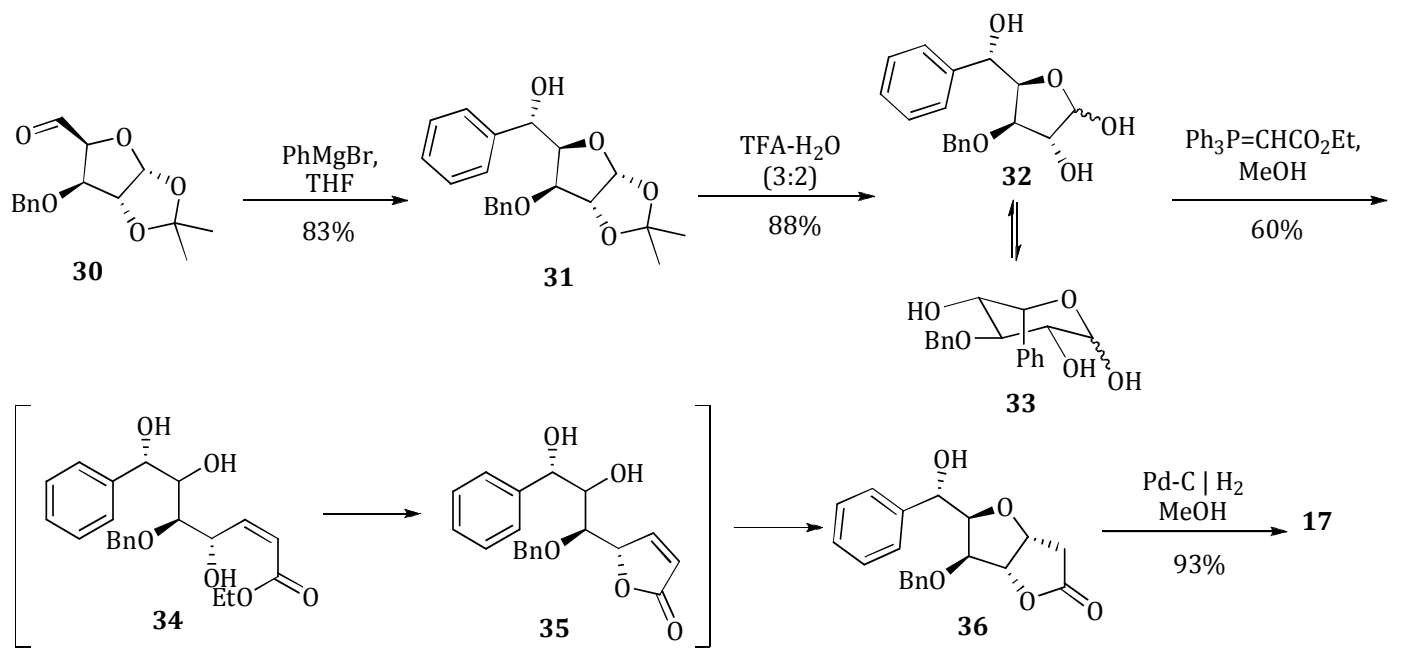

Esquema 16. Síntese da (+)-epi-goniofufurona 17 por Prakash e Rao.

Já para a síntese da (+)-goniofufurona (Esquema 17), duas etapas extras foram necessárias, uma vez que o produto obtido na adição de PhMgBr conduz preferencialmente ao produto derivado de controle quelante31, indesejado para a síntese da (+)-goniofufurona. A relação diastereoisomérica foi melhorada em favor da (+)-goniofufurona a partir de uma sequência oxidação-redução conduzindo a uma razão satisfatória de 10:1 do epímero desejado 38. E para evitar reações indesejadas, a hidroxila na posição 5 também foi protegida com um grupo 
benzil.Reação de Wittig seguida de lactonização e Michael intramolecular conduziram eficientemente ao biciclo furanofurona 40. Hidrogenação na presença de paládio levou a (+)-goniofufurona 13.
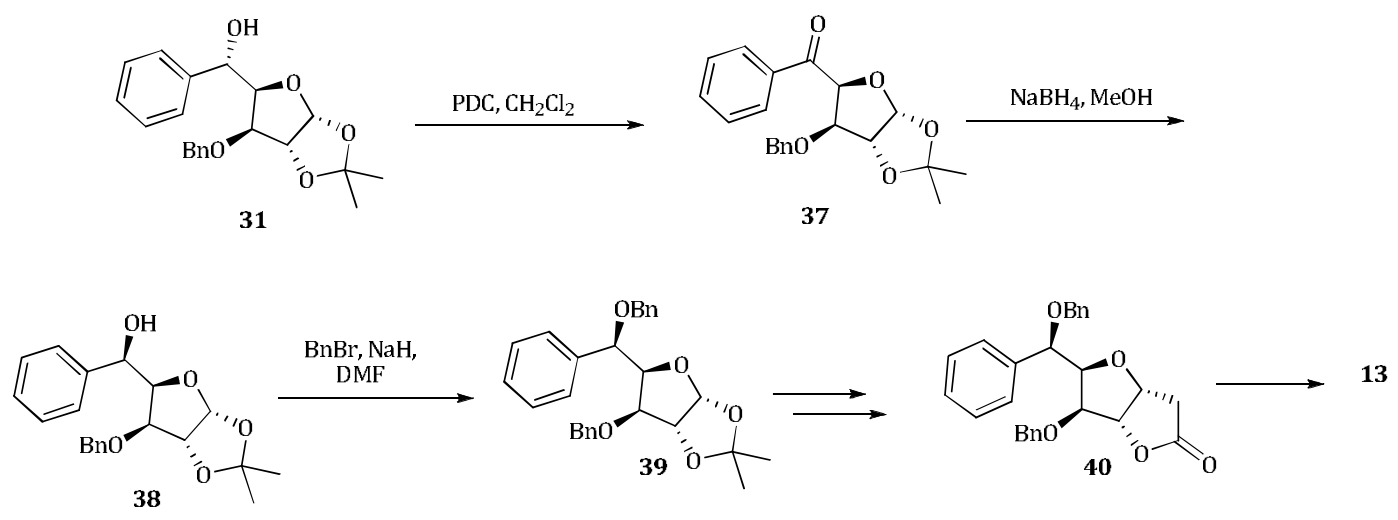

Esquema 17. Síntese da (+)-goniofufurona 13 por Prakash e Rao.

Ainda em 1993, Murphy e Dennison ${ }^{42}$ aplicaram uma estratégia um pouco diferente para a síntese da (+)-goniofufurona. Partindo da $D$-glicose, utilizaram como etapa chave uma ciclização de Wittig não-clássica entre uma fosforana estabilizada e uma butirolactona conforme pode ser observado no Esquema 18.

42 Murphy, P.J.; Dennison, S.T. Tetrahedron, 1993, 49, 6695-6700. 


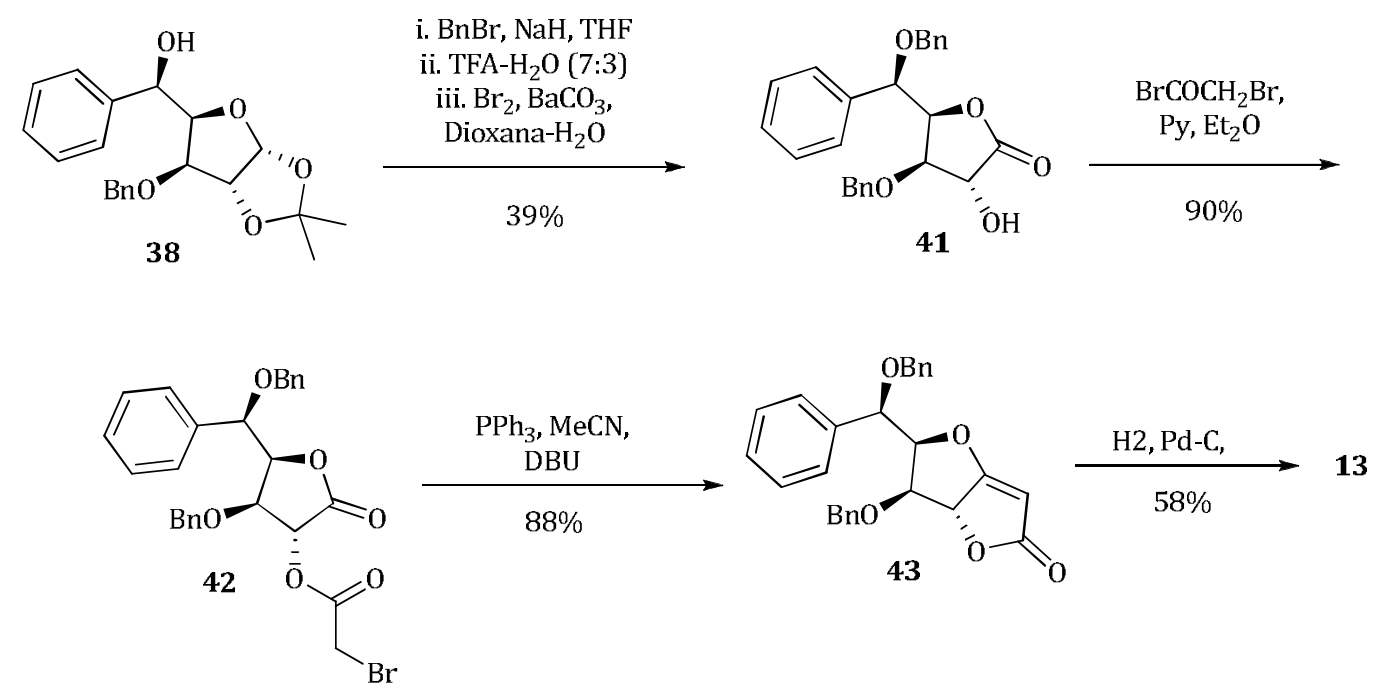

Esquema 18. Síntese da (+)-goniofufurona 13 por Murphy e Dennison.

Köll e colaboradores ${ }^{43}$, em 1999, relataram a síntese dos compostos 13 e 17 utilizando ácido de Méldrum na etapa de formação da lactona, segundo pode ser observado no Esquema 19.
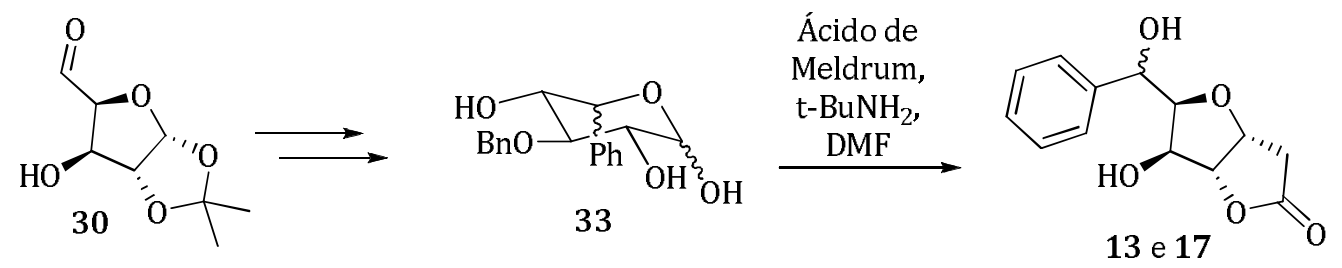

Esquema 19. Síntese da (+)-goniofufurona 13 e (+)-epi-goniofufurona 17 por Köll e colaboradores.

Mais recentemente, em 2007, Popsavin e colaboradores ${ }^{44}$, relataram uma nova abordagem para a síntese da (+)-goniofufurona 13 e (+)-epi-goniofufurona 17 partindo da $D$-xilose. Sua estratégia para preparação de forma eficiente de ambos epímeros, 13 e 17, envolveu uma reação de Mitsunobu como etapa chave para a inversão de configuração do similar de31, o composto 44 (Esquema 20). As etapas usadas na sequência foram reações clássicas já anteriormente descritas.

43 Bruns, R.; Wernicke, A.; Köll, P. Tetrahedron, 1999,55, 9793-9800.

${ }^{44}$ Popsavin, V.; Benedeković, G.; Srećo, B.; Popsavin, M.; Francuz, J.; Kojić, V.; Bogdanović, G. Org. Lett., 2007, 9, 4235-4238. 
<smiles>O=C[C@H]1O[C@@H]2OC3(CCCCC3)O[C@H]2[C@H]1OCc1ccccc1</smiles>

44
1) $\mathrm{PhMgBr} ; \mathrm{THF}$ $\frac{\mathrm{Et}_{2} \mathrm{O}, 0^{\circ} \mathrm{C} \text {-t.a.,3h }}{\text { 2) } \mathrm{BzOH}, \mathrm{Ph}_{3} \mathrm{P}, \mathrm{DEAD}, \mathrm{THF}}$

$0^{\circ} \mathrm{C}$-ta., $3 \mathrm{~h}$ $55 \%$ de 2 etapas

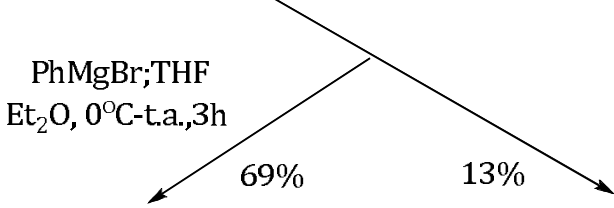

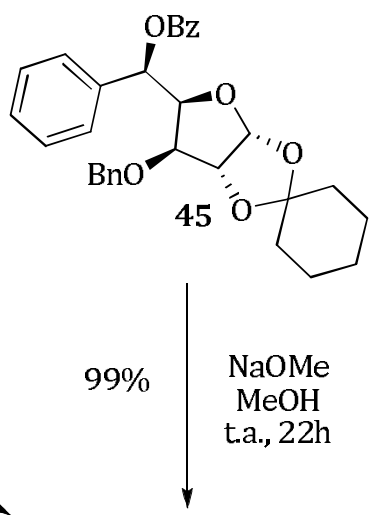
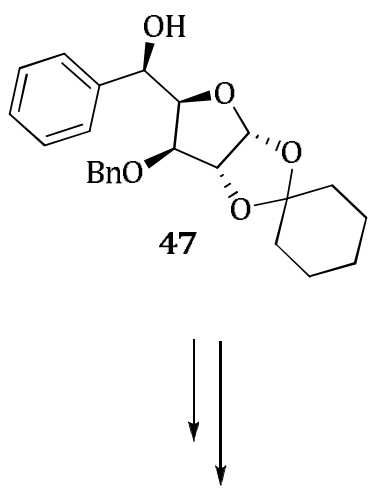

13

Rend. global: $16 \%$

Rend. global: $23 \%$

Esquema 20. Síntese da (+)-goniofufurona 13 e (+)-epi-goniofufurona 17 por Popsavin e colaboradores.

\section{JUSTIFICATIVA E OBJETIVOS PROPOSTOS}

Considerando-se o sucesso obtido na arilação enantiosseletiva de aldeídos com reagentes arilzinco, oriundos da troca boro-zinco, e a reatividade peculiar apresentada por esses reagentes, aliado ao interesse na modificação estrutural de carboidratos para a obtenção de produtos naturais e análogos, o presente trabalho tem por objetivo:

$\Rightarrow 0$ estudo metodológico da adição de reagentes arilzinco à aldeídos quirais, derivados de carboidratos. Em particular, o estudo visa desenvolver uma 
metodologia que permita a obtenção dos álcoois quirais com altos níveis de diastereosseletividade,

$\Rightarrow$ Aplicação na metodologia desenvolvida para a síntese de compostos naturais pertencentes à família das estirillactonas e seus análogos.

\section{APRESENTAÇÃO E DISCUSSÃO DOS RESULTADOS OBTIDOS}

\subsection{Síntese dos aldeídos derivados de carboidratos}

\subsection{1. $D$-Glicose}

O planejamento sintético para a preparação do aldeído $\mathbf{3 0}$, derivado da $D$ glicose, está centrado na aplicação de estratégias quimiosseletivas, conforme mostrado no Esquema 21. A abordagem inicial para a síntese do aldeído desejado envolve a acetalização da glicose usando acetona, na presença de quantidades catalíticas de iodo, fornecendo o bis-acetonídeo $4 \mathbf{4 8}$, em $72 \%$ de rendimento. ${ }^{45}$ Posteriormente, a hidroxila secundária foi devidamente protegida com brometo de benzila, utilizando-se hidróxido de sódio como base e brometo de tetrametilamônio como agente de transferência de fase dos íons hidróxido, conduzindo ao composto 49 em $86 \%$ de rendimento. ${ }^{46}$ Esta proteção faz-se necessária para evitar a formação de produtos de polimerização nas etapas seguintes. Posteriormente o bis-acetonídeo foi hidrolisado seletivamente, com ácido acético diluído, levando ao diol 50, em rendimentos excelentes. Por fim, o

${ }^{45}$ Kartha, K. P. R. Tetrahedron Lett., 1986, 27, 3415-3416.

46Roy, A.; Achari, B.; Mandal, S. B. Synthesis, 2006, 6, 1035-1039. 
aldeído 30 foi obtido, eficientemente, a partir da clivagem oxidativa do diol utilizando-se periodato de sódio. ${ }^{47}$

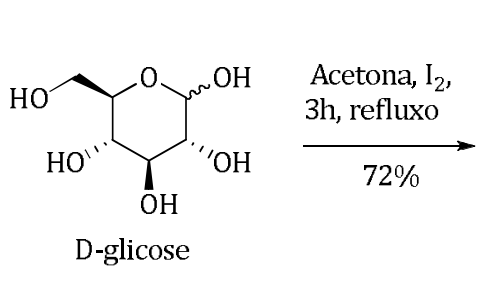

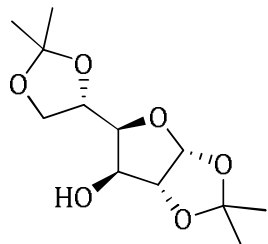

48

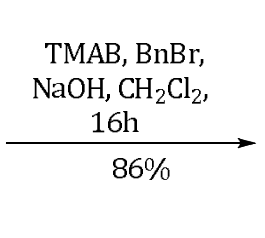

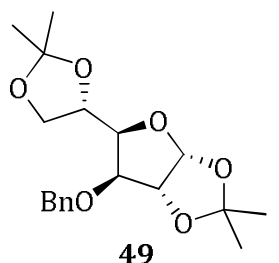

49

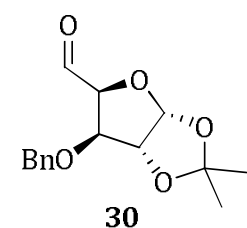

Esquema 21. Síntese do aldeído 30 derivado da $D$-Glicose.

Neste momento é fundamental ressaltar duas observações importantes. A primeira está relacionada à etapa de proteção do álcool secundário com brometo de benzila, sem a qual há dificuldade de isolamento do aldeído, podendo observarse a formação de subprodutos, provavelmente oriundos da polimerização do material. Uma segunda observação que pode ser feita é em relação à estabilidade do aldeído 30 obtido. 0 aldeído deve ser utilizado em alguns dias, pois produtos de decomposição começam a ser observados, mesmo quando armazenado sob refrigeração.

\subsection{2. $D$-Manose}

O aldeído 53, derivado da $D$-manose, pode ser facilmente obtido em apenas 3 etapas. Inicialmente duas modificações estruturais são necessárias, e podem ser realizadas em apenas uma etapa, a bis-acetalização, utilizando acetona, e a

\footnotetext{
${ }^{47}$ Gautam, D.; Naveen Kumar, D.; Venkateswara Rao, B. Tetrahedron: Asymm., 2006, 17, 819-821.
} 
proteção da posição anomérica, usando metanol, ambos os processos catalisados em meio ácido ${ }^{48}$ (Esquema 22). Hidrólise seletiva do bis-acetonídeo $\mathbf{5 1}$ foi realizada com ácido acético diluído, conduzindo ao diol 52 em excelentes rendimentos. Clivagem oxidativa do diol utilizando periodato de sódio levou a formação do aldeído 15 desejado, em $82 \%$ de rendimento. ${ }^{49}$
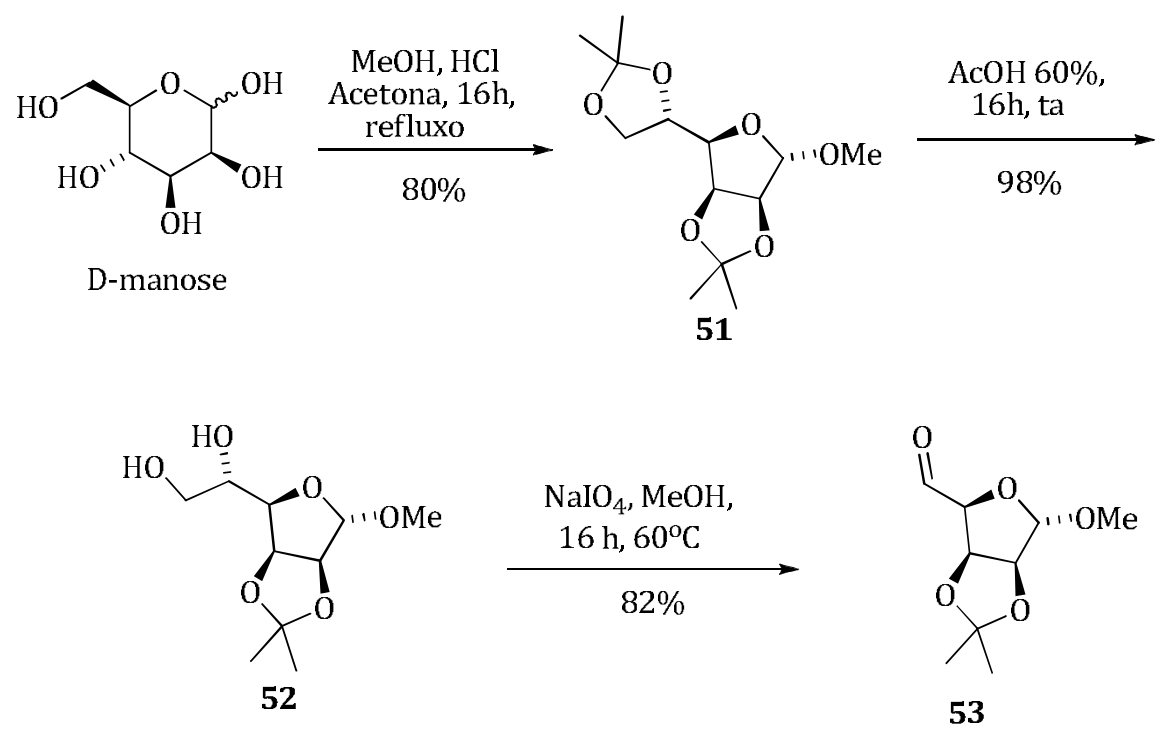

Esquema 22. Rota sintética para a obtenção do aldeído 53.

A primeira etapa sintética, onde ocorre a reorganização estrutural e formação do sistema furanosídico, com concomitante bis-acetalização, é catalisada por $\mathrm{HCl}$. Inicialmente, ocorre a abertura do anel tetraidropirano da $D$-manose, resultando no açúcar de cadeia aberta (Esquema 23). Este processo está em equilíbrio e a ciclização pode ocorrer, desta vez levando ao anel de 5 membros e a formação do bis-acetonídeo por reação das hidroxilas com acetona. A próxima etapa, também envolve catálise ácida, conduzindo a formação de um íon oxônio pela eliminação de água. A adição nucleofílica é altamente estereosseletiva e 
conduz exclusivamente a um anômero ${ }^{50}$ conforme pode ser observado no espectro de RMN ${ }^{1} \mathrm{H}$ (Figura 14).

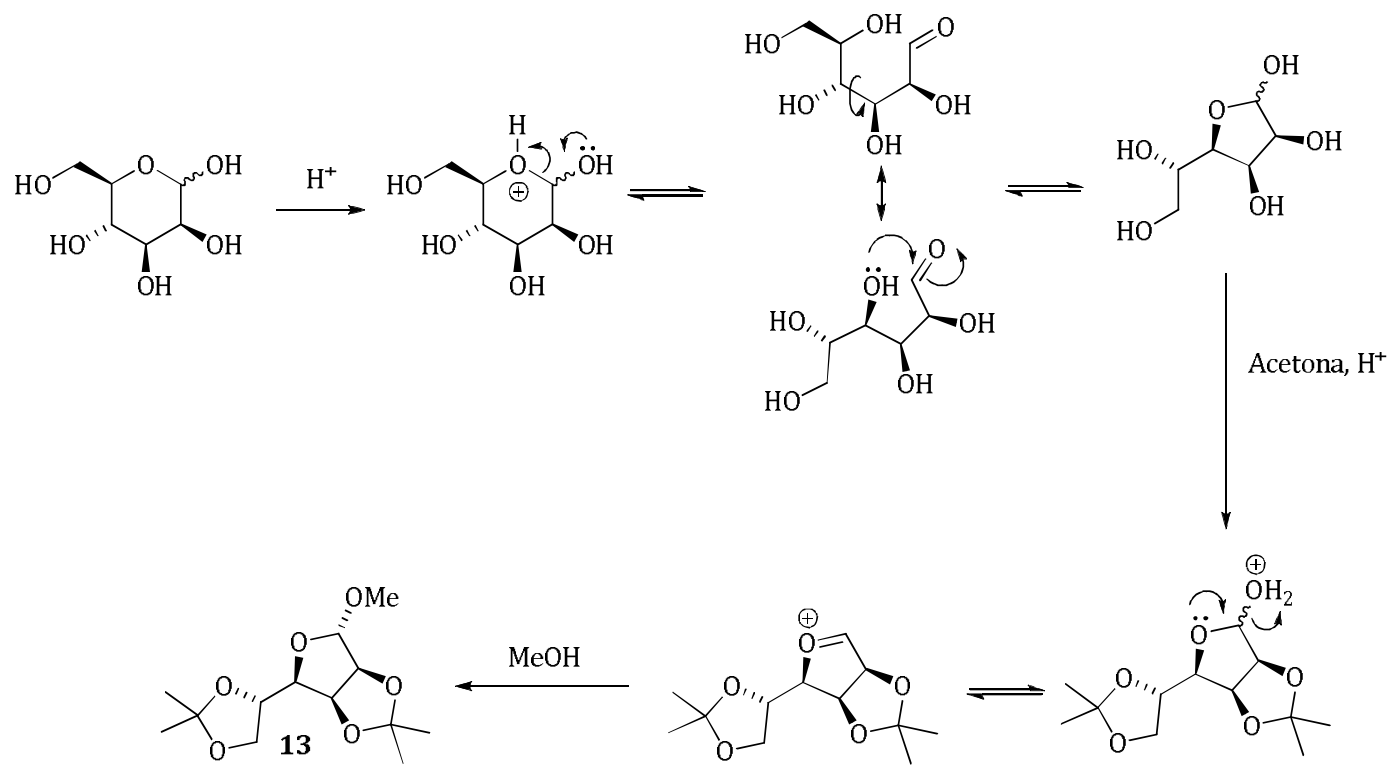

Esquema 23. Mecanismo proposto para a formação do bis-acetonídeo51.

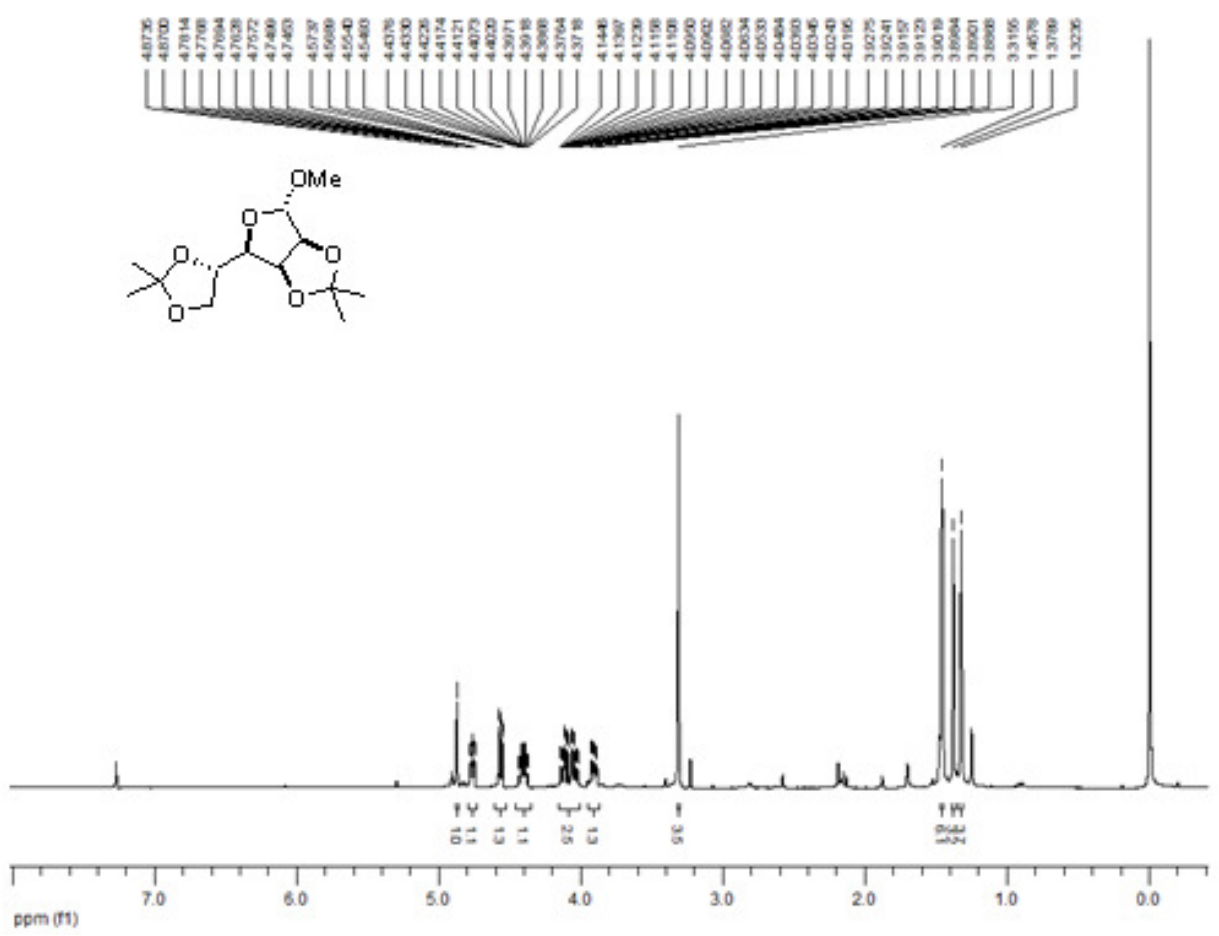

Figura 14. Espectro de ${ }^{1} \mathrm{H}$ RMN do composto 13.

${ }^{50}$ C. V. Ramana, S. B. Narute, R. G. Gonnade, Synthesis, 2008, 11, 1783-1787. 
Reações estereosseletivas em íons oxônio contidos em aneis de cinco membros podem ser entendidas pela avaliação da conformação preferencial de ambos, reagentes e produtos, e suas novas conformações formadas. A conformação preferida em aneis de cinco membros com um íon oxônio, assim como em um anel ciclopenteno, é a forma de um envelope, onde a dupla ligação está na porção plana do anel. ${ }^{51} 0$ ataque nucleofílico, assim como em aneis de seis membros, leva ao produto tetraidrofurano em duas diferentes conformações (Esquema 24). 0 ataque pela face interna do anel conduz a um estado de transição alternado levando a estrutura A (Equação 1), enquanto que o ataque pela face externa do anel passa por um estado de transição eclipsado, levando ao confôrmero B (Equação 2). 0 estado de transição para a formação de A é um processo menos energético, sendo, portanto o mais favorecido. ${ }^{52}$

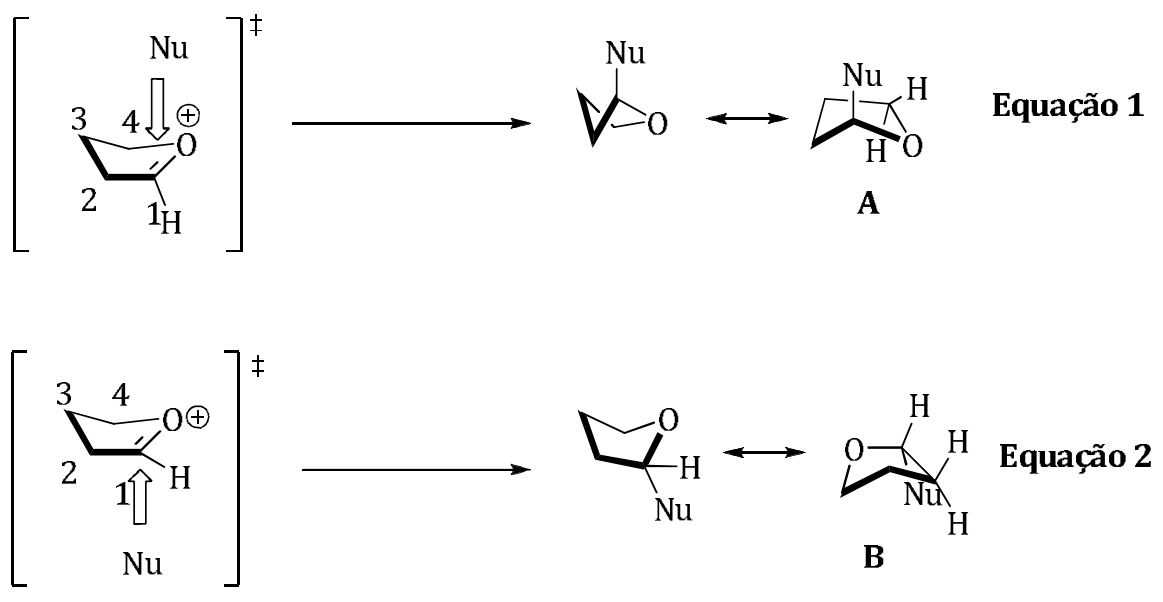

Esquema 24. Conformações para aneis de cinco membros contendo um íon oxônio e conformações dos produtos formados.

51 Toromanoff, E. Tetrahedron, 1980, 36, 2809-2931.

52Larsen, C. H.; Ridgway, B. H.; Shaw, T. J.; Woerpel, K. A. J. Am. Chem. Soc. 1999, 121,12208-12209. 
Adaptando o mecanismo de adição nucleofílica de $\mathrm{MeOH}$ ao íon oxônio(estrutura C, Esquema 25), pode-se observar que adição pela face interna do anel segue o modelo proposto. Entretanto um comportamento anômalo é observado em relação ao modelo de Woerpel, que descreve a adição ao íon oxônio em uma relação cis ao grupo alcóxi na posição 3. Neste caso, um fator que parece contribuir para a formção do anômero $\alpha$ é a interação estérica entre o $\mathrm{MeOH}$ que está sendo adicionado e o substituinte no C-2.

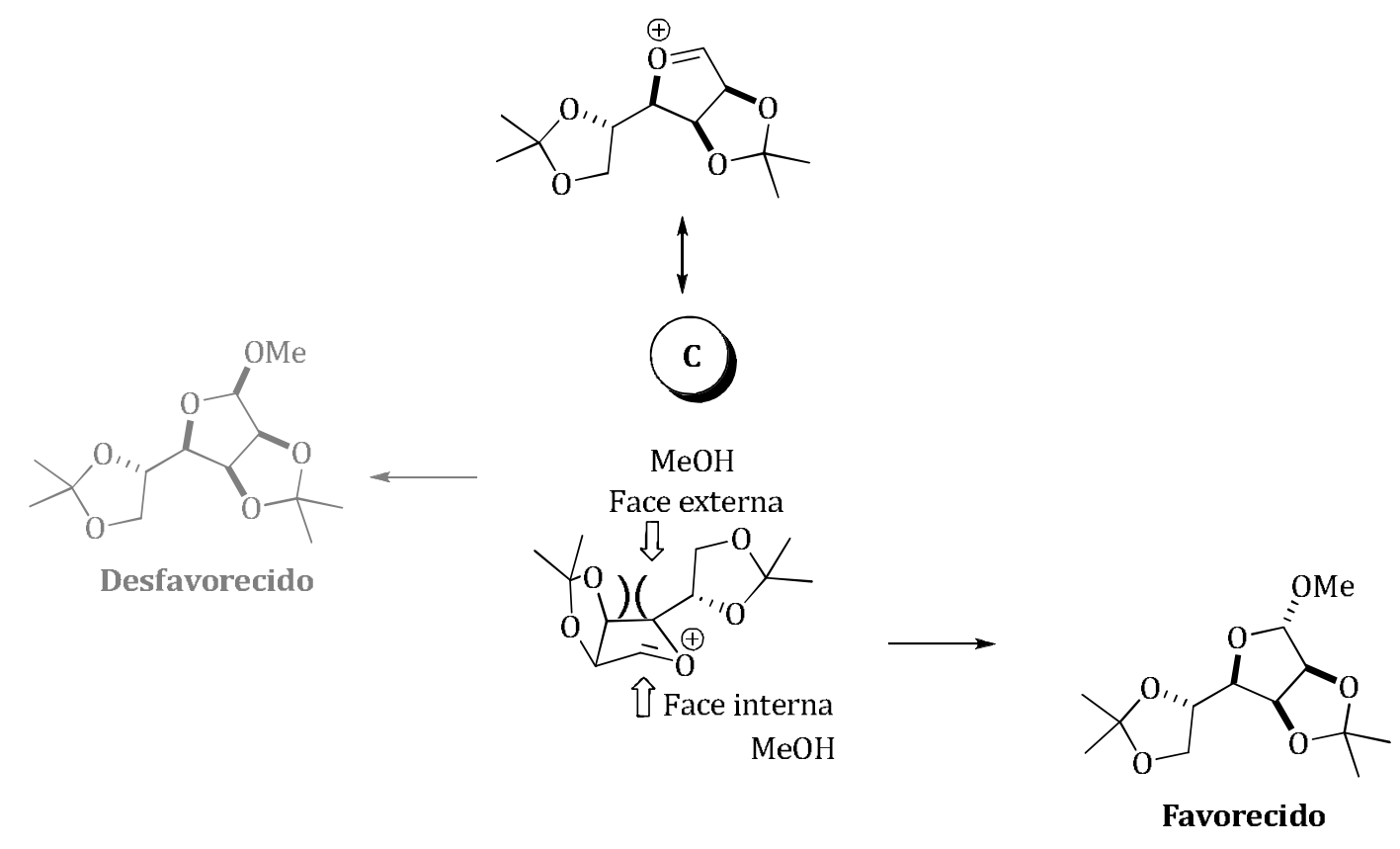

Esquema 25. Mecanismo proposto para a formação do anômero $\alpha$.

\subsection{3. $D$-Ribose}

0 aldeído55 foi preparado a partir da $D$-ribose em apenas 2 etapas sintéticas e em excelentes rendimentos conforme pode ser observado no Esquema 26. A primeira etapa, assim como para a $D$-manose, envolveu 2 modificações na estrutura. A proteção das hidroxilas nas posições 2 e 3 na forma de acetonídeo, 
utilizando acetona, e a proteção da posição anomérica com metanol, ambos processos envolvendo catálise ácida. ${ }^{53} 0$ mecanismo para a formação do anômero $\beta$ é similar ao envolvido no processo de formação no anômero $\alpha$ da $D$-manose. Neste ponto pode-se inferir que a estereoquímica do centro estereogênico vizinho em C-2 pode ter papel fundamental na configuração adotada na adição de $\mathrm{MeOH}$ à posição anomérica. A etapa seguinte envolveu a oxidação do álcool 54na posição 5 ao aldeído 55correspondente,que foi facilmente obtido utilizando-se ácido iodoxibenzóico (IBX) como agente oxidante. ${ }^{54}$ O aldéido 55 foi obtido em excelentes rendimentos e sem necessidade de purificações para uso posterior.
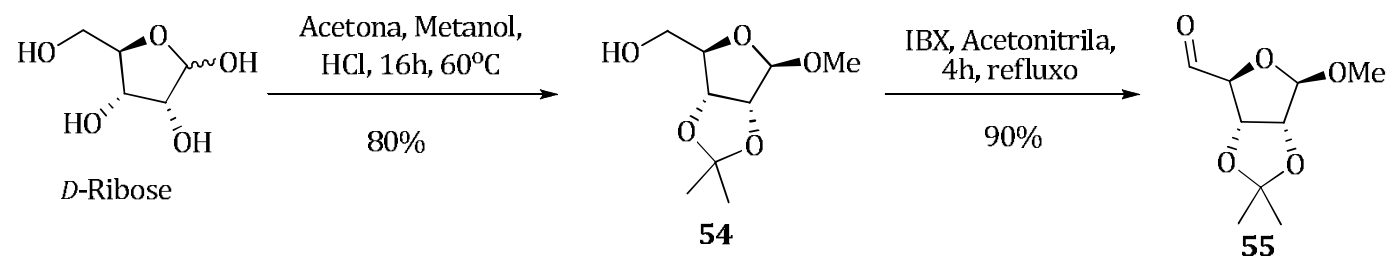

Esquema 26. Preparação do aldeído 55 derivado da $D$-ribose.

\subsection{4. $D$-Galactose}

O aldeído $\mathbf{5 7}$ derivado da $D$-galactose também foi preparado em apenas 2 etapas e excelentes rendimentos foram obtidos como pode ser observado no Esquema 27. Inicialmente a $D$-galactose foi protegida na forma de bis-acetonídeo, utilizando-se acetona e quantidades catalíticas de iodo. Em seguida o álcool 56, oriundo da bis-acetalização foi oxidado ao aldeído 57, utilizando-se IBX como agente oxidante, em $89 \%$ de rendimento.

53 Ginisty, M.; Gravier-Pelletier, C.; Merrer Y. Tetrahedron: Asymmetry2006, 17, 142-150.

${ }^{54}$ More, J. D.; Finney, N. S.Org. Lett., 2002, 4, 3001-3003. 


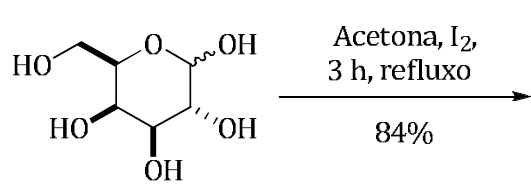

$D$-Galactose

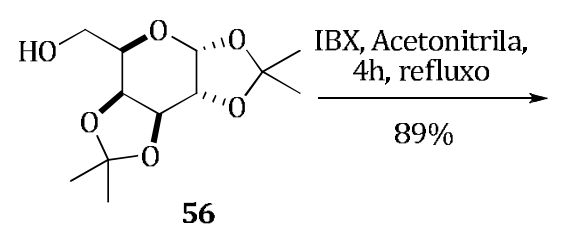

56

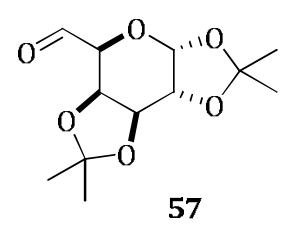

57

Esquema 27. Preparação do aldeído 57 derivados da $D$-galactose.

\subsection{Adição de reagentes arilzinco a aldeídos derivados de carboidratos}

\subsubsection{Adição de reagentes arilzinco ao aldeído derivado da $D$-Glicose:}

Os estudos iniciais foram focados na otimização das condições reacionais para a arilação de aldeídos quirais derivados de carboidratos e, consequentemente, avaliação da influência da estrutura dos aldeídos sobre a diastereosseletividade da reação.

A preparação dos reagentes arilzinco seguiu protocolo desenvolvido anteriormente por nosso grupo. ${ }^{55}$ Os reagentes arilzinco foram preparados pela troca boro-zinco utilizando ácidos arilborônicos como a fonte de grupos arila transferíveis, mediante reação com dietilzinco em tolueno como solvente. Os estudos de otimização das condições reacionais foram conduzidos utilizando-se o ácido fenilborônico e o aldeído 30 derivado da $D$-glicose, como materiais de partida. Uma vez obtido o reagente PhZnEt, o aldeído $\mathbf{3 0}$ foi adicionado, resultando na formação do álcool 31a. Observou-se que a relação diastereoisomérica obtida, bem como os tempos das reações estavam diretamente relacionados à temperatura na qual a reação foi conduzida. Primeiro optou-se por conduzir a

55 Wouters, A. D.; Trossini, G. H. G.; Stefani, H. A.; Lüdtke, D. S. Eur. J. Org. Chem., 2010, 2351-2356. 
reação a $0^{\circ} \mathrm{C}$, a razão diastereoisomérica obtida foi de 20:1, e o tempo de reação de 5 horas (entrada 1). Aumento da temperatura para $25^{\circ} \mathrm{C}$ levou a uma diminuição do tempo de reação para 3 horas, entretanto não foi observada variação na razão diastereoisomérica (entrada 2). Aumento da temperatura para $60^{\circ} \mathrm{C}$, conduziu a uma diminuição no tempo reacional para 1,5 hora, bem como da relação diastereoisomérica que foi de 10:1 (entrada 3). As variações de temperatura testadas não conduziram a variações significativas nos rendimentos das reações. As reações também foram conduzidas com outros solventes, como: diclorometano, THF e hexana, entretanto conduzindo a rendimentos e razões diatereoisoméricas mais baixos. Os resultados decorrentes desses estudos estão resumidos na Tabela 4.

Tabela 4. Estudo das condições reacionais na adição de fenilzinco ao aldeído $\mathbf{3 0 .}$<smiles>Oc1ccccc1</smiles>
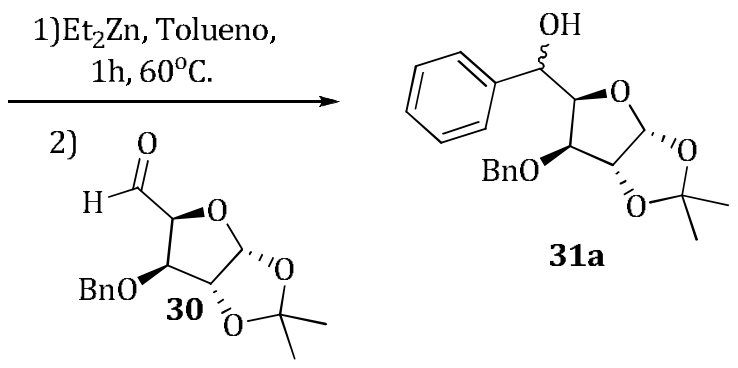

\begin{tabular}{cccccc}
\hline Entrada & Solvente & Temperatura( $\left.^{\circ} \mathrm{C}\right)$ & Tempo(h) & Rendimento(\%) & $\boldsymbol{r d}^{\mathrm{a}}$ \\
\hline $\mathbf{1}$ & Tolueno & 0 & 5 & 66 & $20: 1$ \\
$\mathbf{2}$ & Tolueno & 25 & 3 & 65 & $20: 1$ \\
$\mathbf{3}$ & Tolueno & 60 & 1,5 & 67 & $10: 1$ \\
$\mathbf{4}$ & Hexano & 25 & 2 & 20 & $14: 1$ \\
$\mathbf{5}$ & DCM & 25 & 3 & 40 & $16: 1$ \\
$\mathbf{6}$ & THF & 25 & 3 & 60 & $5: 1$ \\
\hline
\end{tabular}

a Determinada por $\mathrm{RMN}^{1} \mathrm{H}$ 
As razões diastereoisoméricas foram deduzidas a partir dos espectros de RMN ${ }^{1}$ H. A Figura 15 mostra o espectro de Ressonância Magnética Nuclear de Hidrogênio (RMN ${ }^{1} \mathrm{H}$ ) do composto $31 \mathrm{a}$, representativo dos compostos obtidos. A expansão criada no espectro é relativa à região dos sinais do $\mathrm{H}$ denominado $\mathbf{g} \mathrm{e}$ pela integração dos sinais a razão diastereoisomérica observada é >20:1. De acordo com os dados de RMN anteriormente descritos para a síntese da goniofufurona e 7-epi-goniofufurona, ${ }^{56,34}$ concluiu-se que o composto obtido preferencialmente nas reações de adição de arilzinco apresenta configuração absoluta $\boldsymbol{S}$ no novo centro, mesma configuração da 7-epi-goniofufurona .

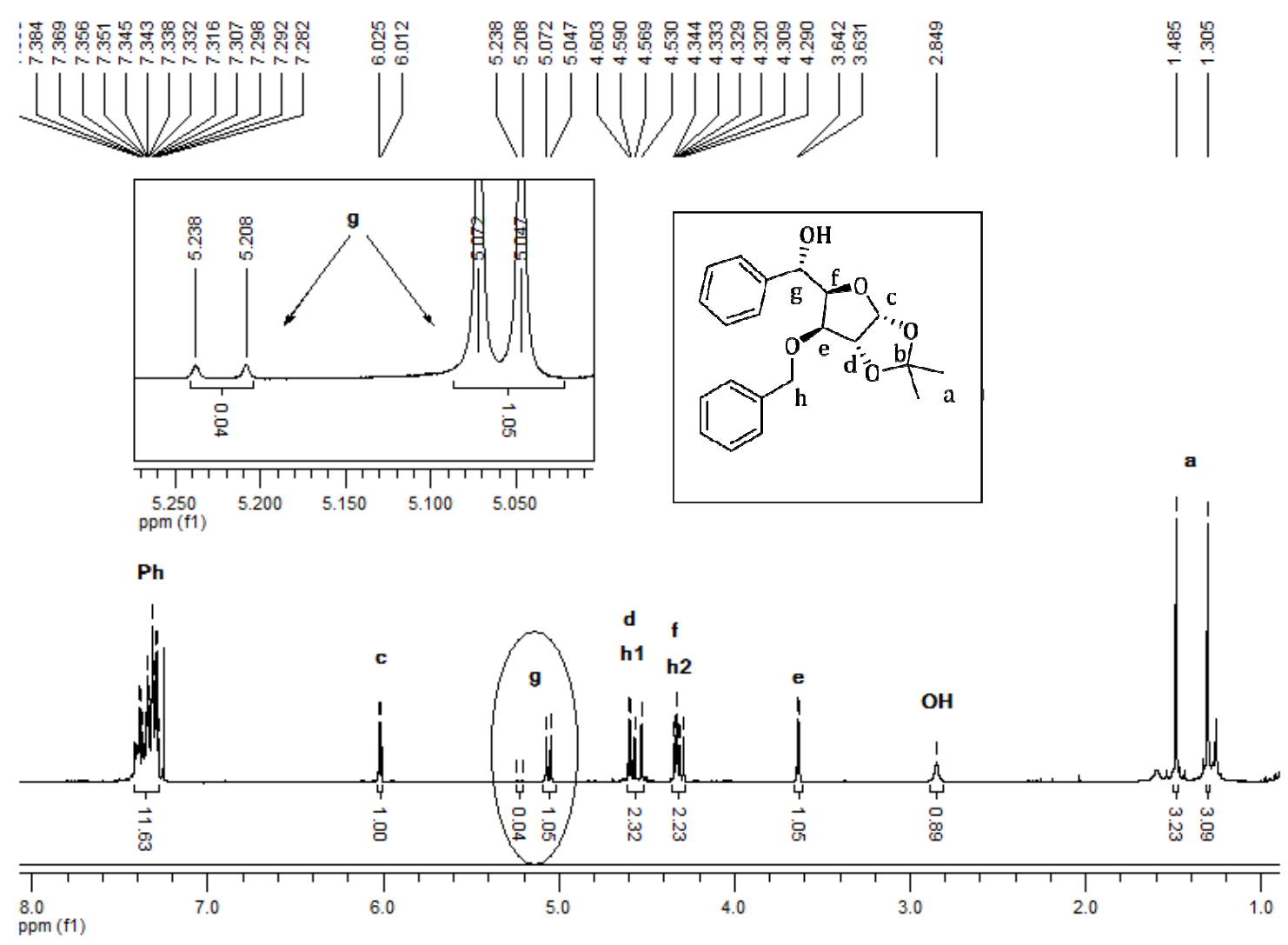

Figura 15. Espectro de $\mathrm{RMN}{ }^{1} \mathrm{H}$ do composto31a.

56 Gracza, T.; Szolcsányi, P. Molecules, 2000, 5, 1386-1398. 
Após avaliação das melhores condições reacionais, a etapa seguinte teve como objetivo ampliação da série de compostos 31. Para isso, outros ácidos borônicos foram usados na troca B-Zn, levando a formação de diversas espécies arilzinco que foram usados na adição ao aldeído 30. A tabela 5 mostra os resultados obtidos.

Tabela 5. Adição de reagentes arilzinco ao aldeído 30.
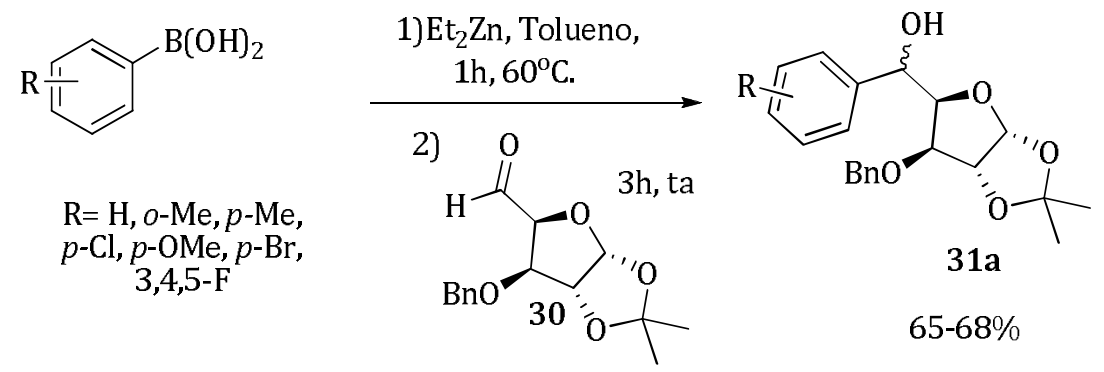

$65-68 \%$

\begin{tabular}{cccc}
\hline Entrada & $\mathbf{R}$ & Rendimento (\%) & $\boldsymbol{r d}^{\mathrm{a}}$ \\
\hline $\mathbf{1}$ & $\mathrm{H}(\mathrm{a})$ & 65 & $>20: 1$ \\
$\mathbf{2}$ & $p-\mathrm{Me}(\mathrm{b})$ & 68 & $>20: 1$ \\
$\mathbf{3}$ & $o-\mathrm{M}(\mathrm{c}) \mathrm{e}$ & 65 & $16: 1$ \\
$\mathbf{4}$ & $p-\mathrm{MeO}(\mathrm{d})$ & 67 & $>20: 1$ \\
$\mathbf{5}$ & $p-\mathrm{Br}(\mathrm{e})$ & 66 & $14: 1$ \\
$\mathbf{6}$ & $p-\mathrm{Cl}(\mathrm{f})$ & 67 & $>20: 1$ \\
$\mathbf{7}$ & $3,4,5-\mathrm{F}(\mathrm{g})$ & 66 & $>20: 1$ \\
\hline
\end{tabular}

aDeterminada por $\mathrm{RMN}^{1} \mathrm{H}$

O progresso das reações foi acompanhado por cromatografia de camada delgada (CCD) e observou-se o consumo total dos materiais de partida após 3 horas de reação. Os produtos foram obtidos em excelentes razões diastereoisoméricas, na maioria dos casos >20:1. 
Uma racionalização dos resultados para a adição de nucleófilos ao aldeído 30 leva em consideração a possibilidade de coordenação do reagente organozinco ao substrato através de complexos quelados 1,2, formando um anel de 5 membros (A), ou 1,3, formando um anel de 6 membros (B). Além dessa hipótese envolvendo controle por quelação, um controle não quelante baseado no modelo de Felkin-Ahn (C) também deve ser levado em consideração (Figura 16). 0 modelo A prevê a formação do novo estereocentro com configuração $S$ enquanto que reação de adição através dos modelos $\mathbf{B}$ e $\mathbf{C}$ conduziriam ao produto com configuração $R$.

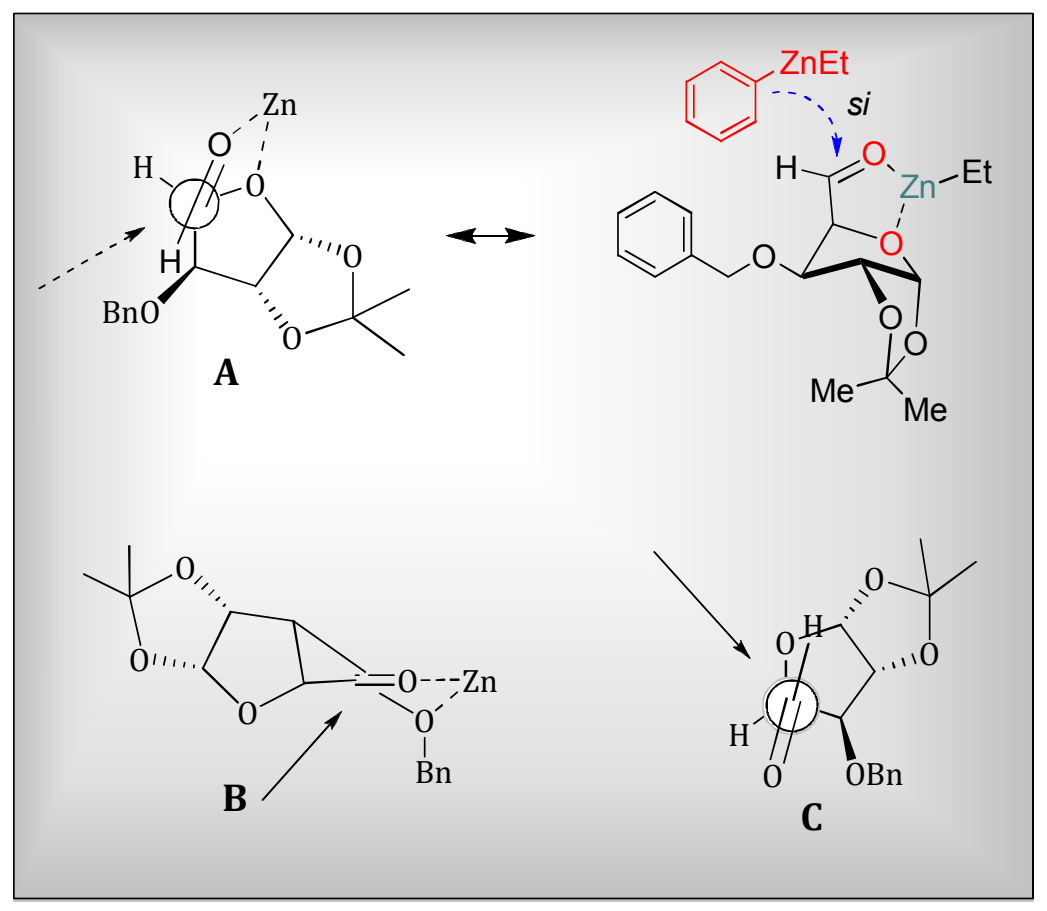

Figura 16. Modelos de adição nucleofílica ao aldeído 30. Modelo quelato 1,2- (A) e

$$
\text { 1,3- (B), e modelo Felkin-Ahn (C) }
$$

Como pode ser observado no espectro de $\mathrm{RMN}^{1} \mathrm{H}$ (Figura 15) e confirmado a partir do modelo quelato 1,2, a adição de fenilzinco ao aldeído30, derivado da $D$ glicose conduza formação do composto 31a com configuração absoluta $S$. 


\subsubsection{Adição de reagentes arilzinco ao aldeído derivado da $D$-Manose}

Com o sucesso da adição de reagentes arilzinco a aldeídos quirais, o escopo da metodologia foi estendido ao aldeído 53 derivado da $D$-manose. A mesma estratégia empregada anteriormente foi estendida para a adição de ArZnEt ao aldeído 53 (Esquema 29). O progresso da reação foi acompanhado por CCD e o consumo total dos materiais de partida foi observado após 6 horas.

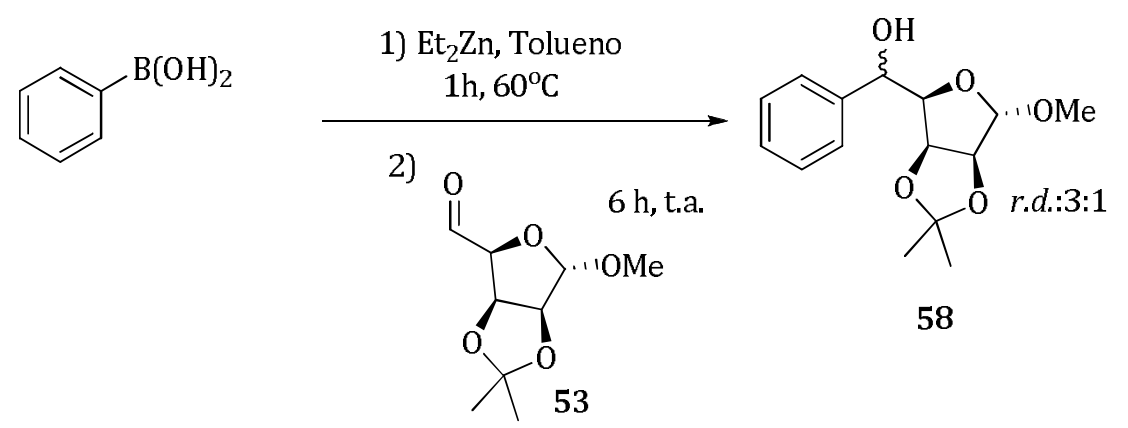

Esquema 28. Adição de fenilzinco ao aldeído 53.

Entretanto, diferente dos resultados obtidos anteriormente, o processo conduziu a diastereosseletividades inferiores, de apenas 3:1 como pode ser observado no espectro de $\mathrm{RMN}^{1} \mathrm{H}$, através da integração dos sinais das metoxilas, que permitem uma melhor análise dos diastereoisômeros formados (Figura 17). 

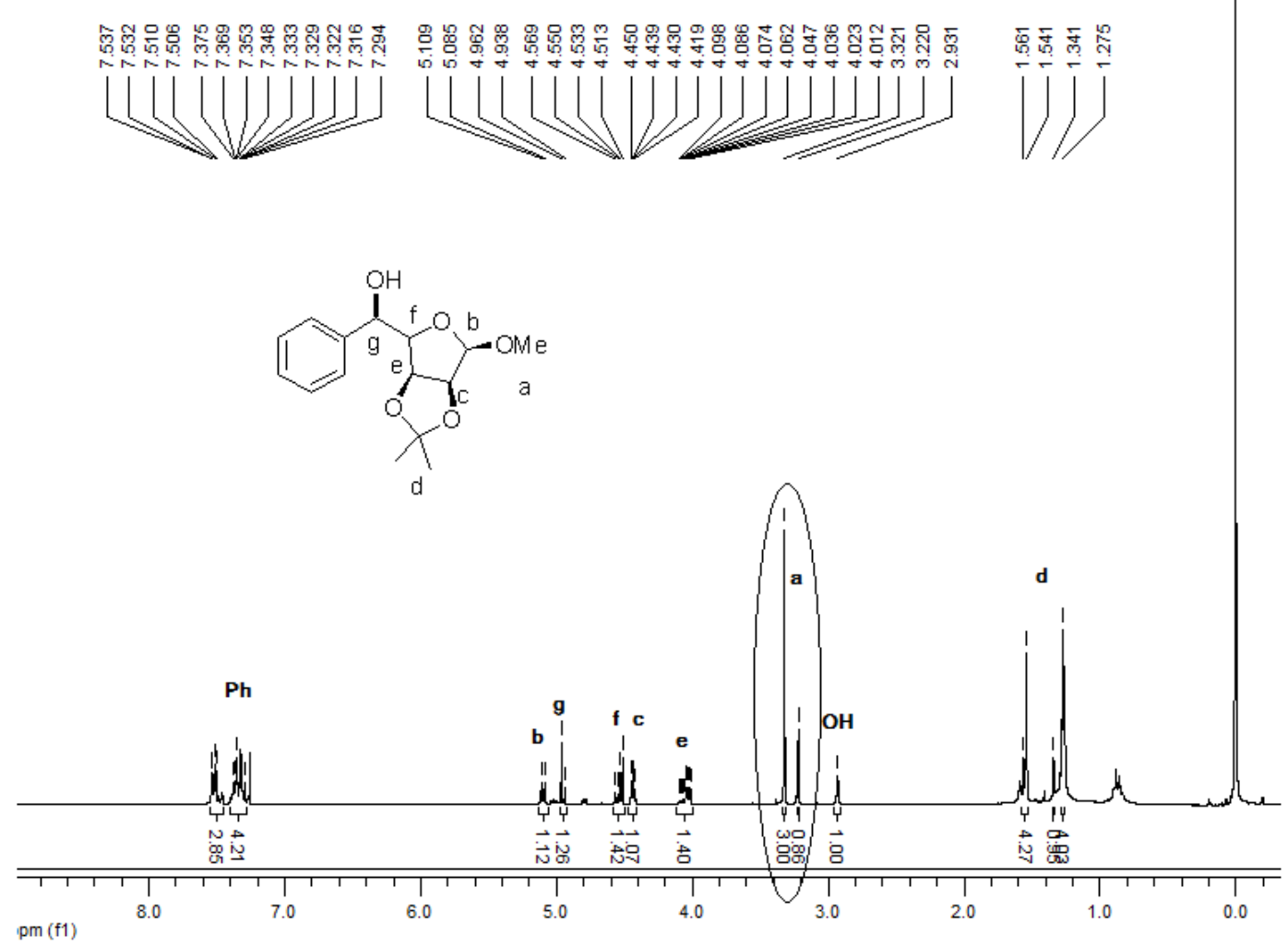

Figura 17. Espectro de $\mathrm{RMN}^{1} \mathrm{H}$ representativo dos derivados obtidos na adição de reagentes arilzinco ao aldeído 53.

De forma similar ao mecanismo de adição nucleofílica proposto anteriormente, para o aldeído $\mathbf{3 0}$, derivado da $D$-glicose, a adição de reagentes arilzinco ao aldeído 53 deve ocorrer via indução assimétrica, principalmente via quelato 1,2 ou 1,3 (Figura 18). Neste caso, diferentemente da adição ao aldeído $\mathbf{3 0}$, o quelato 1,3 parece contribuir de forma mais significativa. Isto provavelmente devido à característica diferenciada do grupo alcóxi na posição C-3. Ao contrário da benzila ligada ao oxigênio na posição C-3 do aldeído 30, o oxigênio de C-3 em 53 está inserido em um acetonídeo, grupo este menor e mais rígido que deve proporcionar maior robustez ao sistema no momento de formação do quelato. 


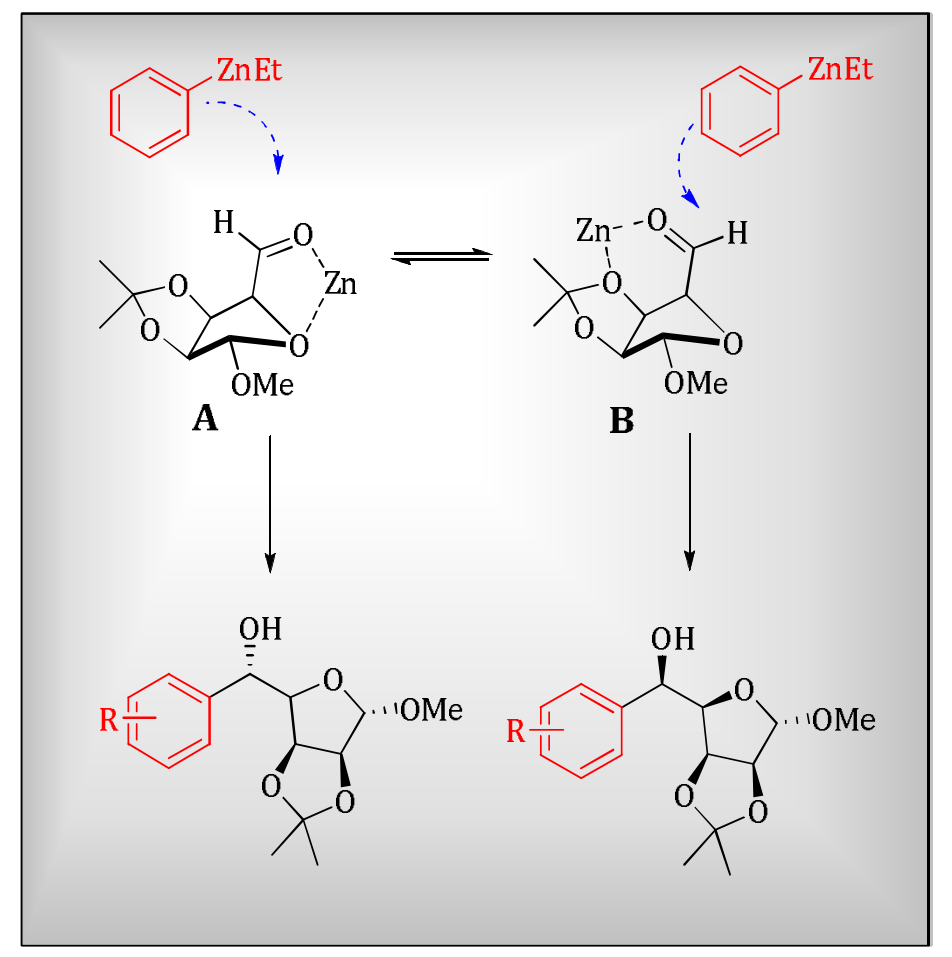

Figura 18. Modelos de adição nucleofílica ao aldeído 53. Modelo quelato 1,2- (A) e 1,3- (B) e respectivos produtos formados.

No intuito de investigar fatores que poderiam afetar potencialmente a estereosseletividade do sistema, algumas variações nas condições reacionais foram avaliadas, dentre elas a mudança de temperatura e a adição de ligantes quirais.

Observações muito interessantes foram feitas durante as tentativas de otimização das condições reacionais (Tabela 6). A diminuição da temperatura para a adição de fenilzinco conduziu a uma diminuição da diastereosseletividade do sistema para 2:1 (entrada 1), e em contrapartida o aumento da temperatura para $60^{\circ} \mathrm{C}$ elevou a razão diastereoisomérica para 4,5:1, além de diminuir o tempo reacional para 3 horas (entrada 2). A mudança de temperatura claramente parece afetar o equilíbrio entre os complexos formados. 
Tabela 6. Estudo das condições reacionais para adição de fenilzinco ao aldeído 53.

\begin{tabular}{ccccc}
\hline Entrada & Temperatura & Tempo & Aditivo(mol\%) & r.d. $^{a}$ \\
\hline $\mathbf{1}$ & 0 & 8 & - & $2: 1$ \\
$\mathbf{2}$ & 60 & 3 & - & $4,5: 1$ \\
$\mathbf{3}$ & 60 & 3 & $\mathbf{1 0 c}(20)$ & $1: 1$ \\
$\mathbf{4}$ & 60 & 3 & $\mathbf{1 0 c}(100)$ & $1: 2$ \\
\hline
\end{tabular}

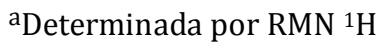

O comportamento da reação na presença de um ligante quiral também foi avaliado. No Capítulo 1 o composto 10c derivado da $D$-Xilose (Figura 19) foi descrito como ligante para a adição de reagentes arilzinco a aldeídos, conduzindo a excelentes enantiosseletevidades, por isso foi selecionado e sua influência sobre o caminho estereoquímico da arilação foi avaliada.

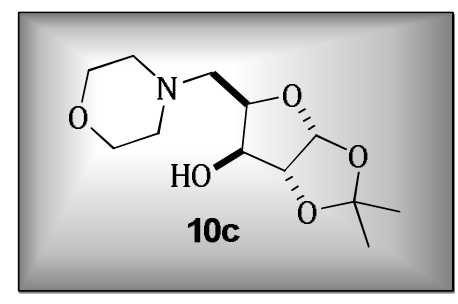

Figura 19. Ligante 10 c utilizado para avaliar variações na diastereosseletividade do sistema.

A adição de $20 \mathrm{~mol} \%$ do ligante ao sistema conduziu a formação dos epímeros em razão de 1:1 (entrada 3), como pode ser observado no espectro de RMN ${ }^{1} \mathrm{H}$ (Figura 20). Este fator deve estar intrinsecamente relacionado ao tipo de interação formada no estado de transição, provavelmente semelhante ao descrito no Esquema 7, onde a estrutura anti-trans $\boldsymbol{C}$ é favorecida e conduz ao produto de configuração absoluta $R$. Neste caso, a adição do ligante estabeleceu-se de forma competitiva ao sistema e possivelmente haja dois fatores operantes, a formação 
dos quelatos 1,2 e 1,3, que devem conduzir aos produtos na mesma razão diatereoisomérica já descrita anteriormente, e a presença do ligante $\mathbf{5 c}$ que deve atuar paralela e independentemente, favorecendo o produto de configuração $R$ no C-5.

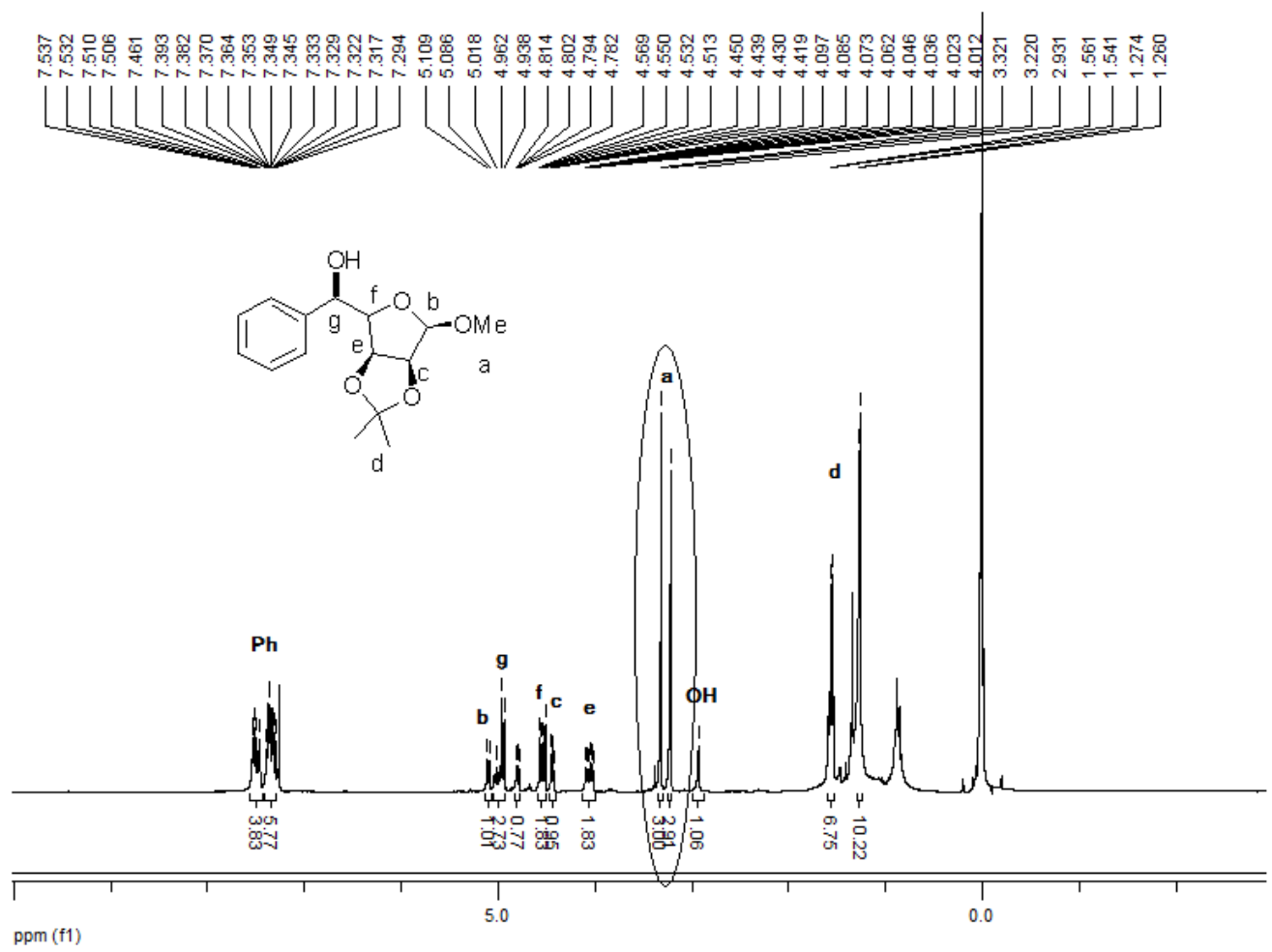

Figura 20. Efeito observado com uso de $20 \mathrm{~mol} \%$ do ligante 5 c na adição de reagentes arilzinco ao aldeído 53.

A fim de confirmar este efeito, 1 equivalente do ligante foi adicionado. 0 resultado pode ser observado no espectro de RMN ${ }^{1} \mathrm{H}$ (Figura 21). 


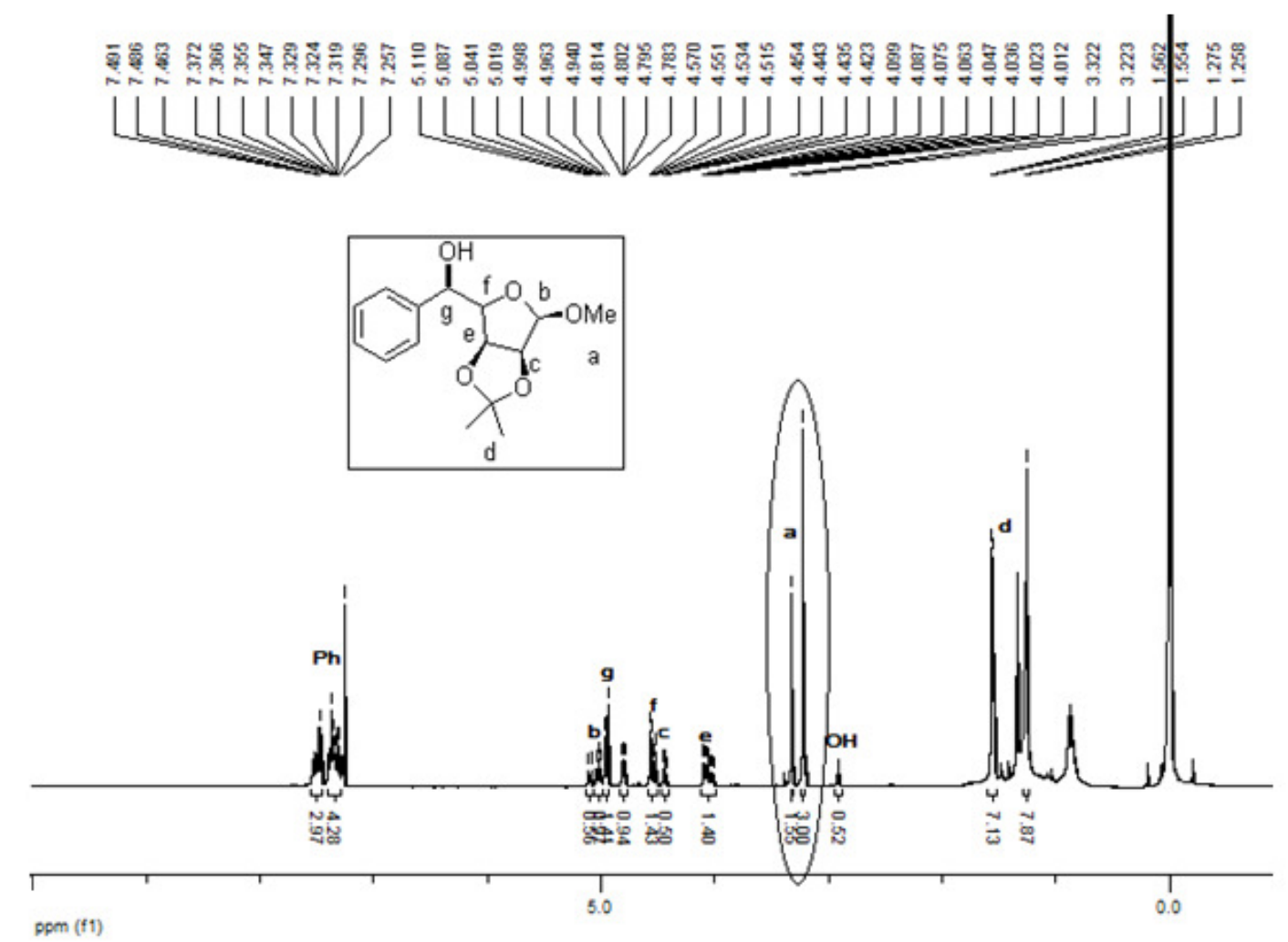

Figura 21. Efeito observado na adição de quantidade estequiométrica do ligante 5c.

Neste momento é importante observar que a formação dos complexos 1,2 e 1,3 parece não ser suprimida quando um ligante é usado, o mesmo parece atuar de forma paralela e independente, e não de forma construtiva.

A partir de então, optou-se por conduzir a adição de reagentes arilzinco ao aldeído 53 de forma similar ao descrito anteriormente para o aldeído 30, apenas aumentando a temperatura de adição para $60^{\circ} \mathrm{C}$. Os produtos $\mathbf{5 8}$ foram obtidos em bons rendimentos e em razões diastereoisoméricas moderadas de até 7:1 (Tabela 7). Exceção para este caso foi quando o grupo metila estava na posição orto, provavelmente devido a interações estéricas durante o estado de transição. 
Tabela 7. Adição de reagentes arilzinco ao aldeído 53.

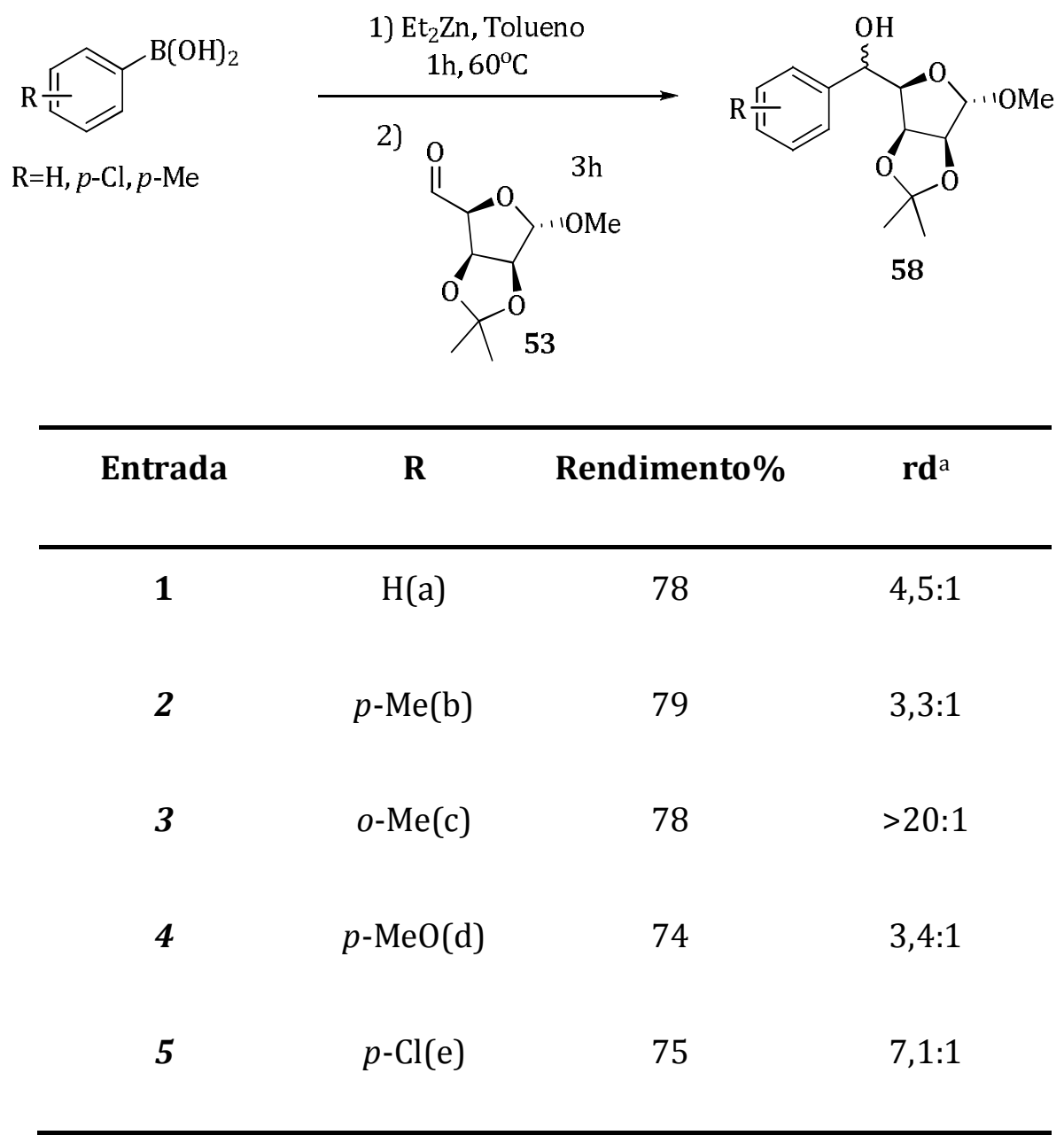

${ }^{a}$ Determinada por $\mathrm{RMN}{ }^{1} \mathrm{H}$

\subsubsection{Adição de reagentes arilzinco ao aldeído derivado da $D$-Ribose}

A continuação da avaliação do escopo da arilação diastereosseletiva ocorreu utilizando-se o aldeído 55, derivado da $D$-ribose. Surpreendentemente, a extensão do protocolo de adição de ArZnEt ao aldeído $\mathbf{5 5}$ resultou em uma reação com excelente diastereosseletividade e essencialmente um único diastereoisômero foi obtido como produto da adição (r.d. >20:1). A reação foi conduzida a temperatura ambiente e o progresso da reação foi acompanhado por CCD, indicando que os materiais de partida haviam sido consumidos após 6 horas. Ao conduzir-se a 
reação a $60^{\circ} \mathrm{C}$, o produto foi obtido após 3 horas e sem qualquer prejuízo para o rendimento e a diastereosseletividade. Expansão dos estudos para uma variedade mais ampla de substratos mostra a abrangência da metodologia, uma vez que uma série de ácidos arilborônicos pode ser utilizada, mantendo-se a mesma eficiência observada anteriormente. Os resultados estão apresentados na Tabela 8.

Tabela 8. Adição de reagentes arilzinco ao aldeído $\mathbf{5 5}$ derivado da $D$-ribose.

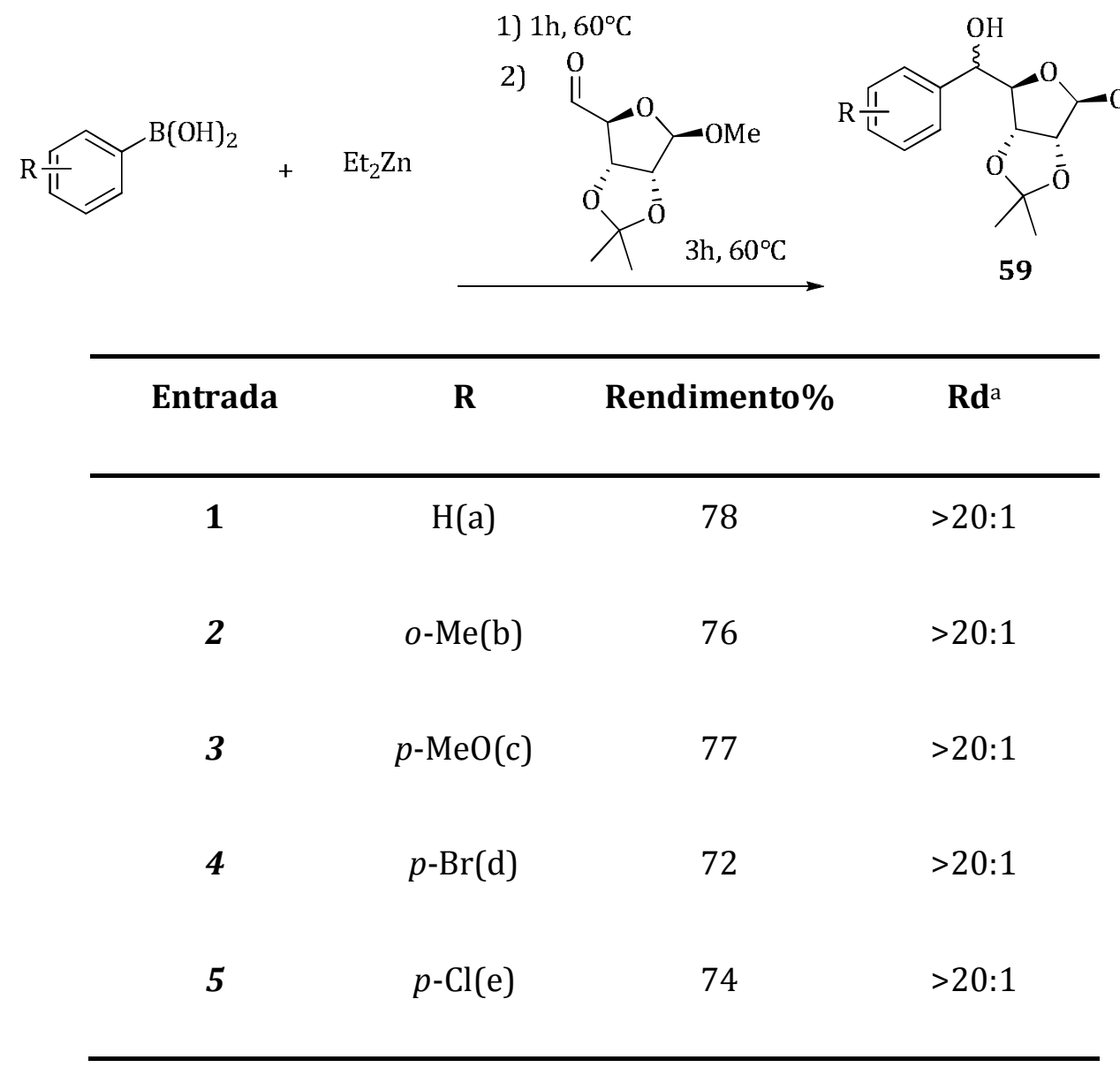

${ }^{a}$ Determinada por $\mathrm{RMN}^{1} \mathrm{H}$

Os produtos foram obtidos em excelentes diastereosseletividades, sendo que em todos os casos estudados essencialmente um único produto foi observado. A Figura 22 mostra o espectro de Ressonância Magnética Nuclear de Hidrogênio $\left(\mathrm{RMN}^{1} \mathrm{H}\right)$ do composto 59a, representativo dos compostos obtidos. O dublete com 
deslocamento químico em 4,8 ppm é referente ao hidrogênio e, ligado ao novo centro estereogênico formado.

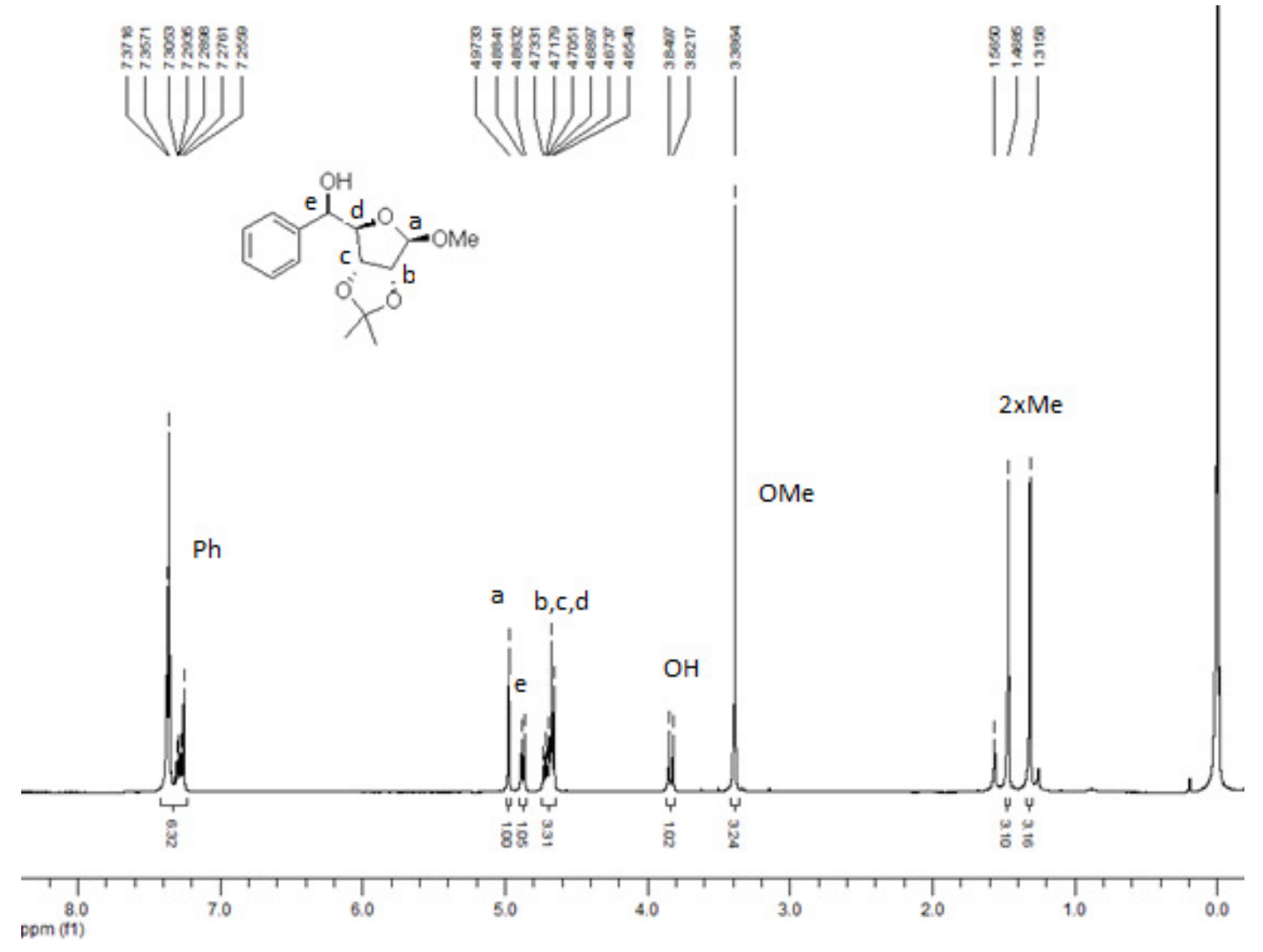

Figura 22. Espectro de $\mathrm{RMN}^{1} \mathrm{H}$ do composto 59a.

A adição nucleofílica de reagentes arilzinco ao aldeído 55 parece seguir a indução assimétrica controlada pelo modelo quelato 1,2, uma vez que não há possibilidade de formação do quelato 1,3 devido à configuração anti estabelecida entre os C-3 e C-4. 0 mecanismo proposto para a formação dos compostos da série 59 pode ser observado na Figura 23. 


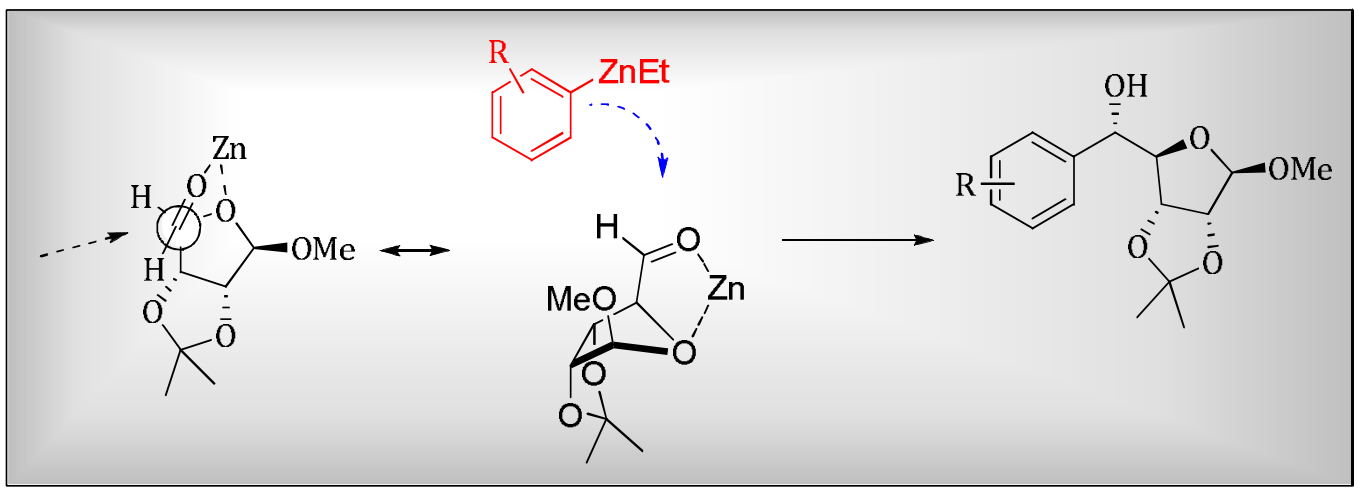

Figura 23. Mecanismo proposto para a formação dos compostos 59.

\subsubsection{Adição de reagentes arilzinco ao aldeído derivado da $D$-galactose}

Com o intuito de avaliar a influência do esqueleto carbônico do aldeído sobre a eficiência da reação, a arilação do aldeído piranosídico 57, derivado da Dgalactose foi estudada. A adição de reagentes arilzinco ao aldeído $\mathbf{5 7}$ foi conduzida nas mesmas condições já dispostas anteriormente para os aldeídos 53 e 55, como pode ser observado na Tabela 9.

Tabela 9. Adição de reagentes arilzinco ao aldeído 57.

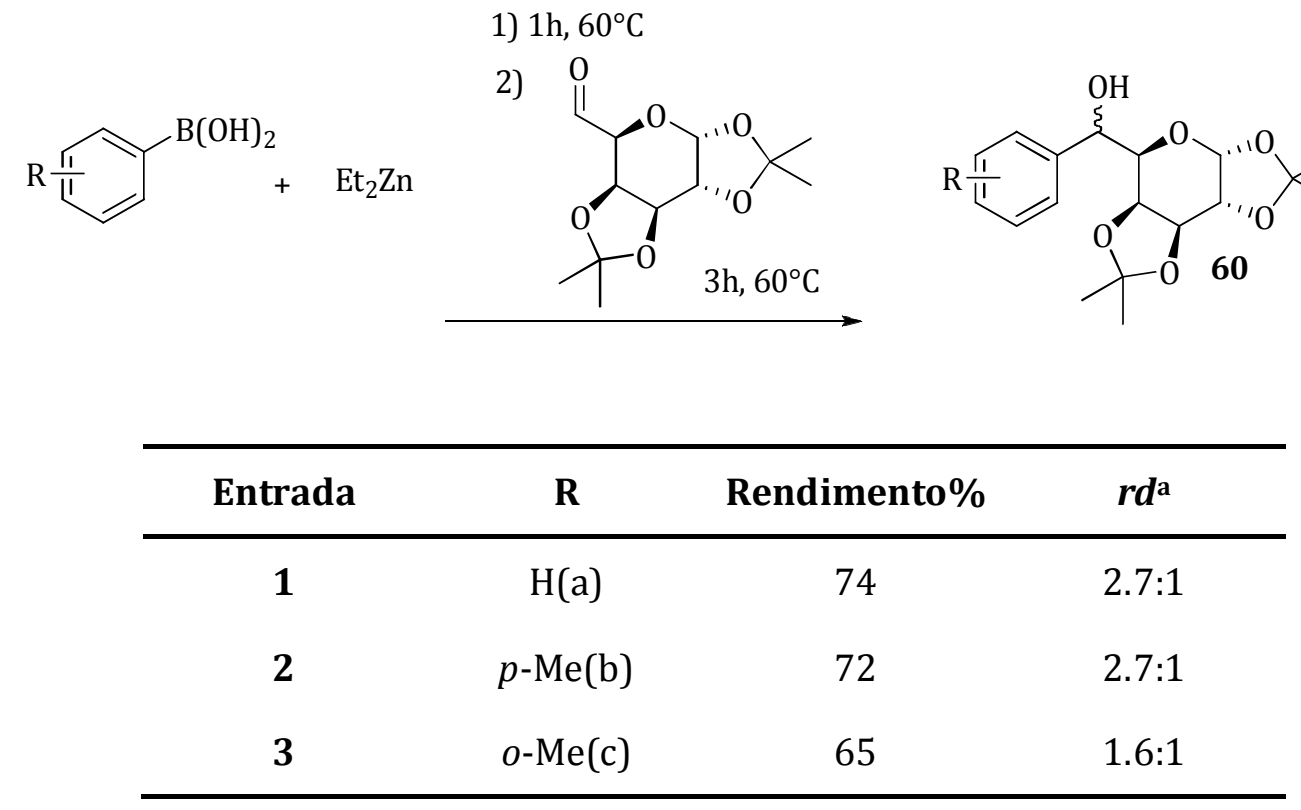

aDeterminada por $\mathrm{RMN}^{1} \mathrm{H}$ 
Infelizmente, a adição de ArZnEt ao aldeído piranosídico 57, apresentou uma menor diastereosseletividade, sendo que os produtos foram obtidos em razões diastereoisoméricas entre 1,6:1 e 2,7:1.

Esta condição foi determinada como ideal, uma vez que após variações de temperatura e adição de ligante, por exemplo, conduziam a resultados similares aos observados na adição de reagentes arilzinco ao aldeído $\mathbf{5 3}$ derivado da $D$ manose. Análise do mecanismo proposto via indução assimétrica, podendo seguir modelo quelato 1,2 e 1,3, conduz as mesmas conclusões (Figura 24), ou seja, o aumento da temperatura parece desfavorecer a formação do quelato 1,3, todavia de forma menos pronunciada que o observado para a $D$-manose. E da mesma forma adição de ligante, conduz paralelamente a um aumento na formação do epímero de configuração absoluta $R$ no C-6, diminuindo também a razão diastereoisomérica.

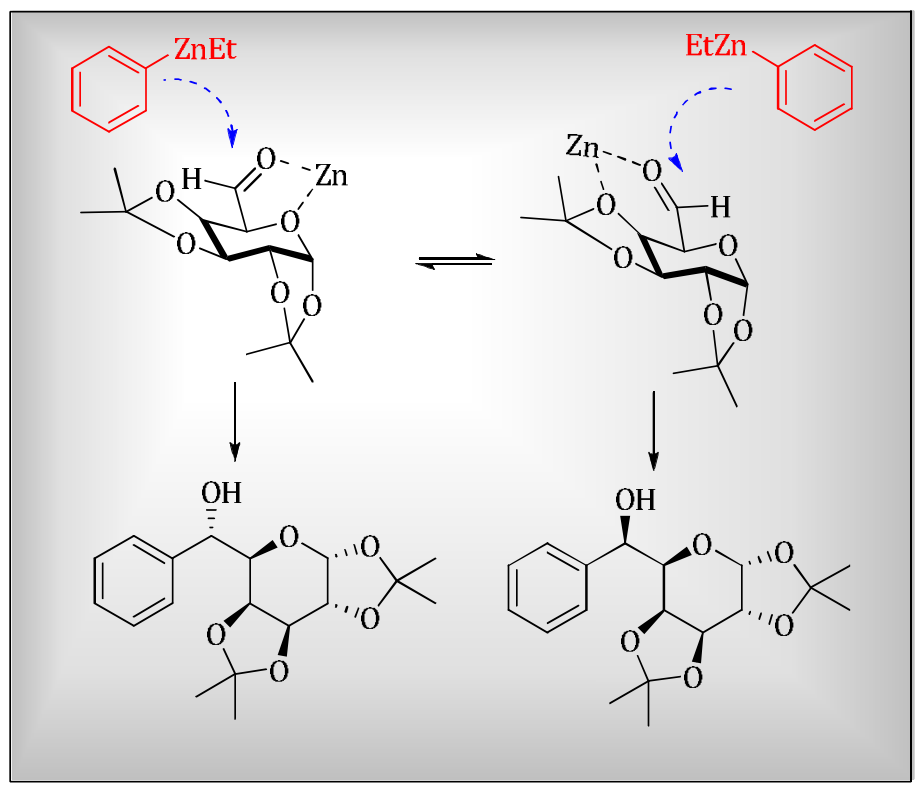

Figura 24. Mecanismo proposto para a formação dos compostos 60. 
De forma geral a adição de reagentes arilzinco ao aldeído $\mathbf{5 7}$, derivado da $D$ galactose, conduziu aos produtos em baixa diastereosseletividade. A Figura 25 mostra o espectro de $\mathrm{RMN}^{1} \mathrm{H}$ do composto 60a, representativo da série.
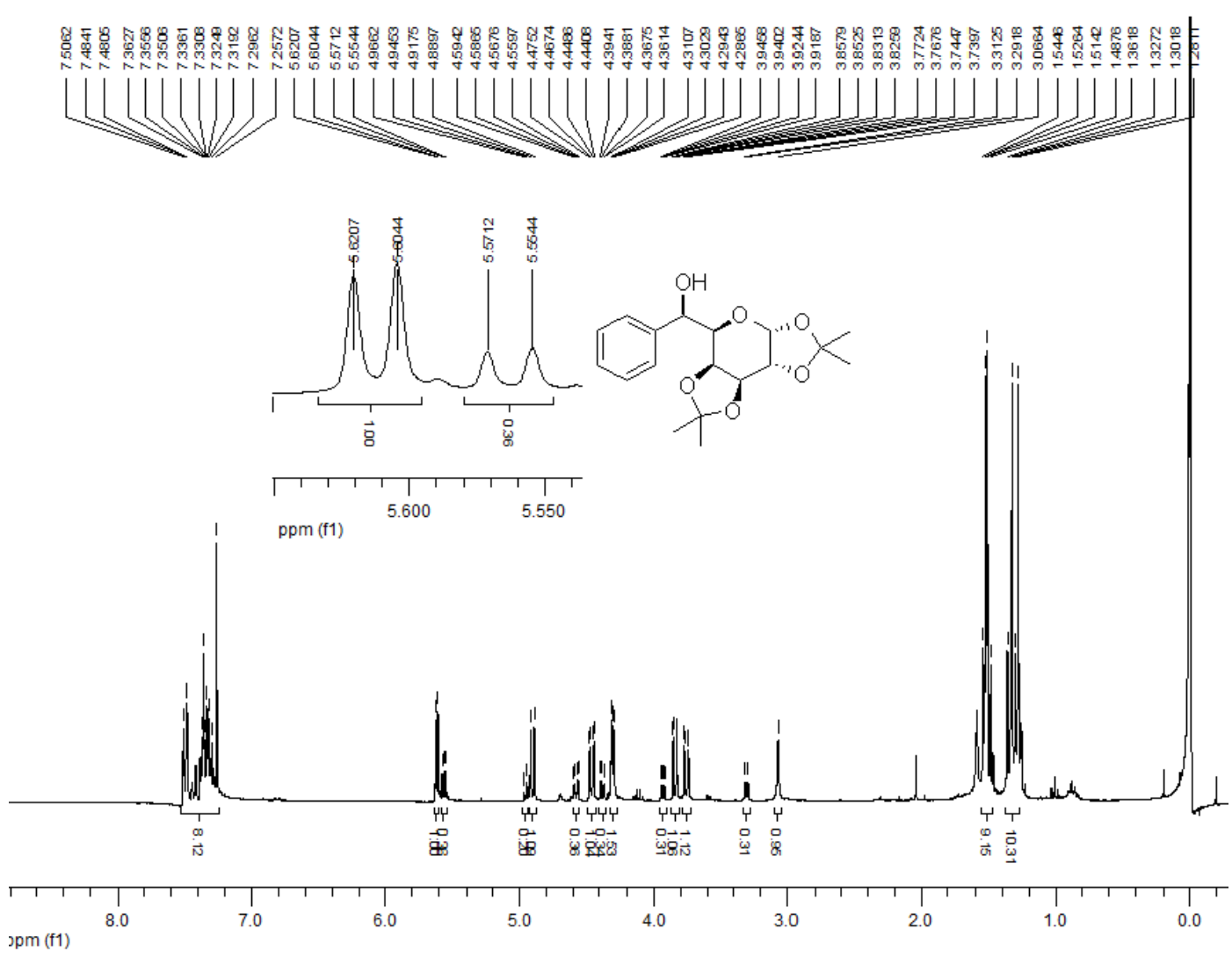

Figura 25. Espectro de ${ }^{1} \mathrm{H}$ RMN do composto 60a.

\subsubsection{Síntese da Epi-Goniofufurona e derivados a partir dos} intermediários 31

A adição de reagentes arilzinco ao aldeído 30, derivado da D-glicose, constitui a etapa chave para a preparação da 7-epi-goniofufurona e de seus derivados. Esta nova metodologia mostra-se muito interessante, uma vez que os compostos $\mathbf{3 1}$ foram obtidos em alta diastereosseletividade e a reação mostrou-se eficiente para uma variedade de grupos arila, o que possibilita a preparação de 
análogos da 7-epi-goniofufurona com diferentes padrões de substituição no grupo aromático da molécula.

A próxima etapa para a síntese da (+)-7-epi-goniofufurona e de seus derivados envolveu a hidrólise dos acetonídeos da série 31, que foi conduzida em solução aquosa de ácido acético. Segundo Prakash e Rao ${ }^{36}$, esta reação poderia conduzir a uma mistura de tautômeros da furanose 32 e da piranose 33 , e de seus respectivos anômeros. Entretanto, apesar de os espectros de $\mathrm{RMN}^{1} \mathrm{H}$ se mostrarem bastantes complexos, os espectros de $\mathrm{RMN}^{13} \mathrm{C}$ parecem mais claros, e conforme já descrito anteriormente por Popsavin e colaboradores ${ }^{40}$, a reação conduz a uma mistura dos anômeros $\alpha$ e $\beta$ da piranose 33 conforme pode ser observado para 0 composto 33c no espectro de RMN ${ }^{13} \mathrm{C}$ Figura 26.

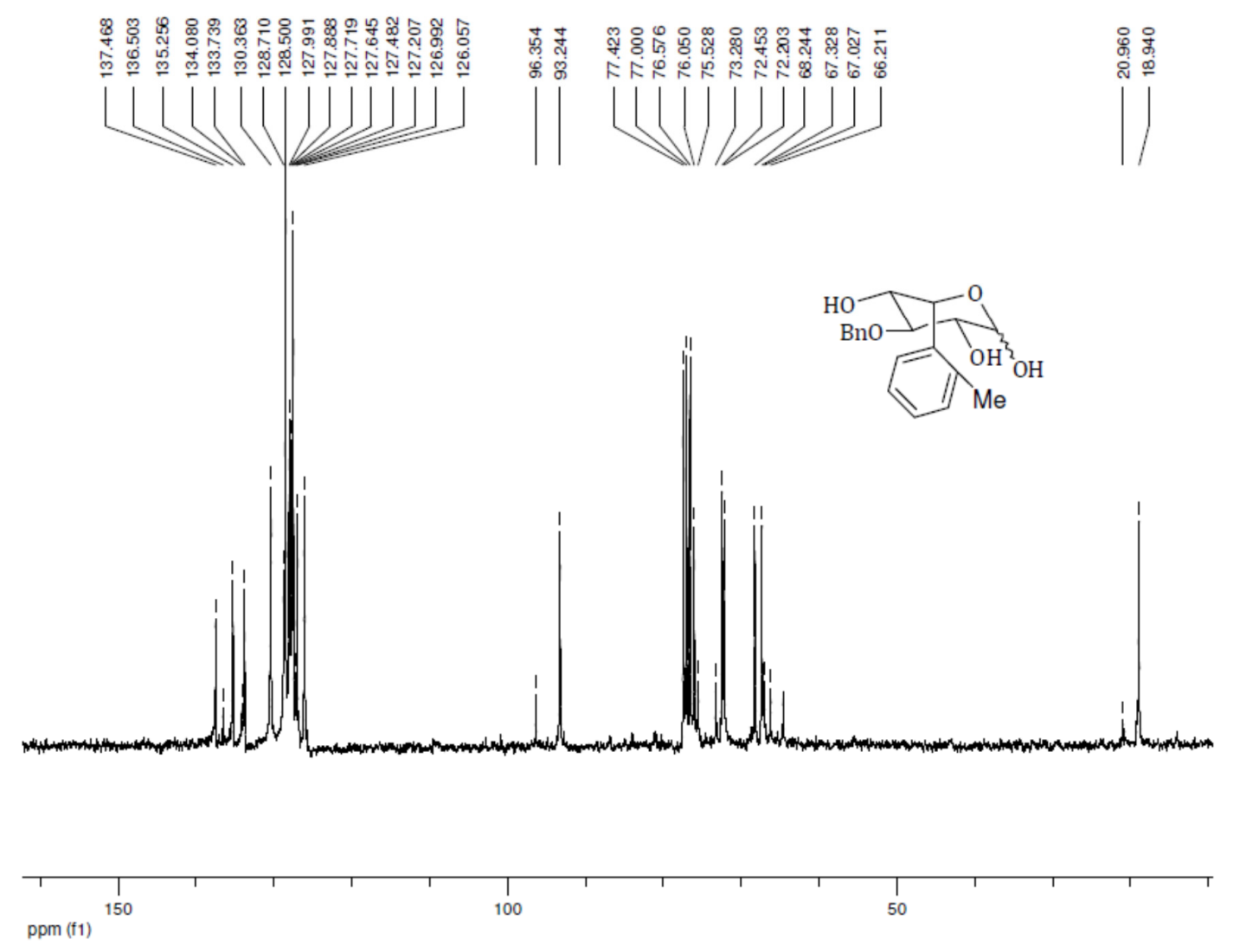

Figura 26. Espectro de $\mathrm{RMN}^{13} \mathrm{C}$ da mistura de anômeros do composto 33c. 
A conclusão desta etapa foi bastante complexa devido a uma série de fatores. Além da mistura de anômeros, muitas impurezas foram observadas por cromatografia em camada delgada e aliado a isso a alta polaridade desses compostos e consequente solubilidade em água, tornaram a purificação muito difícil. Em alguns casos, mesmo após a purificação não foi possível adquirir bons dados espectrais para confirmar as estruturas. Esta etapa contribuiu muito para a diminuição do rendimento global das reações como pode ser observado nos resultados descritos na Tabela 10.

Tabela 10. Hidrólise dos acetonídeos da série31.

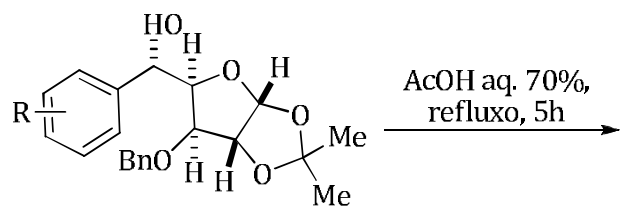

31

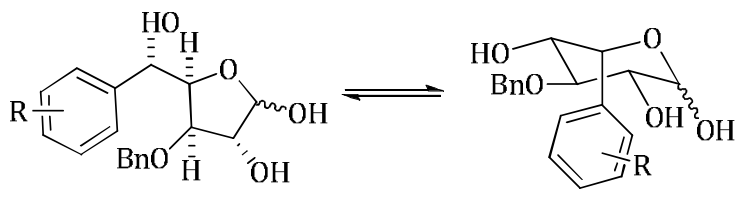

32

\begin{tabular}{ccc}
\hline Entrada & $\mathbf{R}$ & Rendimento\% \\
\hline $\mathbf{1}$ & $\mathrm{H}(\mathrm{a})$ & 43 \\
$\mathbf{2}$ & $p-\mathrm{Me}(\mathrm{b})$ & 38 \\
$\mathbf{3}$ & $o-\mathrm{Me}(\mathrm{c})$ & 41 \\
$\mathbf{4}$ & $p-\mathrm{MeO}(\mathrm{d})$ & 42 \\
$\mathbf{5}$ & $p-\mathrm{Cl}(\mathrm{e})$ & 46 \\
$\mathbf{6}$ & $p-\mathrm{Br}(\mathrm{f})$ & 48 \\
$\mathbf{7}$ & $3,4,5-\mathrm{F}(\mathrm{g})$ & 47 \\
\hline
\end{tabular}

A etapa de formação da lactona, seguida de uma reação tipo Michael, intramolecular, conduziu a formação do biciclo furanofurona e foi promovida por ácido de Méldrum, conforme pode ser observado Tabela 11. 
Tabela 11. Preparação do biciclo furanofurona 36.
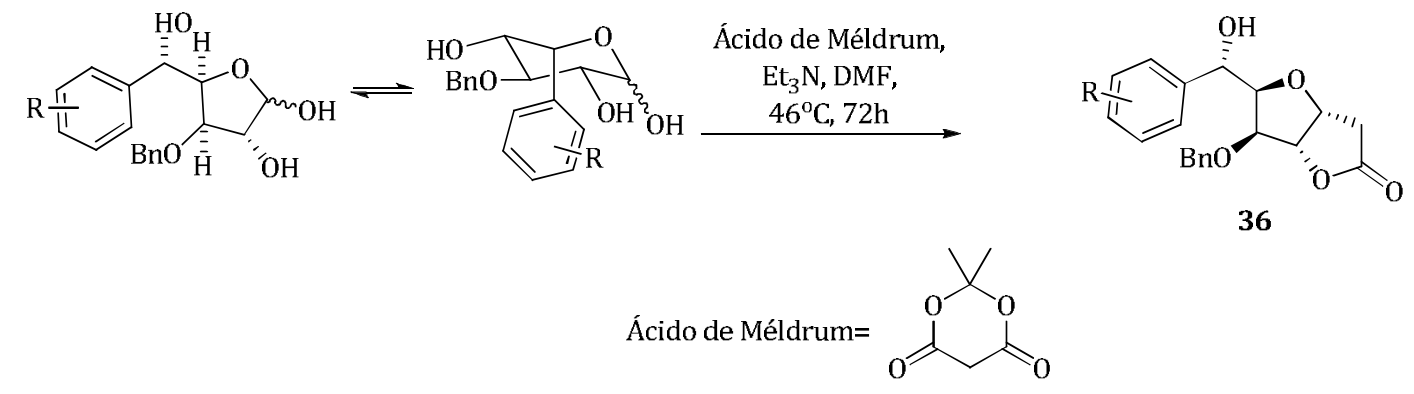

\begin{tabular}{ccc}
\hline Entrada & $\mathbf{R}$ & Rendimento\% \\
\hline $\mathbf{1}$ & $\mathrm{H}(\mathrm{a})$ & 51 \\
$\mathbf{2}$ & $p-\mathrm{Me}(\mathrm{b})$ & 50 \\
$\mathbf{3}$ & $o-\mathrm{Me}(\mathrm{c})$ & 51 \\
$\mathbf{4}$ & $p-\mathrm{MeO}(\mathrm{d})$ & 52 \\
$\mathbf{5}$ & $p-\mathrm{Cl}(\mathrm{e})$ & 53 \\
$\mathbf{6}$ & $p-\mathrm{Br}(\mathrm{f})$ & 55 \\
$\mathbf{7}$ & $3,4,5-\mathrm{F}(\mathrm{g})$ & 56 \\
\hline
\end{tabular}

O mecanismo detalhado desta reação pode ser conferido no Esquema 29. Em um primeiro momento é importante lembrar que o sistema de anômeros 33 está em constante equilíbrio que passa por uma estrutura de cadeia aberta, como pode ser observado no esquema, e é esta espécie que sofre ataque do enol derivado do ácido de Méldrum. Em uma sequência de rearranjos, eliminação e ciclização o composto 36 é obtido. A série de compostos 36 foi obtida facilmente, mas em rendimentos moderados de $50-56 \%$. 


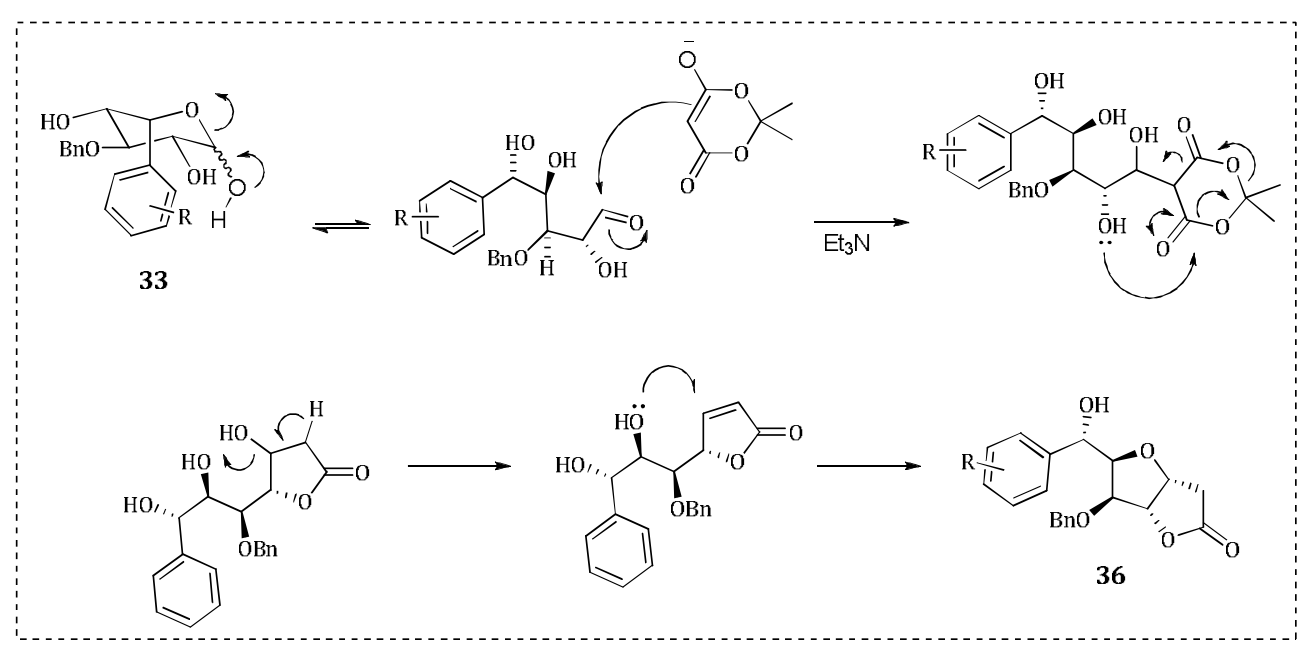

Esquema 29. Mecanismo de reação para a formação do biciclo furanofurona 36.

A desproteção da hidroxila no C-5 constitui a última etapa da síntese da 7epi-goniofufurona e de seus análogos foi realizada através de hidrogenólise, utilizando hidrogênio gasoso e Pd-C como catalisador. De modo geral, esta etapa foi realizada facilmente e conduziu aos produtos em bons rendimentos, conforme pode ser observado na Tabela 12.

Tabela 12. Hidrogenólise do composto 36 conduz a epi-gioniofufurona.

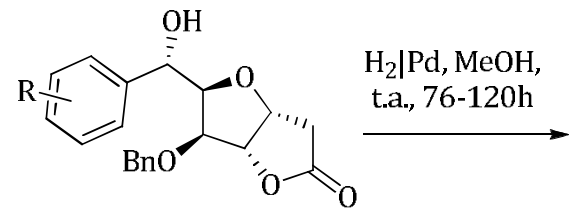

36

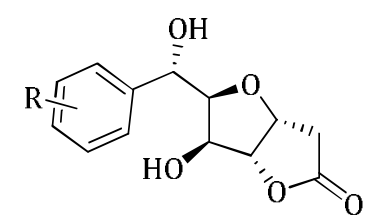

17

\begin{tabular}{cccc}
\hline Entrada & $\mathrm{R}$ & Rendimento $\%$ & {$[\alpha]_{\mathrm{D}}$} \\
\hline $\mathbf{1}$ & $\mathrm{H}(\mathrm{a})$ & 53 & $+102,8$ \\
$\mathbf{2}$ & $o-\mathrm{Me}(\mathrm{c})$ & 57 & $+43,4$ \\
$\mathbf{3}$ & $p-\mathrm{Cl}(\mathrm{e})$ & 56 & +25 \\
$\mathbf{4}$ & $p-\mathrm{Br}(\mathrm{f})$ & 68 & $+87,7$ \\
$\mathbf{5}$ & $3,4,5-\mathrm{F}(\mathrm{g})$ & 72 & $+57,2$ \\
\hline
\end{tabular}




\section{Considerações Finais e Conclusões}

A adição de reagentes arilzinco a aldeídos derivados de açúcares, como substratos quirais, mostrou-se como uma metodologia altamente eficiente no controle da diastereosseletividade na formação do novo centro estereogênico dos compostos derivados da $D$-Glicose conduzindo, em alguns casos, a razões diastereoisoméricas maiores que 20:1. A adição de reagentes arilzinco ao aldeído 30, derivado da D-glicose, constituiu a etapa chave para a preparação da 7-epigoniofufurona e de seus derivados.

A metodologia mostrou-se ainda mais eficaz no caso da $D$-Ribose, onde os produtos de adição foram obtidos, em todos os casos, em diastereosseletividades maiores que 20:1 Infelizmente, quando os esqueletos quirais usados eram derivados da $D$-manose e $D$-galactose, diastereosseletividades muito baixas foram observadas.

A adição de reagentes arilzinco a substratos quirais, como os derivados de carboidratos, mostra-se como uma ferramenta muito interessante, pois permite uma variação estrutural muito grande, dando acesso a derivados nunca preparados, ou seja, este método permite a exploração de uma variedade muito ampla de grupos arila ou até heteroaromáticos a serem transferidos, uma vez que uma gama bastante grande de ácidos borônicos é obtida comercialmente ou pode ser facilmente preparada a partir dos haletos correspondentes. 
MATERIAIS E MÉTODOS 


\section{MATERIAIS E MÉTODOS}

\subsection{Métodos de Identificação e Determinação de Pureza}

\subsubsection{Espectroscopia de Ressonância Magnética Nuclear (RMN)}

Os espectros de RMN ${ }^{1} \mathrm{H}$ e RMN ${ }^{13} \mathrm{C}$ foram obtidos em espectrômetros BRUKER DPX 300 MHz (FCF-USP) e VARIAN MERCURY nas frequências de 200, 300 e $600 \mathrm{MHz}$ no Libniz Intitute of Plant Biochemistry. Os deslocamentos químicos $(\delta)$ estão relacionados em partes por milhão (ppm) em relação ao tetrametilsilano (TMS, utilizado como padrão interno para os espectros de ${ }^{1} \mathrm{H}$, e solventes deuterados para espectros de ${ }^{13} \mathrm{C}$. colocando-se entre parênteses a multiplicidade $(\mathrm{s}=$ singleto, $\mathrm{d}=$ dubleto, $\mathrm{dd}=$ duplo dubleto, $\mathrm{t}=$ tripleto, $\mathrm{m}=$ multipleto, $\mathrm{sl}=$ singleto largo), o número de hidrogênios deduzidos da integral relativa e a constante de acoplamento $($ ) expressa em Hertz (Hz).As amostras foram analisadas em tubos de $5 \mathrm{~mm}$.

\subsubsection{Cromatografia Líquida de Alta Eficiência}

Para a determinação dos excessos enantioméricos dos álcoois secundários quirais, foi empregado um cromatógrafos líquido de alta performance (CLAE), modelo: Shimadzu, LC - 10 AD, utilizando-se colunas quirais Daicel Chiracel e detector de UV visível.

\subsubsection{Polarímetro}

As análises de rotação óptica para os compostos quirais foram realizadas em polarímetro Perkin Elmer 341, com lâmpada de sódio com precisão de 0,05 graus, em cubeta de 50 e $100 \mathrm{~mm}$ de comprimento. 


\subsubsection{Espectrometria de Massas de Alta Resolução}

Os espectros de massas de alta resolução foram obtidos a partir de um aparelho Bruker BioApex 70e (Bruker Daltonics, Billerica, EUA), operando em modo ESI (Íon Electron Spray Ionization) no Leibniz Institute of Plant Biochemistry (Halle - Saale, Alemanha).

\subsection{Solventes e Reagentes}

Os solventes foram purificados e secos antes de serem utilizados, conforme técnicas usuais. Os reagentes comerciais foram convenientemente purificados, quando se fazia necessário. ${ }^{57}$

Foram utilizadas placas para cromatografia em camada delgada para a identificação dos compostos, de alumina e/ou sílica gel. Como métodos de revelação foram utilizados cuba de iodo, luz ultravioleta, solução alcoólica ácida de vanilina e solução alcoólica de ácido fosfonomolíbdico 7\%.

As colunas cromatográficas para purificação foram conduzidas com sílica gel flash400-600 Mesh como fase estacionária.

\subsection{Procedimentos Experimentais}

\subsubsection{Procedimento para a síntese dos ligantes 5a-c ${ }^{19}$}

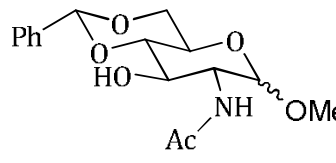

Obtenção do composto 2. Em sistema anidro e sob atmosfera

de argônio, $N$-acetil- $D$-glucosamina foi dissolvida em metanol seco e cloreto de acetila (4,5 equiv) foi adicionado lentamente. A mistura resultante foi agitada

57Perrin, D.; Armarengo, W. L. Purification of Laboratory Chemicals, Pergamon Press, New York, 1996. 
durante 24 horas a temperatura ambiente e após este período o solvente foi completamente evaporado sob pressão reduzida. Dissolveu-se o produto resultante, metil- $N$-acetil- $D$-glucosamina, em benzaldeído ( $1 \mathrm{~mL}$ para cada mmol), adicionou-se cloreto de zinco (3,5 equiv) e submeteu-se o sistema a agitação vigorosa durante 16 horas. Após este período gelo moído e hexano foram adicionados e o sistema agitado durante $20 \mathrm{~min}$. Neste período pode-se observar a precipitação de um sólido branco. Filtrou-se o sobrenadante e o sólido obtido foi lavado diversas vezes com hexano. Após secagem, a mistura de anômeros obtida foi separada por recristalização utilizando-se acetato de etila. Os produtos foram obtidos como sólidos brancos em $62 \%$ de rendimento e em uma proporção $\alpha: \beta=4: 1$.

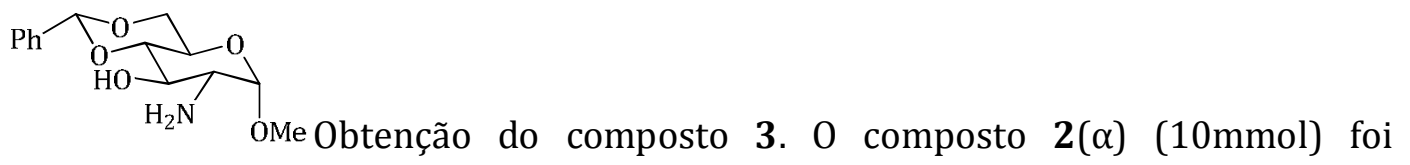
solubilizado em uma solução $4 \mathrm{molL}^{-}$de $\mathrm{KOH}$ em etanol $(100 \mathrm{~mL})$ e submetido a temperatura de refluxo por 4 horas. A solução foi então concentrada e extraída com DCM (200mL) e lavada com água(3x de 200mL). A fase orgânica foi seca com sulfato de magnésio e depois evaporada sob pressão reduzida. 0 produto foi obtido em 76\% de rendimento, como um sólido laranja, sem necessidade de purificação. 


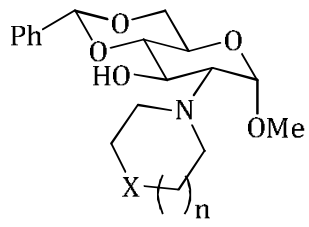

$\mathbf{5 a X}=\mathrm{CH}_{2} ; \mathrm{n}=0 ; 71 \%$

$\mathbf{5 b} \mathrm{X}=\mathrm{CH}_{2} ; \mathrm{n}=1 ; 57 \%$

$\mathbf{5 c X}=0 ; n=1 ; 68 \%$ Obtenção dos compostos 5a-c. 1,1 equivalente de iodeto de alquila e 1,5 equivalentes de carbonato de potássio foram adicionados a uma solução do composto 3 em acetonitrila. As reações foram mantidas sob agitação e temperatura de refluxo durante 48 horas. Após as primeiras 24 horas mais uma porção de 0,5 equivalente do iodeto de alquila foi adicionada. Depois de 48 horas a reação foi resfriada a temperatura ambiente e então filtrada. Purificação foi realizada com coluna cromatográfica, utilizando sílica como fase estacionária e uma mistura de acetato de etila emetanol, em uma proporção de 95:5, como sistema eluente.

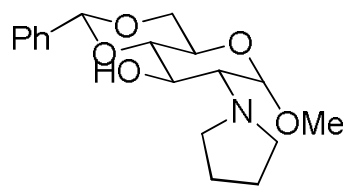

5a. Óleo amarelo obtido em $71 \%$ de rendimento. RMN ${ }^{1} \mathrm{H}$ $\left(\mathrm{CDCl}_{3}, 300 \mathrm{MHz}, \mathrm{ppm}\right) \delta=1,5(\mathrm{~m}, 4 \mathrm{H}) ; 2,6(\mathrm{~m}, 2 \mathrm{H}) ; 2,7(\mathrm{~m}, 2 \mathrm{H}) ; 3,3(\mathrm{~s}, 3 \mathrm{H}) ; 3,5(\mathrm{~m}$, 1H); 3,7 (m, 2H); 4,1 (m, 1H); 4,2 (m, 1H); 4,8 (d; J = $3 \mathrm{~Hz} ; 1 \mathrm{H}) ; 5,5(\mathrm{~s}, 1 \mathrm{H}) ; 7,3(\mathrm{~m}$, 3H); 7,5 (m, 2H); $\mathrm{RMN}{ }^{13} \mathrm{C}\left(\mathrm{CDCl}_{3}, 75 \mathrm{MHz}\right): \delta=51 ; 54,2 ; 62.3 ; 64,8 ; 69,1 ; 69,4$; 83,$4 ; 98,7 ; 101,6 ; 126,3 ; 128,1 ; 128,9 ; 137,3$.

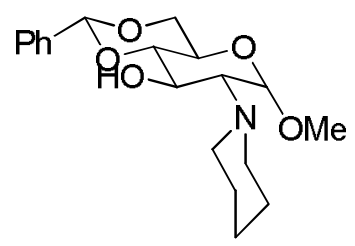

5b. Obtido como um sólido amorfo branco em $57 \%$ de rendimento. $\mathrm{RMN}^{1} \mathrm{H}\left(\mathrm{CDCl}_{3}, 300 \mathrm{MHz}, \mathrm{ppm}\right) \delta=1,5(\mathrm{~m}, 6 \mathrm{H}) ; 2,6(\mathrm{~m}, 2 \mathrm{H}) ; 2,7(\mathrm{~m}$, 
2H); 3,3 (s, 3H); 3,5 (m, 1H); 3,7 (m, 2H); 4,1 (m, 1H); 4,2 (m, 1H); 4,8 (d; J = 3 Hz; 1H); 5,5 (s, 1H); 7,3 (m, 3H); 7,5 (m, 2H); $\mathrm{RMN}^{13} \mathrm{C}\left(\mathrm{CDCl}_{3}, 75 \mathrm{MHz}\right): \delta=24,7 ; 26,9$; $51 ; 54,5 ; 62.2 ; 64,7 ; 69,1 ; 69,4 ; 83,4 ; 98,7 ; 101,6 ; 126,3 ; 128,1 ; 128,9 ; 137,3$.

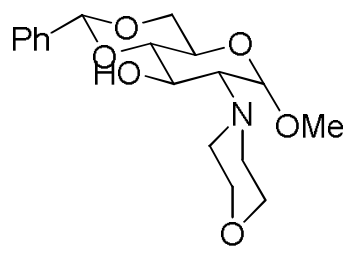

5c. Obtido como um sólido amorfo branco em 57\% de rendimento. $\mathrm{RMN}^{1} \mathrm{H}\left(\mathrm{CDCl}_{3}, 300 \mathrm{MHz}, \mathrm{ppm}\right) \delta=2,8(\mathrm{~m}, 4 \mathrm{H}) ; 3,3(\mathrm{~s}, 3 \mathrm{H}) ; 3,6(\mathrm{~m}$, $8 \mathrm{H}) ; 4,2(\mathrm{~m}, 2 \mathrm{H}) ; 4,8(\mathrm{~d} ; \mathrm{J}=3 \mathrm{~Hz} ; 1 \mathrm{H}) ; 5,5(\mathrm{~s}, 1 \mathrm{H}) ; 7,3(\mathrm{~m}, 3 \mathrm{H}) ; 7,5(\mathrm{~m}, 2 \mathrm{H}) ; \mathrm{RMN}^{13} \mathrm{C}$ $\left(\mathrm{CDCl}_{3}, 75 \mathrm{MHz}\right): \delta=50,2 ; 54,6 ; 62,1 ; 65,1 ; 67,7 ; 68,4 ; 69 ; 83,1 ; 99,3 ; 101,7 ; 126,2 ;$ 128,$1 ; 129 ; 137,1$.

\subsubsection{Procedimento para a síntese dos ligantes $10 a-c^{18,23}$}<smiles>CC1(C)OC[C@H]2O[C@@H]3OC(C)(C)O[C@H]3[C@H]2O1</smiles>

Obtenção do bis-acetonídeo 7. Dissolveu-se iodo $(900 \mathrm{mg}$,

3,54 mmol) em acetona (150 $\mathrm{mL})$ e em seguida, a $D$-xilose $(3 \mathrm{~g}, 20,0 \mathrm{mmol})$. A solução ficou em refluxo durante 3 horas ou até que não se observasse mais carboidrato depositado no fundo do recipiente. Assim, adicionou-se solução aquosa saturada de tiossulfato de sódio para que o iodo remanescente fosse consumido, o que resultou em uma solução incolor, que foi extraída com $\mathrm{CHCl}_{3} \mathrm{e}$ água. 0 produto bruto 7 foi obtido como um óleo amarelo em $94 \%$ de rendimento e utilizado diretamente nas etapas subsequentes, sem purificação. 


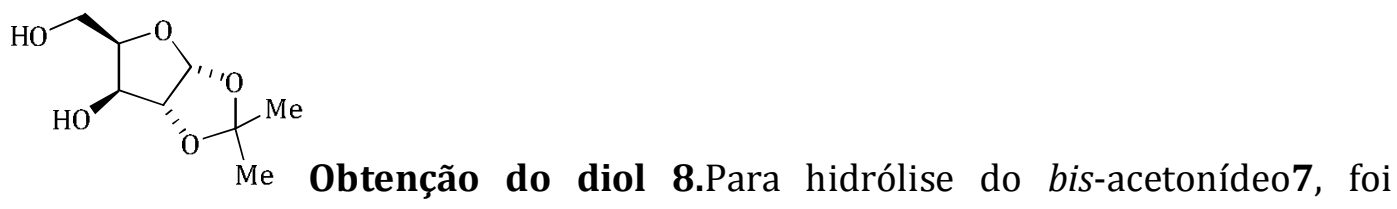

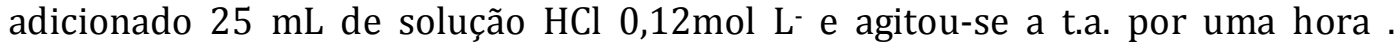
$\mathrm{NaHCO}_{3}$ sólido foi usado para neutralizar a reação até pH 6-7. Depois de evaporar a água, o bruto foi extraído com $\mathrm{CHCl}_{3}$ e água. A fase orgânica foi seca com $\mathrm{MgSO}_{4} \mathrm{e} o$ produto concentrado em vácuo. 0 diol 8 foi obtido em $86 \%$ de rendimento e utilizado diretamente na etapa seguinte, sem purificação.<smiles>CC1(C)O[C@@H]2O[C@H](CO[AsH3])[C@@H](O)[C@H]2O1</smiles>

Obtenção do Tosilato 9. Por fim, cloreto de tosila (1,1 equiv) foi adicionado a $0^{\circ} \mathrm{C}$ a uma solução do diol em piridina. Agitou-se a temperatura ambiente por 3 horas e na sequência, foi adicionada água para remover a piridina sob vácuo, co-evaporando com tolueno duas vezes. Solubilizou-se o bruto em acetato de etila e com água e com solução de $\mathrm{NaCl}$ extraiu-se a solução. Sólido branco. Rendimento: 81\%. $\mathrm{RMN}^{1} \mathrm{H}\left(\mathrm{CDCl}_{3}, 300 \mathrm{MHz}, \mathrm{ppm}\right) \delta=1,29$ (s, 3H); 1,45 (s, 3H); 2,44 (s, 3H);4,20-4,10 (m, 1H); 4,37-4,26 (m, 3H);4,50 (d, J = 3,51, 1H); 5,87 $(\mathrm{d}, J=3,51,1 \mathrm{H}) ; 7,35(\mathrm{~d}, J=8,0,2 \mathrm{H}) ; 7,80(\mathrm{~d}, J=8,2,2 \mathrm{H}) ; \mathrm{RMN}^{13} \mathrm{C}\left(\mathrm{CDCl}_{3}, 75 \mathrm{MHz}\right)$ : $\delta=21.7 ; 26,8 ; 28,2 ; 66,6 ; 85,1 ; 105,0 ; 112,1 ; 128,0 ; 130,0 ; 132,3 ; 145,3$.

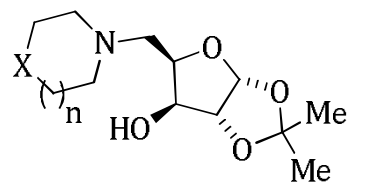

10a $\mathrm{X}=\mathrm{CH}_{2} ; \mathrm{n}=0$ $10 \mathrm{~b} \mathrm{X}=\mathrm{CH}_{2} . \mathrm{n}=1$ 10c $X=0 ; n=1$ Obtenção dos compostos 10a-c. Sob solução do tosilato 9 em iso-propanol, adicionou-se 8 equivalentes de amina (pirrolidina, piperidina ou morfolina) e a solução mantida sob temperatura de refluxo durante 24 horas. Após 
este período a reação foi resfriada a temperatura ambiente e o solvente evaporado sob pressão reduzida. 0 bruto foi então extraído com acetato de etila, lavado com água. A fase orgânica foi seca com sulfato de magnésio e o solvente evaporado. Os respectivos produtos foram purificados em coluna cromatográfica utilizando sílica como fase estacionária e acetato de etila e hexano em proporção de 7:1-9:1 como sistema eluente.

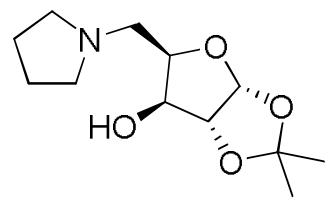

10a. Obtido como umóleo amarelo em $65 \%$ de rendimento. ${ }^{1} \mathrm{H}$ NMR (300 MHz, $\left.\mathrm{CDCl}_{3}\right): \delta$ 1,3 (s, 3H); 1,4 (s, 3H); 1,7 (m, 4H); 2,5 (m, 2H); 2,8 (m, $2 \mathrm{H}) ; 3,0(\mathrm{~m}, 1 \mathrm{H}) ; 3,2(\mathrm{~m}, 1 \mathrm{H}) ; 4,1(\mathrm{q}, \mathrm{J}=2,7 \mathrm{~Hz}, 1 \mathrm{H}) ; 4,3(\mathrm{~m}, 1 \mathrm{H}) ; 4,4(\mathrm{~m}, 1 \mathrm{H}) ; 5,9$ $(\mathrm{d}, \mathrm{J}=3,9 \mathrm{~Hz}, 1 \mathrm{H}) .{ }^{13} \mathrm{C}$ NMR $\left(75 \mathrm{MHz}, \mathrm{CDCl}_{3}\right) \delta 23,5 ; 26,0 ; 26,6 ; 55,5 ; 76,5 ; 85,8$; 104,$8 ; 111,2$.

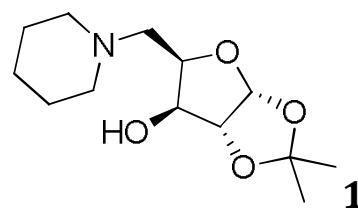

10b: Obtido como um sólido branco em $76 \%$ de rendimento. ${ }^{1} \mathrm{H}$ NMR (300 MHz, $\left.\mathrm{CDCl}_{3}\right): \delta 1,3(\mathrm{~s}, 3 \mathrm{H}) ; 1,4-1,5(\mathrm{~m}, 7 \mathrm{H}) ; 2,4(\mathrm{t}, \mathrm{J}=5,1 \mathrm{~Hz}, 2 \mathrm{H}) ; 2,7-2,8$ (m, 3H); 3,0 (m, 1H); 4,1 (d, J = 2,7 Hz, 1H); 4,2 (d, J = 2,1 Hz, 1H); 4,4 (d, J = 3,6 Hz, $1 \mathrm{H}) ; 5,9(\mathrm{~d}, \mathrm{~J}=3,6 \mathrm{~Hz}, 1 \mathrm{H}) .{ }^{13} \mathrm{C}$ NMR $\left(75 \mathrm{MHz}, \mathrm{CDCl}_{3}\right) \delta 23,5 ; 25,9 ; 26,0 ; 26,6 ; 56,0$; 57,$8 ; 76,5 ; 85,6 ; 104,8 ; 111,1$.

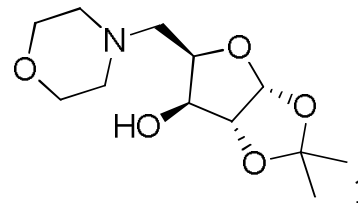

10c: Obtido como um sólido amarelo claro em $86 \%$ de rendimento. ${ }^{1} \mathrm{H}$ NMR $\left(300 \mathrm{MHz}, \mathrm{CDCl}_{3}\right): \delta 1,3(\mathrm{~s}, 3 \mathrm{H}) ; 1,4(\mathrm{~s}, 3 \mathrm{H}) ; 2,4(\mathrm{~m}, 2 \mathrm{H}) ; 2,8$ (m, 3H); $3.0(\mathrm{~m}, 1 \mathrm{H}), 3,6(\mathrm{~m}, 4 \mathrm{H}) ; 4,1(\mathrm{t}, J=2,1 \mathrm{~Hz}, 1 \mathrm{H}) ; 4,2(\mathrm{~m}, 1 \mathrm{H}) ; 4,4(\mathrm{~m}, 1 \mathrm{H}) ; 5,9$ 
(d, $J=3,6 \mathrm{~Hz}, 1 \mathrm{H}) .{ }^{13} \mathrm{C}$ NMR $\left(75 \mathrm{MHz}, \mathrm{CDCl}_{3}\right) \delta 26 ; 26,6 ; 55 ; 57,6 ; 66,8 ; 76,5 ; 85,5$; 104,$7 ; 111,3$.

\subsubsection{Procedimento geral para a síntese dos diarilmetanois 6:}

A uma suspensão de ácido fenilborônico (144mg, 1,2mmol) em tolueno( $2 \mathrm{~mL})$ dietilzinco solução $1 \mathrm{M}$ em tolueno $(3,5 \mathrm{~mL} ; 3,5 \mathrm{mmol})$ foi adicionado a temperatura ambiente. A reação foi agitada a $60^{\circ} \mathrm{C}$ durante 1 hora e então resfriada a temperatura ambiente. Uma solução do catalisador (20mol\%) em tolueno( $1 \mathrm{~mL})$ foi adicionado a reação e o sistema agitado por 20 minutos. A reação foi então resfriada a $0^{\circ} \mathrm{C}$ e então o aldeído $(0,5 \mathrm{mmol})$ foi adicionado. A reação permaneceu sob agitação durante 6 horas. Após este período $20 \mathrm{~mL}$ de água foram adicionados e diclorometano $(3 \times 20 \mathrm{~mL})$ foi usado para a extração. A fase orgânica foi seca com sulfato de magnésio e posteriormente evaporada sob pressão reduzida. A purificação foi conduzida em coluna cromatográfica flash, usando hexano e acetato de etila, em uma proporção de 4:1, como eluentes. Os excessos enantioméricos foram determinados por HPLC usando colunas quirais.<smiles>Cc1ccc(C(O)c2ccccc2)cc1</smiles>

6a. (4-metil)fenilmetanol. $\mathrm{RMN}{ }^{1} \mathrm{H}\left(300 \mathrm{MHz}, \mathrm{CDCl}_{3}\right): \delta 2,3$ $(\mathrm{s}, 3 \mathrm{H}) ; 5,7(\mathrm{~s}, 1 \mathrm{H}) ; 7,1-7,3(\mathrm{~m}, 9 \mathrm{H}) . \mathrm{RMN}{ }^{13} \mathrm{C}\left(75 \mathrm{MHz}, \mathrm{CDCl}_{3}\right) \delta 21 ; 76 ; 126,4 ;$ 126,$5 ; 127,3 ; 128,3 ; 129,1 ; 137,1 ; 140,9 ; 143,9$. Chiralcel $0 D H ; 10 \%$ iPrOH/Hexano; 0,5 mL/min; $(S): 40,3 \mathrm{~min},(R): 42,6 \mathrm{~min}$. 
<smiles>Cc1ccccc1C(O)c1ccccc1</smiles>

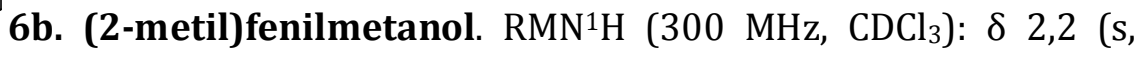
$3 \mathrm{H}) ; 5,9(\mathrm{~d}, J=1,8 \mathrm{~Hz}, 1 \mathrm{H}) ; 7,1-7,4(\mathrm{~m}, 9 \mathrm{H}) .{ }^{13} \mathrm{C} \mathrm{RMN}\left(75 \mathrm{MHz}, \mathrm{CDCl}_{3}\right) \delta 19,3 ; 73,3 ;$ $126 ; 126,2 ; 127 ; 127,5 ; 128,4 ; 130,5 ; 135,3 ; 141,4 ; 142,8$. Chiralpak ADH, $2 \%$ iPrOH/Hexano; 0,5 mL/min; $(R): 16,8 \mathrm{~min}$; $(S): 18,6 \mathrm{~min}$.<smiles>COc1ccc([C@@H](O)c2ccccc2)cc1</smiles>

6c. (4-metoxifenil)fenilmetanol. $\mathrm{RMN}{ }^{1} \mathrm{H}\left(300 \mathrm{MHz}, \mathrm{CDCl}_{3}\right)$ : $\delta 2,3(\mathrm{~s}, 1 \mathrm{H}) ; 3,7(\mathrm{~s}, 3 \mathrm{H}) ; 5,7(\mathrm{~s}, 1 \mathrm{H}) ; 6,8(\mathrm{~m}, 2 \mathrm{H}) ; 7,2-7,3(\mathrm{~m}, 7 \mathrm{H}) . \mathrm{RMN}{ }^{13} \mathrm{C}(75 \mathrm{MHz}$, $\left.\mathrm{CDCl}_{3}\right) \delta 55,2 ; 75,7 ; 113,8 ; 126,3 ; 127,3 ; 127,8 ; 128,3 ; 136,1 ; 144 ; 158,9$. Chiralcel ODH; 10\% i-PrOH/Hexano; 0,5 mL/min; $(S): 20,2 \mathrm{~min}$; $(R): 21,1 \mathrm{~min}$.<smiles>COc1ccccc1C(O)c1ccccc1</smiles>

6d. (2-metoxifenil)fenilmetanol. $\mathrm{RMN}^{1} \mathrm{H}\left(300 \mathrm{MHz}, \mathrm{CDCl}_{3}\right): \delta 3,7$ $(\mathrm{s}, 3 \mathrm{H}) ; 6,0(\mathrm{~d}, J=3,9 \mathrm{~Hz}, 1 \mathrm{H}) ; 6,8-6,9(\mathrm{~m}, 2 \mathrm{H}) ; 7,2-7,3(\mathrm{~m}, 7 \mathrm{H}) \cdot \mathrm{RMN}^{13} \mathrm{C}(75 \mathrm{MHz}$, $\left.\mathrm{CDCl}_{3}\right) \delta 55,2 ; 71,7 ; 110,6 ; 120,6 ; 126,4 ; 126,9 ; 127,6 ; 127,9 ; 128,4 ; 131,9 ; 143,2 ;$ 156,5. Chiralcel ODH; $2 \%$ i-PrOH/Hexano; 0,5 mL/min; $(R): 60,7 \mathrm{~min} ;(S): 73,7 \mathrm{~min}$.<smiles>O[C@H](c1ccccc1)c1ccc(Cl)cc1</smiles>
6e. (4-clorofenil)fenilmetanol.RMN ${ }^{1} \mathrm{H}\left(300 \mathrm{MHz}, \mathrm{CDCl}_{3}\right): \delta$ $2,4(\mathrm{~d}, \mathrm{~J}=3 \mathrm{~Hz}, 1 \mathrm{H}) ; 7,3(\mathrm{~m}, 9 \mathrm{H}) . \mathrm{RMN}^{13} \mathrm{C}\left(75 \mathrm{MHz}, \mathrm{CDCl}_{3}\right) \delta 75,5 ; 126,4 ; 127,7 ;$ 127,$8 ; 128,5 ; 128,5 ; 133,1 ; 142,1 ; 143,3$. Chiralpak ADH; 10\% i-PrOH/Hexano; 1,0 $\mathrm{mL} / \mathrm{min} ;(R): 8,4 \mathrm{~min} ;(S): 9,1 \mathrm{~min}$. 
<smiles>OC(c1ccccc1)c1ccccc1Cl</smiles>

6f. (2-clorofenil)fenilmetanol. $\mathrm{RMN}^{1} \mathrm{H}\left(300 \mathrm{MHz}, \mathrm{CDCl}_{3}\right): \delta 6,2$ (s, 1H); 7,1-7,3 (m, 8H); 7,5 (d, J=7,2 Hz, 1H). $\mathrm{RMN}^{13} \mathrm{C}\left(75 \mathrm{MHz}, \mathrm{CDCl}_{3}\right) \delta 72,6 ; 126,8$; $127 ; 127,3 ; 128 ; 128,4 ; 128,6 ; 129,4 ; 132,4 ; 140,9 ; 142,2$. Chiralcel ODH; $10 \% i-$ PrOH/Hexano; 0,5 mL/min; $(R): 14,7 \mathrm{~min} ;(S): 16,5 \mathrm{~min}$.<smiles>OC(c1ccccc1)c1ccc(Br)cc1</smiles>

6g. (4-bromofenil)fenilmetanol.RMN ${ }^{1} \mathrm{H}\left(300 \mathrm{MHz}, \mathrm{CDCl}_{3}\right): \delta$ 2,4 (sa, 1H); $5,7(\mathrm{~s}, 1 \mathrm{H}) ; 7,2-7,4(\mathrm{~m}, 9 \mathrm{H}) . \mathrm{RMN}^{13} \mathrm{C}\left(75 \mathrm{MHz}, \mathrm{CDCl}_{3}\right) \delta 75,6 ; 121,3$; 126,$4 ; 127,8 ; 128,1 ; 128,6 ; 131,4 ; 142,7 ; 143,3$. Chiralcel $0 B H ; 10 \%$ iPrOH/Hexano; 0,5 mL/min; $(R): 22,6$ min; $(S): 30,2$ min.<smiles>OC(c1ccccc1)c1ccccc1Br</smiles>

6h. (2-bromofenil)fenilmetanol. $\mathrm{RMN}^{1} \mathrm{H}\left(300 \mathrm{MHz}, \mathrm{CDCl}_{3}\right): \delta$ 2,8 (sa, 1H); 6,1 (s,1H); 7,0-7,5 (m, 9H). $\mathrm{RMN}^{13} \mathrm{C}\left(75 \mathrm{MHz}, \mathrm{CDCl}_{3}\right) \delta 74,6 ; 122,7 ; 126,9$; 127,$6 ; 128,3 ; 128,4 ; 129 ; 130,1 ; 132,7 ; 142,1 ; 142,4$. Chiralcel ODH; 10\% iPrOH/Hexano; 0,8 mL/min; $(R): 10,4 \mathrm{~min} ;(S): 11,9 \mathrm{~min}$.

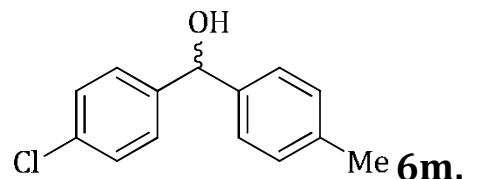

Me 6m. (4-clorofenil)-4-metilfenilmetanol.RMN ${ }^{1} \mathrm{H} \quad(300$ $\left.\mathrm{MHz}, \mathrm{CDCl}_{3}\right): \delta 2,3(\mathrm{~s}, 3 \mathrm{H}) ; 5,7(\mathrm{~s}, 1 \mathrm{H}) ; 7,1-7,3(\mathrm{~m}, 8 \mathrm{H}) . \mathrm{RMN}^{13} \mathrm{C}\left(75 \mathrm{MHz}, \mathrm{CDCl}_{3}\right) \delta$ $21 ; 75,3 ; 126,4 ; 127,7 ; 128,4 ; 129,2 ; 133 ; 137,5 ; 140,5 ; 142,3$. Chiralcel 0DH; $10 \%$ i-PrOH/Hexano; 0,2 mL/min;(R): 40,1 min; (S): 42,1 min. 


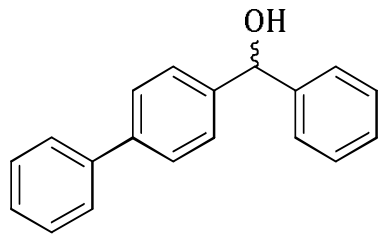

6n. (4-bi-fenil)fenilmetanol. $\mathrm{RMN}^{1} \mathrm{H}\left(300 \mathrm{MHz}, \mathrm{CDCl}_{3}\right): \delta$ 2,3 (s, 3H); 2,4 (s, 1H); 5,7 (s, 1H); 7,1-7,5 (m, 13H). RMN ${ }^{13} \mathrm{C}\left(75 \mathrm{MHz}, \mathrm{CDCl}_{3}\right) \delta 21$; 75,$8 ; 126,4 ; 126,8 ; 127 ; 127,1 ; 127,1 ; 128,6 ; 129,1 ; 137,2 ; 140,2 ; 140,7 ; 140,8$; 142,9. Chiralcel ODH; $10 \% \mathrm{i}$-PrOH/Hexano; 0,2 mL/min; $(R): 40,1 \mathrm{~min}$; $(S): 42,1$ $\min$.

\subsubsection{Procedimento geral para a síntese do aldeído 30:}

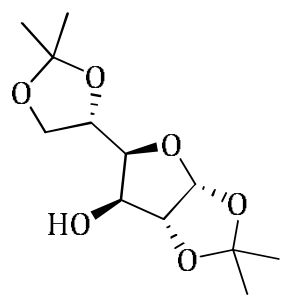

Obtenção do bis-acetonídeo 48. Em um balão de 200mL foram adicionados $100 \mathrm{~mL}$ de acetona, iodo $(0,1$ eq., $2 \mathrm{mmol})$ e por último $D$-Glicose (20mmol, 3,6g). 0 sistema foi acoplado a um condensador de refluxo e aquecido a $60^{\circ} \mathrm{C}$ por 3 horas. Após este período solução saturada de tiossulfato de sódio foi adicionada para que o iodo remanescente fosse consumido. A mistura foi então extraída com clorofórmio e a fase orgânica lavada com água (3 vezes de 100mL). Posteriormente a fase orgânica foi seca com sulfato de magnésio e concentrada em rotaevaporador. 0 produto foi obtido como um sólido branco em $72 \%$ de rendimento. $\mathrm{RMN}^{1} \mathrm{H}\left(\mathrm{CDCl}_{3}, 300 \mathrm{MHz}, \mathrm{ppm}\right) \delta=1,32(\mathrm{~s}, 3 \mathrm{H}) ; 1,36(\mathrm{~s}, 3 \mathrm{H}) ; 1,44(\mathrm{~s}$, 3H); 1,49 (s, 3H); 2,56 (d, $J=3,72,0 H) ; 3,97$ (dd, $J=9 ; J=1,2,1 \mathrm{H}) ; 3,99$ (dd, $J=8,4 ; J$ $=1,2,1 \mathrm{H}) ; 4,06(\mathrm{dd}, J=7,8 ; J=2,7 ; 1 \mathrm{H}) ; 4,16(\mathrm{dd}, J=8,5 ; J=6.3 ; 1 \mathrm{H}) ; 4,3(\mathrm{~m}, 1 \mathrm{H})$; 
$4,53(\mathrm{~d}, \mathrm{~J}=3,6 ; 1 \mathrm{H}) ; 5,93(\mathrm{~d}, \mathrm{~J}=3,6 ; 1 \mathrm{H}) . \mathrm{RMN}^{13} \mathrm{C}\left(\mathrm{CDCl}_{3}, 75 \mathrm{MHz}\right): \delta=26,12 ; 26,15$;

26,$7 ; 26,8 ; 67,6 ; 73,3 ; 75 ; 81,1 ; 85 ; 105,2 ; 109,5 ; 111,7$.

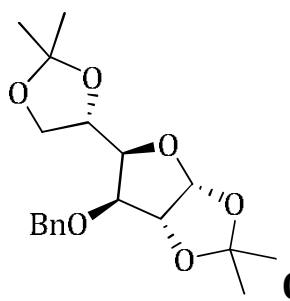

Obtenção de 49. Em balão de $100 \mathrm{~mL} 48$ (15mmol) foi solubilizado em $30 \mathrm{~mL}$ de diclorometano, foram adicionados $16 \mathrm{~mL}$ de solução $50 \%(\mathrm{~m} / \mathrm{v})$ de hidróxido de sódio, brometo de tetrametilamônio $(0,1$ eq.) e brometo de benzila (1,5 eq.). 0 sistema foi mantido sob agitação vigorosa durante 16 horas. Extração foi conduzida com diclorometano (200 mL), lavando 3 vezes com água (3x $100 \mathrm{~mL}$ ). A fase orgânica foi seca com sulfato de magnésio e concentrada em rotaevaporador. 0 produto foi purificado por coluna cromatográfica utilizando sílica como fase estacionária e como eluente uma mistura de acetato/hexano (20\%). 0 produto foi obtido como óleo amarelo em $86 \%$ de rendimento. $\mathrm{RMN}^{1} \mathrm{H}\left(\mathrm{CDCl}_{3}, 300 \mathrm{MHz}, \mathrm{ppm}\right) \delta=1,31(\mathrm{~s}, 3 \mathrm{H}) ; 1,37(\mathrm{~s}, 3 \mathrm{H})$; $1,42(\mathrm{~s}, 3 \mathrm{H}) ; 1,48(\mathrm{~s}, 3 \mathrm{H}) ; 3,9(\mathrm{~m}, 2 \mathrm{H}) ; 4,1(\mathrm{~m}, 2 \mathrm{H}) ; 4,3(\mathrm{dd}, J=6 ; J=1,8 ; 1 \mathrm{H}) ; 4,5(\mathrm{~d}, J$ $=3,9 ; 1 \mathrm{H}) ; 4,6(\mathrm{~d}, \mathrm{~J}=3,9 ; 2 \mathrm{H}) ; 5,8(\mathrm{~d}, \mathrm{~J}=3,9 ; 1 \mathrm{H}) ; 7,3(\mathrm{~m}, 5 \mathrm{H}) . \mathrm{RMN}{ }^{13} \mathrm{C}\left(\mathrm{CDCl}_{3}, 75\right.$ MHz): $\delta=25 ; 26,2 ; 26,7 ; 26,8 ; 67 ; 72,3 ; 72,5 ; 81,3 ; 81,7 ; 82,6 ; 105,2 ; 108 ; 111$; 127,$5 ; 127,7 ; 128 ; 137$. 


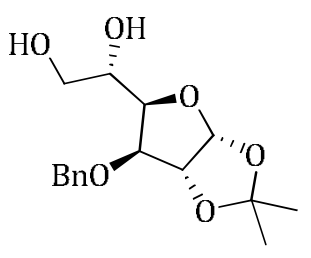

Obtenção do diol 50. Em balão de $100 \mathrm{~mL}, 49$ (5 mmol) foi solubilizado em 40 mL de solução 60\%(v/v) de ácido acético. Agitou-se a solução resultante vigorosamente por 16 horas. 0 solvente foi evaporado eco-evaporando com água (2x de $25 \mathrm{~mL}$ ) e por último com tolueno (2x de $20 \mathrm{~mL}$ ). 0 produto foi obtido como um óleo amarelo em $96 \%$ de rendimento. $\mathrm{RMN}{ }^{1} \mathrm{H}\left(\mathrm{CDCl}_{3}, 300 \mathrm{MHz}\right.$, ppm) $\delta=1,32(\mathrm{~s}, 3 \mathrm{H}) ; 1,48(\mathrm{~s}, 3 \mathrm{H}) ; 3,6(\mathrm{~m}, 1 \mathrm{H}) ; 3,8(\mathrm{~m}, 1 \mathrm{H}) ; 4,0(\mathrm{~m}, 1 \mathrm{H}) ; 4,1(\mathrm{~m}$, $2 \mathrm{H}) ; 4,5$ e $4,7\left(2 \mathrm{xd}, J_{g e m}=11,7 ; 2 \mathrm{H}\right) ; 4,6(\mathrm{~d}, J=3,8 ; 1 \mathrm{H}) ; 5,9(\mathrm{~d}, \mathrm{~J}=3,7 ; 1 \mathrm{H}) ; 7,3(\mathrm{~m}$, 5H). $\mathrm{RMN}^{13} \mathrm{C}\left(\mathrm{CDCl}_{3}, 75 \mathrm{MHz}\right): \delta=26,1 ; 26,6 ; 64 ; 69 ; 72,3 ; 79 ; 81,3 ; 82 ; 105,2 ; 111$; $127 ; 128,5 ; 128,9 ; 137,2$.

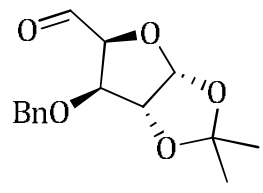

Obtenção do aldeído 30 . Em balão de $100 \mathrm{~mL}$, solubilizou-se $\mathbf{5 0}$ ( $5 \mathrm{mmol}$ ) em $15 \mathrm{~mL}$ de metanol e $1 \mathrm{~mL}$ de solução saturada de bicarbonato de sódio. Em um béquer o periodato de sódio (2 eq.) e sílica (300 mg) foram suspensos em $4 \mathrm{~mL}$ de água quente e adicionados ao balão. Deixa-se sob agitação durante 16 horas a $60^{\circ} \mathrm{C}$. Os solventes foram evaporados e o bruto extraído com diclorometano (300 mL), lavando com água (3x $100 \mathrm{~mL})$. A fase orgânica foi seca com sulfato de magnésio e evaporada em rotaevaporador. 0 produto foi purificado por coluna cromatográfica utilizando sílica como fase estacionária e como eluente uma mistura de acetato/hexano (30\%). 0 produto foi obtido como um óleo amarelo viscoso em $83 \%$ de rendimento. $\mathrm{RMN}^{1} \mathrm{H}\left(\mathrm{CDCl}_{3}, 300 \mathrm{MHz}, \mathrm{ppm}\right) \delta=1,3(\mathrm{~s}$, $3 \mathrm{H}) ; 1,4(\mathrm{~s}, 3 \mathrm{H}) ; 4,3(\mathrm{~d}, J=3,7 ; 1 \mathrm{H}) ; 4,5(\mathrm{~m}, 4 \mathrm{H}) ; 6,1(\mathrm{~d}, \mathrm{~J}=3,5 ; 1 \mathrm{H}) ; 7,3(\mathrm{~m}, 5 \mathrm{H}) ; 9,6$ 
$(\mathrm{d}, \mathrm{J}=1,5 ; 1 \mathrm{H}) . \mathrm{RMN}{ }^{13} \mathrm{C}\left(\mathrm{CDCl}_{3}, 75 \mathrm{MHz}\right): \delta=26,3 ; 26,9 ; 72,4 ; 82,2 ; 83,7 ; 84,6$; 106,$2 ; 112,5 ; 127,7 ; 128,1 ; 128,5 ; 136,6 ; 199,8$.

\subsubsection{Procedimento geral para a síntese do aldeído 5350,51:}

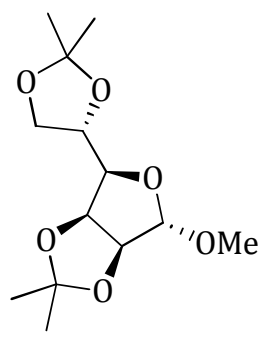

Obtenção do bis-acetonídeo 51. Em balão de 200mL, a uma solução de $D$-Manose $(20 \mathrm{mmol})$ em metanol $(60 \mathrm{~mL})$ e acetona $(60 \mathrm{~mL})$, adicionouse ácido clorídrico $(1,5 \mathrm{~mL})$. Colocou-se a temperatura de refluxo e o sistema foi deixado sob agitação por 16 horas. Após este período resfriou-se o sistema e neutralizou-se com piridina $(5 \mathrm{~mL})$. A solução foi extraída com éter etílico (2x $150 \mathrm{~mL}$ ) e a fase orgânica lavada com solução $1 \mathrm{M}$ de sulfato de cobre $(100 \mathrm{~mL})$ e posteriormente com água (2x 100mL). Secou-se com sulfato de magnésio e os solventes foram evaporados em rotaevaporador. 0 produto foi obtido como um óleo amarelo e $80 \%$ de rendimento, sem necessidade de purificação.

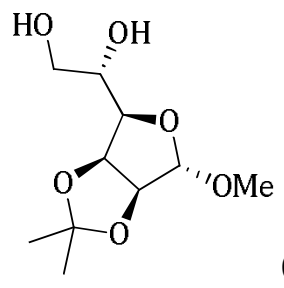

Obtenção do diol 52. Em balão de $100 \mathrm{~mL}$, o composto 51(10mmol) foi solubilizado em $50 \mathrm{~mL}$ de solução $60 \%(\mathrm{v} / \mathrm{v})$ de ácido acético. Agitou-se a solução resultante vigorosamente por 16 horas. 0 solvente foi evaporado, co-evaporando com água (2x de $50 \mathrm{~mL}$ ) e por último com tolueno (2x de $25 \mathrm{~mL}$ ). 0 produto é obtido como um óleo incolor em $98 \%$ de rendimento. 


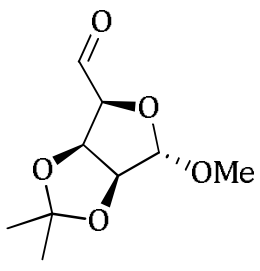

Obtenção do aldeído 53. Em balão de $100 \mathrm{~mL}$, solubilizou-se $\mathbf{5 2}(10 \mathrm{mmol})$ em 30mL de metanol e $2 \mathrm{~mL}$ de solução saturada de bicarbonato de sódio. Em um béquer periodato de sódio (2 eq.) e sílica $(600 \mathrm{mg}$ ) foram suspensos em 8 mL de água quente e adicionados ao balão. 0 sistema ficou sob agitação sob agitação vigorosa durante 16 horas a $60^{\circ} \mathrm{C}$. Evaporou-se os solventes e extraiu-se o bruto com diclorometano (400mL), lavando com água (3x 200mL). A fase orgânica foi seca com sulfato de magnésio e evaporada em rotaevaporador. O produto foi purificado por coluna cromatográfica utilizando sílica como fase estacionária e como eluente uma mistura de acetato/hexano (30\%). 0 produto foi obtido como um óleo incolor em $82 \%$ de rendimento. $\mathrm{RMN}^{1} \mathrm{H}\left(\mathrm{CDCl}_{3}, 300 \mathrm{MHz}, \mathrm{ppm}\right) \delta=1,2(\mathrm{~s}$, $3 \mathrm{H}) ; 1,4(\mathrm{~s}, 3 \mathrm{H}) ; 3,3(\mathrm{~s}, 3 \mathrm{H}), 4,3(\mathrm{~d}, J=4,1 ; 1 \mathrm{H}) ; 4,6(\mathrm{~d}, J=5,8 ; 1 \mathrm{H}) ; 5.0(\mathrm{~d}, \mathrm{~J}=1,4$; 1H); 5,08 (s, 1H); 9,6 (s, 1H); $\mathrm{RMN}^{13} \mathrm{C}\left(\mathrm{CDCl}_{3}, 75 \mathrm{MHz}\right): \delta=24,5 ; 25,8 ; 54,9 ; 80,8$; 83,8; 84,5; 107,8 113,4; 197.

\subsubsection{Procedimento geral para a síntese do aldeído $55^{50}$}

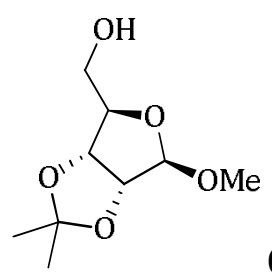

Obtenção do acetonídeo 54. Em balão de 200mL, a uma solução de $D$-Ribose $(20 \mathrm{mmol})$ em metanol $(60 \mathrm{~mL})$ e acetona $(60 \mathrm{~mL})$, adicionou-se ácido clorídrico $(1,5 \mathrm{~mL})$. Colocou-se a temperatura de refluxo e o sistema foi deixado sob agitação por 16 horas. Após este período resfriou-se o sistema e neutralizou-se com piridina (5mL). A solução foi extraída com éter $(300 \mathrm{~mL})$ e a fase orgânica 
lavada com solução $1 \mathrm{M}$ de sulfato de cobre $(100 \mathrm{~mL})$ e posteriormente com água (2x 100mL). Secou-se com sulfato de magnésio e os solventes foram evaporados em rotaevaporador. 0 produto foi obtido como um óleo amarelo e $80 \%$ de rendimento, sem necessidade de purificação para uso posterior.<smiles>CO[C@H]1OC(C=O)[C@H]2OC(C)(C)O[C@H]12</smiles>

Obtenção do aldeído 55. Em um balão de 100mL, acoplado a um condensador de refluxo, o composto $\mathbf{5 4}$ foi solubilizado em $50 \mathrm{~mL}$ de acetonitrila. Ácido iodoxibenzóico (IBX) (3,5eq.) foi adicionado e a reação agitada vigorosamente a $80^{\circ} \mathrm{C}$ durante 4 horas. Após este período o sistema reacional foi resfriado a temperatura ambiente e filtrado sob funil sinterizado contendo $3 \mathrm{~cm}$ de sílica. 0 filtrado foi seco com sulfato de magnésio e então evaporado sob pressão reduzida. 0 produto foi obtido como um óleo amarelo muito viscoso e em $90 \%$ de rendimento sem necessidade de purificação para posterior uso. $\mathrm{RMN}{ }^{1} \mathrm{H}\left(\mathrm{CDCl}_{3}\right.$, $300 \mathrm{MHz}, \mathrm{ppm}) \delta=1,3(\mathrm{~s}, 3 \mathrm{H}) ; 1,4(\mathrm{~s}, 3 \mathrm{H}) ; 3,4(\mathrm{~s}, 3 \mathrm{H}), 4,4(\mathrm{~m}, 2 \mathrm{H}) ; 5.0(\mathrm{~d}, \mathrm{~J}=5,8$; 1H); 5,07 (s, 1H); 9,5 (s, 1H).

\subsubsection{Procedimento geral para a síntese do aldeído 57:}

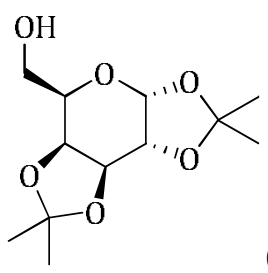

Obtenção do bis-acetonídeo 56. Em balão de 200mL acoplado a condensador de refluxo, solubilizou-se iodo (0,1eq.) em acetona (120mL) e adicionou-se $D$-galactose $(20 \mathrm{mmol})$. Colocou-se a temperatura de refluxo e o 
sistema foi deixado sob agitação por 3 horas. Após este período solução saturada de tiossulfato de sódio foi adicionada para que o iodo remanescente fosse consumido. A mistura foi então extraída com clorofórmio e a fase orgânica lavada com água (3 vezes de 100mL). Posteriormente a fase orgânica foi seca com sulfato de magnésio e concentrada em rotaevaporador. 0 produto foi obtido como um óleo amarelo em $84 \%$ de rendimento e foi utilizado sem necessidade de purificação.

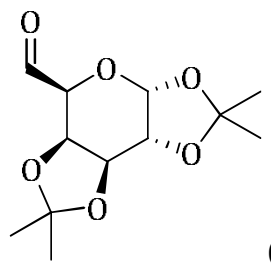

Obtenção do aldeído 57. Em um balão de 100mL, acoplado a um condensador de refluxo, o composto 56 foi solubilizado em $50 \mathrm{~mL}$ de acetonitrila. Ácido iodoxibenzóico (IBX) (3,5eq.) foi adicionado e a reação agitada vigorosamente a $80^{\circ} \mathrm{C}$ durante 4 horas. Após este período o sistema reacional foi resfriado a temperatura ambiente e filtrado sob funil sinterizado contendo $3 \mathrm{~cm}$ de sílica. 0 filtrado foi seco com sulfato de magnésio e então evaporado sob pressão reduzida. 0 produto foi obtido como um óleo incolor muito viscosoe em $89 \%$ de rendimento sem necessidade de purificação para posterior uso. $\mathrm{RMN}{ }^{1} \mathrm{H}\left(\mathrm{CDCl}_{3}\right.$, $300 \mathrm{MHz}, \mathrm{ppm}) \delta=1,3(\mathrm{~s}, 3 \mathrm{H}) ; 1,35(\mathrm{~s}, 3 \mathrm{H}) ; 1,4(\mathrm{~s}, 3 \mathrm{H}) ; 1,5(\mathrm{~s}, 3 \mathrm{H}) ; 4,1(\mathrm{~d}, J=1,7$; $1 \mathrm{H}) ; 4,3(\mathrm{dd}, J=4,7 ; J=2,1,1 \mathrm{H}) ; 4,6(\mathrm{~m}, 2 \mathrm{H}) ; 5.6(\mathrm{~d}, \mathrm{~J}=4,8 ; 1 \mathrm{H}) ; 9,6(\mathrm{~s}, 1 \mathrm{H}) \cdot \mathrm{RMN}^{13} \mathrm{C}$ $\left(\mathrm{CDCl}_{3}, 75 \mathrm{MHz}\right): \delta=24,1 ; 24,7 ; 25,7 ; 25,9 ; 70,3 ; 70,4 ; 71,6 ; 73,1 ; 96,1 ; 108,9 ; 109,9$; 200. 


\subsubsection{Procedimento geral para a síntese os álcoois 31, 58, 59 e 60:}

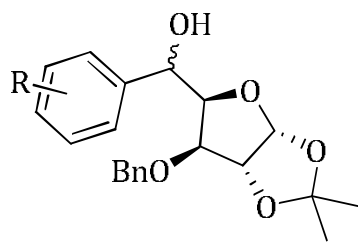

Obtenção dos álcoois 31. Em balão de duas bocas de $25 \mathrm{~mL}$, sob atmosfera de argônio e anidra, adicionou-se dietilzinco solução $1 \mathrm{~mol} \mathrm{~L}^{-}$(7,2 eq., 3,5mmol, 3,5mL) sob suspensão do ácido borônico correspondente (2,4 eq., $1,2 \mathrm{mmol}$ ) em tolueno ( $2 \mathrm{~mL}$ ). Deixou-se sob agitação a $60^{\circ} \mathrm{C}$ durante 1 hora. Após este período resfriou-se o sistema a temperatura ambiente e adicionou-se o aldeído $(0,5 \mathrm{mmol})$ solubilizado em $1 \mathrm{~mL}$ de tolueno. 0 sistema ficou sob agitação por 6 horas. Extraiu-se a reação com acetato de etila $(50 \mathrm{~mL})$ e lavou-se com água (2x100mL). Os produtos foram purificados por coluna cromatográfica utilizando sílica como fase estacionária e como eluente uma mistura de acetato/hexano (30\%). Os produtos obtidos foram obtidos em rendimentos entre 65-68 \%.

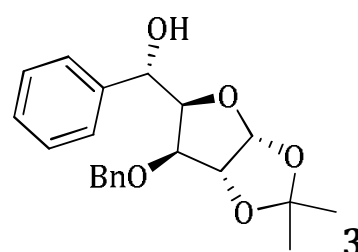

31a. Obtido como um óleo amarelo e $65 \%$ de rendimento. $\mathrm{RMN}^{1} \mathrm{H}\left(\mathrm{CDCl}_{3}, 300 \mathrm{MHz}, \mathrm{ppm}\right) \delta=1,3(\mathrm{~s}, 3 \mathrm{H}) ; 1,4(\mathrm{~s}, 3 \mathrm{H}) ; 2,8(\mathrm{sl}, \mathrm{OH}) ; 3,6(\mathrm{~d}, J=$ $3,2 ; 1 \mathrm{H}) ; 4,3(\mathrm{~m}, 2 \mathrm{H}) ; 4,59$ e 4,54 (2d, Jgem $=11,5,2 \mathrm{H}) ; 5,0(\mathrm{~d}, \mathrm{~J}=7,4 ; 1 \mathrm{H}) ; 6,0(\mathrm{~d}, \mathrm{~J}=$ $3,7 ; 1 \mathrm{H}) ; 7,3(\mathrm{~m}, 10 \mathrm{H}) . \mathrm{RMN}{ }^{13} \mathrm{C}\left(\mathrm{CDCl}_{3}, 75 \mathrm{MHz}\right): \delta=26,1 ; 26,7 ; 71,7 ; 72,3 ; 82 ; 82,1$; 84,$4 ; 106 ; 111,8 ; 127,0 ; 127,5 ; 127,9 ; 128,2 ; 128,4 ; 136,9 ; 139 .[\alpha] \frac{20}{D}=-28(\mathrm{c}=1$, $\left.\mathrm{CHCl}_{3}, \mathrm{l}=10 \mathrm{~mm}\right)$. HRMS m/z calculada para $\mathrm{C}_{21} \mathrm{H}_{24} \mathrm{O}_{5}: 356,1624$. Encontrado: $[\mathrm{M}+\mathrm{Na}]^{+}$379,1520. 


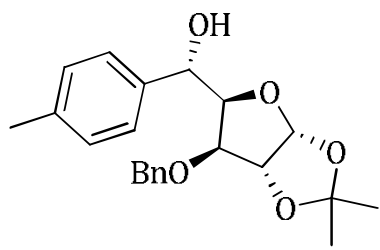

31b. Obtido como um óleo amarelo em $68 \%$ de rendimento. $\mathrm{RMN}{ }^{1} \mathrm{H}\left(\mathrm{CDCl}_{3}, 300 \mathrm{MHz}, \mathrm{ppm}\right) \delta=1,3(\mathrm{~s}, 3 \mathrm{H}) ; 1,4(\mathrm{~s}, 3 \mathrm{H}) ; 2,3(\mathrm{~s}, \mathrm{CH} 3)$; $2,7(\mathrm{sa}, 0 \mathrm{H}) ; 3,6(\mathrm{~d}, J=3,2 ; 1 \mathrm{H}) ; 4,2(\mathrm{~d}, J=3,8 ; 1 \mathrm{H}) ; 4,3(\mathrm{~m}, 1 \mathrm{H}) ; 4,5(\mathrm{~m}, 2 \mathrm{H}) ; 5,0(\mathrm{~d}, \mathrm{~J}$ $=7,5 ; 1 \mathrm{H}) ; 6,0(\mathrm{~d}, \mathrm{~J}=3,7 ; 1 \mathrm{H}) ; 7,1-7,3(\mathrm{~m}, 9 \mathrm{H}) . \mathrm{RMN}{ }^{13} \mathrm{C}\left(\mathrm{CDCl}_{3}, 75 \mathrm{MHz}\right): \delta=21$; 26,$2 ; 26,7 ; 71,7 ; 72,1 ; 82,1 ; 82,18 ; 84,5 ; 105,1 ; 111,7 ; 126,9 ; 127,5 ; 127,8 ; 128,4$; 128,$9 ; 136,7 ; 137 ; 137,5 .[\alpha] \frac{20}{D}=-21\left(\mathrm{c}=1, \mathrm{CHCl}_{3}, \mathrm{l}=10 \mathrm{~mm}\right)$. HRMS m/z calculada para $\mathrm{C}_{22} \mathrm{H}_{26} \mathrm{O}_{5}: 370,1780$. Encontrado: $[\mathrm{M}+\mathrm{Na}]^{+} 393,1678$.

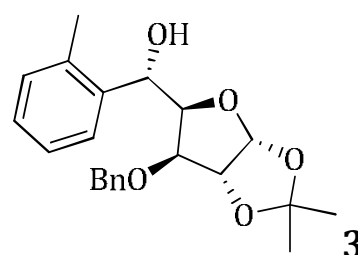

31c. Obtido como um sólido amarelo em $65 \%$ de rendimento. $\mathrm{RMN}^{1} \mathrm{H}\left(\mathrm{CDCl}_{3}, 300 \mathrm{MHz}, \mathrm{ppm}\right) \delta=1,3(\mathrm{~s}, 3 \mathrm{H}) ; 1,5(\mathrm{~s}, 3 \mathrm{H}) ; 2,3(\mathrm{~s}, 3 \mathrm{H}) ; 2,7$ (sa, OH); $3,7(\mathrm{~d}, J=3,4 ; 1 \mathrm{H}) ; 4,1$ e $4,4\left(2 \mathrm{~d}, \mathrm{~J}_{g e m}=11,5,2 \mathrm{H}\right) ; 4,5(\mathrm{~m}, 2 \mathrm{H}) ; 5,2(\mathrm{~d}, J=7 ; 1 \mathrm{H}) 6,0$ $(\mathrm{d}, \mathrm{J}=3,7 ; 1 \mathrm{H}) ; 7,1-7,4(\mathrm{~m}, 9 \mathrm{H}) . \mathrm{RMN}{ }^{13} \mathrm{C}\left(\mathrm{CDCl}_{3}, 75 \mathrm{MHz}\right): \delta=19,2 ; 26,3 ; 26,8 ; 69,1 ;$ 71,$9 ; 82,3 ; 82,6 ; 83,3 ; 105,1 ; 111,8 ; 126,1 ; 127,0 ; 127,7 ; 127,9 ; 128,4 ; 130,5 ; 136,2 ;$ 136,7; 137,6. $[\alpha] \frac{20}{D}=-23\left(\mathrm{c}=1, \mathrm{CHCl}_{3}, \mathrm{l}=10 \mathrm{~mm}\right)$. HRMS m/z calculada para $\mathrm{C}_{22} \mathrm{H}_{26} \mathrm{O}_{5}: 370,1780$. Encontrado: $[\mathrm{M}+\mathrm{Na}]^{+} 393,1674$. 


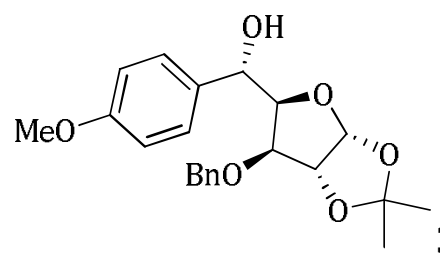

31d. Obtido como um óleo amarelo em $67 \%$ de rendimento. $\mathrm{RMN}^{1} \mathrm{H}\left(\mathrm{CDCl}_{3}, 300 \mathrm{MHz}, \mathrm{ppm}\right) \delta=1,3(\mathrm{~s}, 3 \mathrm{H}) ; 1,4(\mathrm{~s}, 3 \mathrm{H}) ; 3,6(\mathrm{~s}, \mathrm{OH})$; $3,7(\mathrm{~s}, 3 \mathrm{H}) ; 4,2(\mathrm{~m}, 2 \mathrm{H}) ; 4,53$ e 4,58 $\left(2 \mathrm{~d}, \mathrm{~J}_{g e m}=11,5,2 \mathrm{H}\right) ; 5,0(\mathrm{~d}, \mathrm{~J}=7,6 ; 1 \mathrm{H}) ; 6,0(\mathrm{~d}, \mathrm{~J}$ $=3,7 ; 1 \mathrm{H}) ; 6,8(\mathrm{~d}, \mathrm{~J}=8,7,2 \mathrm{H}) ; 7,3(\mathrm{~m}, 7 \mathrm{H}) . \mathrm{RMN}{ }^{13} \mathrm{C}\left(\mathrm{CDCl}_{3}, 75 \mathrm{MHz}\right): \delta=26,2 ; 26,7$; 55,$2 ; 71,8 ; 71,9 ; 82,1 ; 82,2 ; 84,6 ; 105,1 ; 111,8 ; 113,7 ; 127,6 ; 127,9 ; 128,3 ; 128,5$; 131,$9 ; 137 ; 159 .[\alpha] \frac{20}{D}=-25\left(\mathrm{c}=1, \mathrm{CHCl}_{3}, \mathrm{l}=10 \mathrm{~mm}\right)$. HRMS m/z calculada para $\mathrm{C}_{22} \mathrm{H}_{26} \mathrm{O}_{6}: 386,1729$. Encontrado: $[\mathrm{M}+\mathrm{Na}]^{+} 409,1625$.

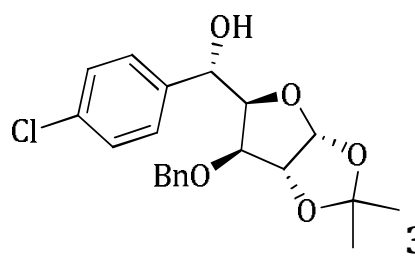

31e. Obtido como um óleo amarelo em $67 \%$ de rendimento. $\mathrm{RMN}^{1} \mathrm{H}\left(\mathrm{CDCl}_{3}, 300 \mathrm{MHz}, \mathrm{ppm}\right) \delta=1,3(\mathrm{~s}, 3 \mathrm{H}) ; 1,4(\mathrm{~s}, 3 \mathrm{H}) ; 2,9(\mathrm{~s}, \mathrm{OH})$; $3,6(\mathrm{~d}, J=3,2 ; 1 \mathrm{H}) ; 4,2(\mathrm{dd}, \mathrm{J}=7,1, \mathrm{~J}=3,3,1 \mathrm{H}) ; 4,3\left(\mathrm{~d}, \mathrm{~J}_{\text {gem }}=11,5,1 \mathrm{H}\right) ; 4,6(\mathrm{~m}, 2 \mathrm{H})$; $5,0(\mathrm{~d}, \mathrm{~J}=7,0 ; 1 \mathrm{H}) ; 6,0(\mathrm{~d}, \mathrm{~J}=3,7 ; 1 \mathrm{H}) ; 7,3(\mathrm{~m}, 9 \mathrm{H}) . \mathrm{RMN}{ }^{13} \mathrm{C}\left(\mathrm{CDCl}_{3}, 75 \mathrm{MHz}\right): \delta$ $=26,1 ; 26,7 ; 71,6 ; 71,7 ; 81,9 ; 82,1 ; 84,2 ; 105 ; 111,8 ; 127,6 ; 128 ; 128,3 ; 128,5$; 133,$6 ; 136,7 ; 138,2 .[\alpha] \frac{20}{D}=-26\left(\mathrm{c}=1, \mathrm{CHCl}_{3}, \mathrm{l}=10 \mathrm{~mm}\right)$. HRMS m/z calculada para $\mathrm{C}_{21} \mathrm{H}_{23} \mathrm{ClO}_{5}: 390,1234$. Encontrado: [M+Na]+ 413,1126. 


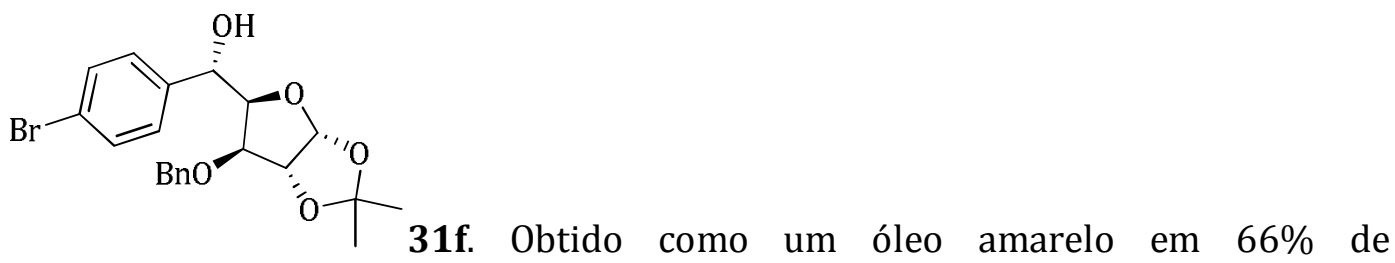

rendimento. $\mathrm{RMN}^{1} \mathrm{H}\left(\mathrm{CDCl}_{3}, 300 \mathrm{MHz}, \mathrm{ppm}\right) \delta=1,3(\mathrm{~s}, 3 \mathrm{H}) ; 1,4(\mathrm{~s}, 3 \mathrm{H}) ; 2,8(\mathrm{~m}, 1 \mathrm{H})$; $3,6(\mathrm{~d}, J=3,3 ; 1 \mathrm{H}) ; 4,2(\mathrm{dd}, \mathrm{J}=7,1 ; \mathrm{J}=3,3 ; 1 \mathrm{H}) ; 4,3\left(\mathrm{~d}, \mathrm{~J}_{\text {gem }}=11,5,1 \mathrm{H}\right) ; 4,6(\mathrm{~m}, 2 \mathrm{H}) ;$ $5,0(\mathrm{~d}, \mathrm{~J}=7,5 ; 1 \mathrm{H}) ; 6,0(\mathrm{~d}, \mathrm{~J}=3,7 ; 1 \mathrm{H}) ; 7,3(\mathrm{~m}, 9 \mathrm{H}) . \mathrm{RMN}{ }^{13} \mathrm{C}\left(\mathrm{CDCl}_{3}, 75 \mathrm{MHz}\right): \delta$ $=26,2 ; 26,8 ; 71,8 ; 76,5 ; 82 ; 82,2 ; 84,1 ; 105,1 ; 112 ; 121,9 ; 127,7 ; 128,1 ; 128,6$; 128,$7 ; 131,4 ; 136,7 ; 138,7 .[\alpha] \frac{20}{D}=-28\left(\mathrm{c}=1, \mathrm{CHCl}_{3}, \mathrm{l}=10 \mathrm{~mm}\right)$.<smiles>CC1(C)O[C@H]2OC([C@H](O)c3cc(F)c(F)c(F)c3)[C@H](O)[C@H]2O1</smiles>

31g. Obtido como um óleo amarelo em $66 \%$ de rendimento. $\mathrm{RMN}^{1} \mathrm{H}\left(\mathrm{CDCl}_{3}, 300 \mathrm{MHz}, \mathrm{ppm}\right) \delta=1,3(\mathrm{~s}, 3 \mathrm{H}) ; 1,4(\mathrm{~s}, 3 \mathrm{H}) ; 3,7(\mathrm{~d}, J=3,3 ; 1 \mathrm{H}) ; 4,1$ $(\mathrm{dd}, \mathrm{J}=6,3 ; \mathrm{J}=3,3 ; 1 \mathrm{H}) 4,3\left(\mathrm{~d}, \mathrm{~J}_{\text {gem }}=11,4,1 \mathrm{H}\right) ; 4,6(\mathrm{~m}, 2 \mathrm{H}) ; 4,9(\mathrm{~d}, \mathrm{~J}=6,3 ; 1 \mathrm{H}) ; 6,0$ $(\mathrm{d}, \mathrm{J}=3,7 ; 1 \mathrm{H}) ; 7,0(\mathrm{~m}, 2 \mathrm{H}) ; 7,3(\mathrm{~m}, 5 \mathrm{H}) . \mathrm{RMN}{ }^{13} \mathrm{C}\left(\mathrm{CDCl}_{3}, 75 \mathrm{MHz}\right): \delta=26,1 ; 26,7 ;$ $71 ; 71,9 ; 81,7 ; 82,2 ; 83,5 ; 105 .[\alpha] \frac{20}{D}=-32\left(\mathrm{c}=1, \mathrm{CHCl}_{3}, \mathrm{l}=10 \mathrm{~mm}\right)$.

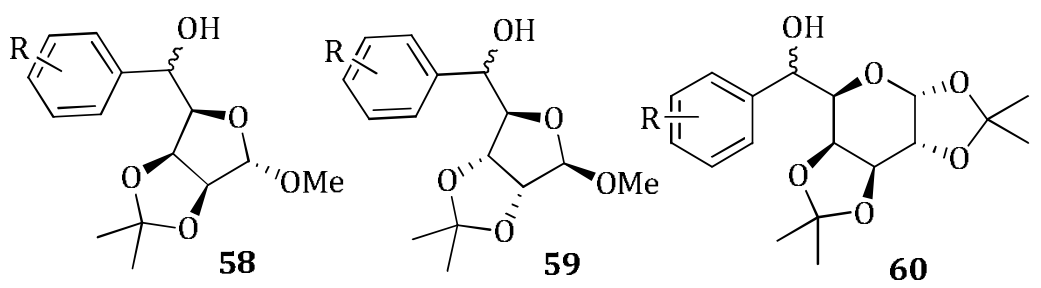

Obtenção dos

álcoois 58, 59 e 60. Em balão de duas bocas de $25 \mathrm{~mL}$, sob atmosfera inerte e 
anidra, adicionar dietilzinco solução $1 \mathrm{M}(7,2$ eq., 3,5mmol, 3,5mL) sob suspensão do ácido borônico correspondente (2,4 eq., 1,2mmol) em tolueno (2mL). Deixou-se sob agitação a $60^{\circ} \mathrm{C}$ durante 1 hora. Após este período adicionou-se o aldeído (0,5mmol) solubilizado em $1 \mathrm{~mL}$ de tolueno. 0 sistema ficou sob agitação por 3 horas a $60^{\circ} \mathrm{C}$. Extraiu-se a reação com acetato de etila $(50 \mathrm{~mL})$ e lavou-se com água (2x100mL). Os produtos foram purificados por coluna cromatográfica sílica como fase estacionária e como eluente uma mistura de acetato/hexano (30\%). Os produtos da série $\mathbf{5 8}$ foram obtidos em rendimentos de 74-79\%, já os da série $\mathbf{5 9}$ entre $72-80 \%$ e os álcoois 60 foram obtidos em rendimentos entre 48-74\%.
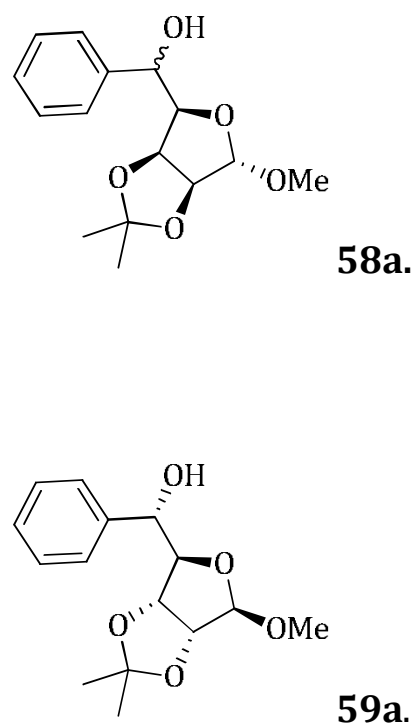

59a. Obtido como um óleo amarelo em 78\% de rendimento. RMN ${ }^{1} \mathrm{H}\left(\mathrm{CDCl}_{3}, 300 \mathrm{MHz}, \mathrm{ppm}\right) \delta=1,3(\mathrm{~s}, 3 \mathrm{H}) ; 1,4(\mathrm{~s}, 3 \mathrm{H}) ; 3,3(\mathrm{~s}, 3 \mathrm{H}) ; 3,8(\mathrm{~d}, J=$ $8,4 ; 1 \mathrm{H}) ; 4,6(\mathrm{~m}, 3 \mathrm{H}) ; 4,8(\mathrm{~d}, \mathrm{~J}=6,2 ; 1 \mathrm{H}) ; 4,9(\mathrm{~s}, 1 \mathrm{H}) ; 7,3(\mathrm{~m}, 5 \mathrm{H}) . \mathrm{RMN}{ }^{13} \mathrm{C}\left(\mathrm{CDCl}_{3}\right.$, $75 \mathrm{MHz}): \delta=24,9 ; 26,4 ; 56,9 ; 73,8 ; 82 ; 82,1 ; 85,6 ; 91 ; 110,3 ; 112,3 ; 126,0 ; 127,5$; 128,$4 ; 140,6 \cdot[\alpha] \frac{20}{D}=-6\left(\mathrm{c}=1, \mathrm{CHCl}_{3}, \mathrm{l}=10 \mathrm{~mm}\right)$. HRMS $\mathrm{m} / \mathrm{z}$ calculada para $\mathrm{C}_{15} \mathrm{H}_{20} \mathrm{O}_{5}: 280,1311$. Encontrado: [M+Na]+ 303, 1230. 


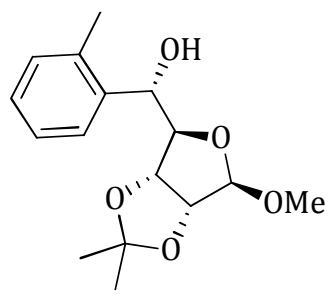

59b.Obtido como um óleo amarelo em 76\% de rendimento. $\mathrm{RMN}^{1} \mathrm{H}\left(\mathrm{CDCl}_{3}, 300 \mathrm{MHz}, \mathrm{ppm}\right) \delta=1,3(\mathrm{~s}, 3 \mathrm{H}) ; 1,4(\mathrm{~s}, 3 \mathrm{H}) ; 2,3(\mathrm{~s}, 3 \mathrm{H}) ; 3,5(\mathrm{~s}, 3 \mathrm{H})$; $3,7(\mathrm{~d}, J=8,1 ; O H) ; 4,5(\mathrm{~d}, \mathrm{~J}=4,5 ; 1 \mathrm{H}) ; 4,6(\mathrm{~d}, \mathrm{~J}=2,9 ; 1 \mathrm{H}) ; 4,7(\mathrm{~d}, \mathrm{~J}=5,9 ; 1 \mathrm{H}) ; 4,9$ $(\mathrm{m}, 1 \mathrm{H}) ; 5,0(\mathrm{~s}, 1 \mathrm{H}) ; 7,2(\mathrm{~m}, 4 \mathrm{H}) . \mathrm{RMN}{ }^{13} \mathrm{C}\left(\mathrm{CDCl}_{3}, 75 \mathrm{MHz}\right): \delta=19,4 ; 24,9 ; 26,4$; 56,$3 ; 71 ; 82,3 ; 85,6 ; 90,7 ; 110,7 ; 112,3 ; 126,0 ; 126,2 ; 127,6 ; 130,6 ; 134,8$; 138,3. $[\alpha] \frac{20}{D}=-9\left(\mathrm{c}=1, \mathrm{CHCl}_{3}, \mathrm{l}=10 \mathrm{~mm}\right)$. HRMS m/z calculada para $\mathrm{C}_{16} \mathrm{H}_{22} \mathrm{O}_{5}$ : 294,1467. Encontrado: $[\mathrm{M}+\mathrm{Na}]+317,1398$.<smiles>COc1ccc([C@@H](O)C2OC(OC)[C@H]3OC(C)(C)O[C@H]23)cc1</smiles>

59c. Obtido como um sólido amarelo amorfo. RMN ${ }^{1} \mathrm{H}$ $\left(\mathrm{CDCl}_{3}, 300 \mathrm{MHz}, \mathrm{ppm}\right) \delta=1,3(\mathrm{~s}, 3 \mathrm{H}) ; 1,4(\mathrm{~s}, 3 \mathrm{H}) ; 3,3(\mathrm{~s}, 3 \mathrm{H}) ; 3,6(\mathrm{~d}, J=7,5 ; \mathrm{OH})$; $3,8(\mathrm{~s}, 3 \mathrm{H}) ; 4,6(\mathrm{~m}, 3 \mathrm{H}) ; 4,8(\mathrm{~d}, J=5,9 ; 1 \mathrm{H}) ; 4,9(\mathrm{~s}, 1 \mathrm{H}) ; 6,9(\mathrm{~m}, 2 \mathrm{H}) ; 7,2(\mathrm{~m}, 2 \mathrm{H})$. $\mathrm{RMN}^{13} \mathrm{C}\left(\mathrm{CDCl}_{3}, 75 \mathrm{MHz}\right): \delta=24,8 ; 26,4 ; 55,2 ; 55,9 ; 73,6 ; 81,9 ; 85,5 ; 91,6 ; 110,3$; 112,$3 ; 113,9 ; 127,5 ; 132,6 ; 159 .[\alpha] \frac{20}{D}=-5\left(\mathrm{c}=1, \mathrm{CHCl}_{3}, \mathrm{l}=10 \mathrm{~mm}\right) . \mathrm{HRMS} \mathrm{m} / \mathrm{z}$ calculada para $\mathrm{C}_{16} \mathrm{H}_{22} \mathrm{O}_{6}: 310,1416$. Encontrado: [M+Na]+ 333,1334.

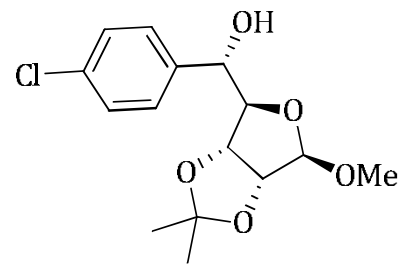

59d. Obtido como um óleo amarelo em $74 \%$ de rendimento. $\mathrm{RMN}{ }^{1} \mathrm{H}\left(\mathrm{CDCl}_{3}, 300 \mathrm{MHz}, \mathrm{ppm}\right) \delta=1,3(\mathrm{~s}, 3 \mathrm{H}) ; 1,4(\mathrm{~s}, 3 \mathrm{H}) ; 3,3(\mathrm{~s}, 3 \mathrm{H})$; 
$3,9(\mathrm{~d}, J=8,7 ; \mathrm{OH}) ; 4,6(\mathrm{~m}, 3 \mathrm{H}) ; 4,8(\mathrm{~d}, J=5,8 ; 1 \mathrm{H}) ; 4,9(\mathrm{~s}, 1 \mathrm{H}) ; 7,3(\mathrm{~m}, 4 \mathrm{H}) . \mathrm{RMN}^{13} \mathrm{C}$ $\left(\mathrm{CDCl}_{3}, 75 \mathrm{MHz}\right): \delta=24,8 ; 26,3 ; 55,9 ; 73,2 ; 81,8 ; 85,5 ; 91,3 ; 110,3 ; 112,4 ; 127,5$; 128,$5 ; 133,3 ; 139,2 .[\alpha] \frac{20}{D}=-9\left(\mathrm{c}=1, \mathrm{CHCl}_{3}, \mathrm{l}=10 \mathrm{~mm}\right)$. HRMS m/z calculada para $\mathrm{C}_{15} \mathrm{H}_{19} \mathrm{O}_{5} \mathrm{Cl}: 314,0921$. Encontrado: $[\mathrm{M}+\mathrm{Na}]^{+} 337,0838$.

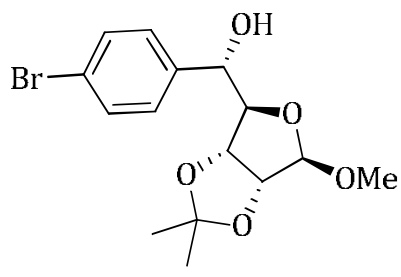

59e. Obtido como um sólido branco amorfo em $72 \%$ de rendimento. $\mathrm{RMN}^{1} \mathrm{H}\left(\mathrm{CDCl}_{3}, 300 \mathrm{MHz}, \mathrm{ppm}\right) \delta=1,3(\mathrm{~s}, 3 \mathrm{H}) ; 1,4(\mathrm{~s}, 3 \mathrm{H}) ; 3,3(\mathrm{~s}, 3 \mathrm{H})$; $3,9(\mathrm{~d}, J=8,6 ; 0 \mathrm{H}) ; 4,6(\mathrm{~m}, 3 \mathrm{H}) ; 4,8(\mathrm{~d}, J=5,9 ; 1 \mathrm{H}) ; 4,9(\mathrm{~s}, 1 \mathrm{H}) ; 7,2(\mathrm{~m}, 2 \mathrm{H}) ; 7,4(\mathrm{~m}$, 2H). $\mathrm{RMN}{ }^{13} \mathrm{C}\left(\mathrm{CDCl}_{3}, 75 \mathrm{MHz}\right): \delta=24,8 ; 26,3 ; 56,0 ; 73,2 ; 81,8 ; 86,5 ; 91,3 ; 110,3$; 112,$4 ; 121,4 ; 127,8 ; 131,5 ; 139,8 .[\alpha] \frac{20}{D}=-6\left(\mathrm{c}=1, \mathrm{CHCl}_{3}, \mathrm{l}=10 \mathrm{~mm}\right) . \mathrm{HRMS} \mathrm{m} / \mathrm{z}$ calculada para $\mathrm{C}_{15} \mathrm{H}_{19} \mathrm{BrO}_{5}:$ 358,0416. Encontrado: $[\mathrm{M}+\mathrm{Na}]^{+} 381,0329$ e . $[\mathrm{M}+2+\mathrm{Na}]^{+} 383,0305$

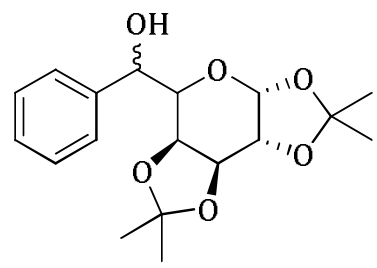

60a. Obtido como um óleo amarelo em $74 \%$ de rendimento.1,26 (s, 3H); 1,30(s, 1H);1,32 (s, 3H); 1,36 (s, 1H); 1,48 (s, 1H); 1,51 (s, $3 \mathrm{H}) ; 1,52(\mathrm{~s}, 3 \mathrm{H}) ; 1,54(\mathrm{~s}, 1 \mathrm{H}) ; 3,0(\mathrm{~s}, 1 \mathrm{H}) ; 3,3(\mathrm{~d}, \mathrm{~J}=6,2 ; 0,3 \mathrm{H}) ; 3,7(\mathrm{~m}, 1 \mathrm{H}) ; 3,8(\mathrm{~m}$, 1H); 3,9 (m; 0,3H); 4,2 (m; 1,3H); 4,3 (m;0,3H); 4,4 (m, 1H); 4,5 (m;0,3H); 4,9 (m; 
1,3H); 5,5 (d; J = 5; 0,3H); 5,6 (d; J = 4,8; $1 \mathrm{H}) . \mathrm{HRMS} \mathrm{m} / \mathrm{z}$ calculada para $\mathrm{C}_{15} \mathrm{H}_{19} \mathrm{BrO}_{5}$ :

336.1573. Encontrado: $[\mathrm{M}+\mathrm{Na}]+359,1483$.

\subsubsection{Procedimento geral para a síntese da (+)-7-epi-goniofufurona}

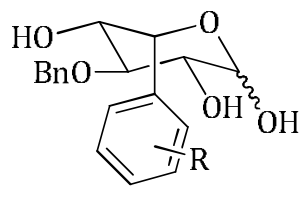

Obtenção do compostos 33. Os acetonídeos da série 31 foram

hidrolizados com solução 70\% de ácido acético aos respectivos compostos da série 33. 0 composto 31 a, representativo da série, foi solubilizado em solução $70 \%$ de ácido acético e submetido à temperatura de refluxo por 5 horas. Após este período a reação foi resfriada a temperatura ambiente e os solventes evaporados e coevaporados 2 vezes com água e outras 2 vezes com tolueno. Os compostos da série 33 foram purificados por coluna cromatográfica, utilizando-se sílica como fase estacionária e uma mistura de DCM-EtOAc (7:3) como eluente. Os produtos foram obtidos como óleos amarelos em rendimentos de 38-48\%.

Obtençãodas Lactonas 36. Solubilizou-se o composto 33a em DMF e adicionou-se 1 equivalente de $\mathrm{Et}_{3} \mathrm{~N}$. Submeteu-se o sistema reacional a $46^{\circ} \mathrm{C}$ durante 72 horas. Após este período, resfriou-se a reação a temperatura ambiente e evaporou-se o solvente sob pressão reduzida. Os compostos desta série foram purificados por coluna cromatográfica utilizando-se éter etílico como eluente. 


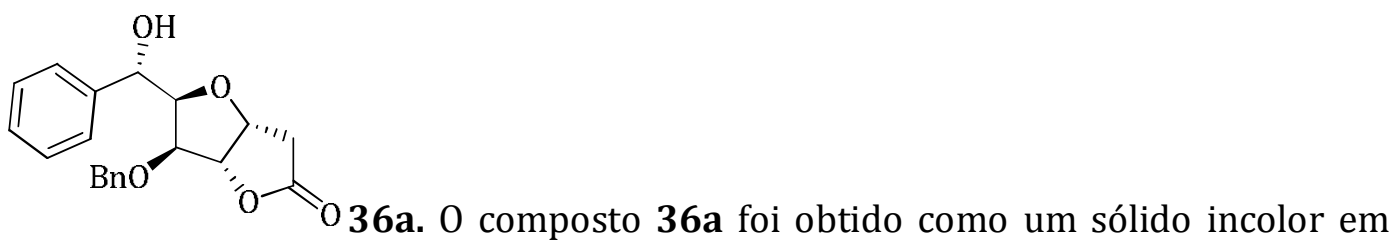

$51 \%$ de rendimento. $\mathrm{RMN}^{1} \mathrm{H}\left(\mathrm{CDCl}_{3}, 300 \mathrm{MHz}, \mathrm{ppm}\right) \delta=2,7(\mathrm{~m}, 3 \mathrm{H}) ; 3,9(\mathrm{~d}, J=3,9$; $1 \mathrm{H}) ; 4,2(\mathrm{dd}, J=6,6 ; J=3,9 ; 1 \mathrm{H}) ; 4,4$ e $4,5\left(2 \mathrm{~d}, \mathrm{~J}_{g e m}=11,7,2 \mathrm{H}\right) ; 4,9(\mathrm{~d}, \mathrm{~J}=4,2 ; 1 \mathrm{H}) ;$ $5,03(\mathrm{~d}, \mathrm{~J}=6,9 ; 1 \mathrm{H}) ; 5,09(\mathrm{~m}, 1 \mathrm{H}) ; 7,3(\mathrm{~m}, 10 \mathrm{H}) . \mathrm{RMN}^{13} \mathrm{C}\left(\mathrm{CDCl}_{3}, 75 \mathrm{MHz}\right): \delta=36$; 72,$8 ; 81,8 ; 84,6 ; 85,1 ; 126,8 ; 127,8 ; 128,2 ; 128,3 ; 128,4 ; 128,6 ; 136,5 ; 139,5 ; 175,2$.

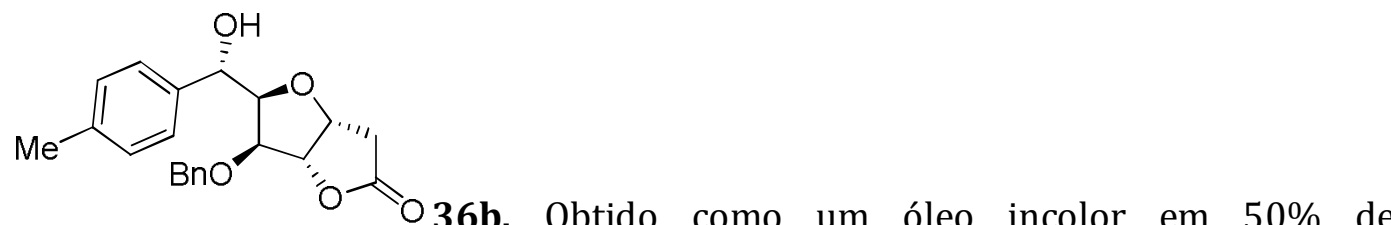
rendimento. $\mathrm{RMN}{ }^{1} \mathrm{H}\left(\mathrm{CDCl}_{3}, 300 \mathrm{MHz}, \mathrm{ppm}\right) \delta=2,3(\mathrm{~s}, 3 \mathrm{H}) ; 2,6(\mathrm{sl}, \mathrm{OH}) ; 2,7(\mathrm{~m}$, $2 \mathrm{H}) ; 3,9(\mathrm{~d}, J=3,9 ; 1 \mathrm{H}) ; 4,2(\mathrm{dd} J=6,9 ; J=4,2 ; 1 \mathrm{H}) ; 4,4$ e $4,5\left(2 \mathrm{~d}, \mathrm{~J}_{g e m}=11,7,2 \mathrm{H}\right)$; $4,8(\mathrm{~d}, \mathrm{~J}=4,5 ; 1 \mathrm{H}) ; 5,0(\mathrm{~d}, \mathrm{~J}=6,9 ; 1 \mathrm{H}) ; 5,09(\mathrm{~m}, 1 \mathrm{H}) ; 7,2(\mathrm{~m}, 9 \mathrm{H}) . \mathrm{RMN}{ }^{13} \mathrm{C}\left(\mathrm{CDCl}_{3}\right.$, $75 \mathrm{MHz}): \delta=21,1 ; 36 ; 72,6 ; 81,8 ; 84,7 ; 85,1 ; 126,7 ; 127,7 ; 128,2 ; 128,6 ; 129,1$; 136,$6 ; 137,9 ; 175,2$.

36c. Obtido como um óleo amarelo e em 51\% de rendimento. RMN ${ }^{1} \mathrm{H}\left(\mathrm{CDCl}_{3}, 300 \mathrm{MHz}, \mathrm{ppm}\right) \delta=2,2(\mathrm{~m}, 4 \mathrm{H}) ; 2,7(\mathrm{~m}, 2 \mathrm{H}) ; 4,0(\mathrm{~m}, 1 \mathrm{H}) ; 4,3$ e 4,5 $\left(2 \mathrm{~d}, \mathrm{~J}_{g e m}=11,7,2 \mathrm{H}\right) ; 4,4(\mathrm{dd}, J=6 \mathrm{~Hz} J=4,5 \mathrm{~Hz} ; 1 \mathrm{H}) ; 4,9(\mathrm{~d}, J=4,6 \mathrm{~Hz} ; 1 \mathrm{H}) ; 5,1(\mathrm{~m}$, $1 \mathrm{H}) ; 5,2(\mathrm{~d}, J=5,7 ; 1 \mathrm{H}) ; 7,1-7,3(\mathrm{~m}, 9 \mathrm{H}) . \mathrm{RMN}{ }^{13} \mathrm{C}\left(\mathrm{CDCl}_{3}, 75 \mathrm{MHz}\right): \delta=19,2 ; 36$; 
69,$3 ; 72,8 ; 82,2 ; 83,4 ; 85,5 ; 126,2 ; 126,7 ; 127,9 ; 128 ; 128,3 ; 128,6 ; 130,5 ; 136,4$; 136,$6 ; 137,6 ; 175$.<smiles>C=C1C[C@H]2O[C@@H]([C@H](O)c3ccc(OC)cc3)[C@H](Br)[C@H]2O1</smiles>

36d. Obtido como um óleo amarelo e em 52\% de rendimento. $\mathrm{RMN}^{1} \mathrm{H}\left(\mathrm{CDCl}_{3}, 300 \mathrm{MHz}, \mathrm{ppm}\right) \delta=1,8(\mathrm{~d}, \mathrm{~J}=4,1 \mathrm{~Hz}, 1 \mathrm{H}) ; 2,2(\mathrm{~d}, \mathrm{~J}=$ $4 \mathrm{~Hz}, 1 \mathrm{H}) ; 3,8(\mathrm{~m}, 4 \mathrm{H}) 4,1(\mathrm{~m}, 1 \mathrm{H}) ; 4,8(\mathrm{~m}, 4 \mathrm{H}) ; 5,3(\mathrm{~d}, J=3 \mathrm{~Hz} ; 1 \mathrm{H}) ; 6,9(\mathrm{~m}, 2 \mathrm{H}) ; 7,3$ (m, 7H). RMN ${ }^{13} \mathrm{C}\left(\mathrm{CDCl}_{3}, 75 \mathrm{MHz}\right): \delta=30,2 ; 55,2 ; 72,5 ; 73,5 ; 81,7 ; 83,3 ; 92,8 ; 114$; 127,$9 ; 128,5 ; 128,6 ; 128,8 ; 138,4 ; 159,7 ; 175$.<smiles>O=C1C[C@H]2O[C@@H]([C@H](O)c3ccc(Cl)cc3)[C@H](Br)[C@H]2O1</smiles>

36e. Obtido como um óleo incolor e em 53\% de rendimento. $\mathrm{RMN}^{1} \mathrm{H}\left(\mathrm{CDCl}_{3}, 300 \mathrm{MHz}, \mathrm{ppm}\right) \delta=2,7(\mathrm{~m}, 2 \mathrm{H}) ; 3,9(\mathrm{~d}, J=4,2 ; 1 \mathrm{H}) ; 4,1$ $(\mathrm{dd}, J=6,3 ; J=4,2 ; 1 \mathrm{H}) ; 4,4$ e 4,6 $\left(2 \mathrm{~d}, \mathrm{~J}_{g e m}=11,7,2 \mathrm{H}\right) ; 4,9(\mathrm{~d}, J=3,9 ; 1 \mathrm{H}) ; 4,99(\mathrm{~d}, \mathrm{~J}=$ $6,3 ; 1 \mathrm{H}) ; 5,09(\mathrm{~m}, 1 \mathrm{H}) ; 7,3(\mathrm{~m}, 9 \mathrm{H}) . \mathrm{RMN}{ }^{13} \mathrm{C}\left(\mathrm{CDCl}_{3}, 75 \mathrm{MHz}\right): \delta=36 ; 65,8 ; 72,2 ;$ 81,$9 ; 84,4 ; 85 ; 127.8 ; 128,2 ; 128,4 ; 128,6 ; 128,7 ; 133.9 ; 136,3 ; 138 ; 175$.<smiles>C=C1C[C@H]2OC([C@H](O)c3ccc(Br)cc3)[C@H](OBr)[C@H]2O1</smiles>

36f. $\mathrm{RMN}{ }^{1} \mathrm{H}\left(\mathrm{CDCl}_{3}, 300 \mathrm{MHz}, \mathrm{ppm}\right) \delta=2,7(\mathrm{~m}, 2 \mathrm{H}) ; 3,9$ $(\mathrm{d}, J=4,2 ; 1 \mathrm{H}) ; 4,1(\mathrm{dd}, J=6 ; J=4,2 ; 1 \mathrm{H}) ; 4,4$ e 4,6 $\left(2 \mathrm{~d}, \mathrm{~J}_{\text {gem }}=11,7,2 \mathrm{H}\right) ; 4,93(\mathrm{~d}, J=$ $4,5 ; 1 \mathrm{H}) ; 4,98(\mathrm{~d}, \mathrm{~J}=6 ; 1 \mathrm{H}) ; 5,0(\mathrm{~m}, 1 \mathrm{H}) ; 7,3(\mathrm{~m}, 9 \mathrm{H}) . \mathrm{RMN}{ }^{13} \mathrm{C}_{\left(\mathrm{CDCl}_{3}, 75 \mathrm{MHz}\right): \delta=}$ 
$36 ; 72,2 ; 72,8 ; 76,6 ; 81,9 ; 84,4 ; 85 ; 122,1 ; 127,8 ; 128,5 ; 128,7 ; 131,5 ; 136,3 ; 138,5$; 175.<smiles>O=C1C[C@H]2O[C@@H]([C@H](O)c3cc(F)c(F)c(F)c3)[C@H](Br)[C@H]2O1</smiles>

36g. Obtido como um óleo amarelo e em 56\% de rendimento. $\mathrm{RMN}^{1} \mathrm{H}\left(\mathrm{CDCl}_{3}, 300 \mathrm{MHz}, \mathrm{ppm}\right) \delta=2,7(\mathrm{~m}, 3 \mathrm{H}) ; 4,1(\mathrm{~m}, 2 \mathrm{H}) ; 4,5$ e 4,6 $\left(2 \mathrm{~d}, \mathrm{~J}_{g e m}=11,3,2 \mathrm{H}\right) ; 4,92(\mathrm{~d}, J=4,6 ; 1 \mathrm{H}) ; 4,97(\mathrm{~d}, \mathrm{~J}=4,6 ; 1 \mathrm{H}) ; 5,0(\mathrm{~m}, 1 \mathrm{H}) ; 6,9(\mathrm{~m}$, 2H); 7,3 (m, 5H). RMN ${ }^{13} \mathrm{C}\left(\mathrm{CDCl}_{3}, 75 \mathrm{MHz}\right): \delta=35,9 ; 71,4 ; 72,9 ; 82 ; 83,8 ; 85 ; 110,7$; $111 ; 127,8 ; 128 ; 128,6 ; 128,7 ; 128,8 ; 135,9 ; 149,3 ; 152,7 ; 175$.

Obtençãoda (+)-epi-goniofufurona 17 e análogos. Os compostos 36 foram solubilizados em metanol e hidrogenados sob $\mathrm{Pd}-\mathrm{C} 10 \%(0,06$ equiv) por um período de 72-120horas. As reações foram acompanhadas por CCD. Após término das reações os produtos foram purificados por coluna cromatográfica utilizando-se mistura de DCM-MeOH (98:2-95:5) como sistema eluente.<smiles>C=C1C[C@H]2OC([C@H](O)c3ccccc3)[C@H](O)[C@H]2O1</smiles>

O 17a. Obtido como sólido incolor em 53\% de rendimento, $[\alpha] \frac{20}{D}=+102,8\left(\mathrm{c}=0,003 \mathrm{~g} \mathrm{~mL}^{-}\right.$, etanol, $l=50 \mathrm{~mm}^{2} . \mathrm{RMN}^{1} \mathrm{H}\left(\mathrm{CD}_{3} \mathrm{OD}, 300 \mathrm{MHz}, \mathrm{ppm}\right) \delta$ $=2,1(\mathrm{~s}, \mathrm{OH}) ; 2,6(\mathrm{~d}, J=18,6 ; 1 \mathrm{H}) ; 2,8(\mathrm{dd} J=18,6 ; J=6,3 ; 1 \mathrm{H}) ; 3,7(\mathrm{~d}, J=2,6 ; 1 \mathrm{H})$; $3,9(\mathrm{dd}, J=7,9 ; J=2,9 ; 1 \mathrm{H}) ; 4,8(\mathrm{~d}, \mathrm{~J}=4,2 ; 1 \mathrm{H}) ; 4,9(\mathrm{~d}, \mathrm{~J}=8,4 ; 1 \mathrm{H}) ; 5,0(\mathrm{~m} ; 1 \mathrm{H}) ; 7,3$ (m, 3H); 7,4 (m, 2H). RMN ${ }^{13} \mathrm{C}\left(\mathrm{CD}_{3} \mathrm{OD}, 75 \mathrm{MHz}\right): \delta=36 ; 8$ 73,8; 74,6; 78,6; 86,3; 
89,$7 ; 128,2 ; 129 ; 129,3 ; 142,4 ; 178,2 . \mathrm{HRMS} \mathrm{m} / \mathrm{z}$ calculada para $\mathrm{C}_{13} \mathrm{H}_{14} \mathrm{O}_{5}$ : 250,0841. Encontrado: $[\mathrm{M}+\mathrm{Na}+\mathrm{MeOH}]+305,0993$.<smiles>C=C1C[C@H]2OC([C@H](O)c3ccccc3C)[C@H](O)[C@H]2O1</smiles>

17b. Obtido como sólido incolor em 57\% de rendimento, $[\alpha] \frac{20}{D}=+43,4(\mathrm{c}=0,003 \mathrm{~g} \mathrm{~mL}$, etanol, $l=50 \mathrm{~mm}) \cdot \mathrm{RMN}^{1} \mathrm{H}\left(\mathrm{CD}_{3} \mathrm{OD}, 300 \mathrm{MHz}, \mathrm{ppm}\right) \delta=$ $2,1(\mathrm{~s}, \mathrm{OH}) ; 2,4(\mathrm{~s}, 3 \mathrm{H}) ; 2,6(\mathrm{~d}, \mathrm{~J}=18,6 \mathrm{~Hz}, 1 \mathrm{H}) ; 2,8(\mathrm{dd}, \mathrm{J}=18,6 \mathrm{~Hz}, 1 \mathrm{H}) ; 3,8(\mathrm{~d}, \mathrm{~J}=$ $2,8 \mathrm{~Hz}, 1 \mathrm{H}) ; 4,2(\mathrm{dd}, \mathrm{J}=7,6 \mathrm{~Hz}, \mathrm{~J}=3,1 \mathrm{~Hz}, 1 \mathrm{H}) ; 4,8(\mathrm{~d}, J=3,6 ; 1 \mathrm{H}) ; 5(\mathrm{~m}, 1 \mathrm{H}) ; 5,1(\mathrm{~J}=$ 7,6Hz, 1H); 7,1-7,4 (m, 4H). RMN ${ }^{13} \mathrm{C}\left(\mathrm{CD}_{3} \mathrm{OD}, 75 \mathrm{MHz}\right): \delta=19,5 ; 36,9 ; 70,1 ; 75,1$; 78,$5 ; 85,9 ; 89,9 ; 128,1 ; 128,9 ; 129 ; 129,2 ; 131,5 ; 137,4 ; 178,2$. HRMS m/z calculada para $\mathrm{C}_{13} \mathrm{H}_{14} \mathrm{O}_{5}: 264,0998$. Encontrado: [M+Na+MeOH]+ 319,1151.

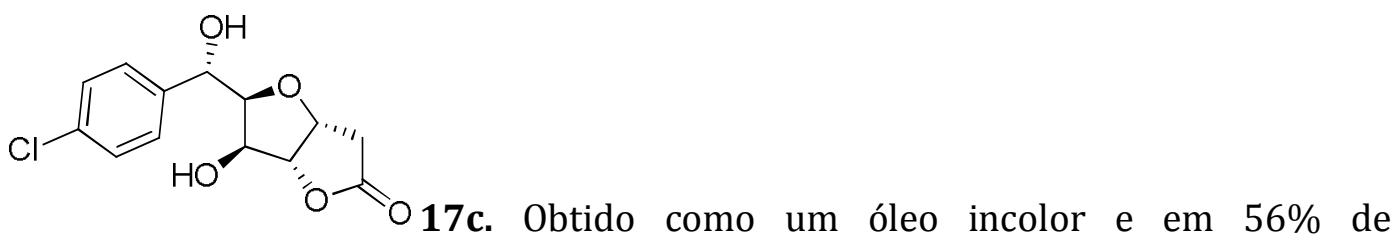

rendimento, $[\alpha] \frac{20}{D}=+25(\mathrm{c}=0,003 \mathrm{~g} \mathrm{~mL}$, etanol, $l=50 \mathrm{~mm}) \cdot \mathrm{RMN}^{1} \mathrm{H}\left(\mathrm{CDCl}_{3}, 300 \mathrm{MHz}\right.$, ppm) $\delta=2,7(\mathrm{~m}, 2 \mathrm{H}) ; 3,47(\mathrm{~s}, \mathrm{OH}) ; 3,48(\mathrm{~s}, \mathrm{OH}) ; 4,1(\mathrm{~m}, 1 \mathrm{H}) ; 4,4(\mathrm{~m}, 1 \mathrm{H}) ; 4,8(\mathrm{~d}, J=$ $3,2 ; 1 \mathrm{H}) ; 5,0(\mathrm{~d}, \mathrm{~J}=3 \mathrm{~Hz} ; 1 \mathrm{H}) ; 5,1(\mathrm{~m}, 1 \mathrm{H}) ; 7,3(\mathrm{~m}, 4 \mathrm{H}) . \mathrm{RMN}{ }^{13} \mathrm{C}\left(\mathrm{CD}_{3} \mathrm{OD}, 75 \mathrm{MHz}\right): \delta$ $=36 ; 8 ; 73,9 ; 74,7 ; 77,8 ; 83,4 ; 89,8 ; 127,3 ; 129,4 ; 130,3 ; 139,8 ; 173,9$. HRMS m/z calculada para $\mathrm{C}_{13} \mathrm{H}_{13} \mathrm{ClO}_{5}: 284,0452$. Encontrado: [M+Na+MeOH]+339,0605. 
<smiles>O=C1C[C@H]2OC([C@H](O)c3ccc(Br)cc3)[C@H](O)[C@H]2O1</smiles>

17d. Obtido como um sólido branco e em 68\% de

rendimento, $[\alpha] \frac{20}{D}=+87,7(\mathrm{c}=0,003 \mathrm{~g} \mathrm{~mL}$; etanol, $l=50 \mathrm{~mm}) \cdot \mathrm{RMN}^{1} \mathrm{H}\left(\mathrm{CD}_{3} \mathrm{OD}, 300\right.$ $\mathrm{MHz}, \mathrm{ppm}) \delta=2,1(\mathrm{~s}, \mathrm{OH}) ; 2,6(\mathrm{~d}, J=18 \mathrm{~Hz}, 1 \mathrm{H}) ; 2,8(\mathrm{dd}, J=18,6 \mathrm{~Hz}, J=6,3 \mathrm{~Hz}, 1 \mathrm{H}) ;$ $3,7(\mathrm{~s}, 1 \mathrm{H}) ; 3,9(\mathrm{dd}, J=9,3 \mathrm{~Hz}, J=2,9 \mathrm{~Hz}, 1 \mathrm{H}) ; 4,8(\mathrm{~d}, J=3,7 \mathrm{~Hz}, 1 \mathrm{H}) ; 4,9(\mathrm{~d}, J=7,9 \mathrm{~Hz}$, $1 \mathrm{H}) ; 5,0(\mathrm{~m}, 1 \mathrm{H}) ; 7,3(\mathrm{~m}, 4 \mathrm{H}) . \mathrm{RMN}{ }^{13} \mathrm{C}\left(\mathrm{CD}_{3} \mathrm{OD}, 75 \mathrm{MHz}\right): \delta=36 ; 8 ; 73,9 ; 74,6 ; 78,6$; 86,$3 ; 89,7 ; 128,2 ; 129 ; 129,3 ; 142,4 ; 178,2$.HRMS m/z calculada para $\mathrm{C}_{13} \mathrm{H}_{13} \mathrm{BrO}_{5}$ : 327,9946. Encontrado: $[\mathrm{M}+\mathrm{Na}+\mathrm{MeOH}]+383,0101$.

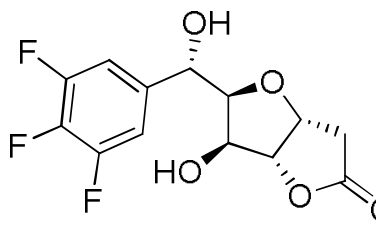

17e. Obtido como um sólido branco e em $72 \%$ de rendimento, $[\alpha] \frac{20}{D}=+57,2(\mathrm{c}=0,003 \mathrm{~g} \mathrm{~mL}$, etanol, $l=50 \mathrm{~mm}) \cdot \mathrm{RMN}^{1} \mathrm{H}\left(\mathrm{CDCl}_{3}, 300\right.$ MHz, ppm) $\delta=2,7(\mathrm{~m}, 2 \mathrm{H}) ; 3,4(\mathrm{~d}, J=5 \mathrm{~Hz}, 1 \mathrm{H}) ; 3,7(\mathrm{~s}, \mathrm{OH}) ; 4,1(\mathrm{~m}, 1 \mathrm{H}) ; 4,4(\mathrm{~d}, J=$ $3,2 \mathrm{~Hz}, 1 \mathrm{H}) ; 4,9(\mathrm{~d}, J=3,8 \mathrm{~Hz}, 1 \mathrm{H}) ; 5,0(\mathrm{~d}, J=4,2 \mathrm{~Hz}, 1 \mathrm{H}) ; 7,3(\mathrm{~m}, 4 \mathrm{H}) . \mathrm{RMN}{ }^{13} \mathrm{C}$ $\left(\mathrm{CD}_{3} \mathrm{OD}, 75 \mathrm{MHz}\right): \delta=36 ; 8 ; 72,5 ; 74,8 ; 78,8 ; 86 ; 89,8 ; 112,2 ; 112,5 ; 139,81 ; 139,89$; 150,$6 ; 153,8 ; 178 . \mathrm{HRMS} \mathrm{m} / \mathrm{z}$ calculada para $\mathrm{C}_{13} \mathrm{H}_{11} \mathrm{~F}_{3} \mathrm{O}_{5}: 304,0559$. Encontrado: $[\mathrm{M}+\mathrm{Na}+\mathrm{MeOH}]+359,0720 .:::>>>::::>>>:::$ 
ESPECTROS SELECIONADOS 


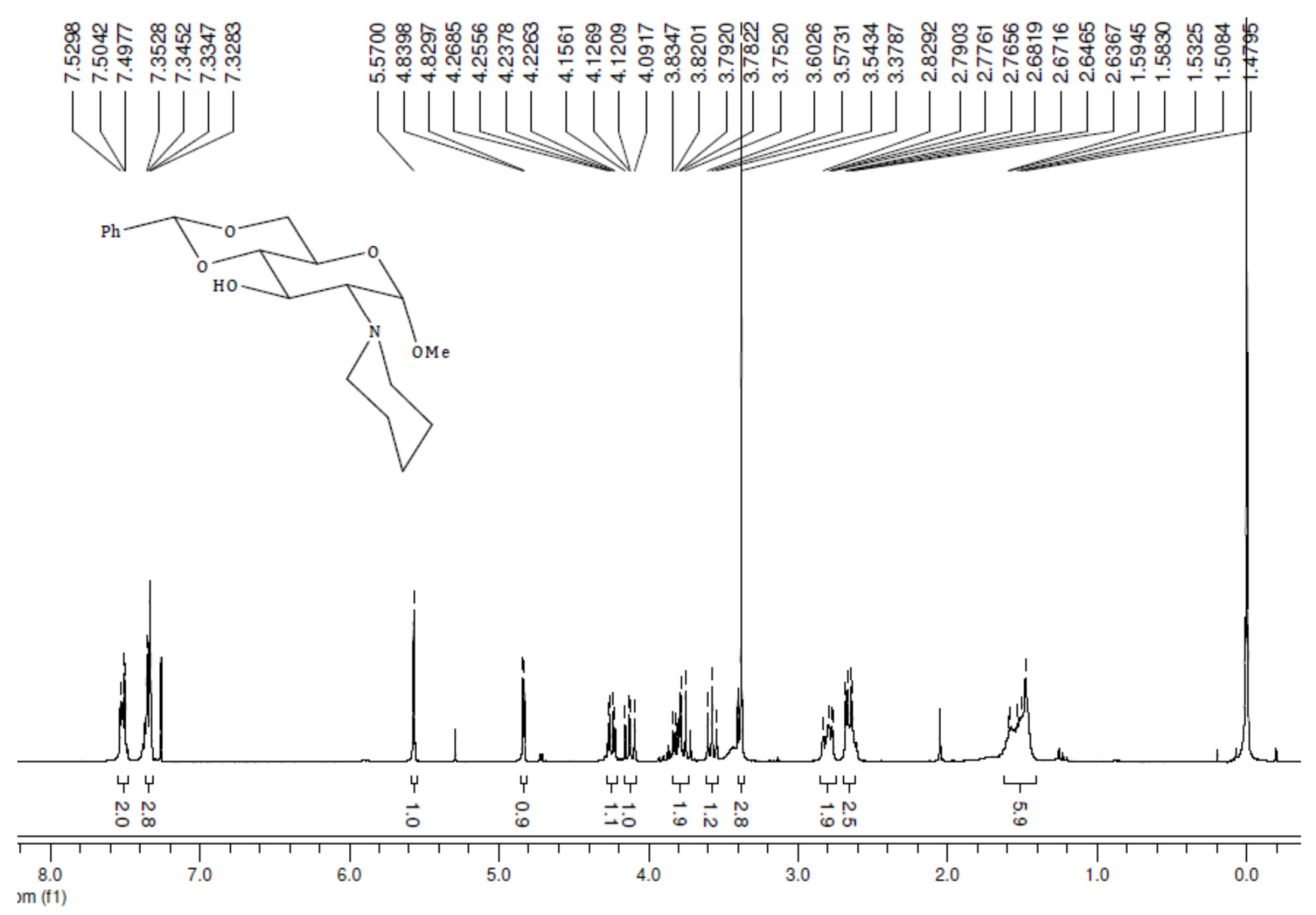

Figura 27. Espectro de RMN ${ }^{1} \mathrm{H}$ a $300 \mathrm{MHz}$ do composto $\mathbf{5 b}$.

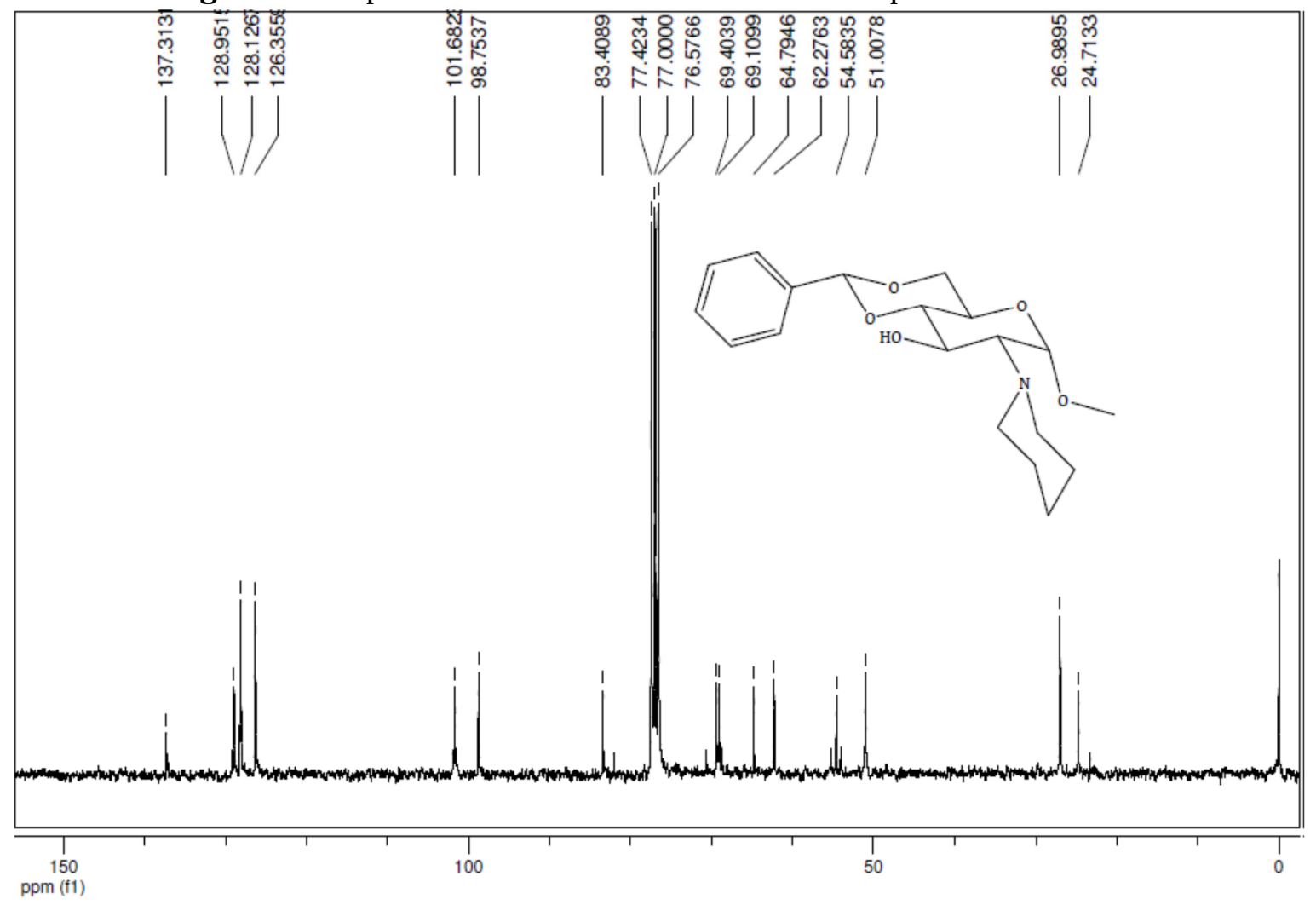

Figura 28. Espectro de $\mathrm{RMN}^{13} \mathrm{C}$ a $75 \mathrm{MHz}$ do composto $5 \mathbf{b}$. 


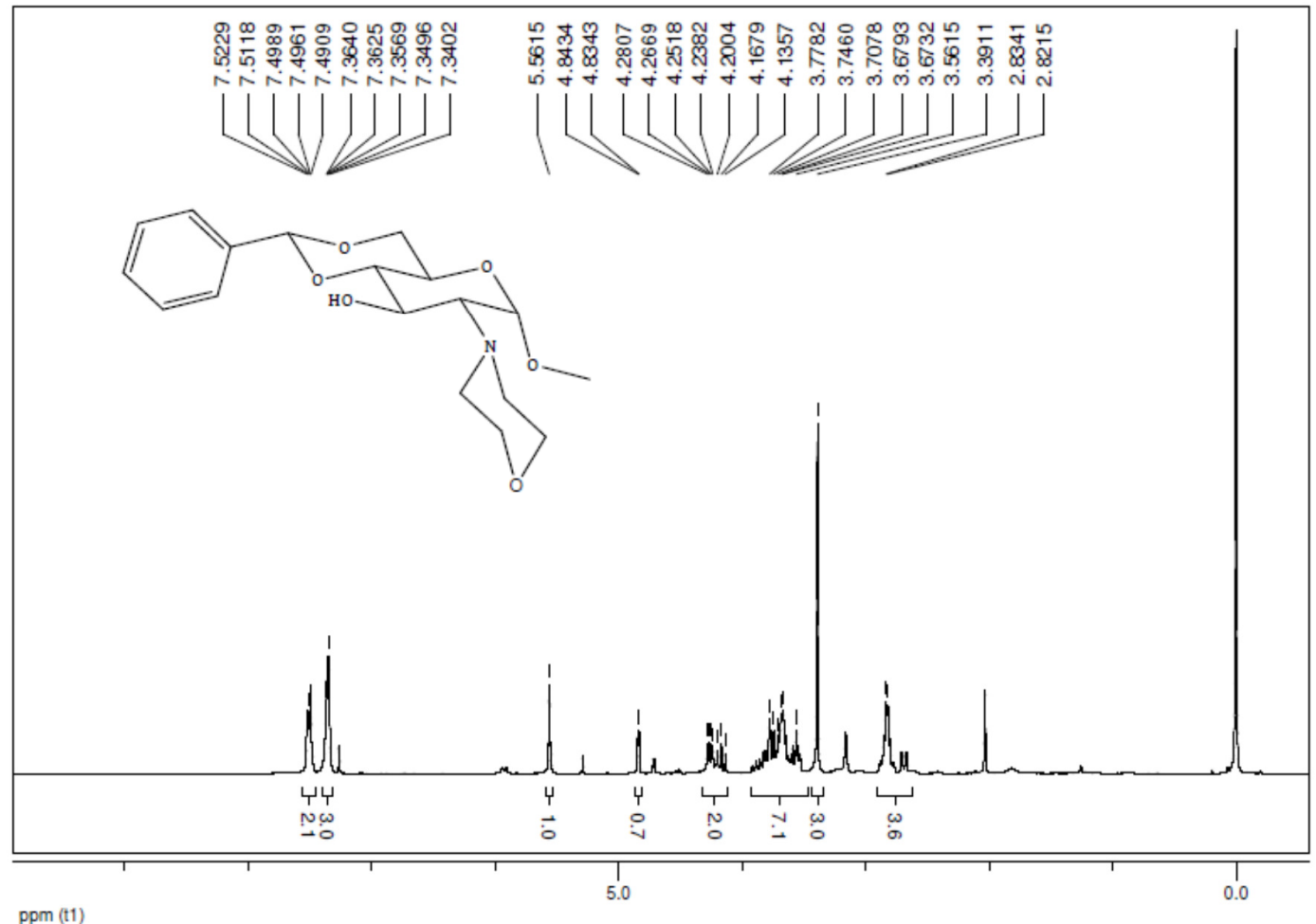

ppm (t1)

Figura 29. Espectro de $\mathrm{RMN}^{1} \mathrm{H}$ a $300 \mathrm{MHz}$ do composto 5c.

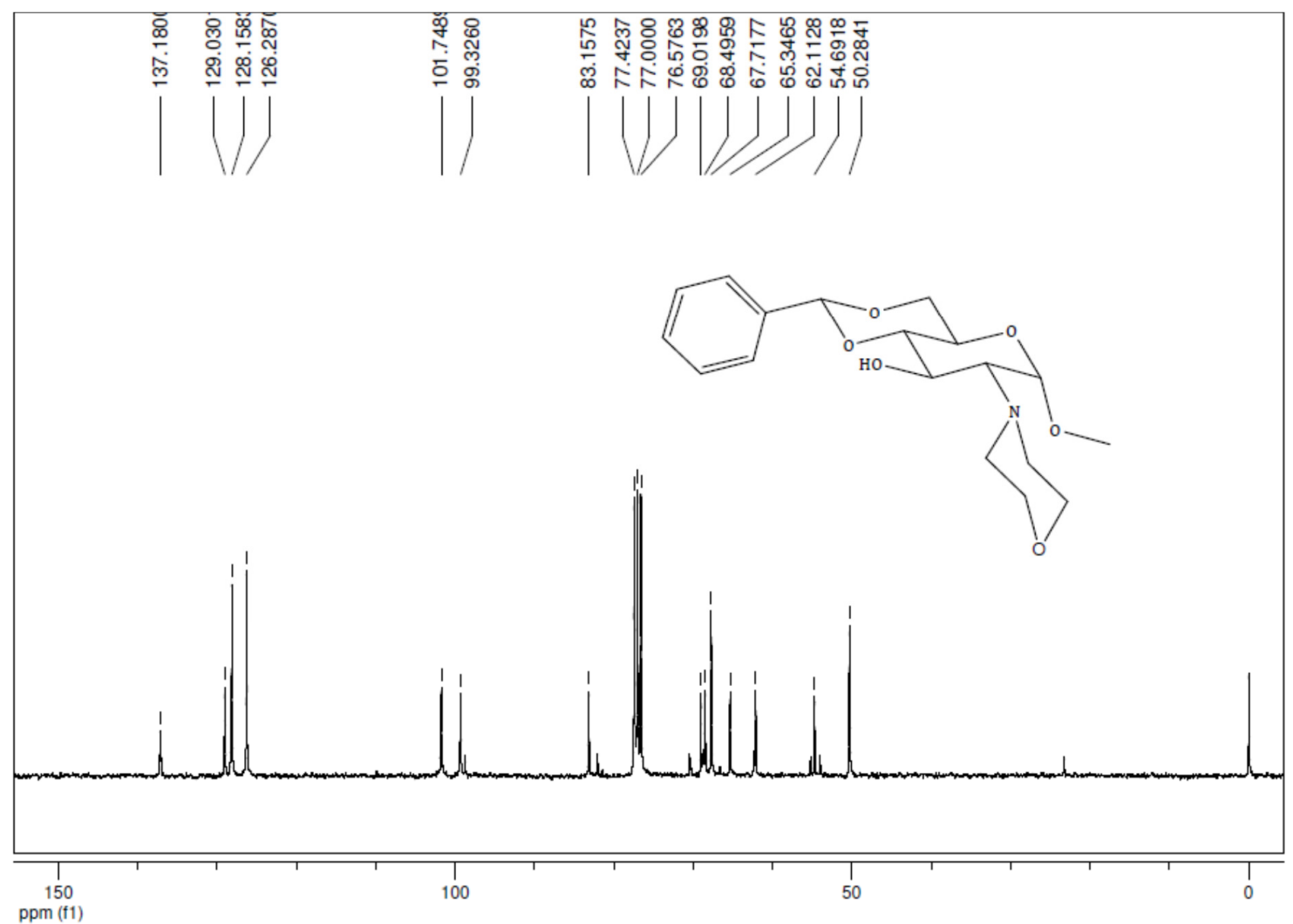

Figura 30. Espectro de $\mathrm{RMN}{ }^{13} \mathrm{C}$ a $75 \mathrm{MHz}$ do composto $5 \mathbf{c}$. 


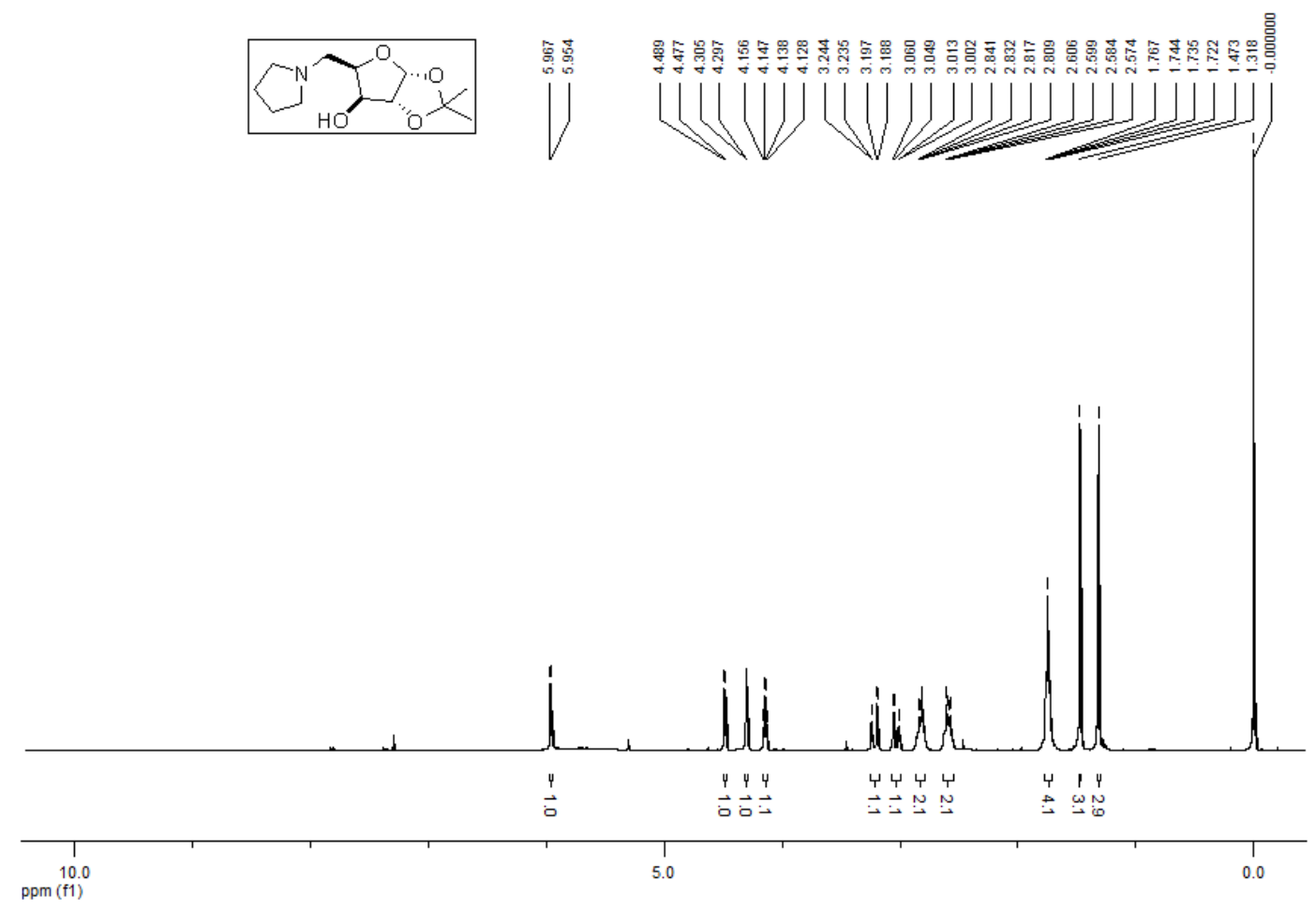

Figura 31. Espectro $\mathrm{RMN}^{1} \mathrm{H}$ a $300 \mathrm{MHz}$ do composto10a.
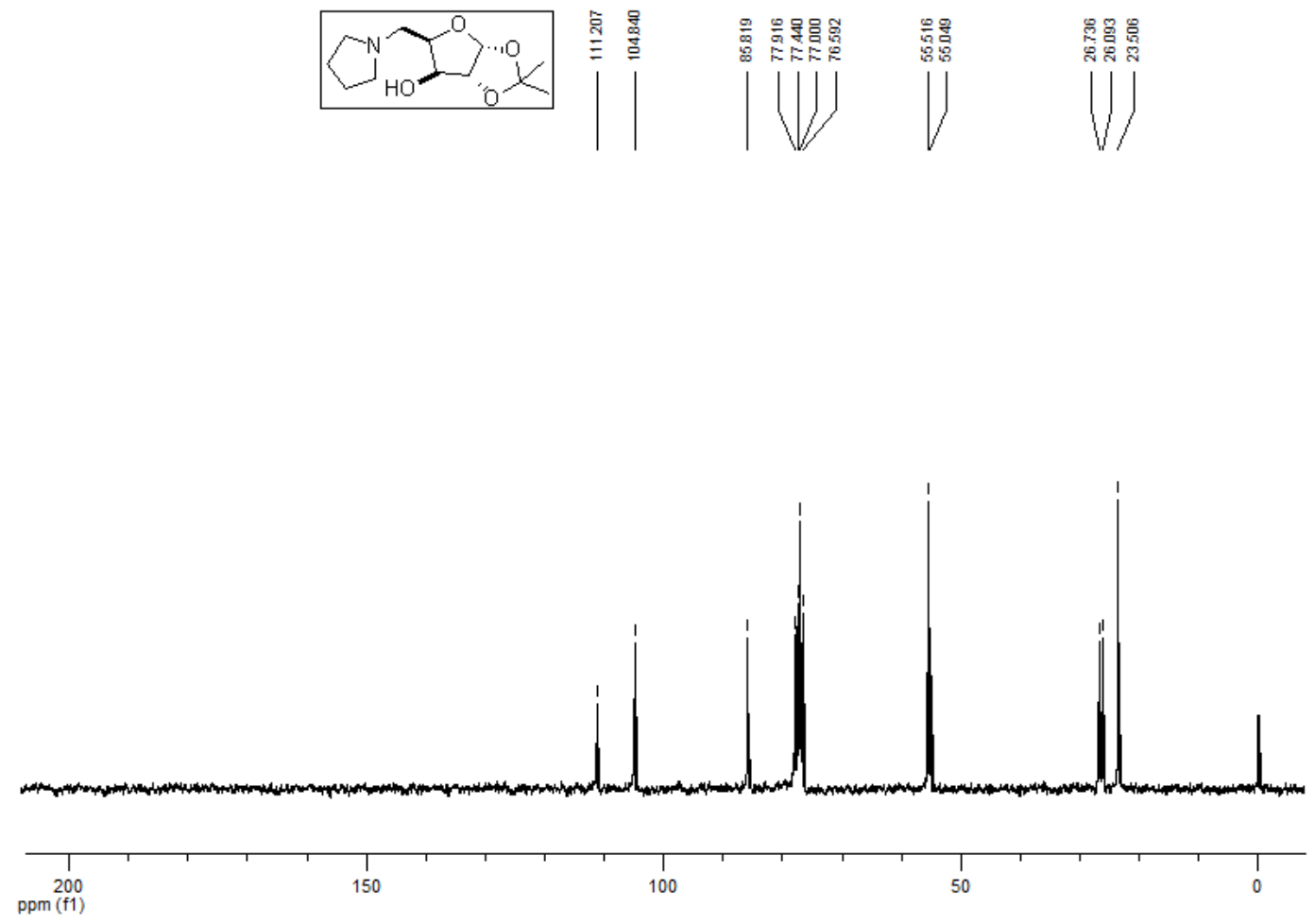

Figura 32. Espectro $\mathrm{RMN}^{13} \mathrm{C}$ a $75 \mathrm{MHz}$ do composto10a. 

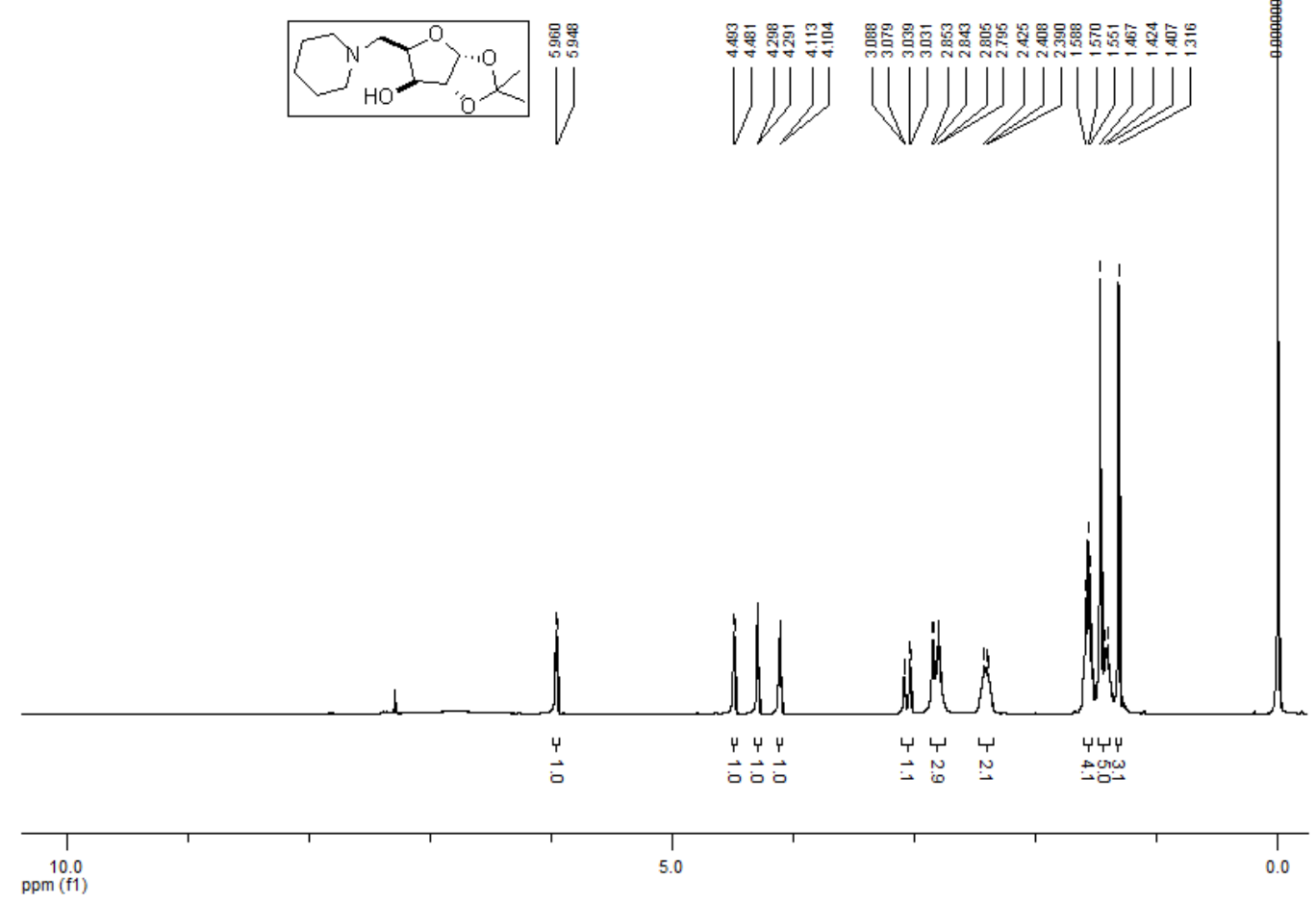

Figura 33. Espectro RMN ${ }^{1} \mathrm{H}$ a $300 \mathrm{MHz}$ do composto $\mathbf{1 0 b}$.
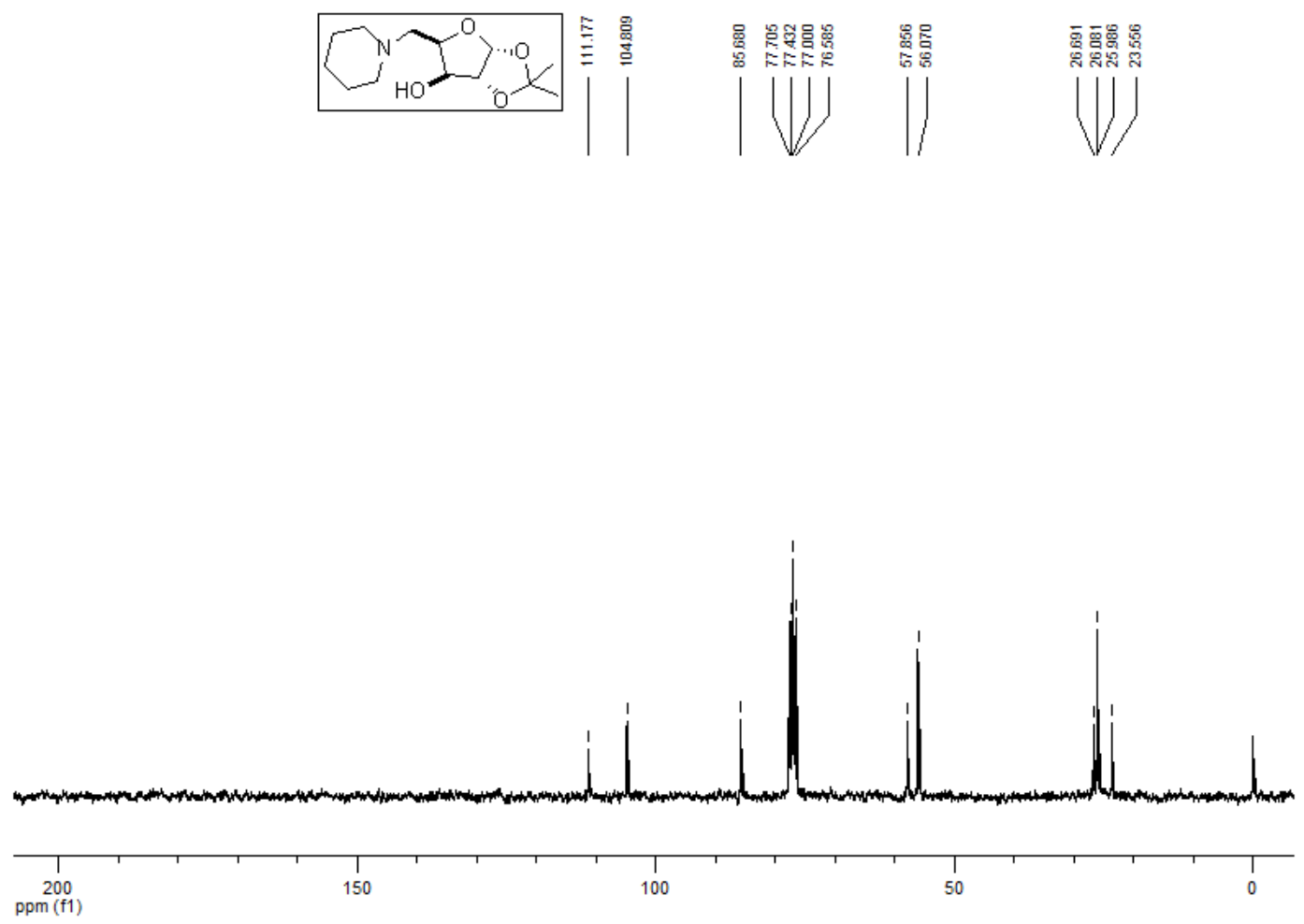

Figura 34. Espectro $\mathrm{RMN}{ }^{13} \mathrm{Ca} 75 \mathrm{MHz}$ do composto $\mathbf{1 0 b}$. 


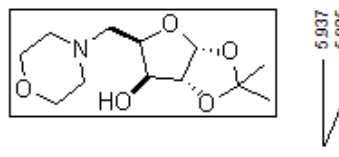

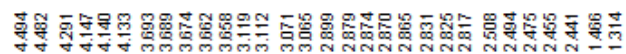
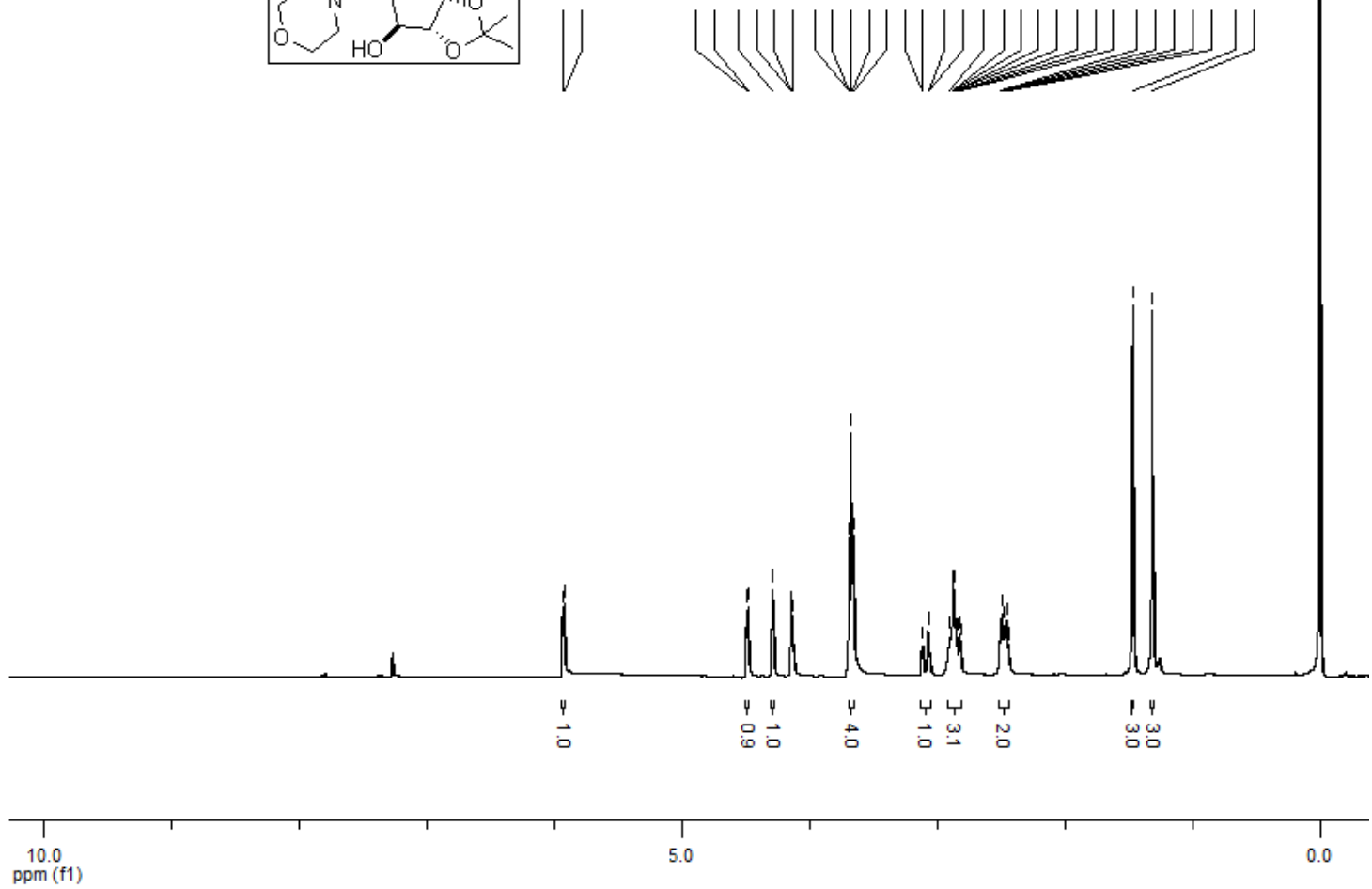

Figura 35. Espectro $\mathrm{RMN}^{1} \mathrm{H}$ a $300 \mathrm{MHz}$ do composto 10c.
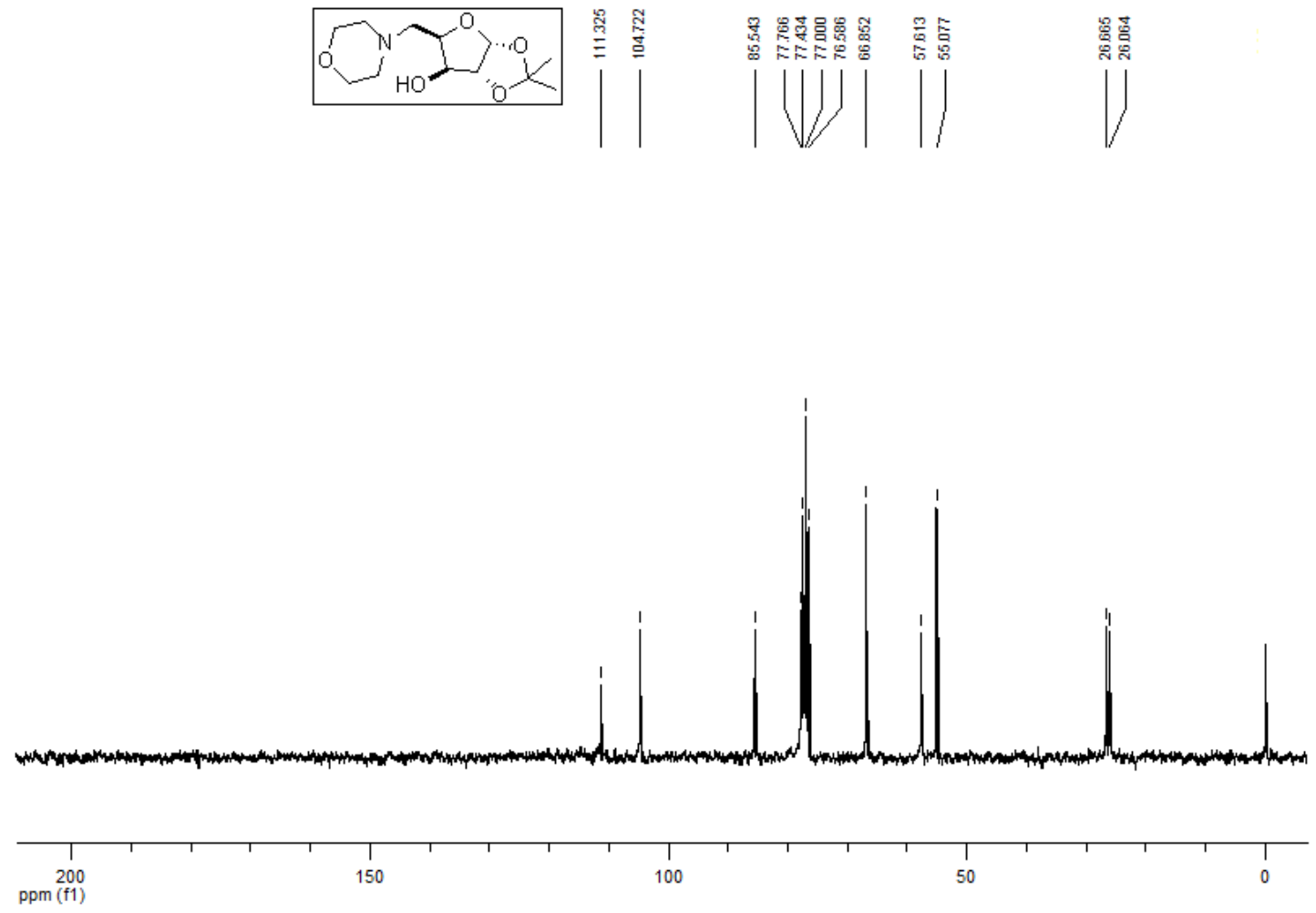

Figura 36. Espectro $\mathrm{RMN}{ }^{13} \mathrm{C}$ a $75 \mathrm{MHz}$ do composto $\mathbf{1 0 c}$. 

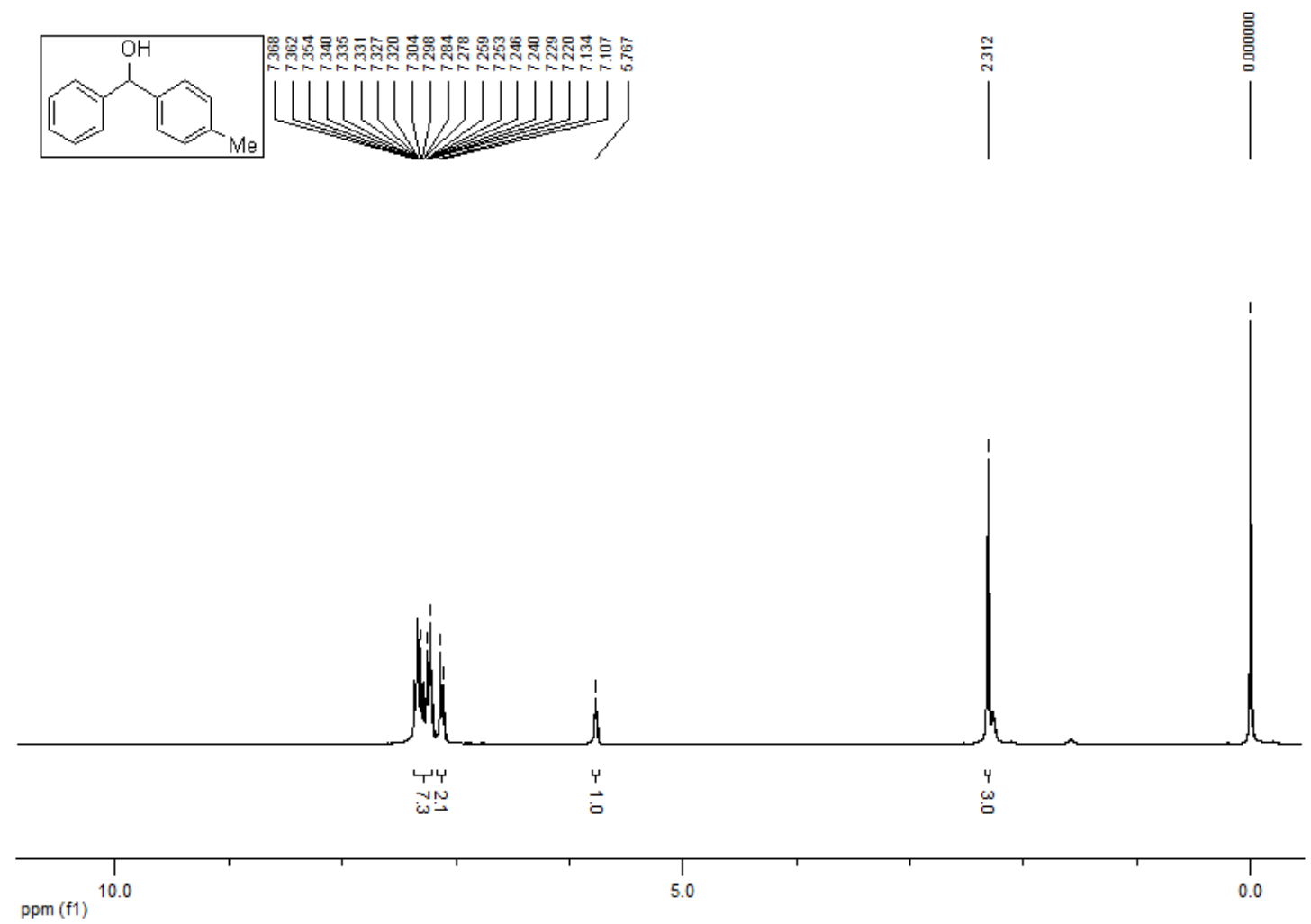

Figura 37. Espectro de $\mathrm{RMN}^{1} \mathrm{H}$ a $300 \mathrm{MHz}$ do composto $6 \mathbf{a}$.
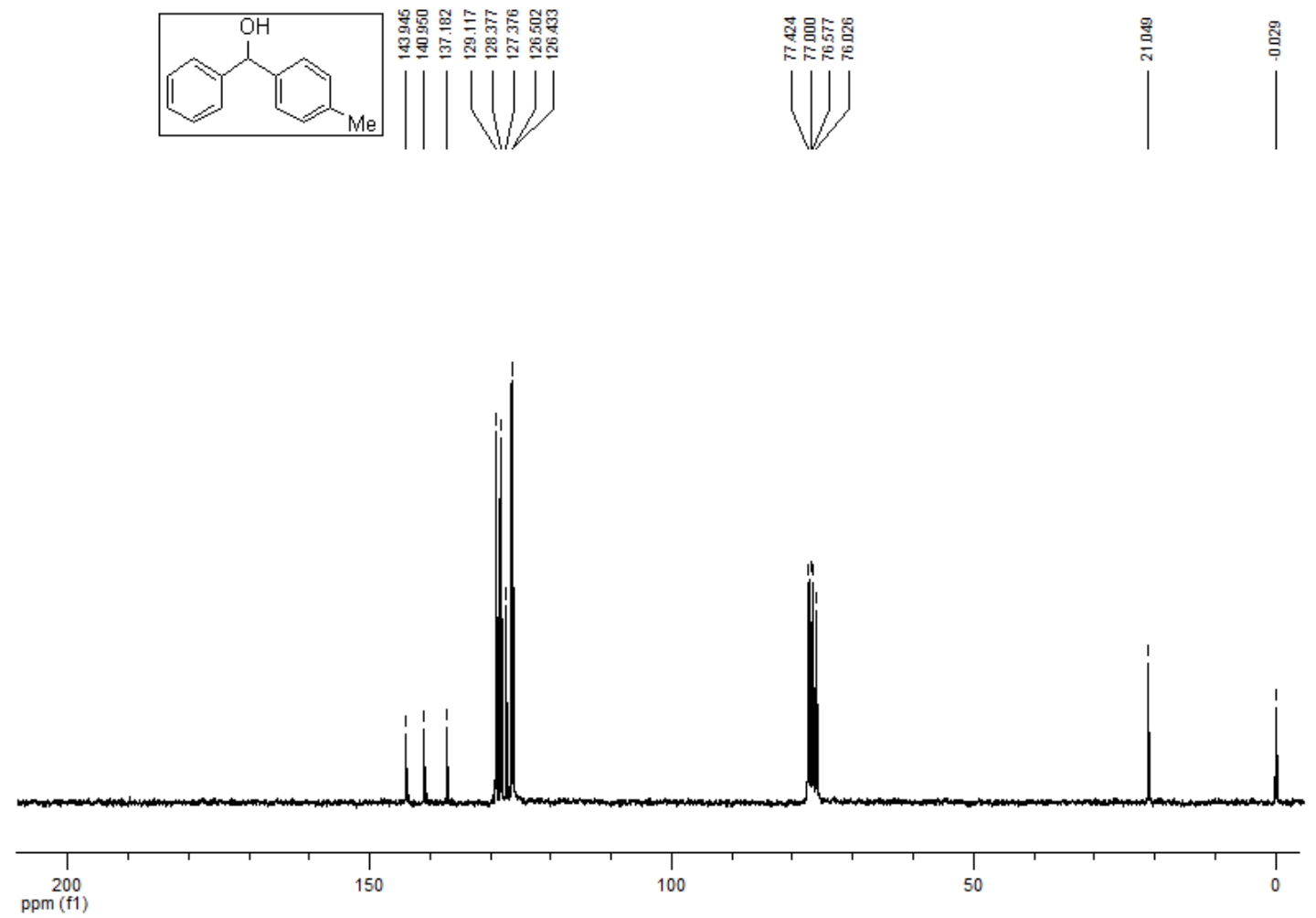

Figura 38. Espectro de $\mathrm{RMN}{ }^{13} \mathrm{C}$ a $75 \mathrm{MHz}$ do composto $6 \mathbf{a}$. 

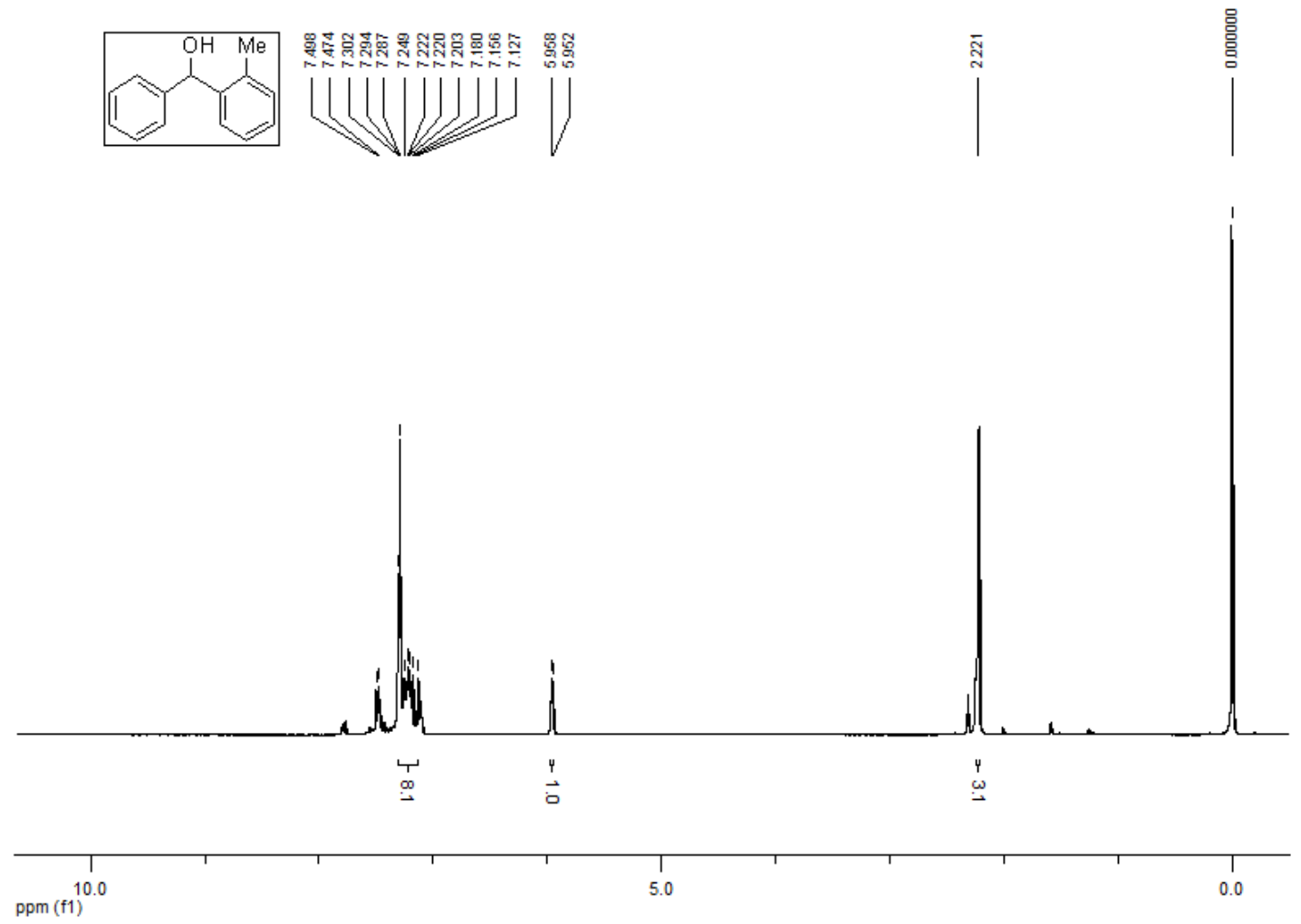

Figura 39. Espectro $\mathrm{RMN}^{1} \mathrm{H}$ a $300 \mathrm{MHz}$ do composto6b.
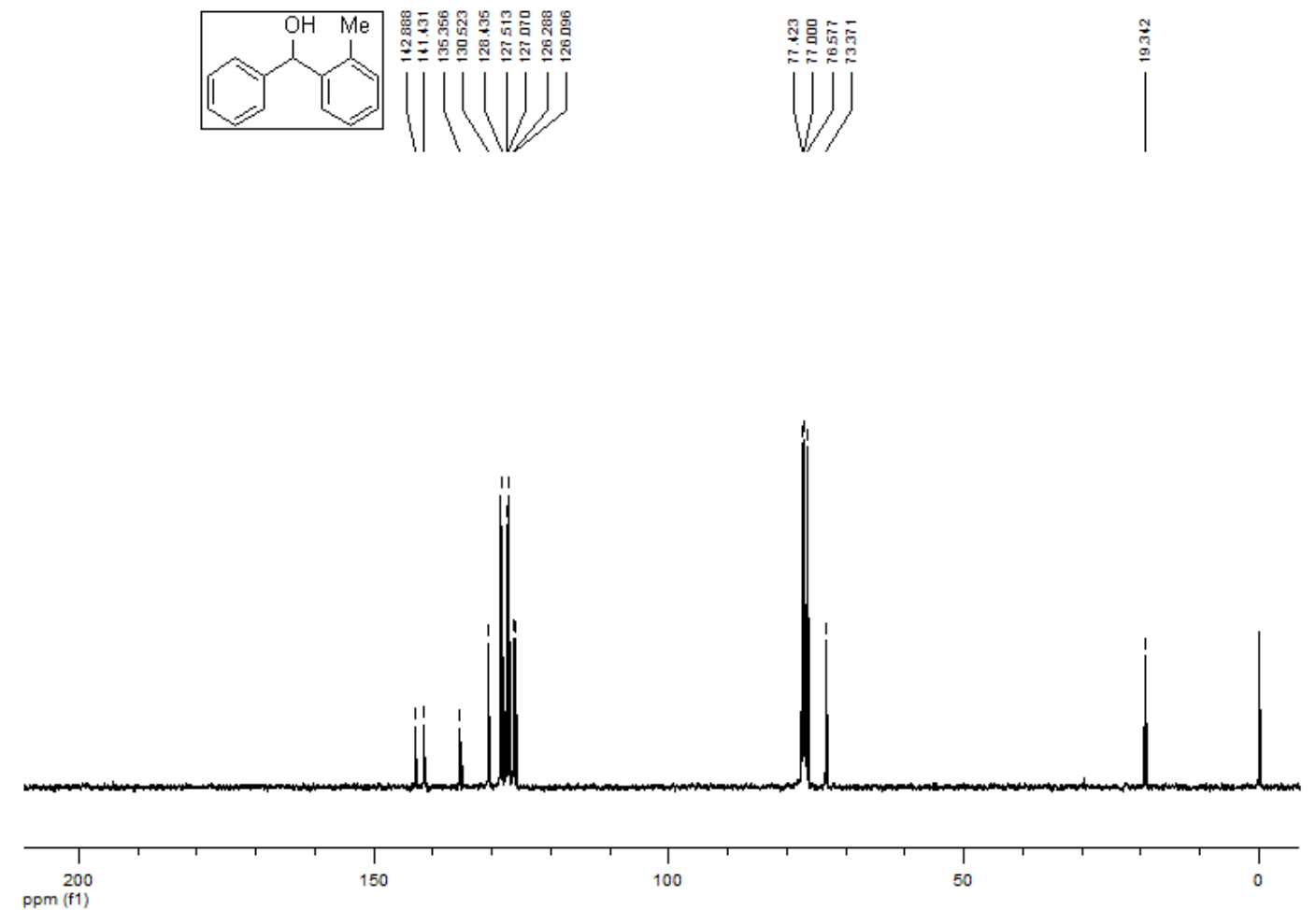

Figura 40. Espectro $\mathrm{RMN}^{13} \mathrm{C}$ a $75 \mathrm{MHz}$ do composto6b. 

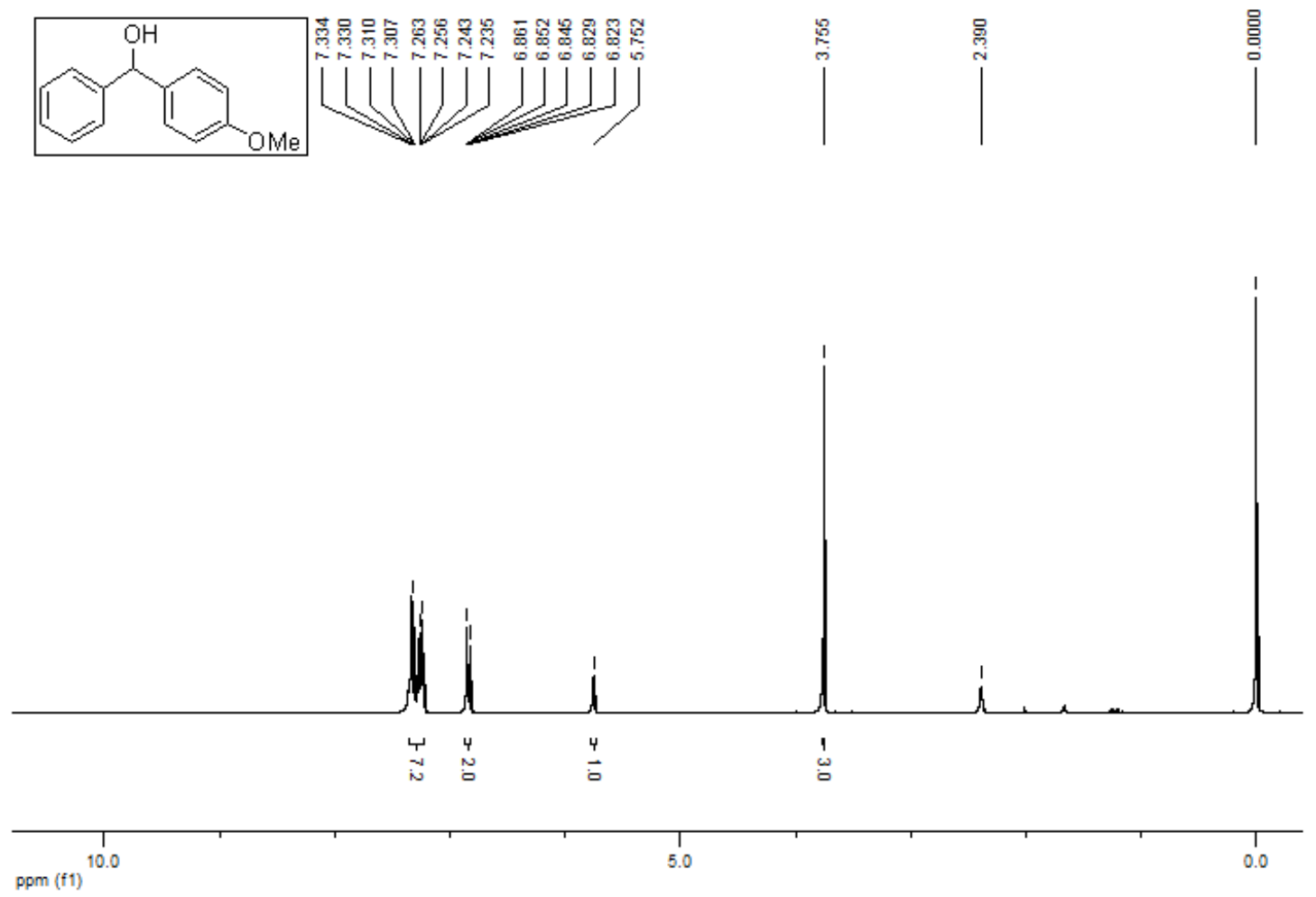

Figura 41. Espectro de $\mathrm{RMN}^{1} \mathrm{H}$ a $300 \mathrm{MHz}$ do composto 6c.
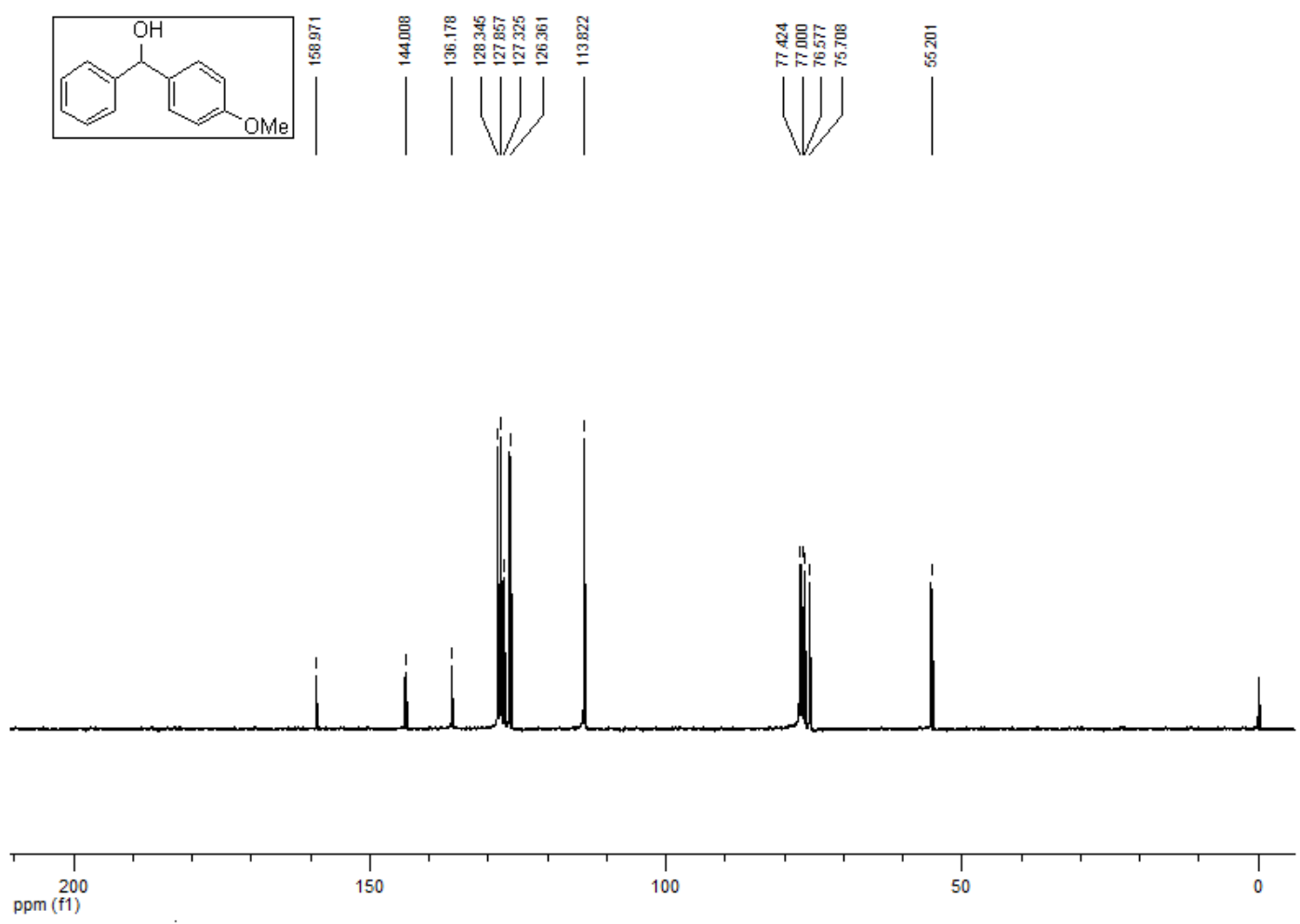

Figura 42. Espectro de $\mathrm{RMN}{ }^{13} \mathrm{C}$ a $75 \mathrm{MHz}$ do composto $6 \mathbf{c}$. 

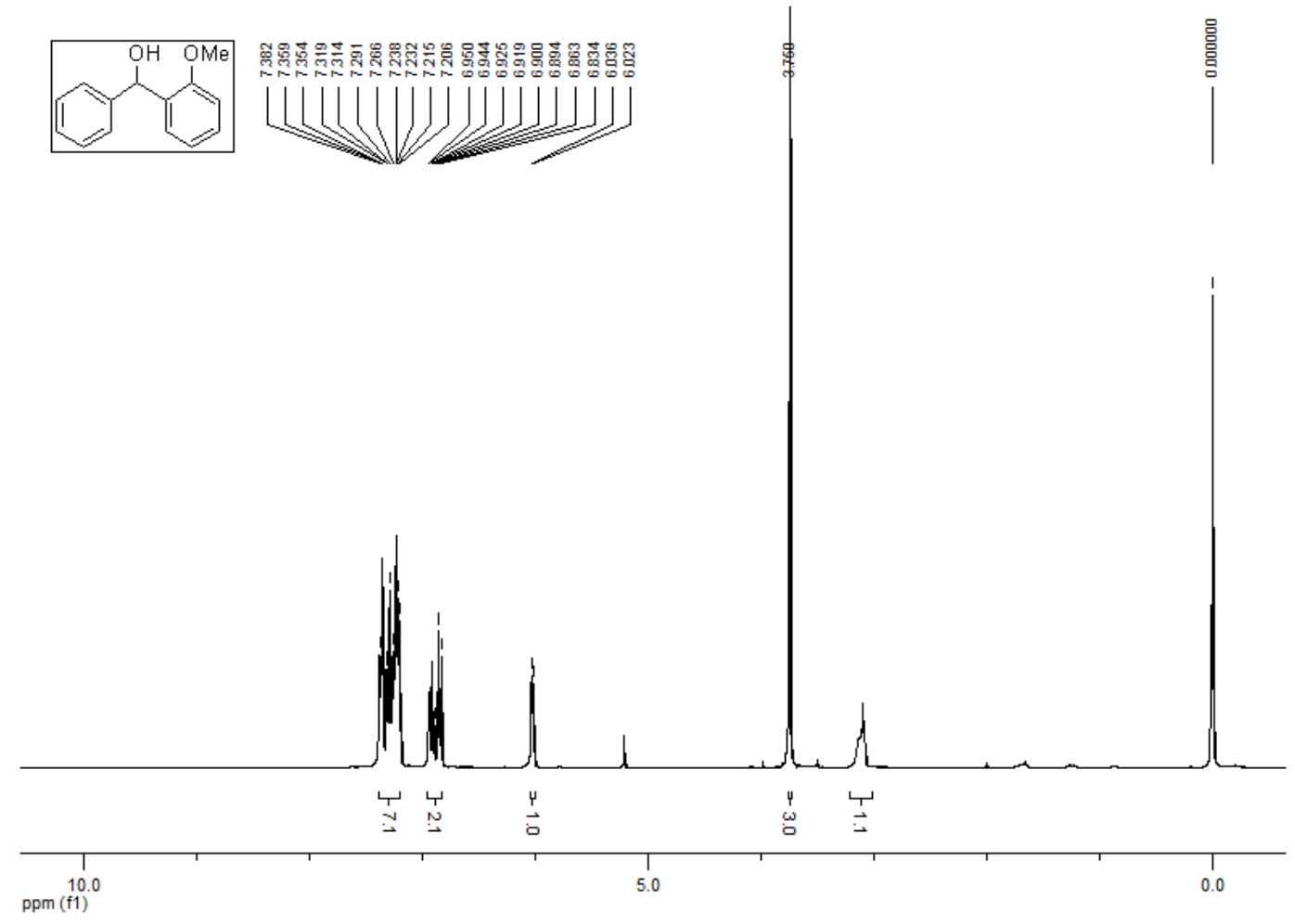

Figura 43. Espectro de $\mathrm{RMN}^{1} \mathrm{H}$ a $300 \mathrm{MHz}$ do composto6d.
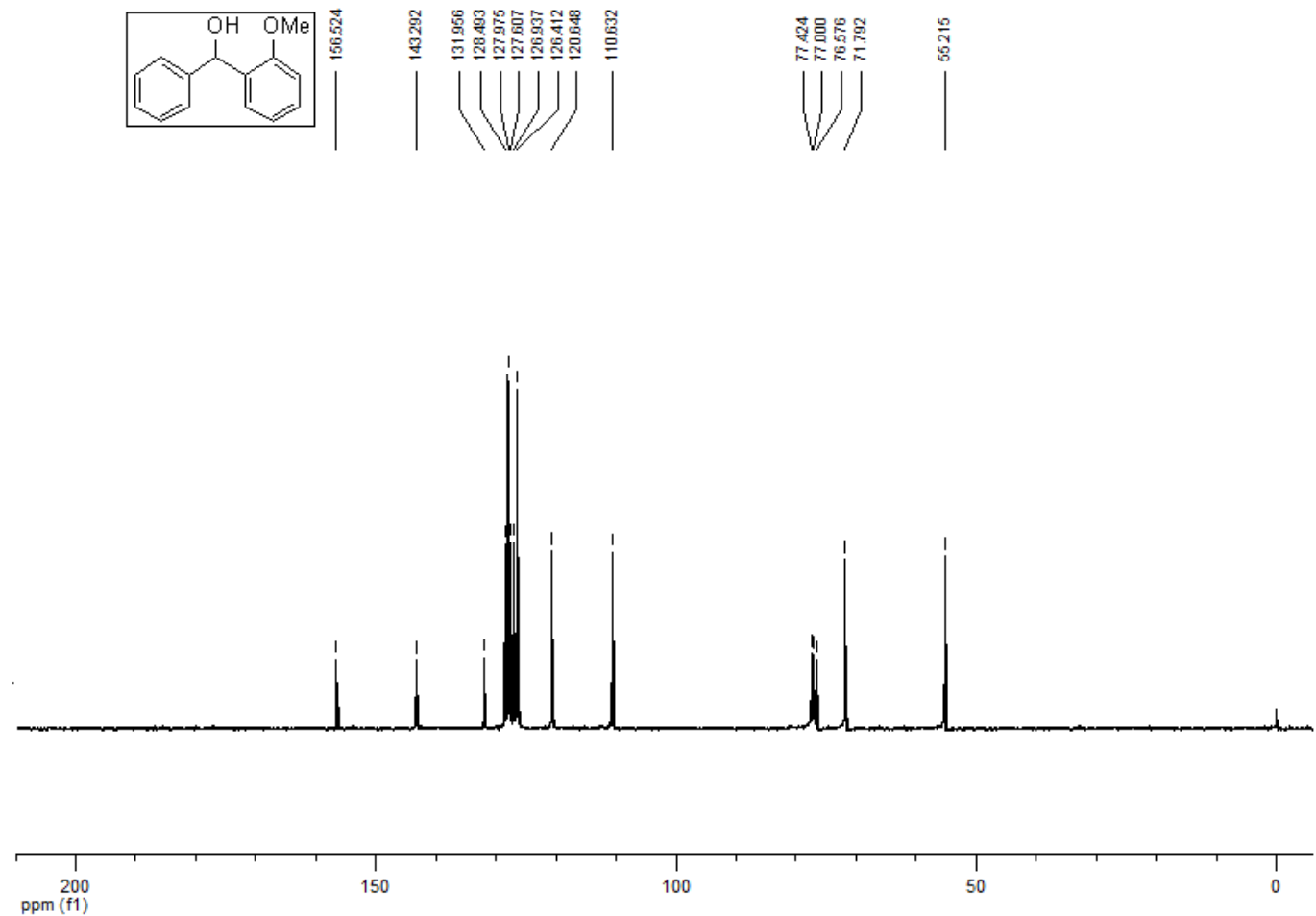

Figura 44. Espectro de RMN ${ }^{13} \mathrm{C}$ a $75 \mathrm{MHz}$ do composto6d. 

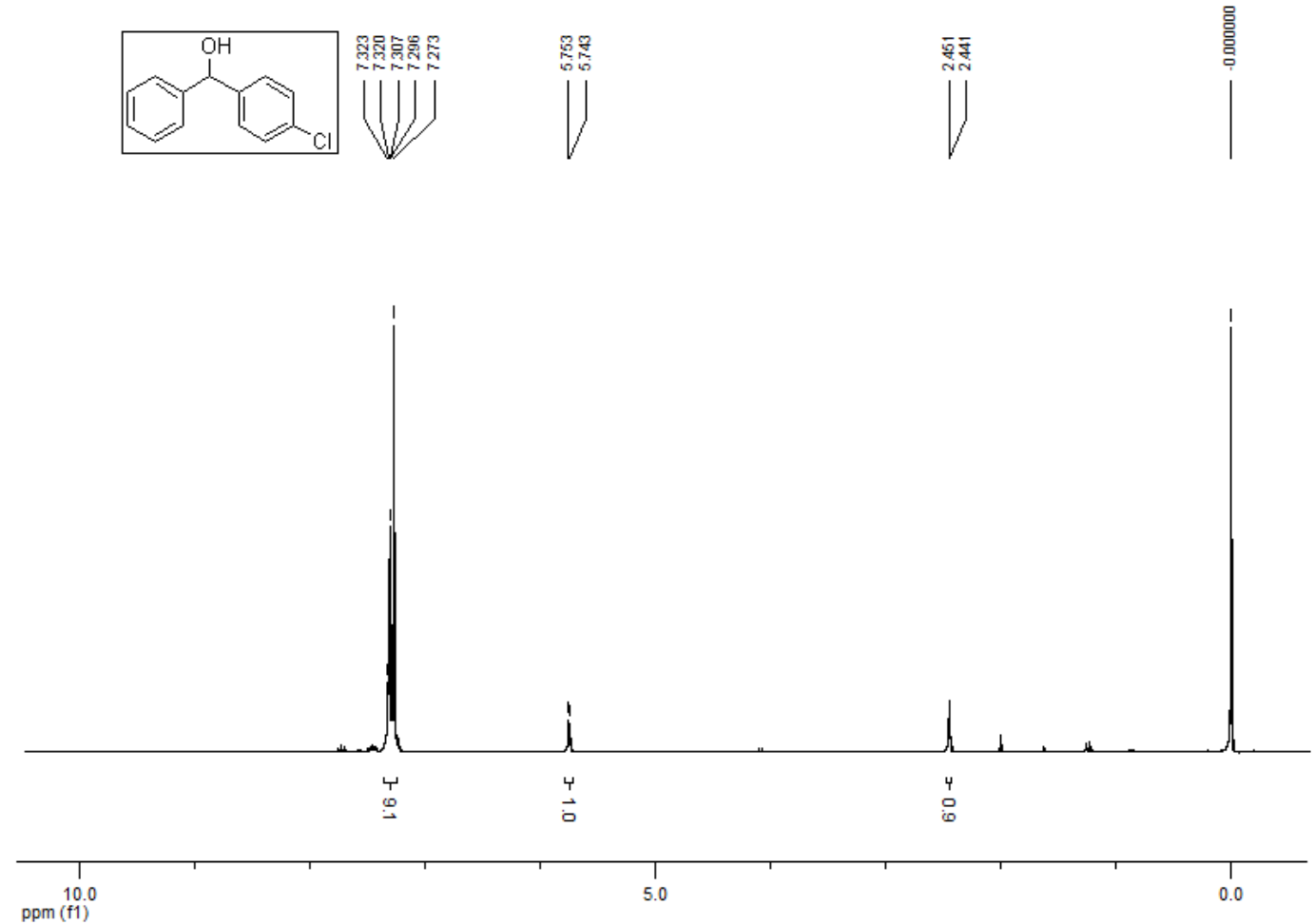

Figura 45. Espectro de $\mathrm{RMN}^{1} \mathrm{H}$ a $300 \mathrm{MHz}$ do composto $6 \mathbf{e}$.
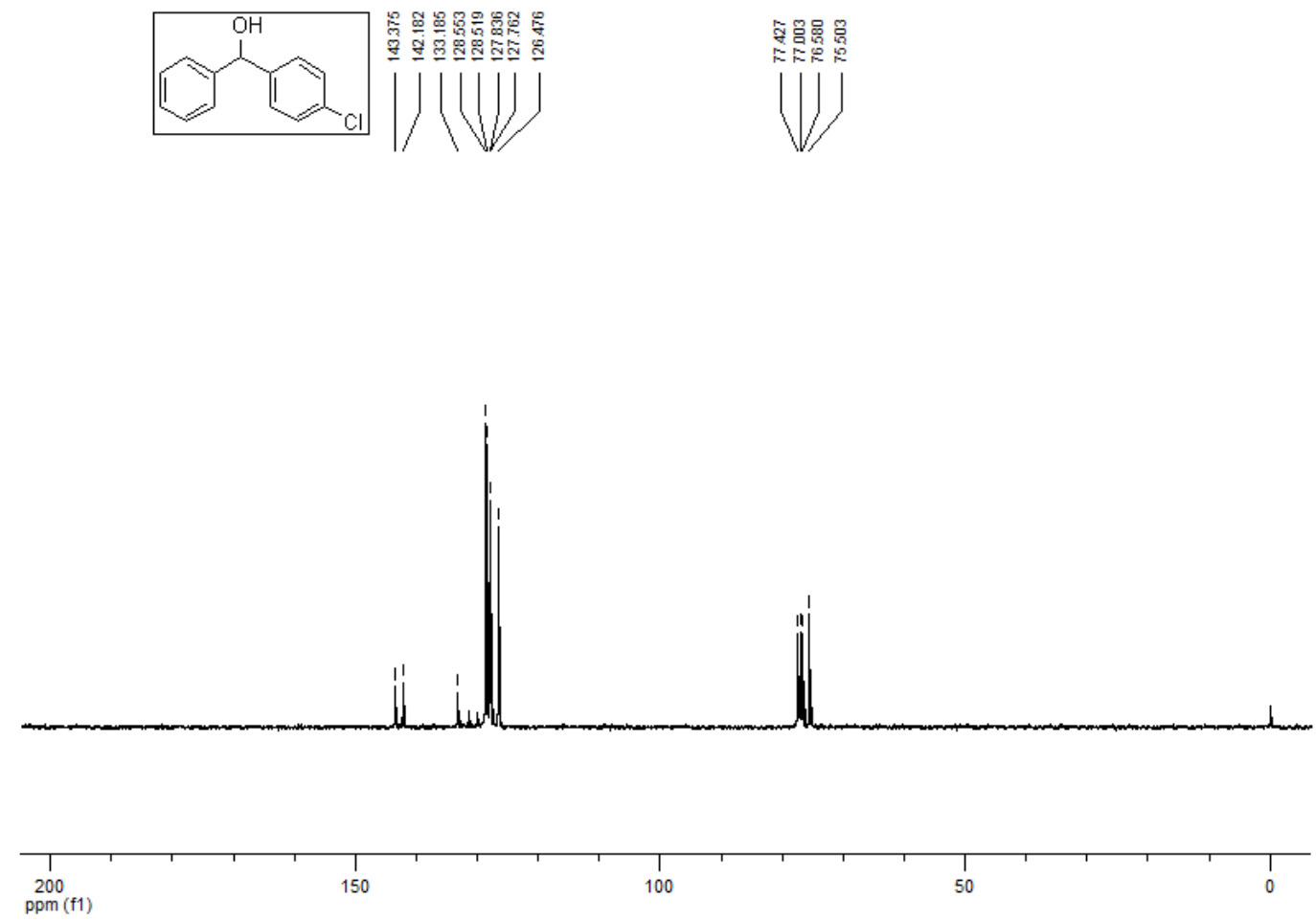

Figura 46. Espectro de $\mathrm{RMN}{ }^{13} \mathrm{C}$ a $75 \mathrm{MHz}$ do composto 6 e. 

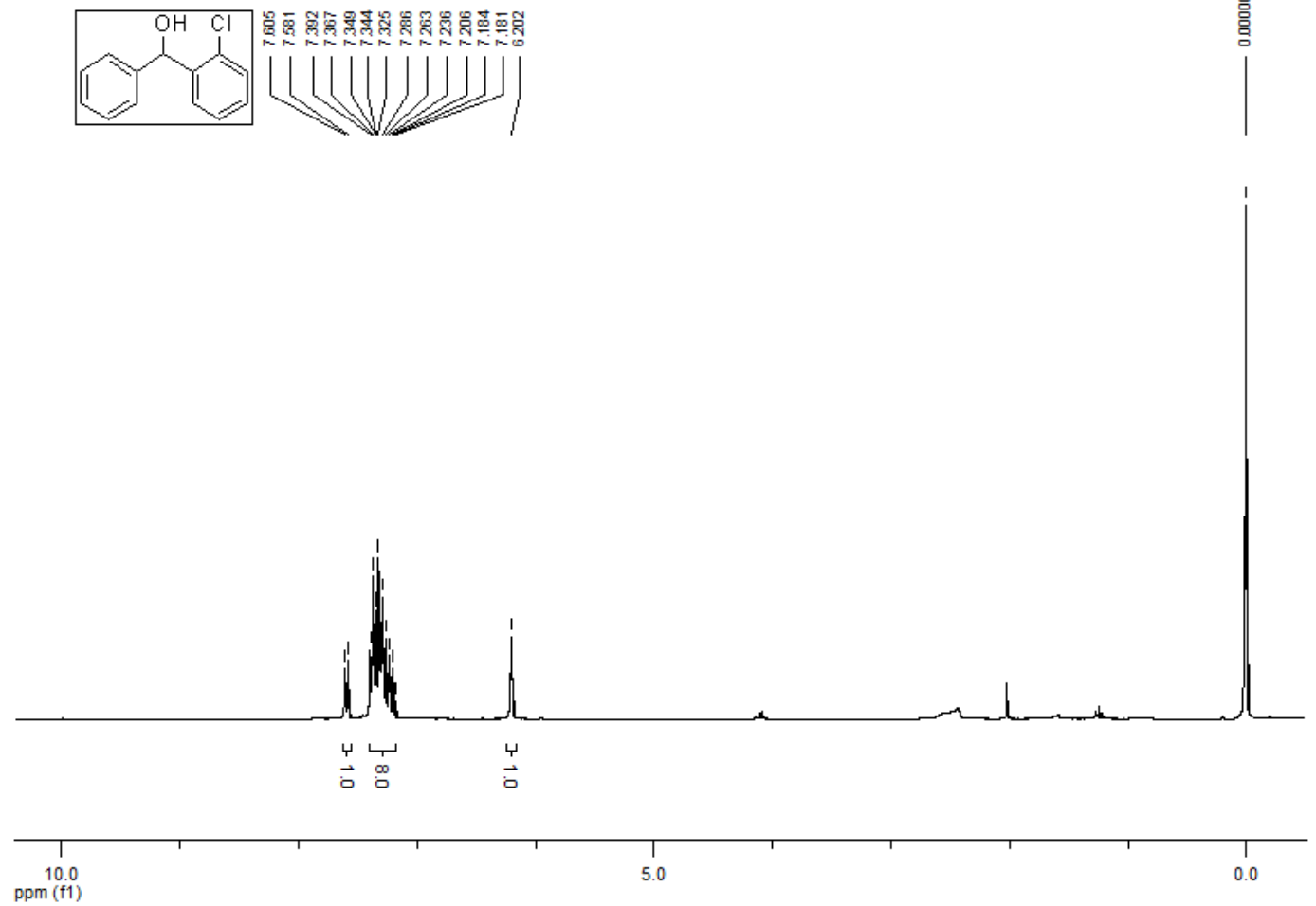

Figura 47. Espectro $\mathrm{RMN}^{1} \mathrm{H}$ a $300 \mathrm{MHz}$ do composto $6 \mathbf{f}$.
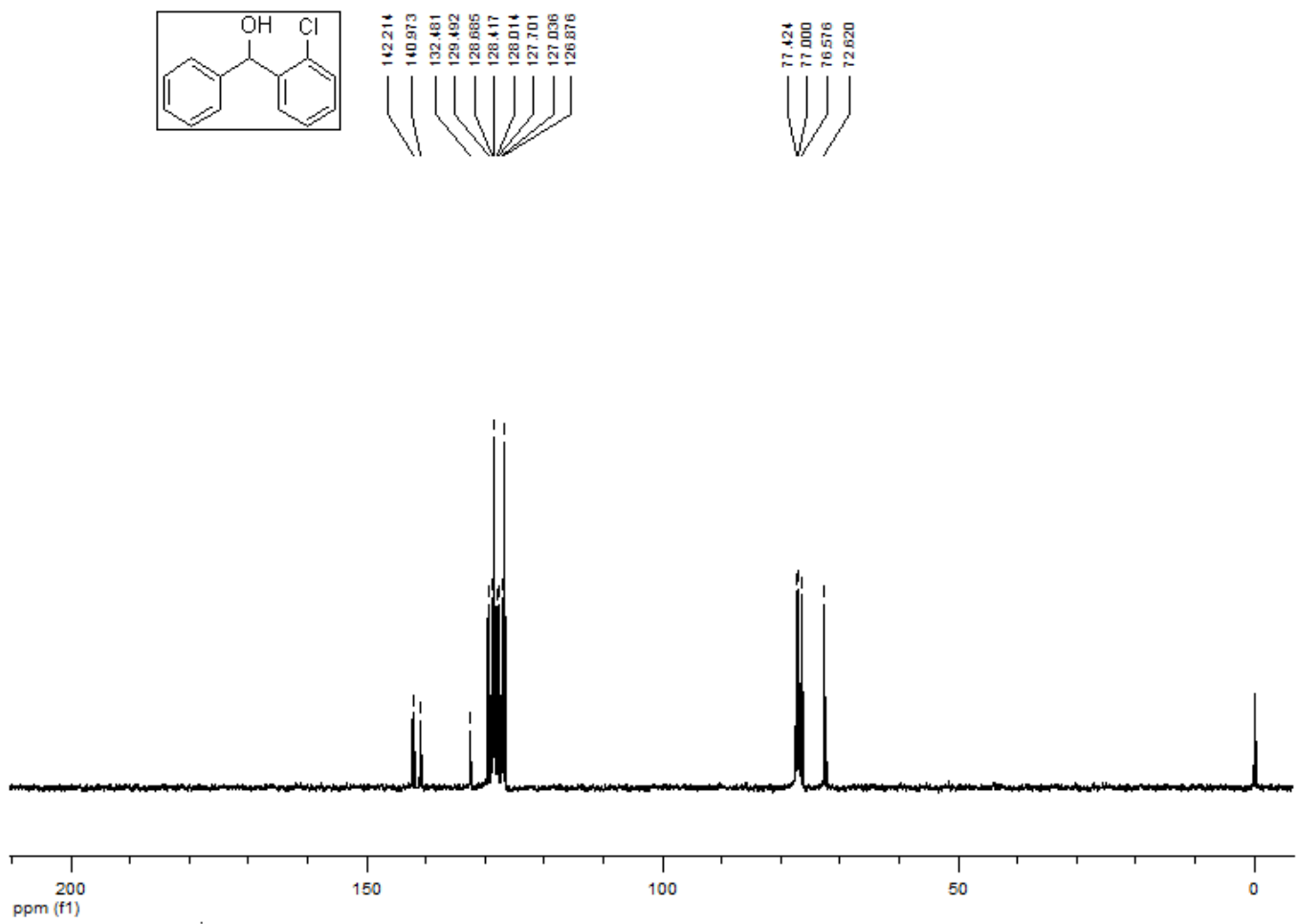

Figura 48. Espectro $\mathrm{RMN}{ }^{13} \mathrm{C}$ a $75 \mathrm{MHz}$ do composto $6 \mathbf{f}$. 

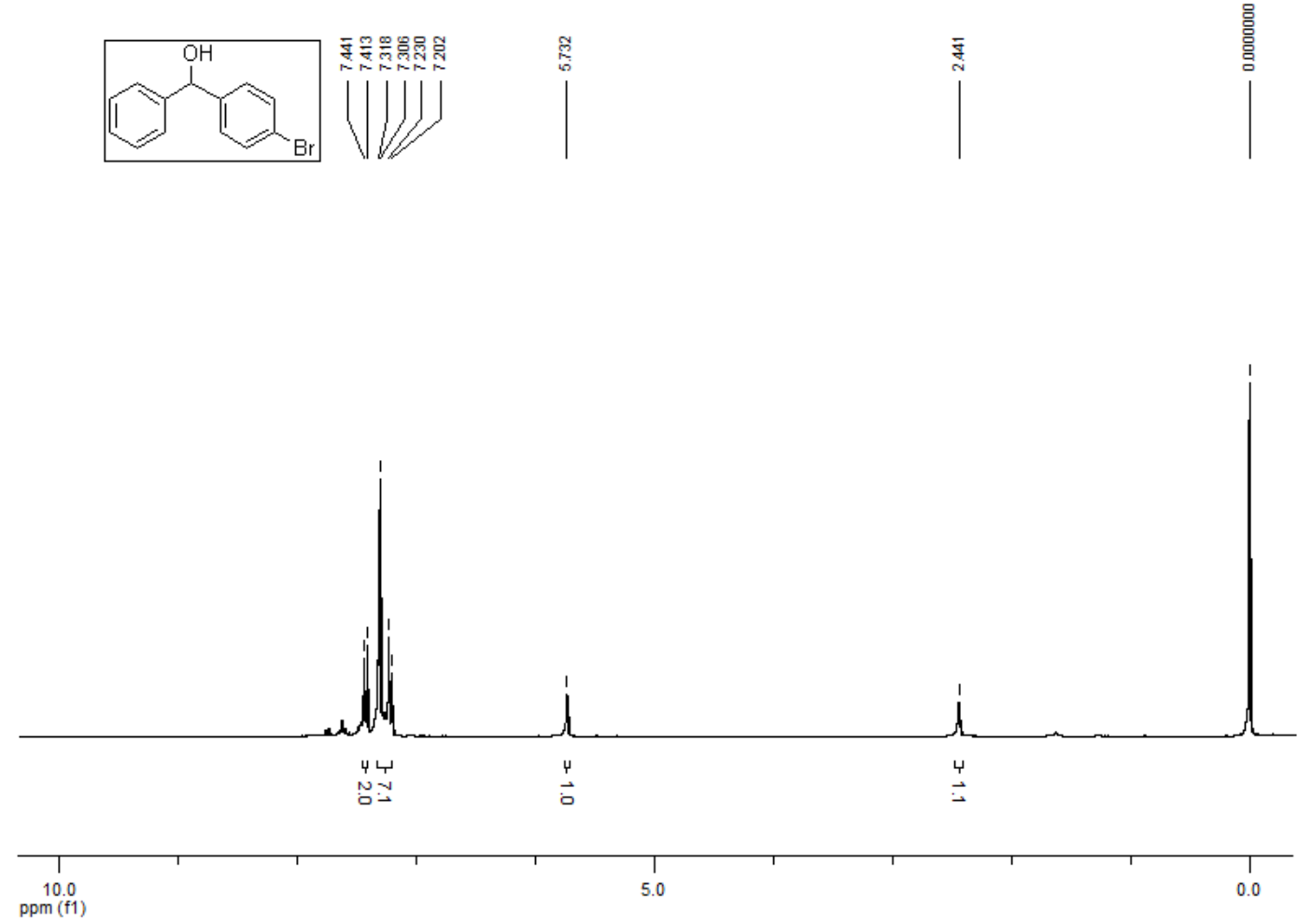

Figura 49. Espectro de $\mathrm{RMN}^{1} \mathrm{H}$ a $300 \mathrm{MHz}$ do composto $6 \mathbf{g}$.
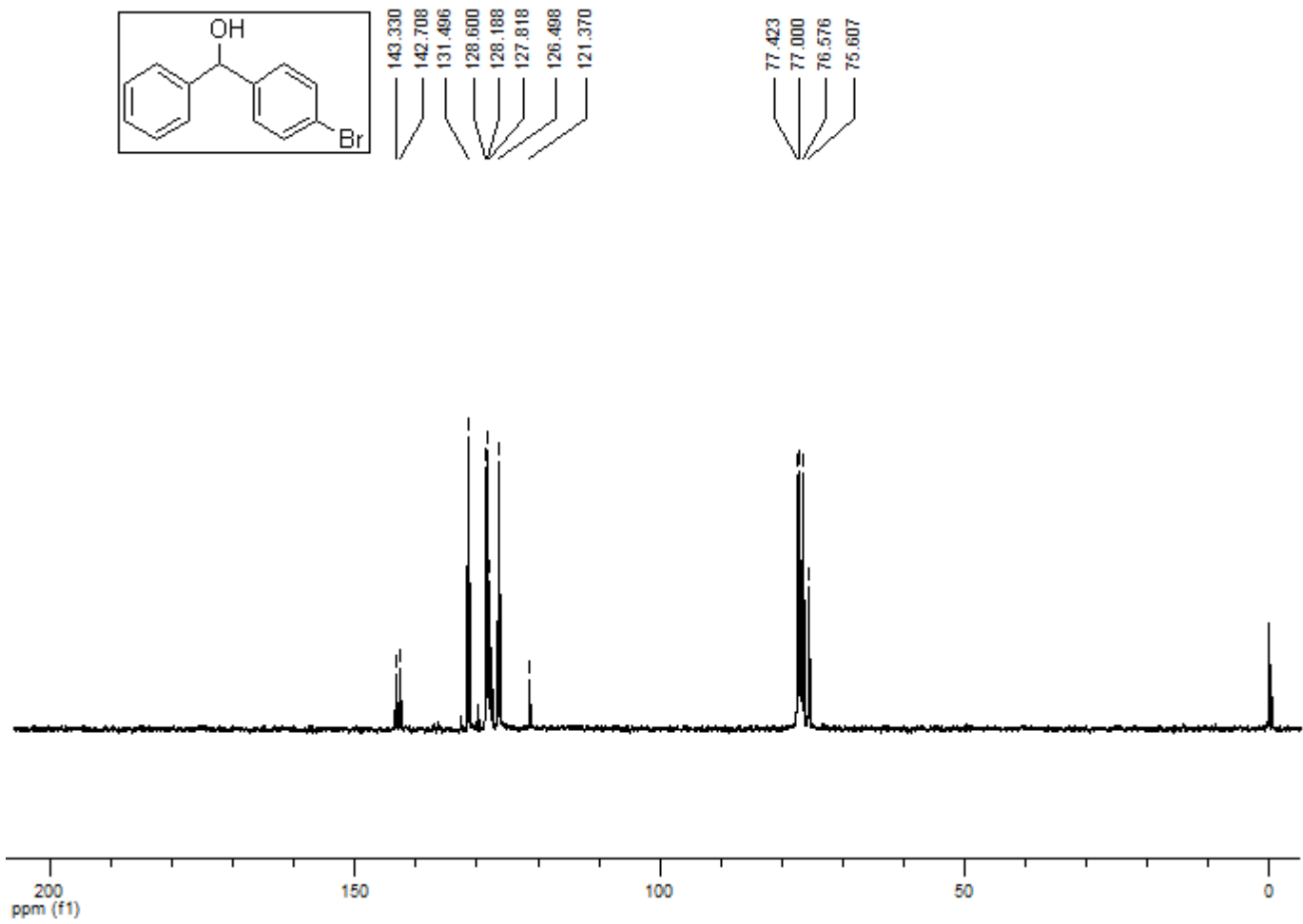

Figura 50. Espectro de $\mathrm{RMN}{ }^{13} \mathrm{C}$ a $75 \mathrm{MHz}$ do composto $\mathbf{6 g}$. 

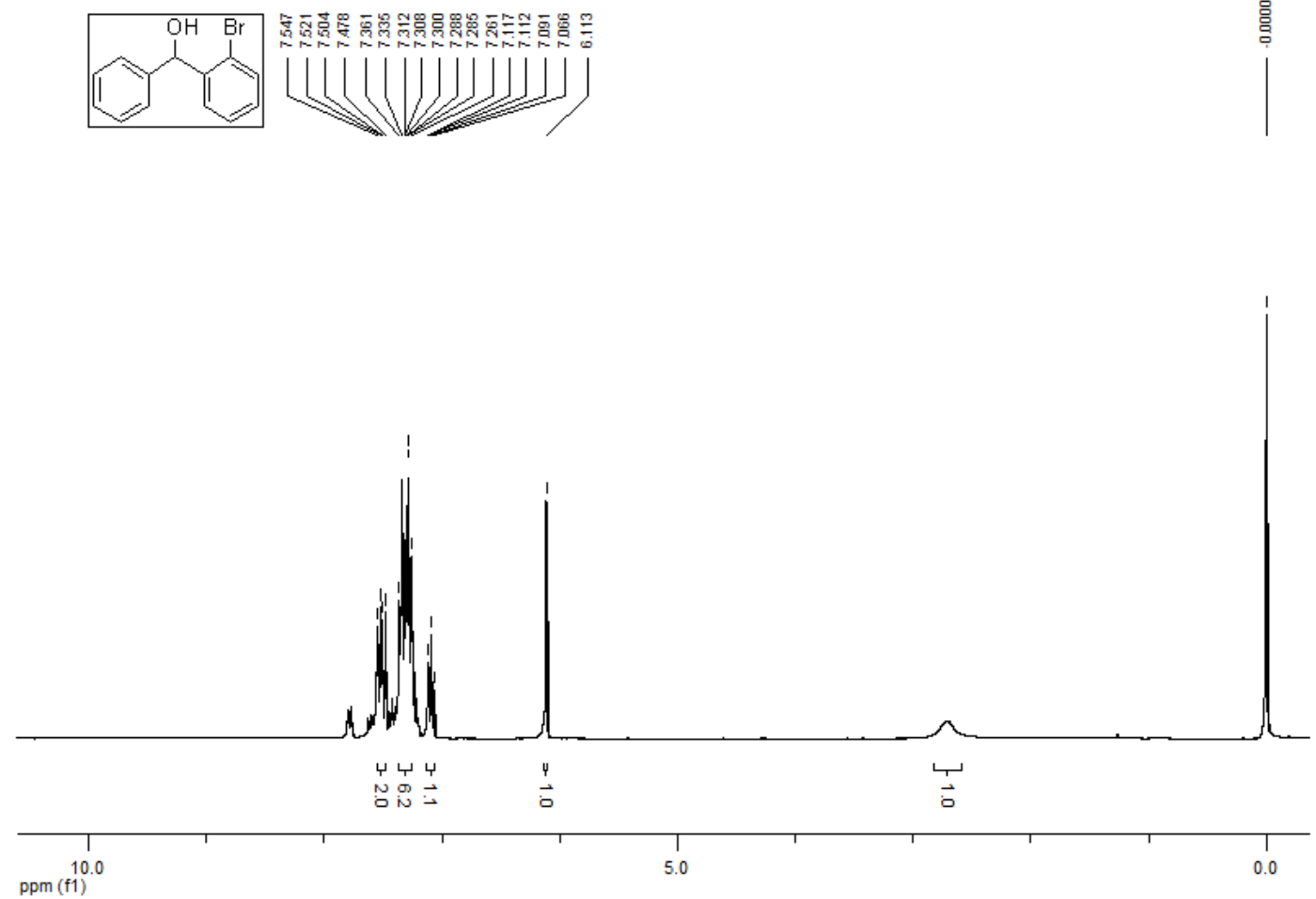

Figura 51. Espectro de $\mathrm{RMN}{ }^{1} \mathrm{Ha} 300 \mathrm{MHz}$ do composto $6 \mathbf{h}$.
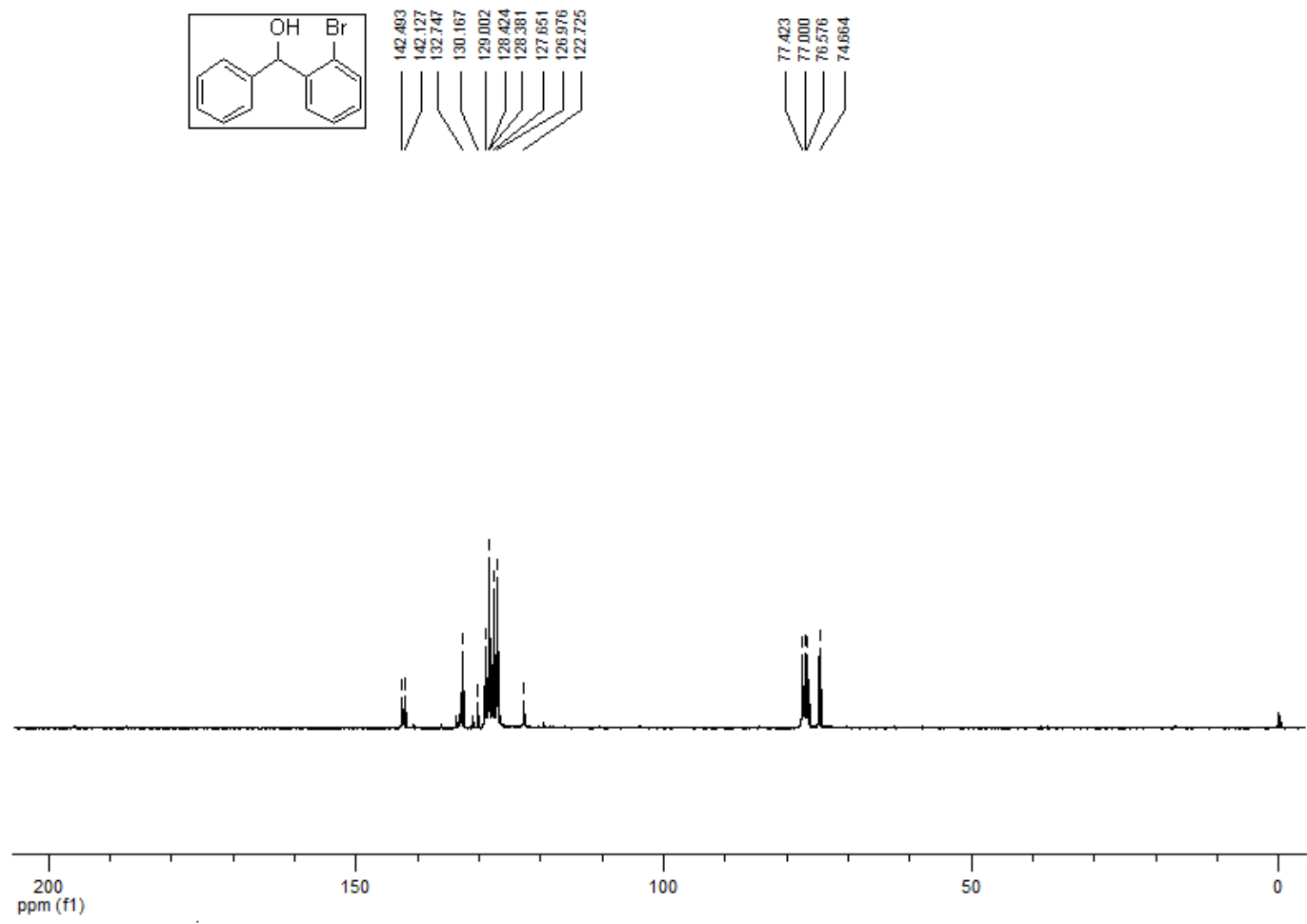

Figura 52. Espectro de $\mathrm{RMN}{ }^{13} \mathrm{C}$ a $75 \mathrm{MHz}$ do composto $\mathbf{6 h}$. 


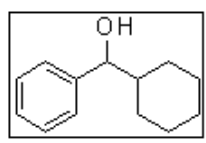

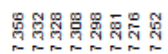

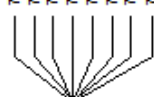

$\mid$

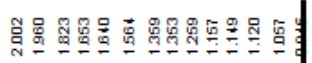

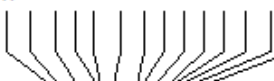

$(M, 1 / 2$
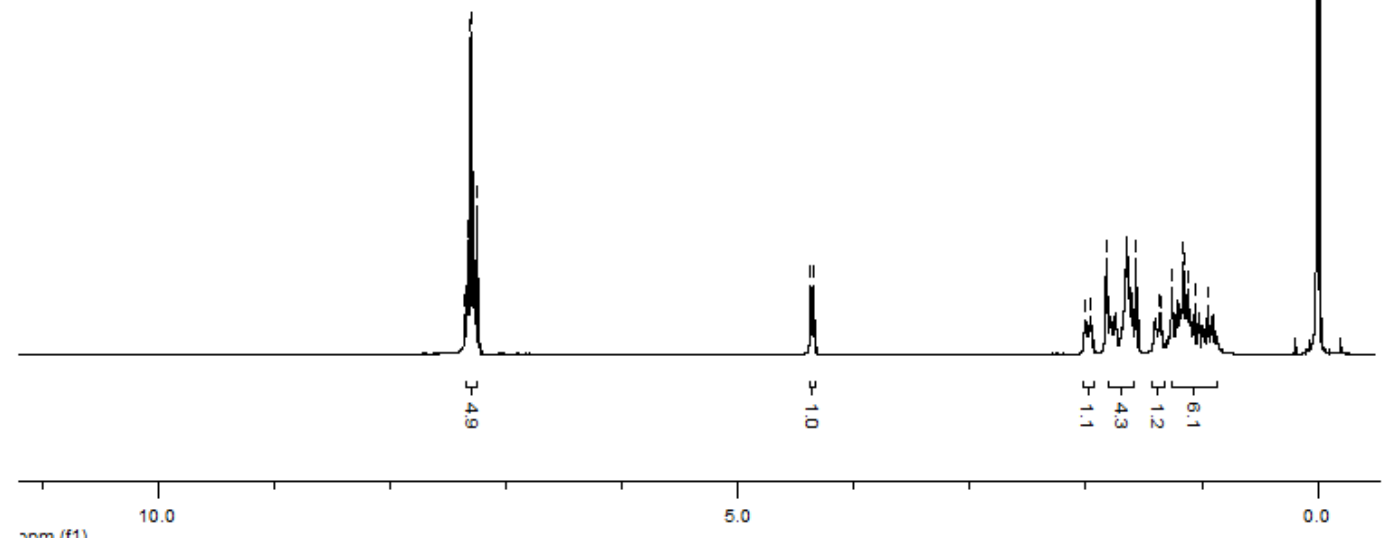

Figura 53. Espectro de $\mathrm{RMN}^{1} \mathrm{H}$ a $300 \mathrm{MHz}$ do composto $6 \mathbf{i}$.
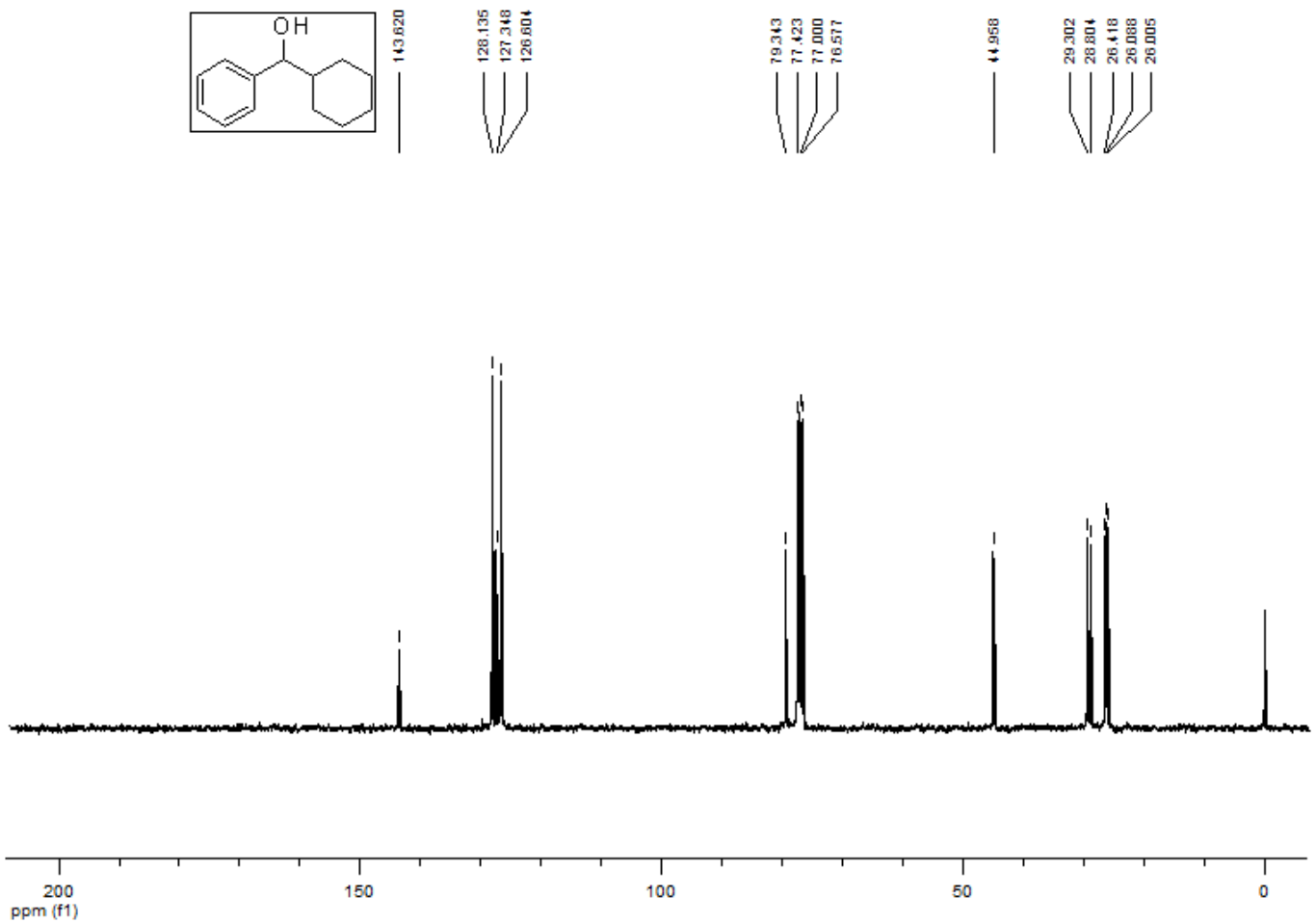

Figura 54. Espectro de $\mathrm{RMN}{ }^{13} \mathrm{C}$ a $75 \mathrm{MHz}$ do composto $6 \mathbf{i}$. 

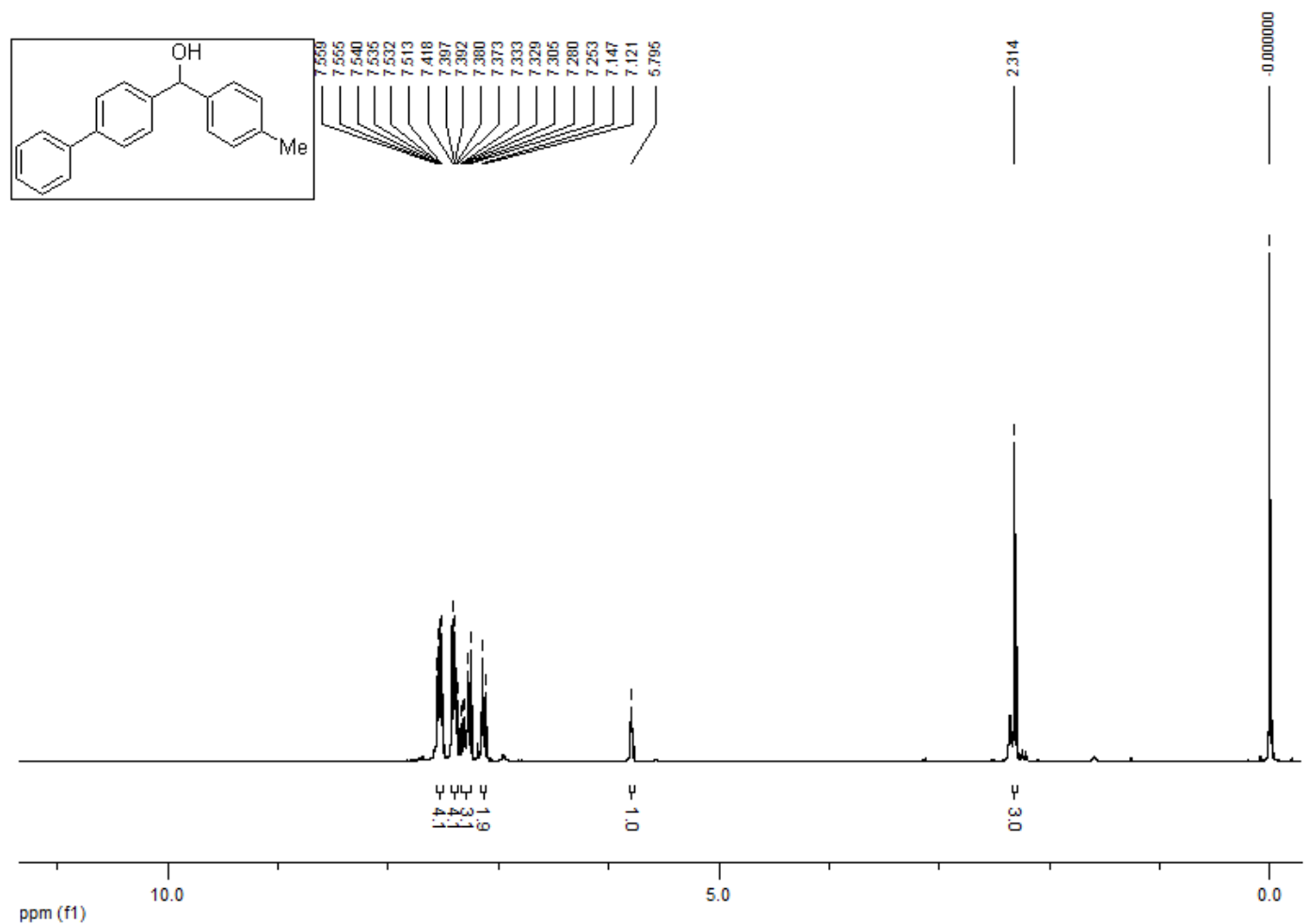

Figura 55 Espectro de $\mathrm{RMN}^{1} \mathrm{H}$ a $300 \mathrm{MHz}$ do composto $6 \mathbf{n}$.
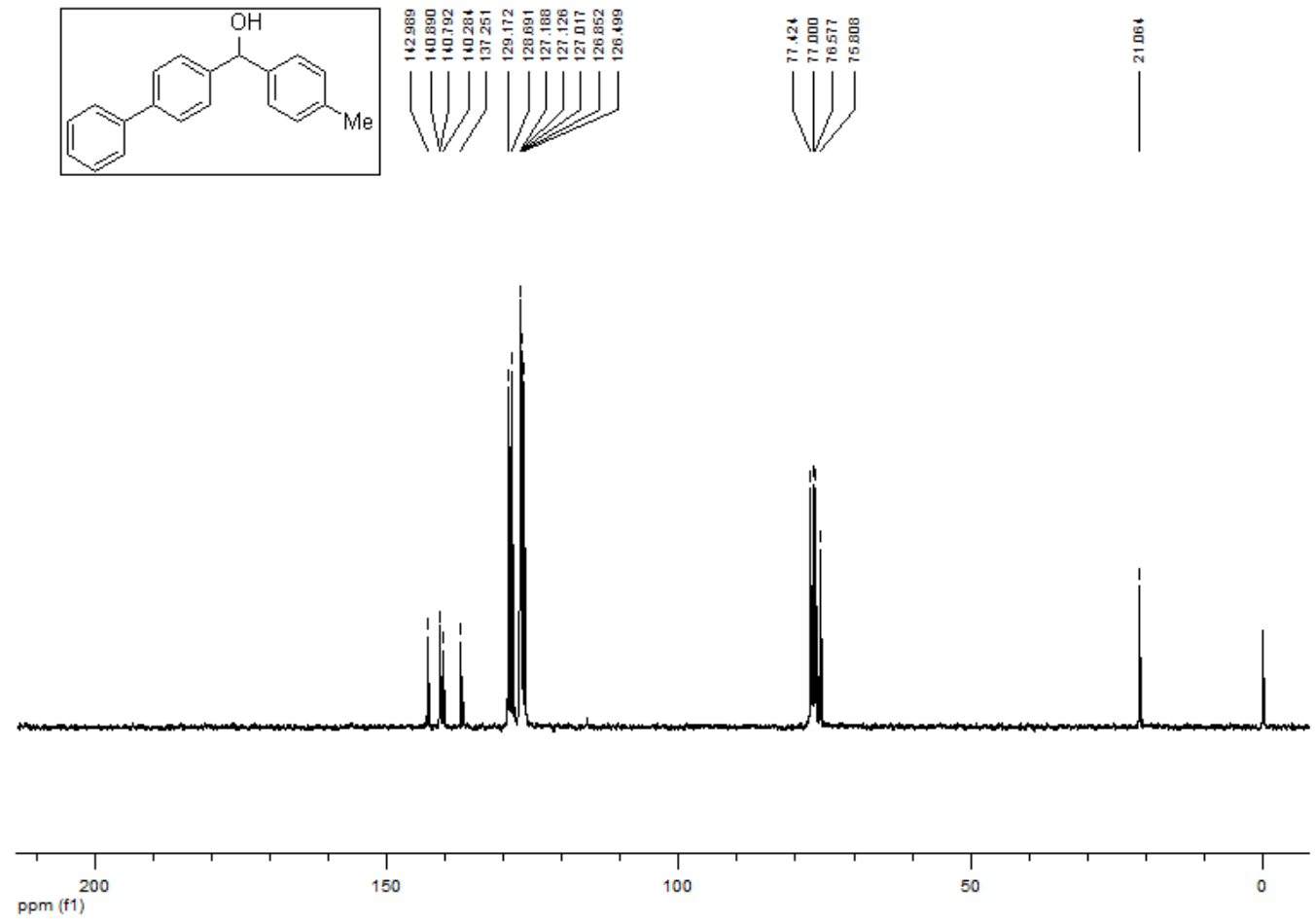

Figura 56. Espectro de $\mathrm{RMN}{ }^{13} \mathrm{C}$ a $75 \mathrm{MHz}$ do composto $6 \mathbf{n}$. 

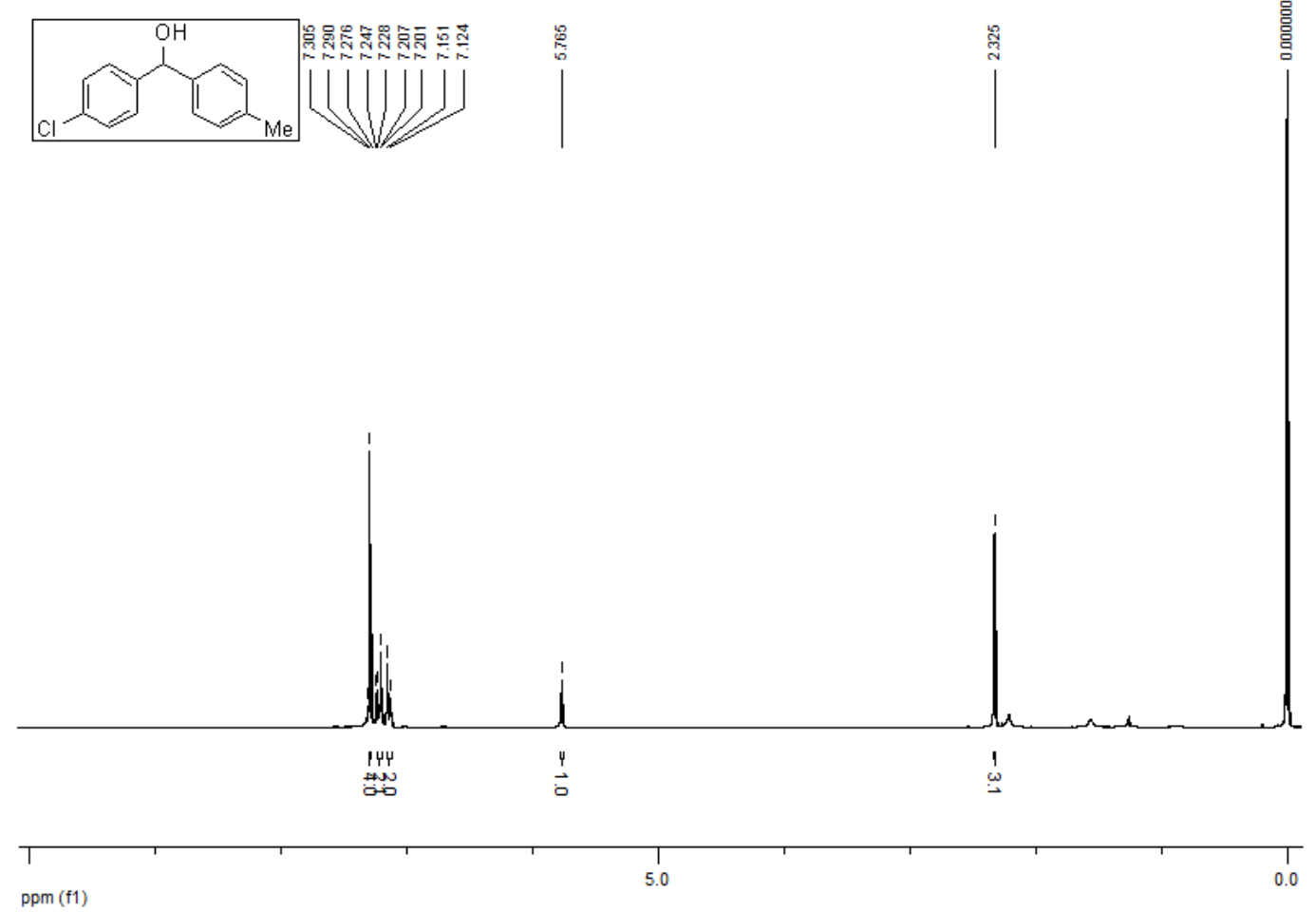

Figura 57. Espectro de RMN ${ }^{1} \mathrm{Ha} 300 \mathrm{MHz}$ do composto 6m.
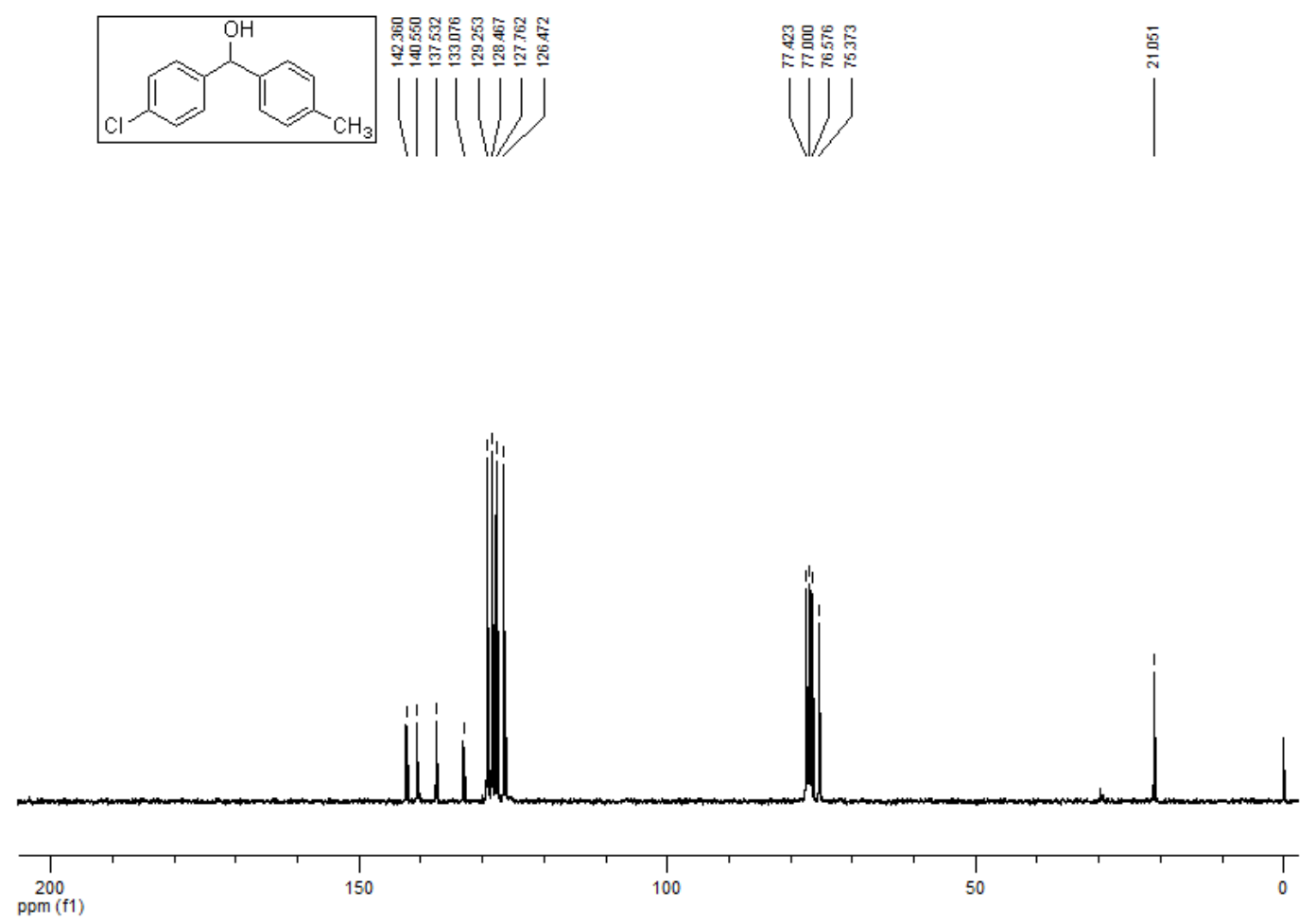

Figura 58. Espectro de $\mathrm{RMN}{ }^{13} \mathrm{C}$ a $75 \mathrm{MHz}$ do composto 6m. 


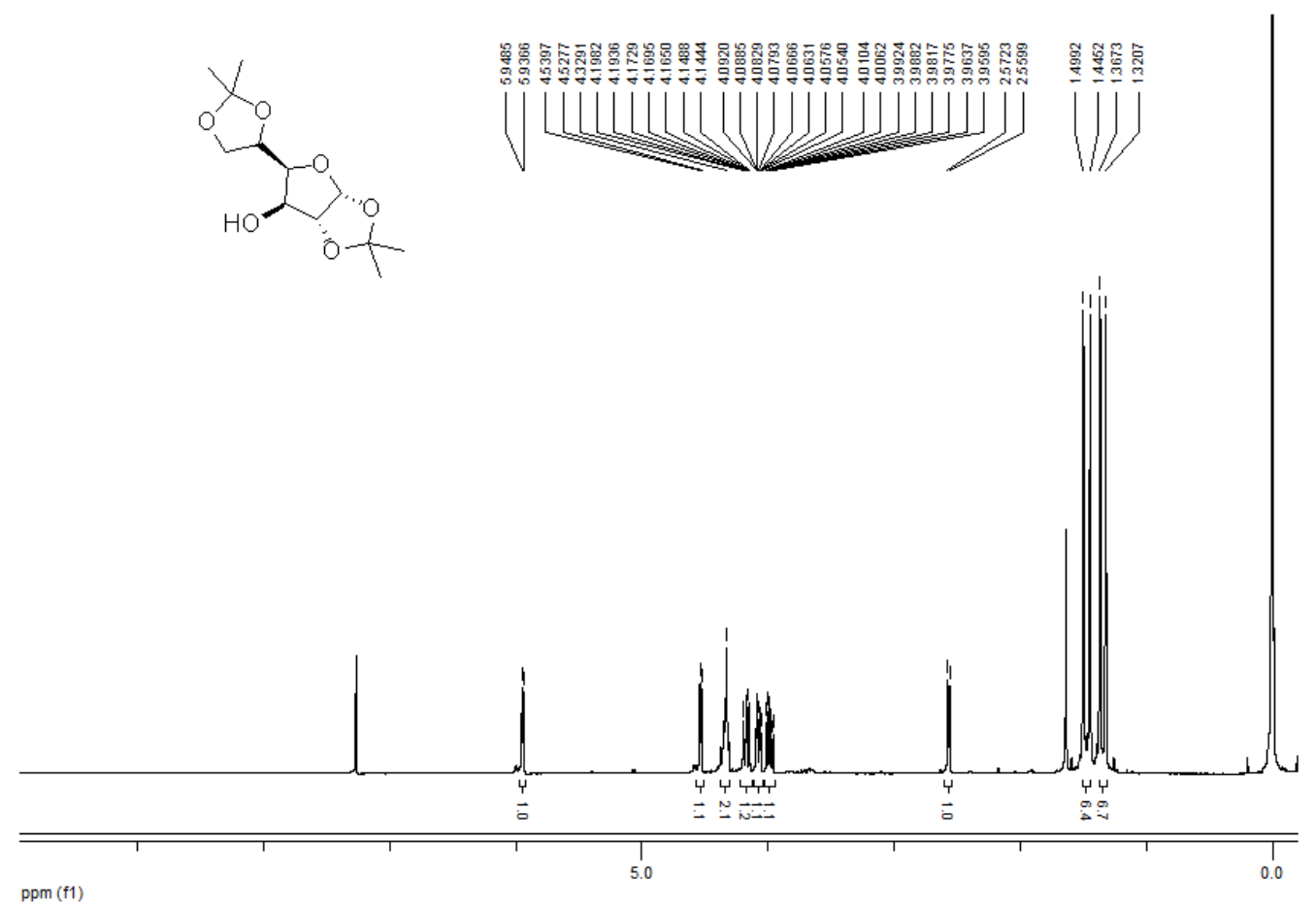

Figura 59. Espectro de $\mathrm{RMN}^{1} \mathrm{H}$ a $300 \mathrm{MHz}$ do composto 48.
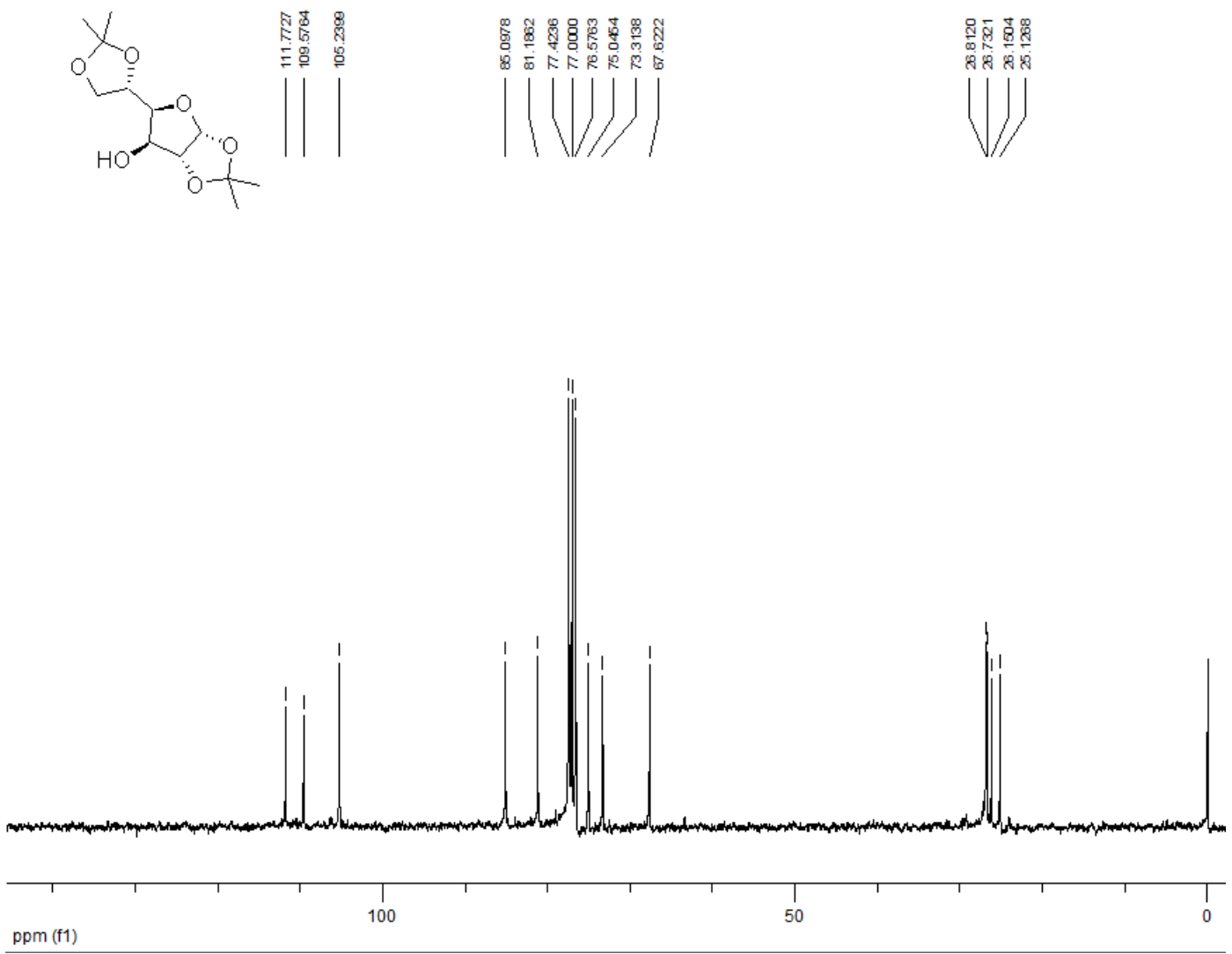

Figura 60. Espectro de $\mathrm{RMN}{ }^{13} \mathrm{C}$ a $75 \mathrm{MHz}$ do composto 48. 

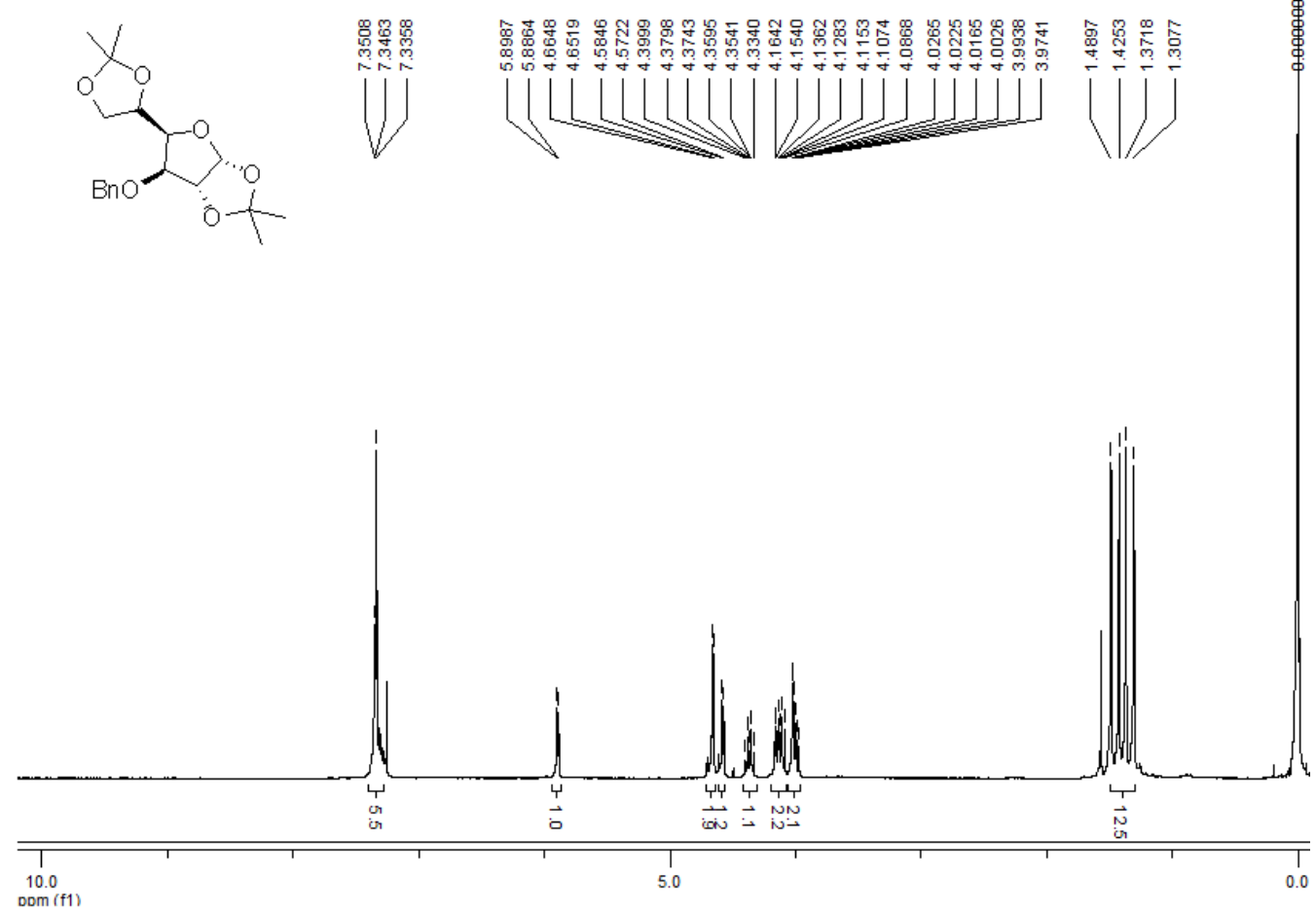

Figura 61. Espectro de $\mathrm{RMN}{ }^{1} \mathrm{H}$ a $300 \mathrm{MHz}$ do composto 49.
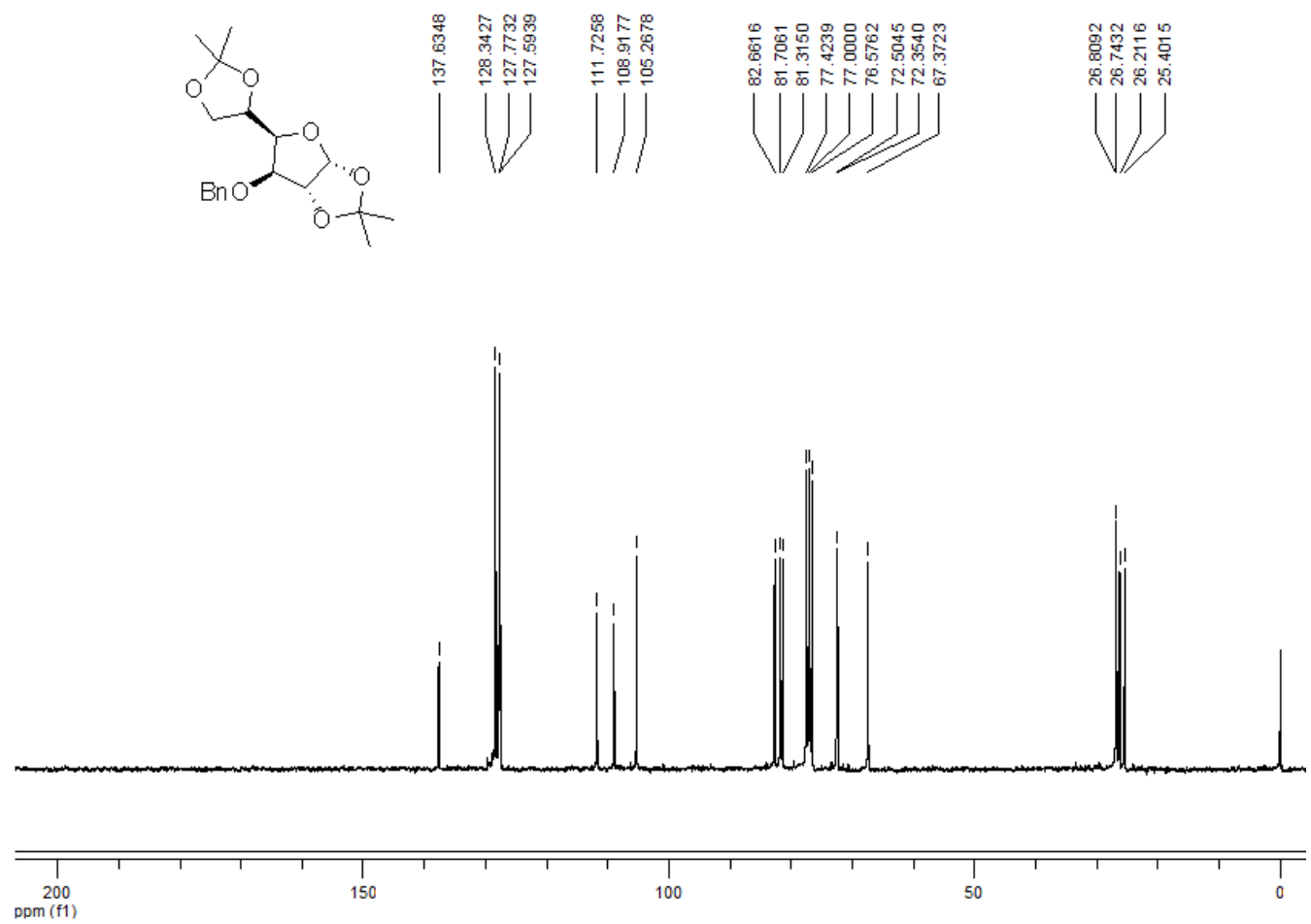

Figura 62. Espectro de RMN ${ }^{13} \mathrm{C}$ a $75 \mathrm{MHz}$ do composto49. 

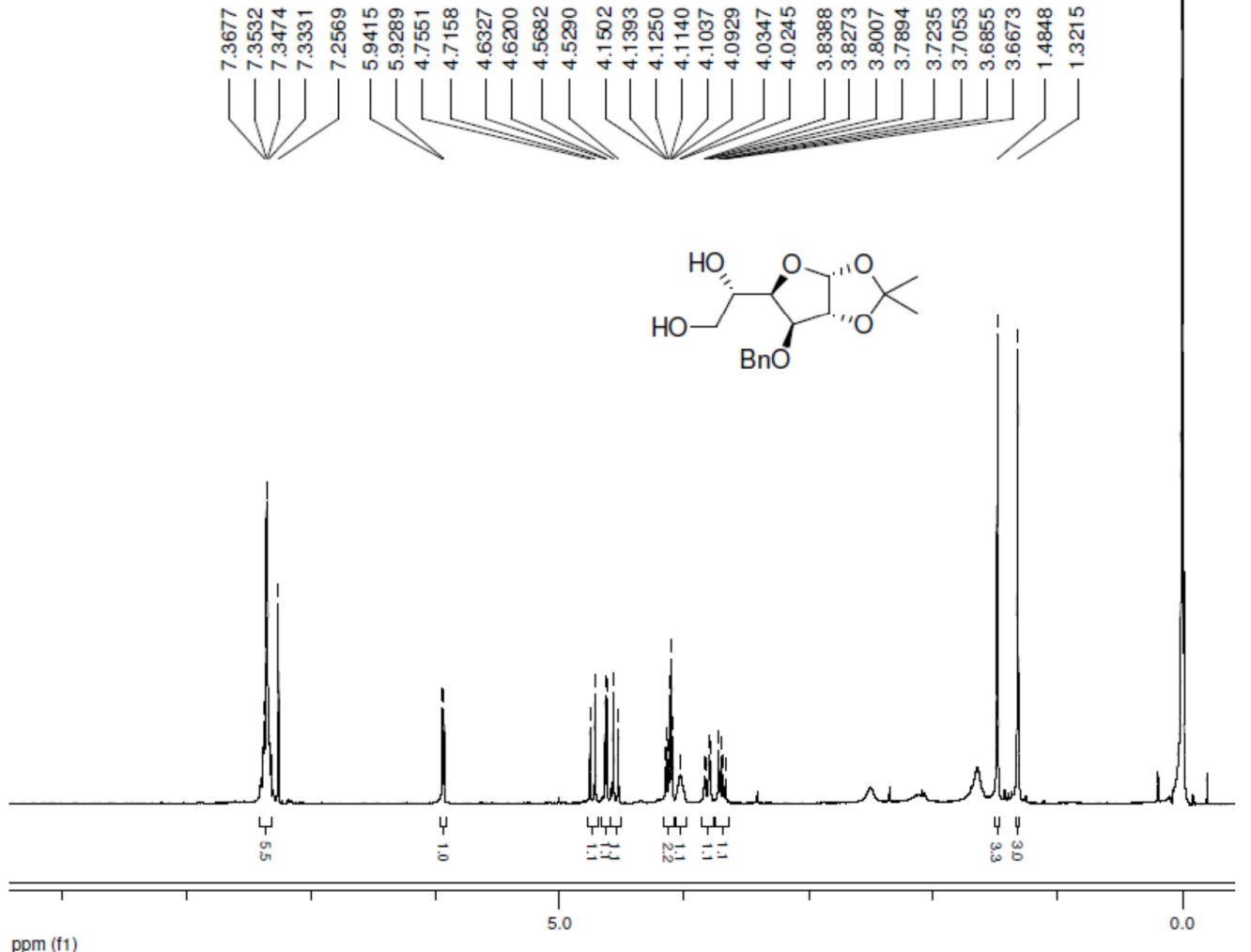

Figura 63. Espectro de $\mathrm{RMN}^{1} \mathrm{H}$ a $300 \mathrm{MHz}$ do composto 50.
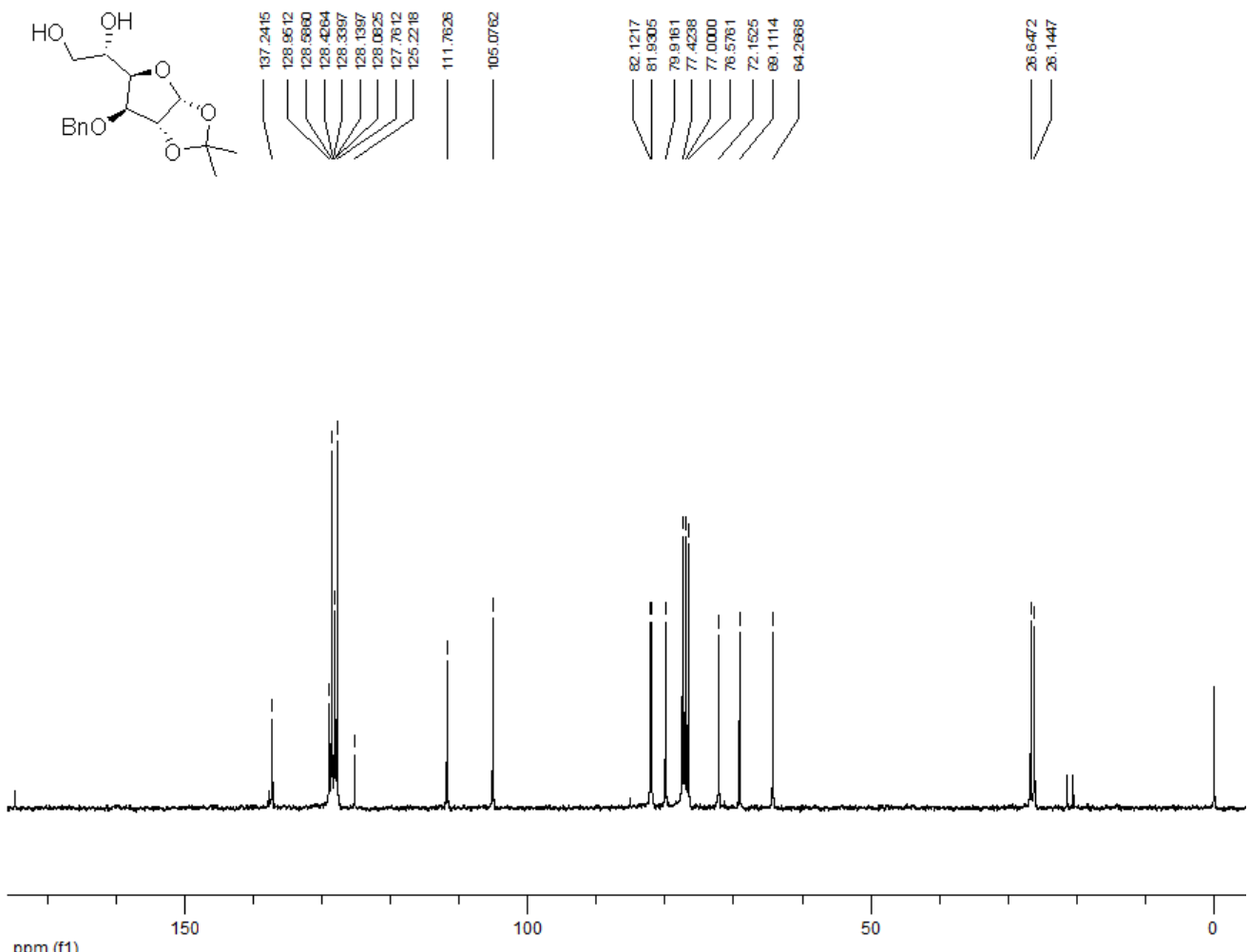

Figura 64. Espectro de $\mathrm{RMN}{ }^{13} \mathrm{C}$ a $75 \mathrm{MHz}$ do composto50. 

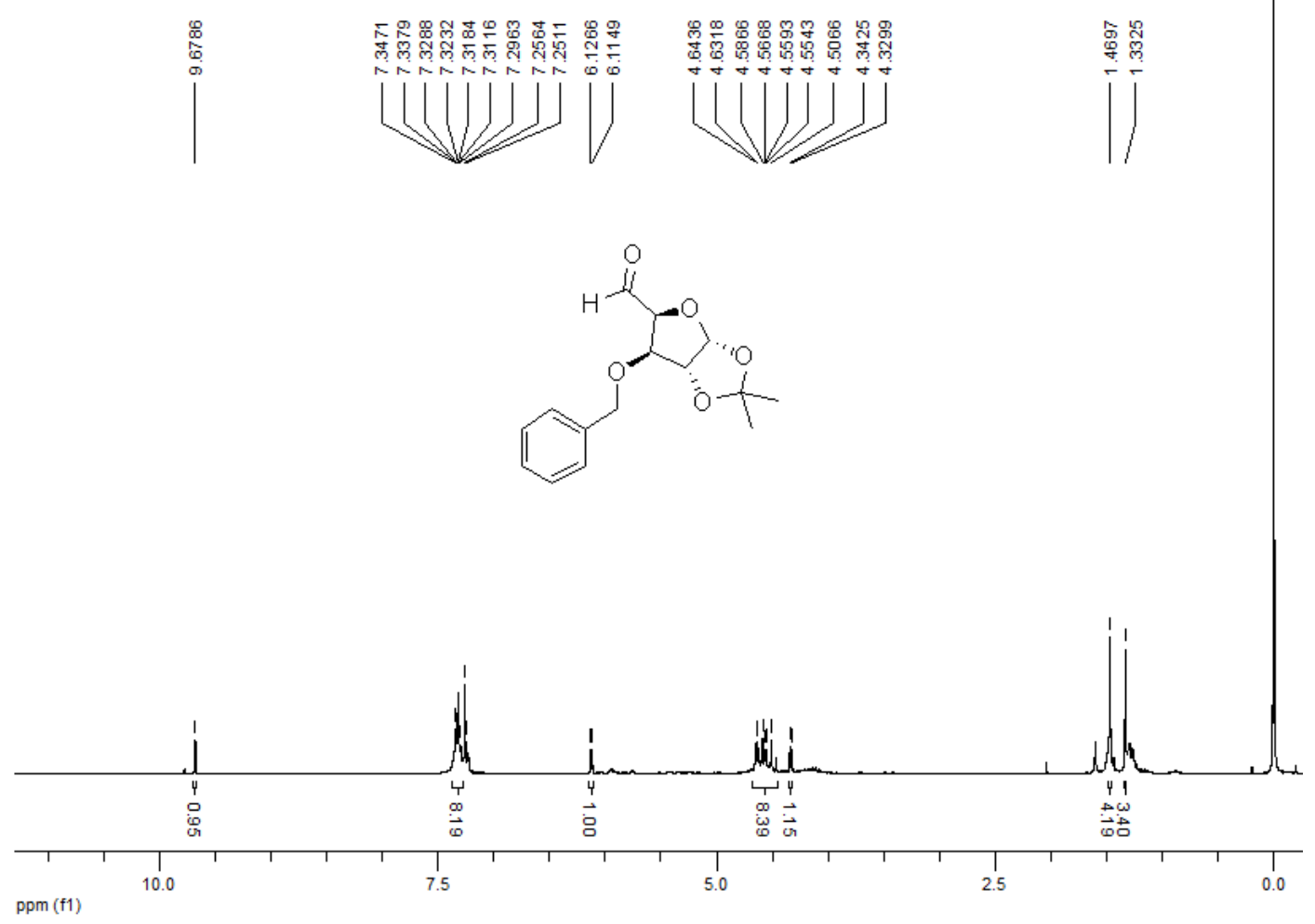

Figura 65. Espectro de RMN ${ }^{1} \mathrm{H}$ a $300 \mathrm{MHz}$ do composto30.
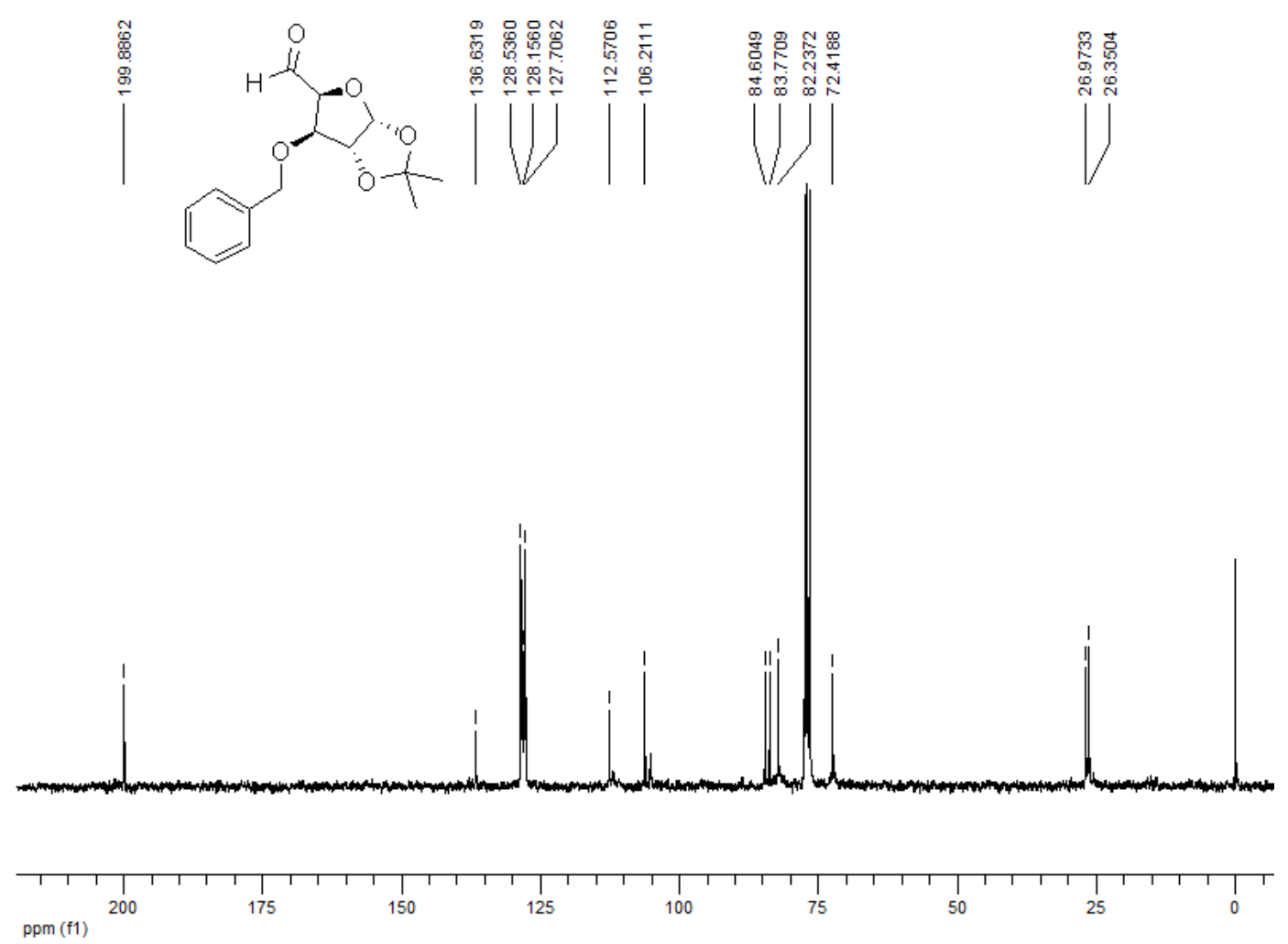

Figura 66. Espectrode $\mathrm{RMN}^{13} \mathrm{C}$ a $75 \mathrm{MHz}$ do composto 30. 


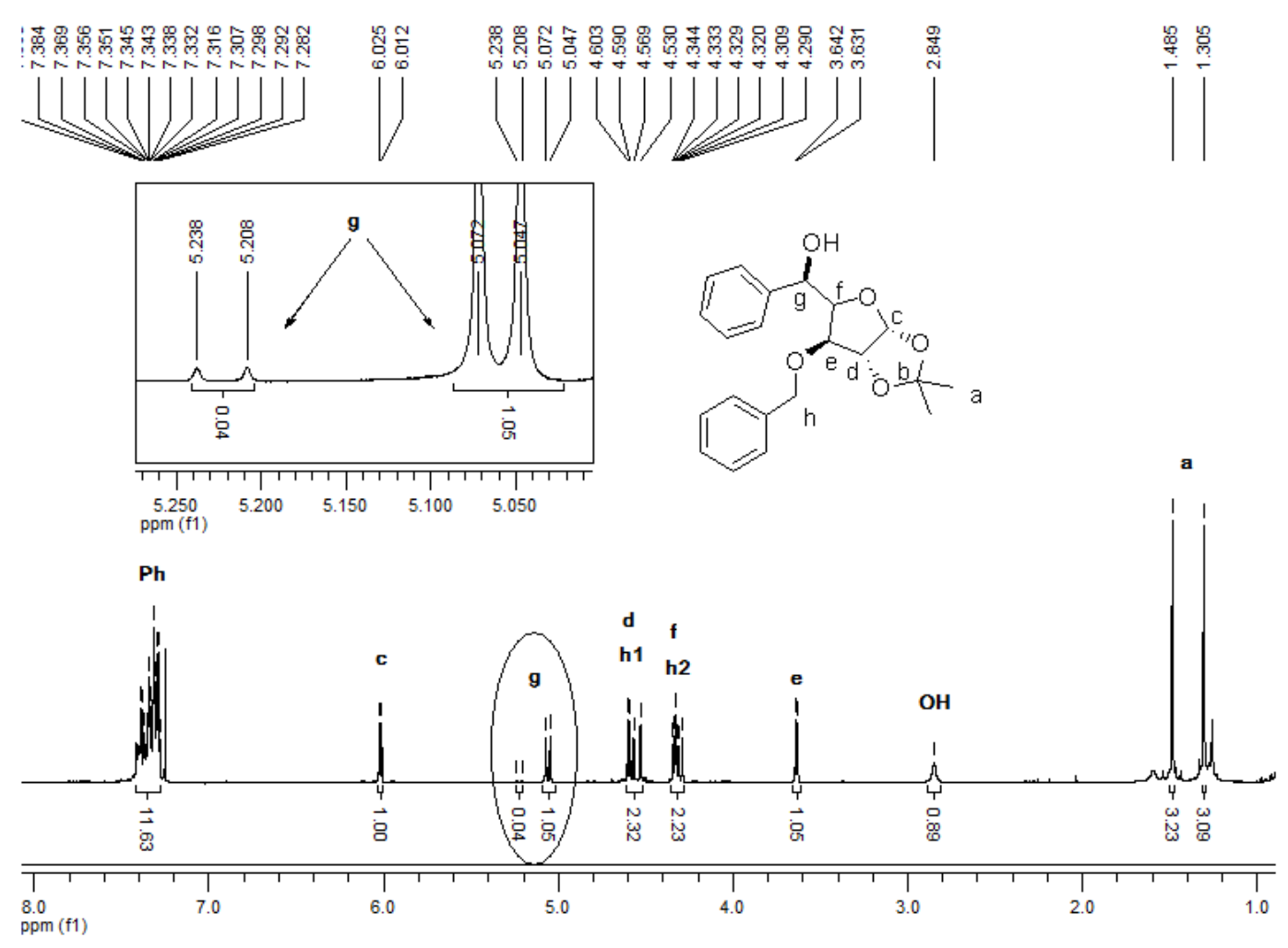

Figura 67. Espectro de $\mathrm{RMN}{ }^{1} \mathrm{H}$ a $300 \mathrm{MHz}$ do composto31a.
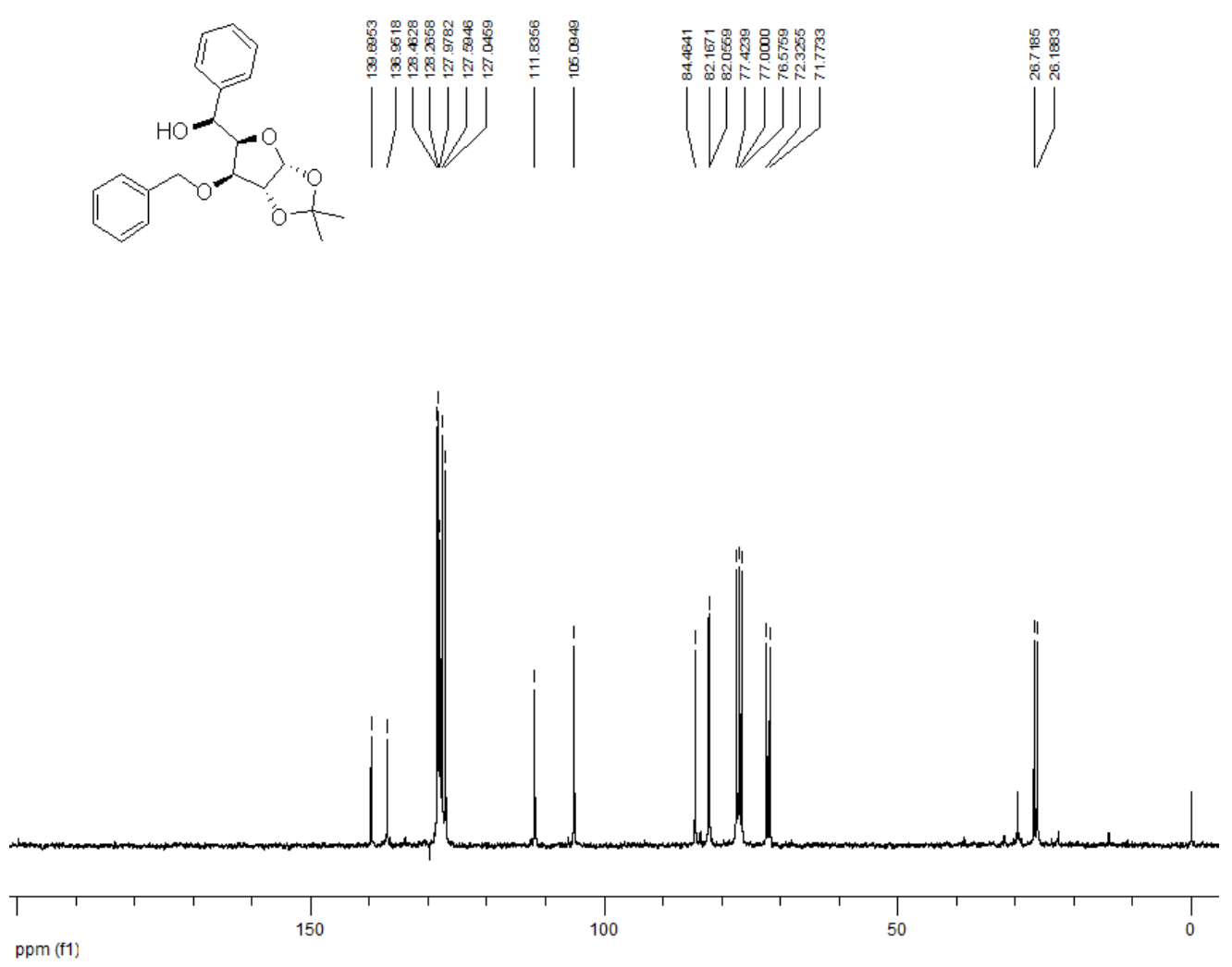

Figura 68. Espectro de $\mathrm{RMN}{ }^{13} \mathrm{C}$ a $75 \mathrm{MHz}$ do composto31a. 


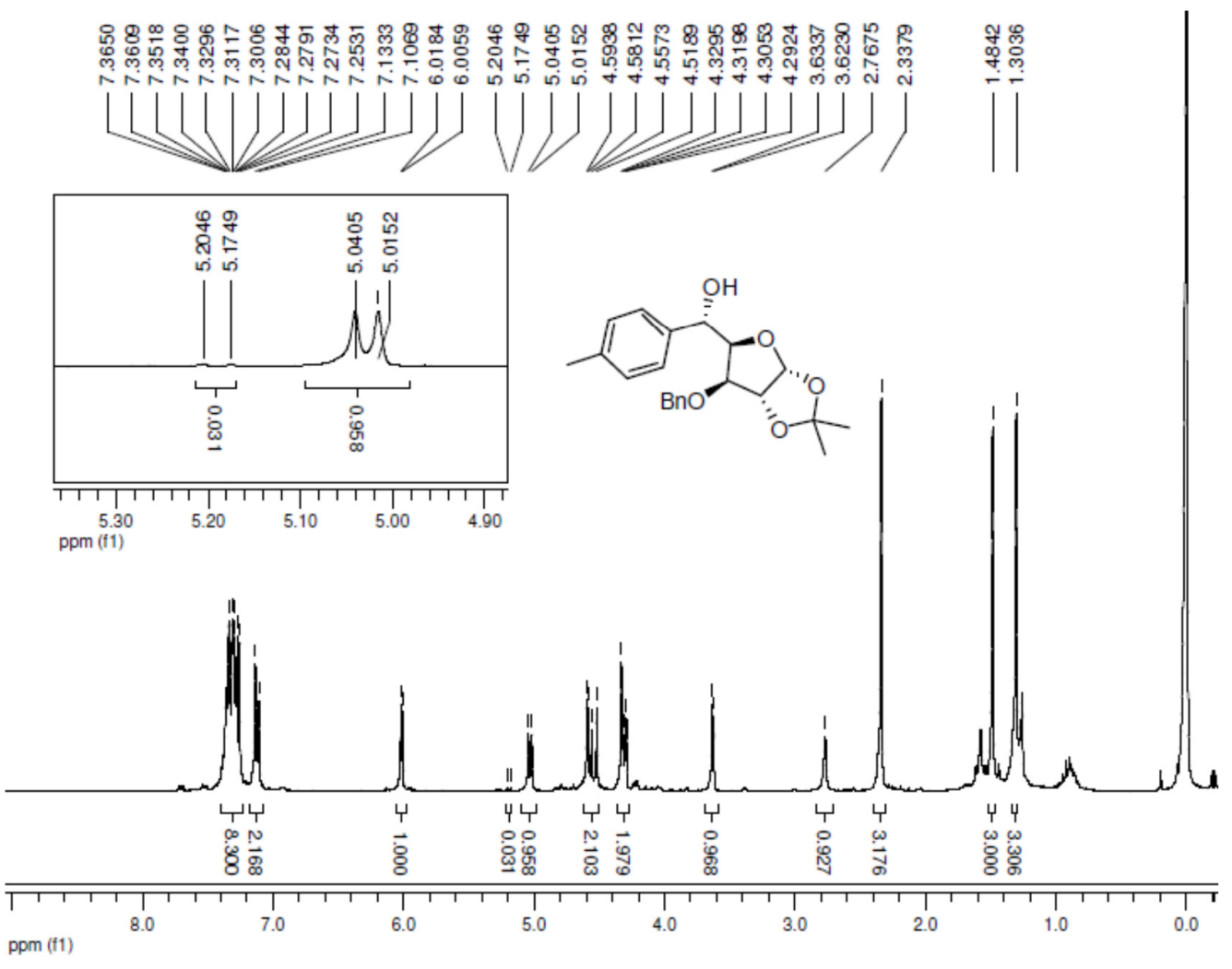

Figura 69. Espectro de $\mathrm{RMN}^{1} \mathrm{H}$ a $300 \mathrm{MHz}$ do composto $\mathbf{3 1 b}$.
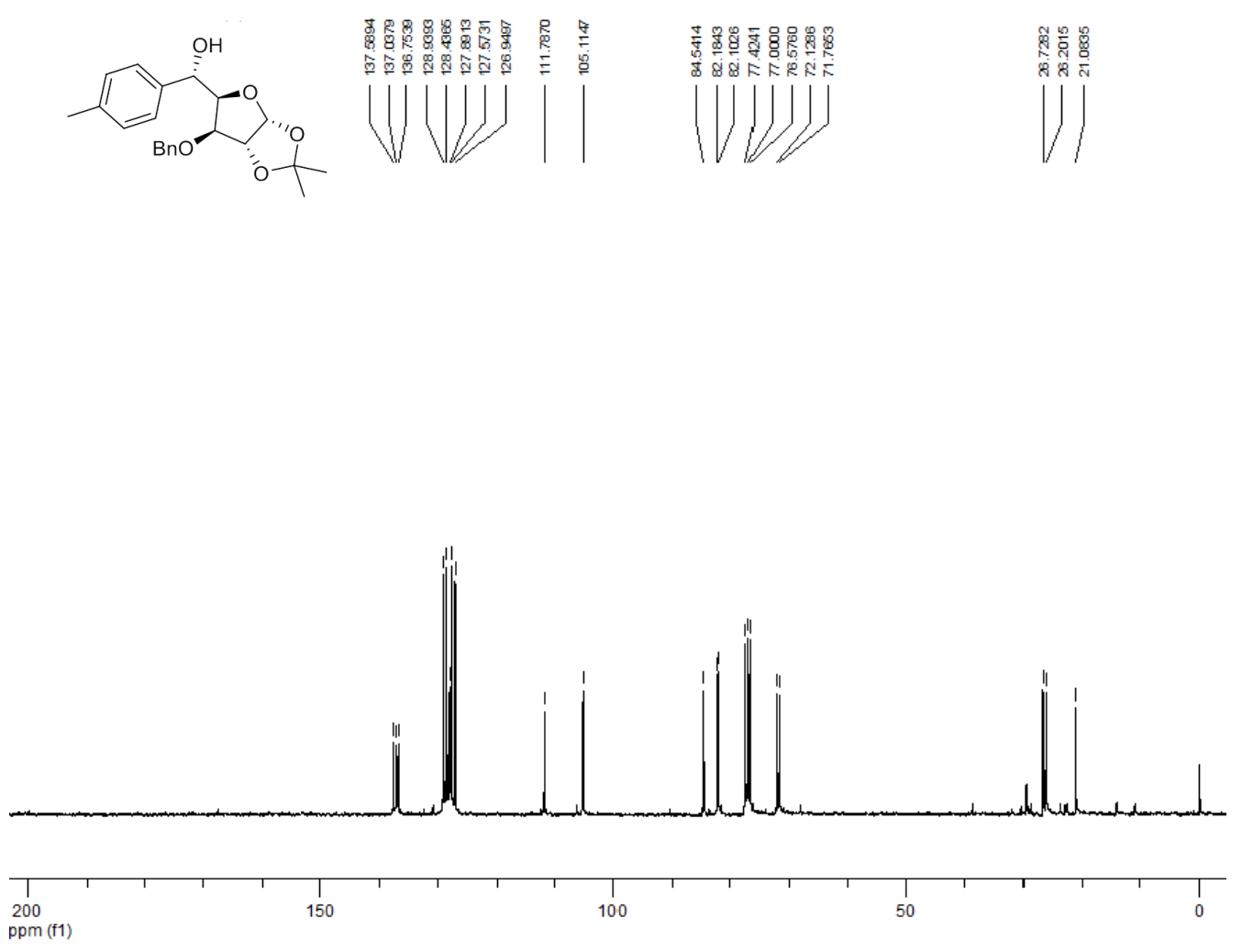

Figura 70. Espectro de $\mathrm{RMN}{ }^{13} \mathrm{C}$ a $75 \mathrm{MHz}$ do composto $\mathbf{3 1 b}$. 


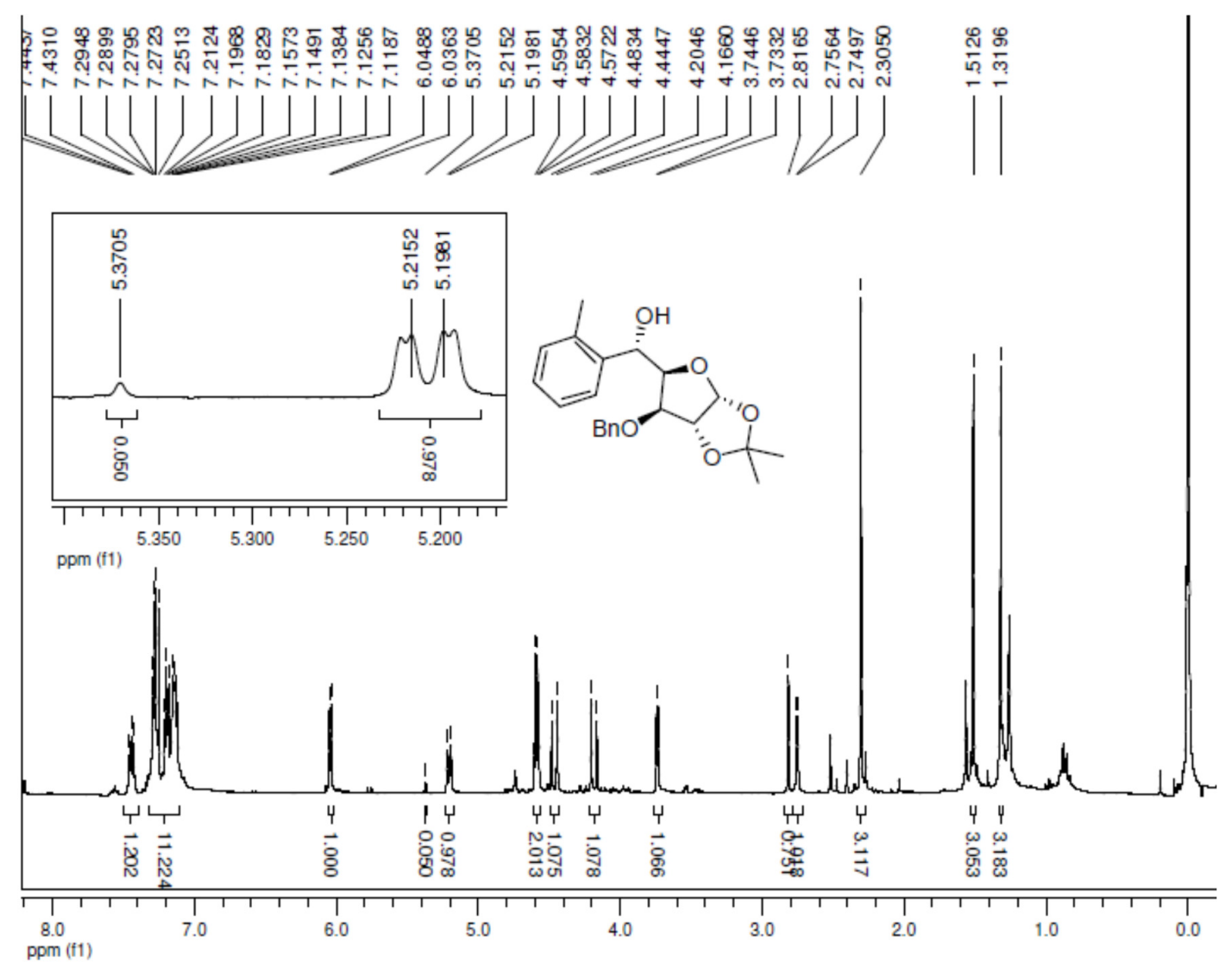

Figura 71. Espectro de $\mathrm{RMN}^{1} \mathrm{H}$ a $300 \mathrm{MHz}$ do composto 31c.
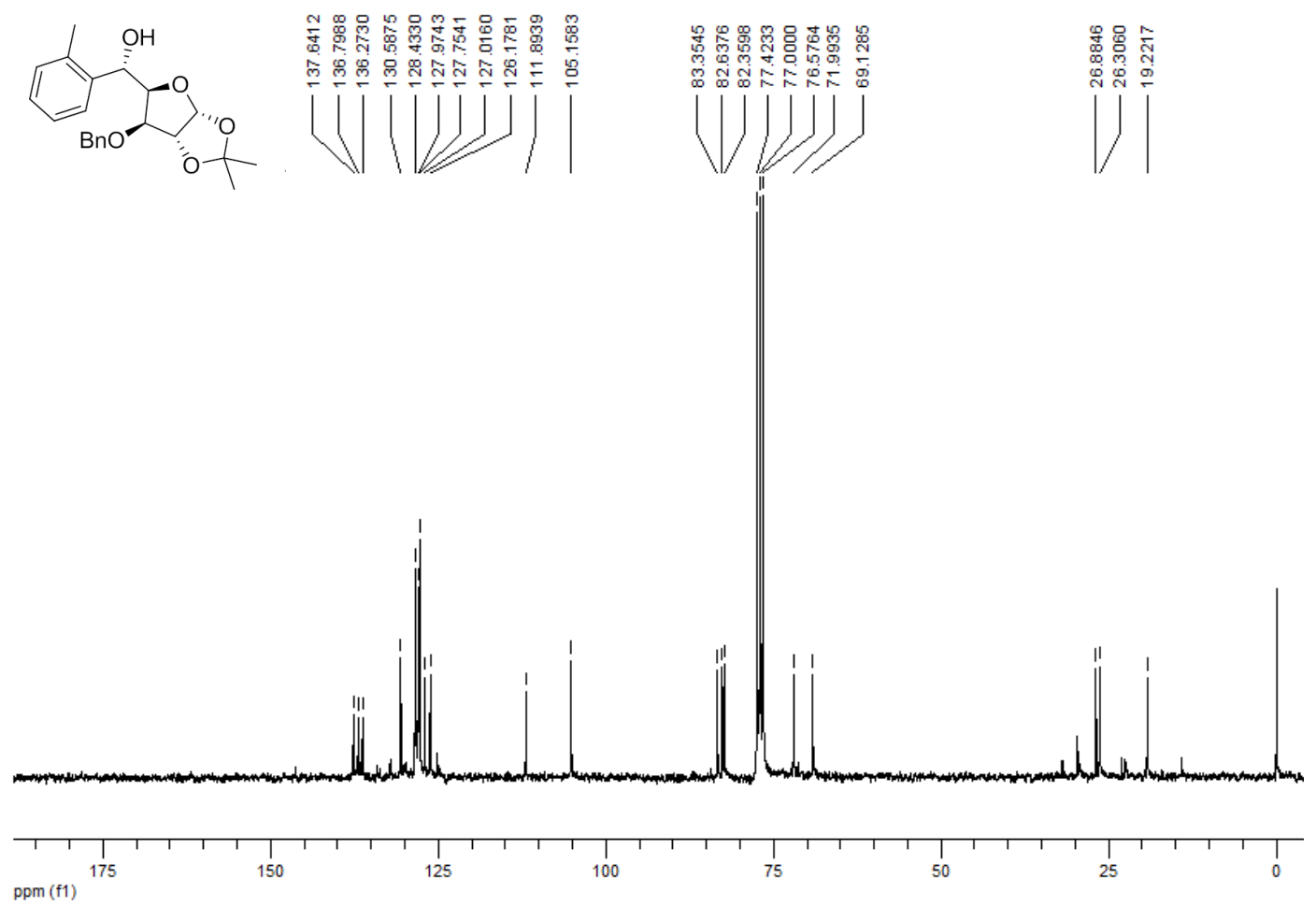

Figura 72. Espectro de $\mathrm{RMN}{ }^{13} \mathrm{C}$ a $75 \mathrm{MHz}$ do composto $31 \mathrm{c}$. 


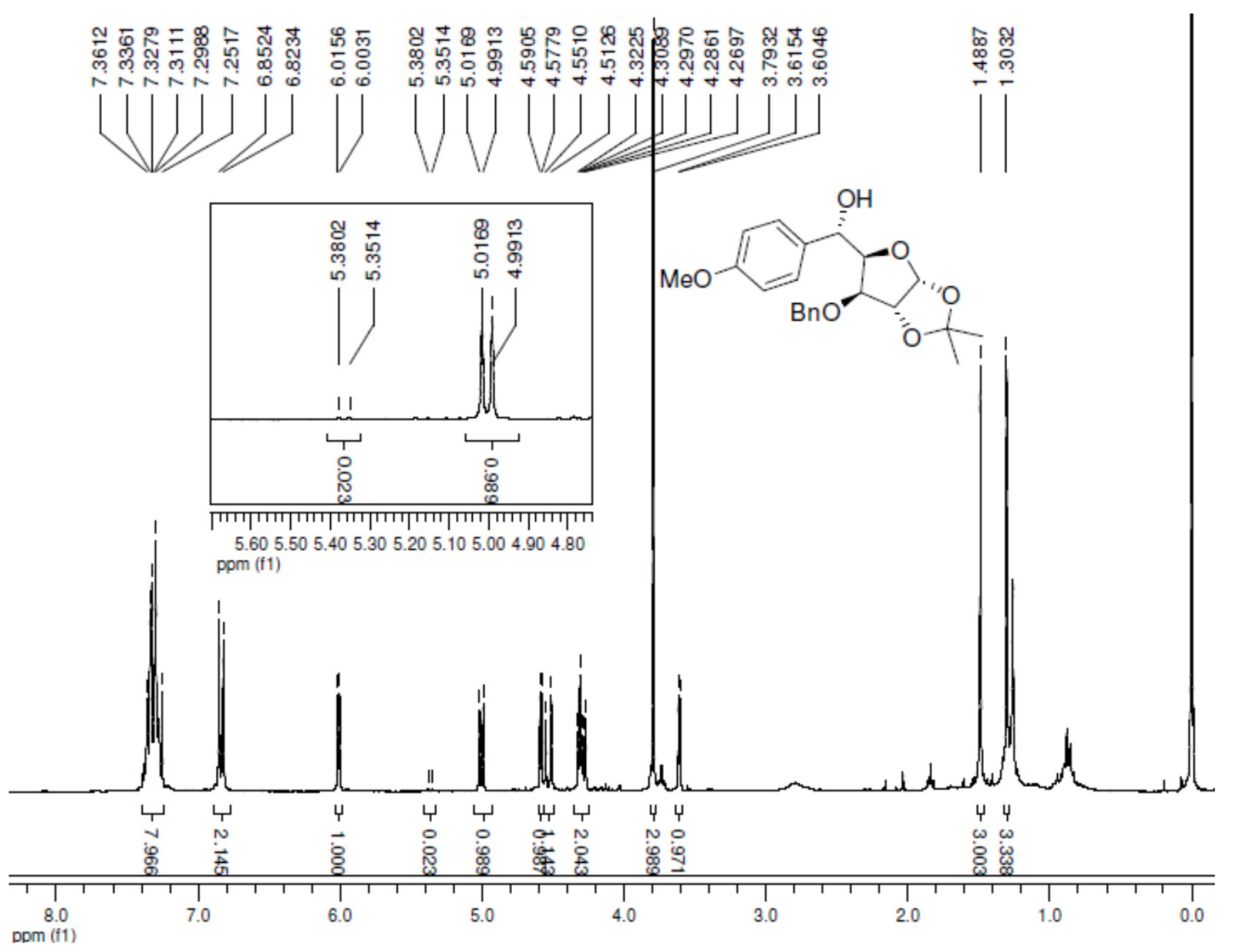

Figura 73. Espectro de $\mathrm{RMN}^{1} \mathrm{H}$ a $300 \mathrm{MHz}$ do composto 31d.
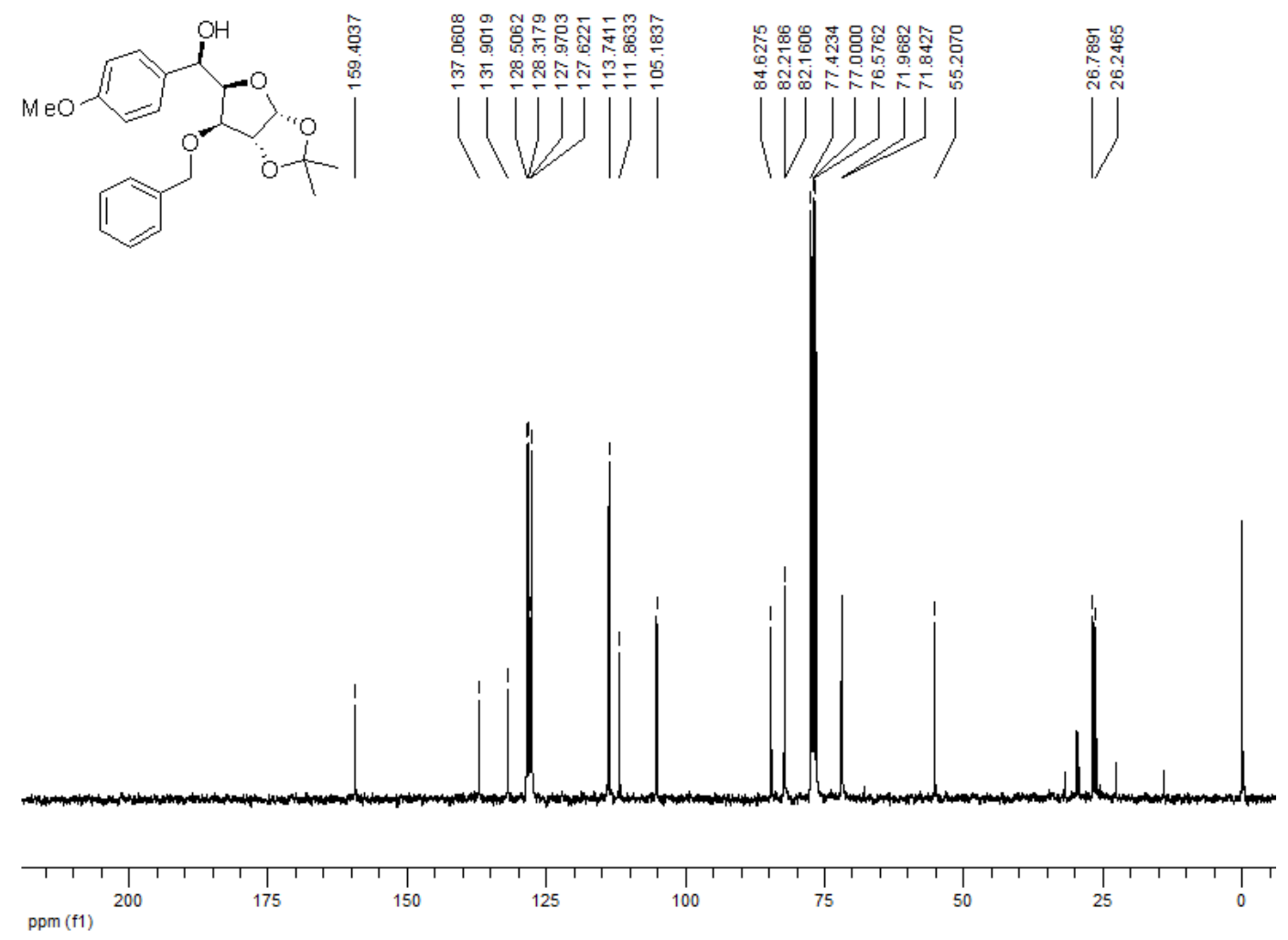

Figura 74. Espectro de $\mathrm{RMN}{ }^{13} \mathrm{C}$ a $75 \mathrm{MHz}$ do composto $31 \mathrm{~d}$. 


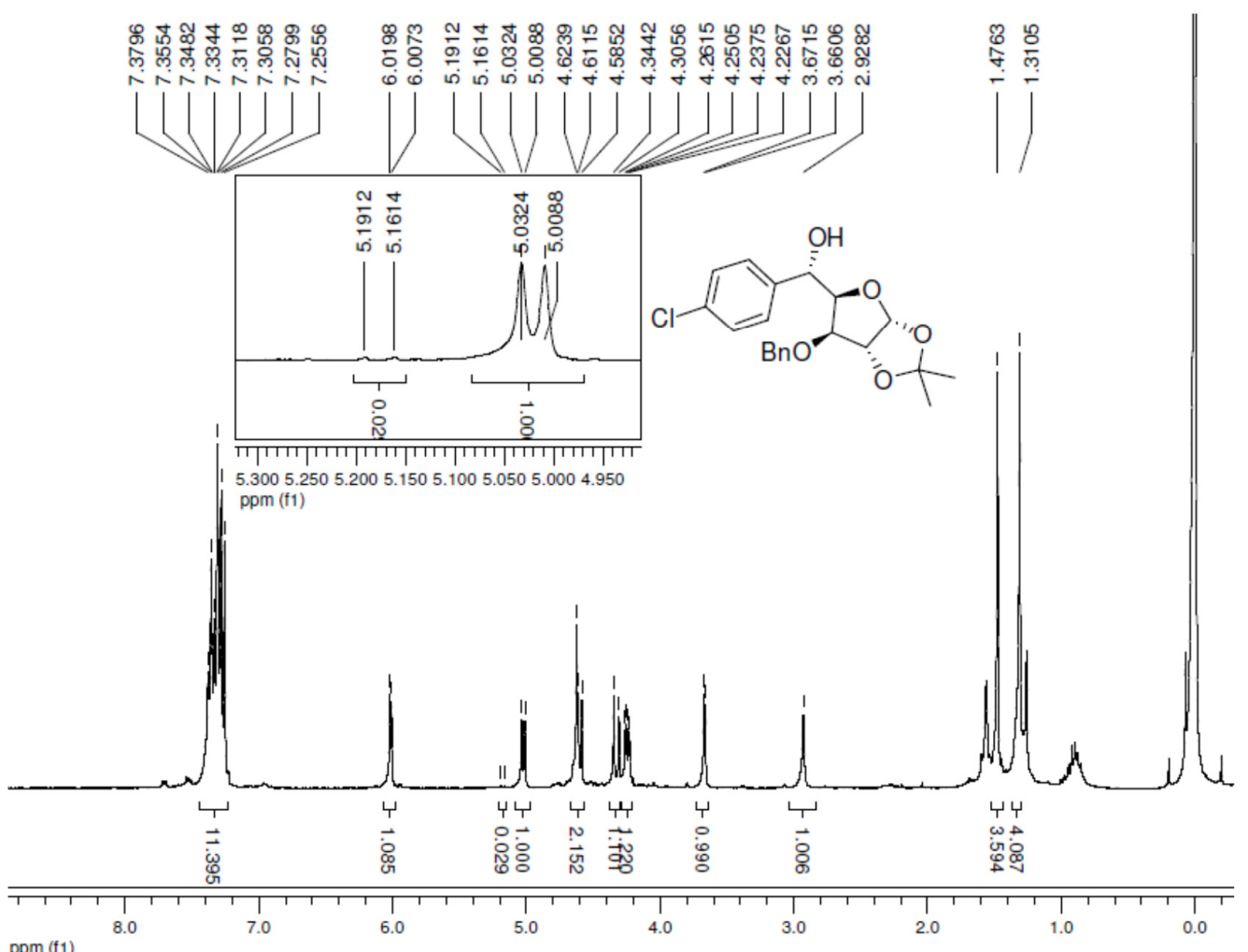

Figura 75. Espectro de RMN ${ }^{1} \mathrm{H}$ a $300 \mathrm{MHz}$ do composto $31 \mathrm{e}$.

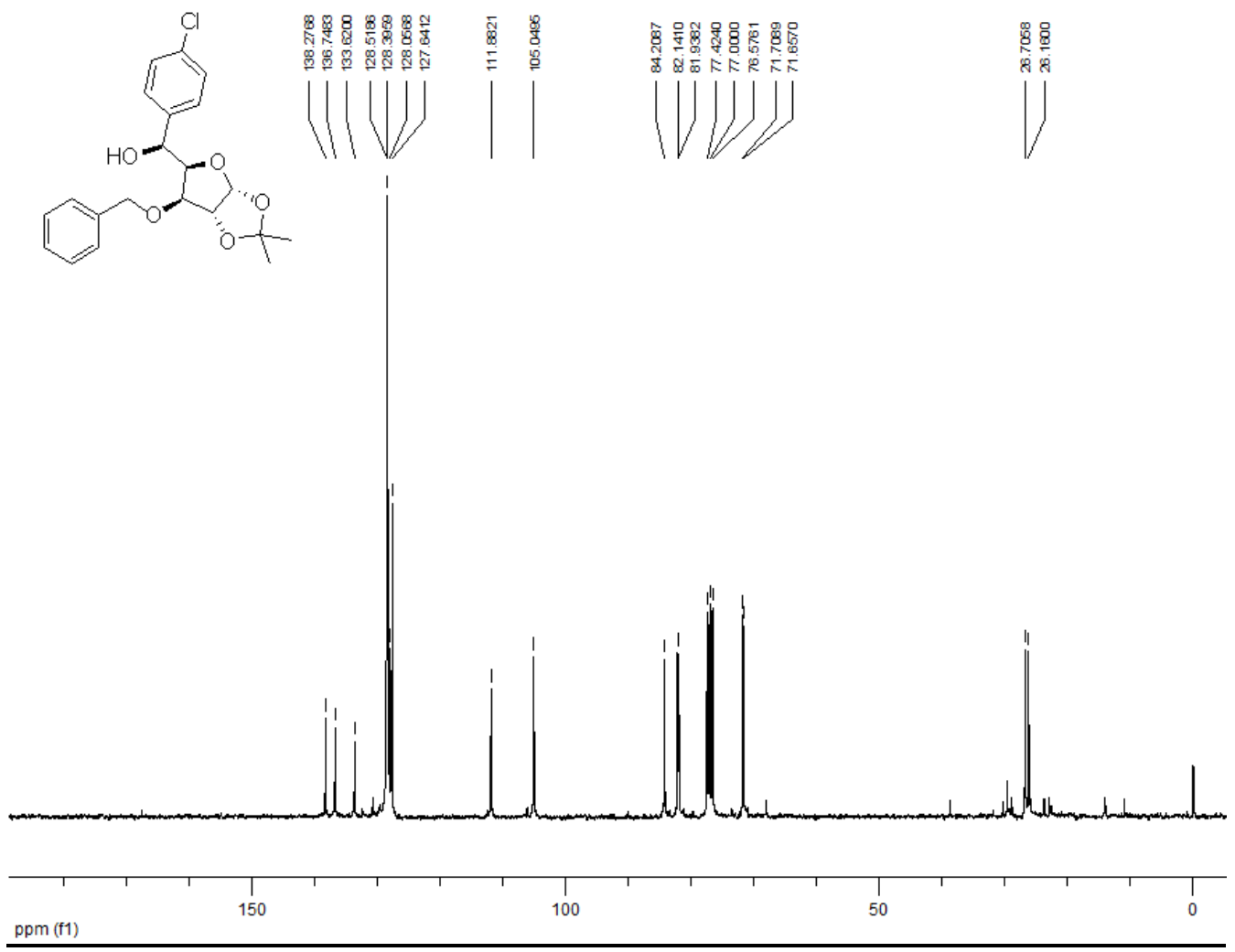

Figura 76. Espectro de $\mathrm{RMN}^{13} \mathrm{C}$ a $75 \mathrm{MHz}$ do composto 31e. 

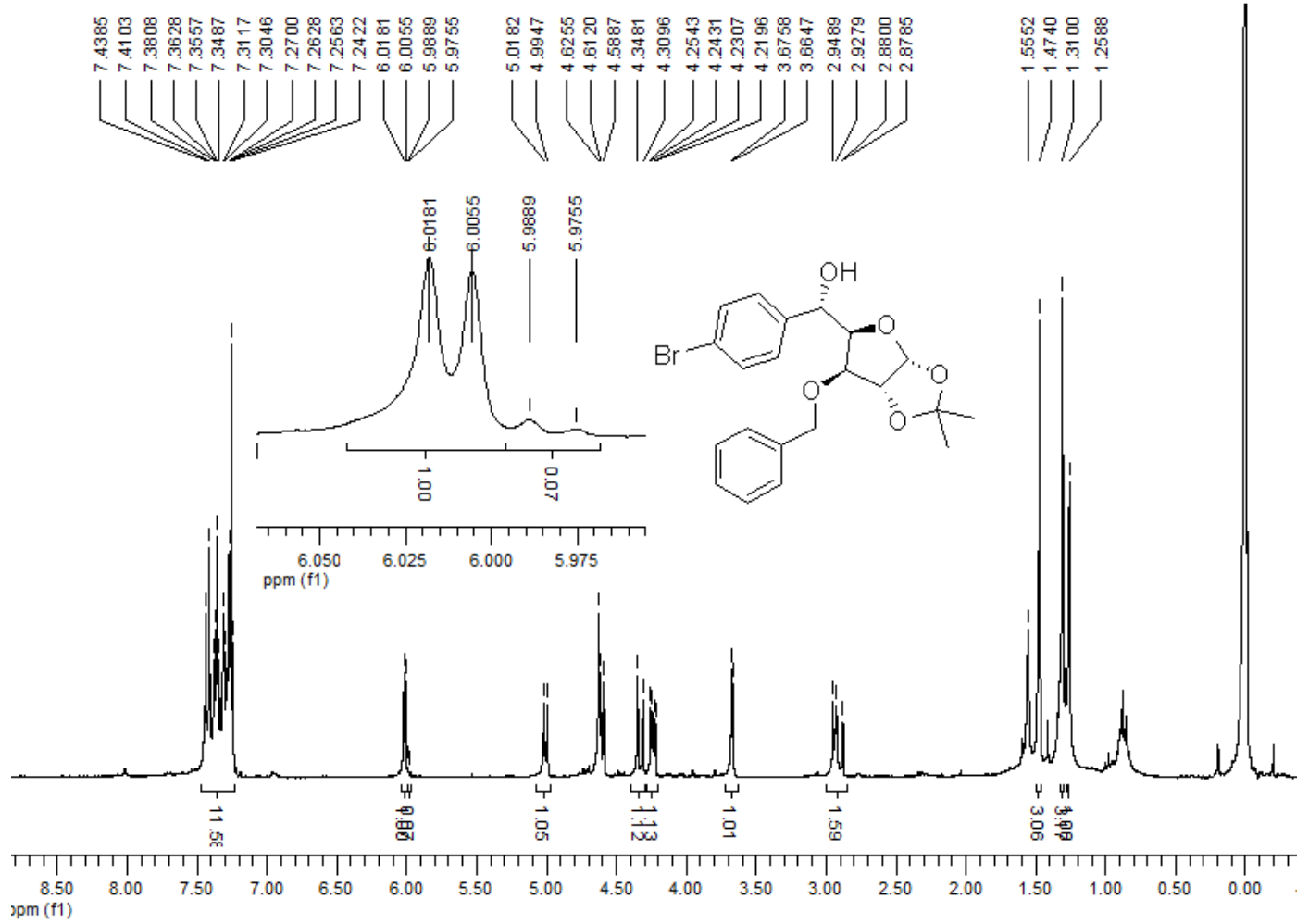

Figura 77. Espectro de $\mathrm{RMN}^{1} \mathrm{H}$ a $300 \mathrm{MHz}$ do composto $\mathbf{3 1 f}$.
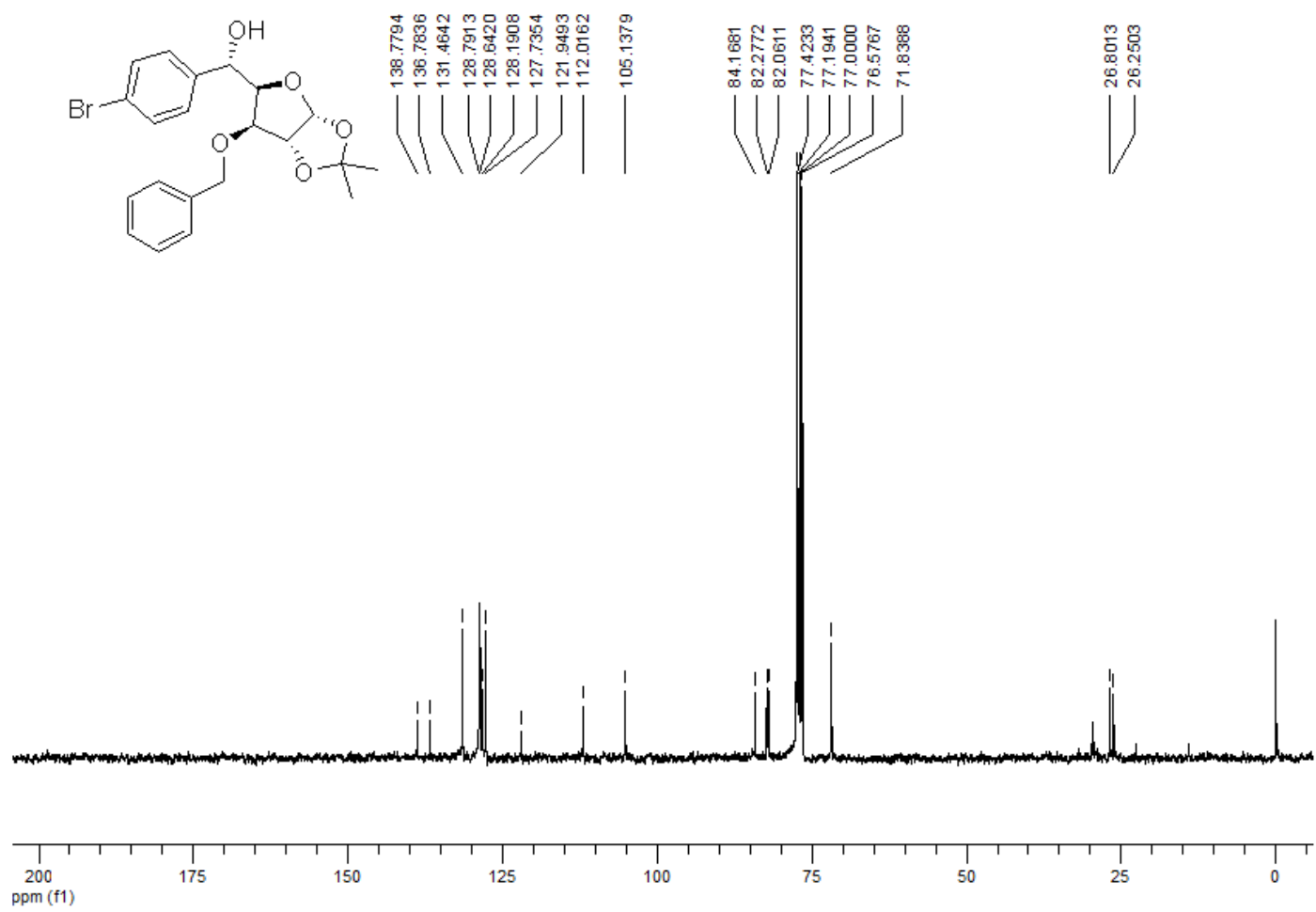

Figura 78. Espectro de RMN ${ }^{1} \mathrm{H}$ a $75 \mathrm{MHz}$ do composto $31 \mathrm{f}$. 


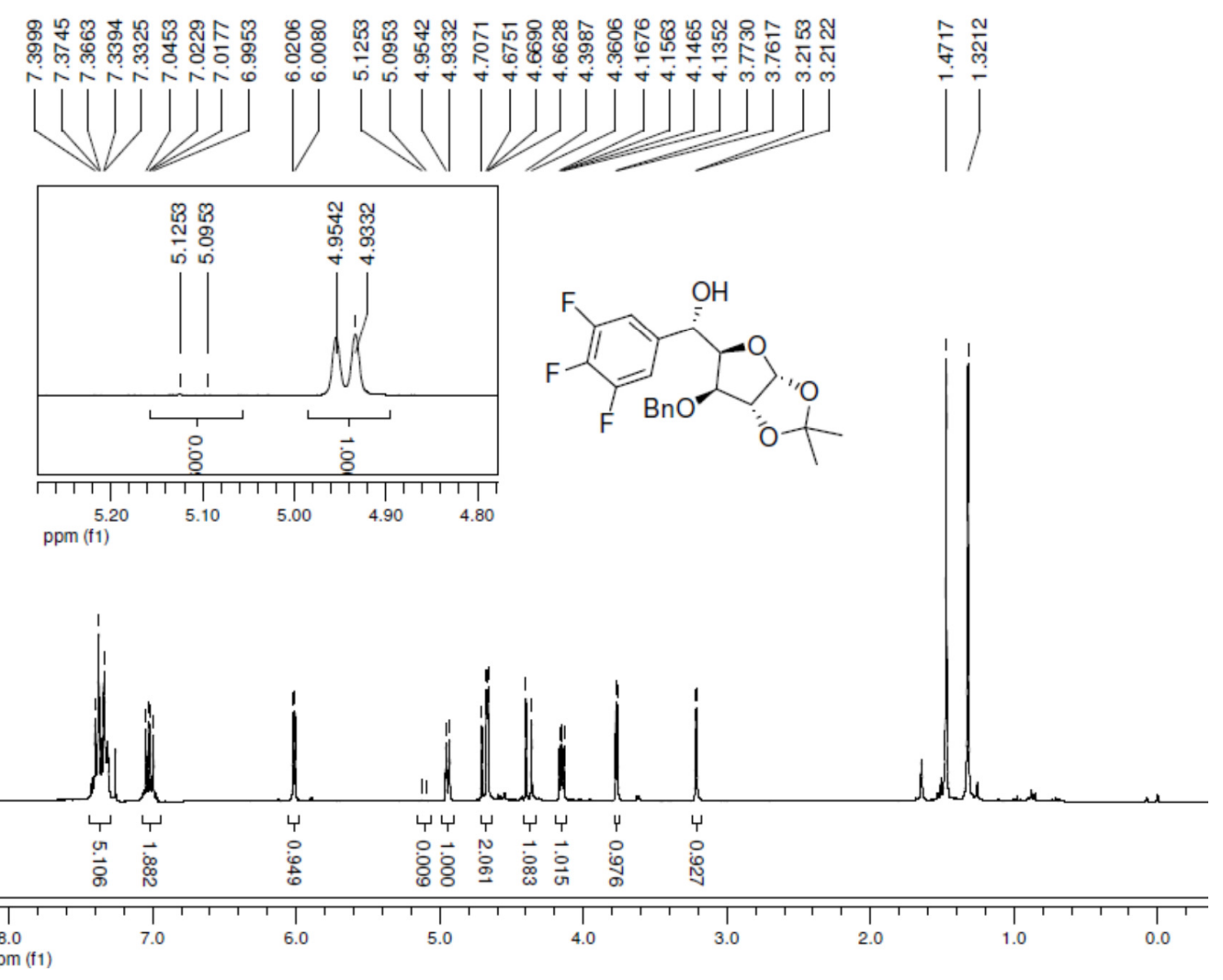

Figura 79. Espectro de RMN ${ }^{1} \mathrm{H}$ a $300 \mathrm{MHz}$ do composto 31g.

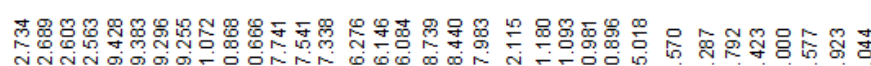

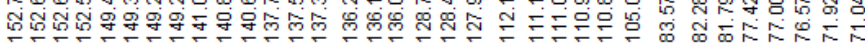
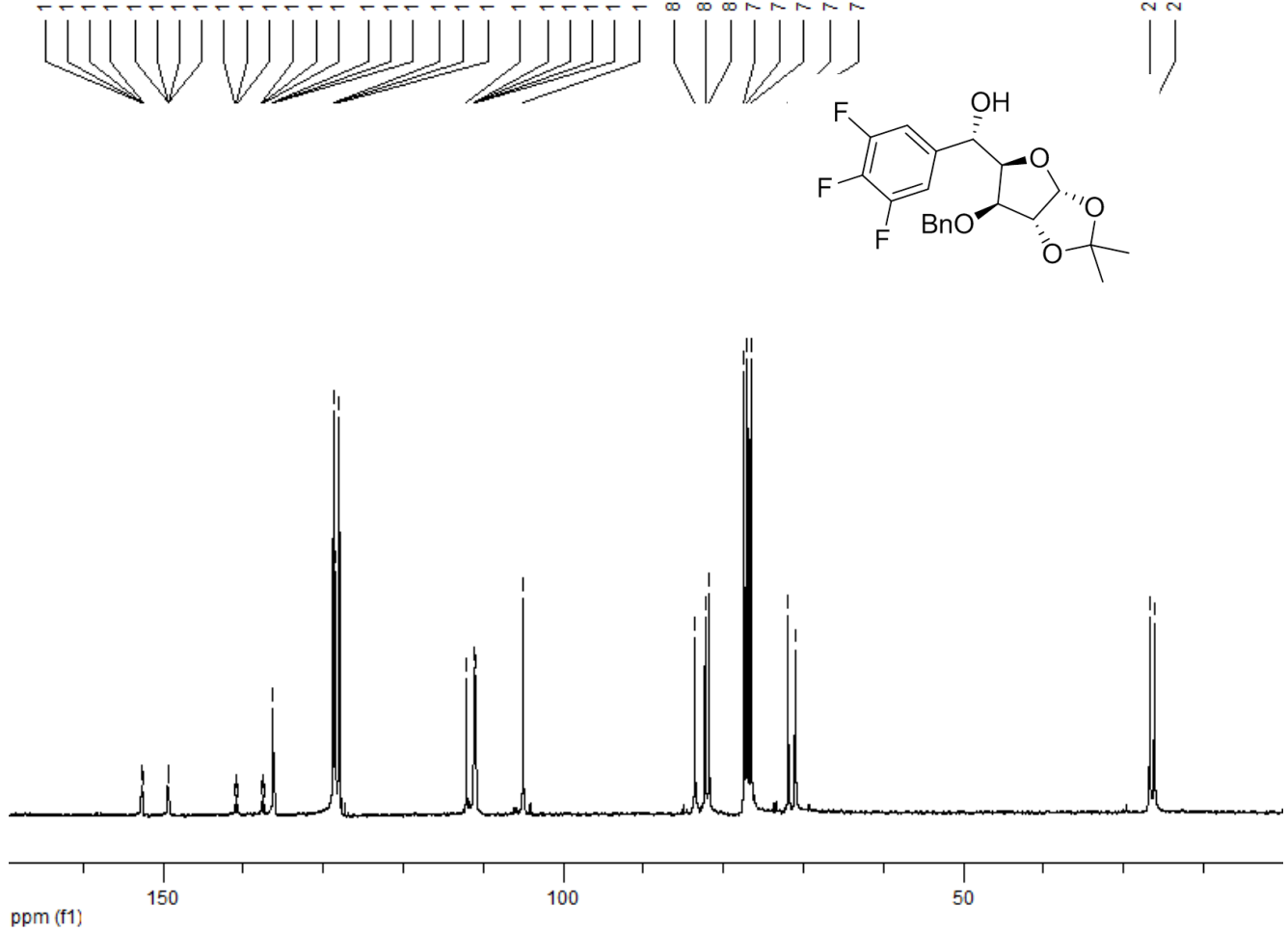

Figura 80. Espectro de $\mathrm{RMN}^{13} \mathrm{C}$ a $75 \mathrm{MHz}$ do composto 31g. 


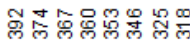

(1) 11$)$

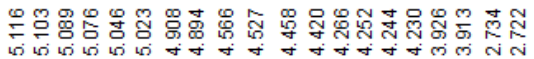
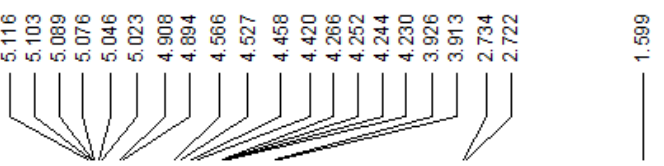

응

$\mathrm{OH}$
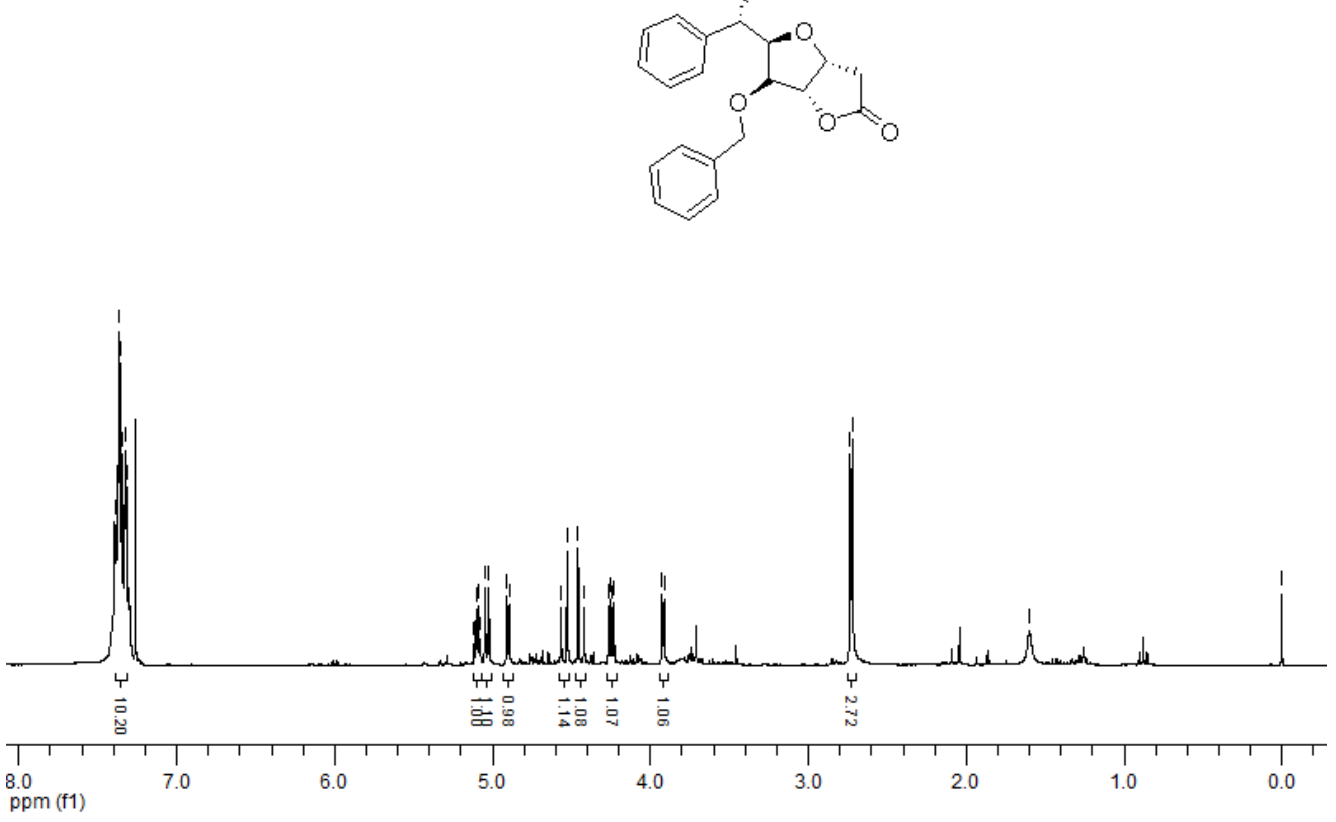

Figura 81. Espectro de RMN ${ }^{1} \mathrm{Ha} 300 \mathrm{MHz}$ do composto36a.

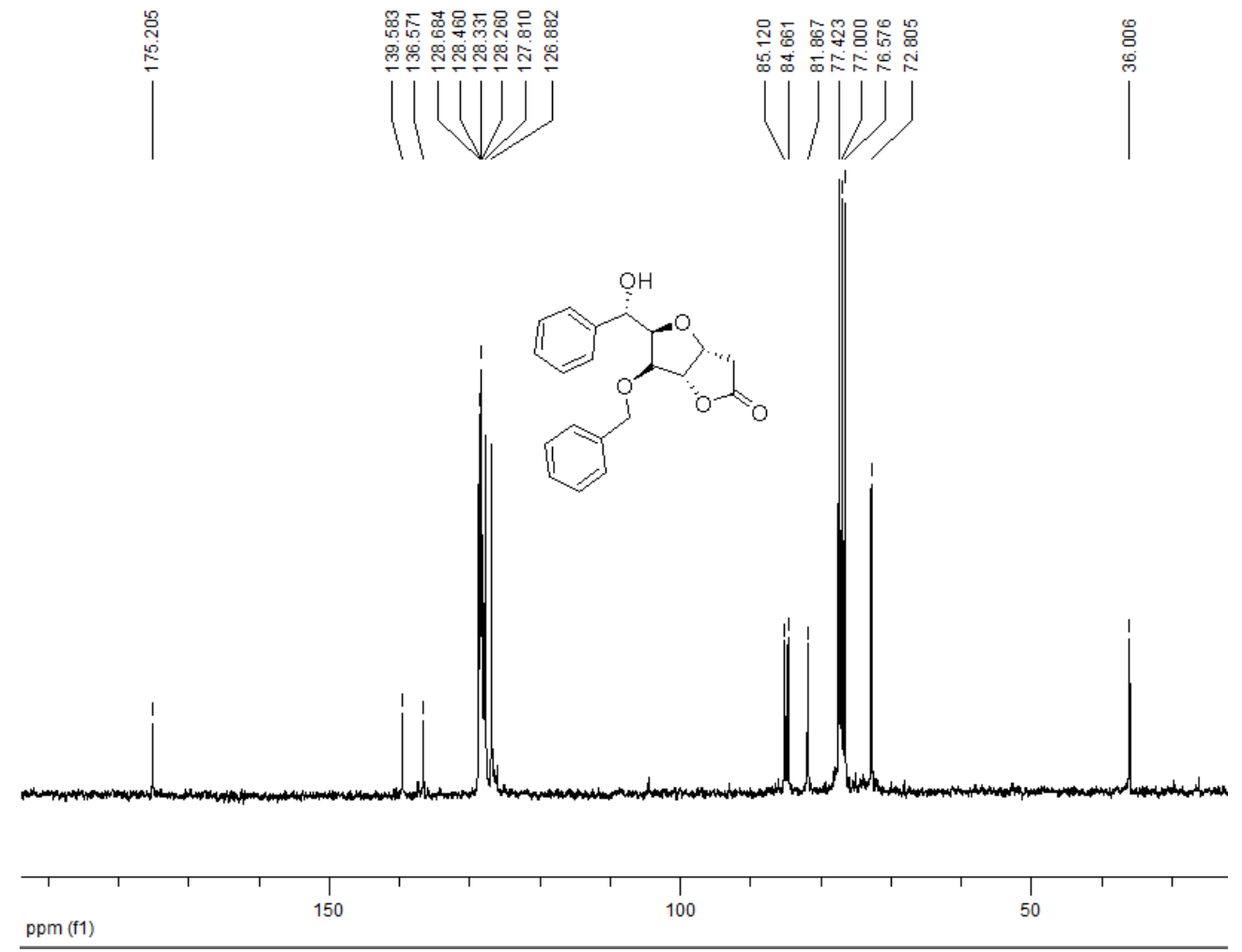

Figura 82. Espectro de $\mathrm{RMN}^{13} \mathrm{C}$ a $75 \mathrm{MHz}$ do composto36a. 

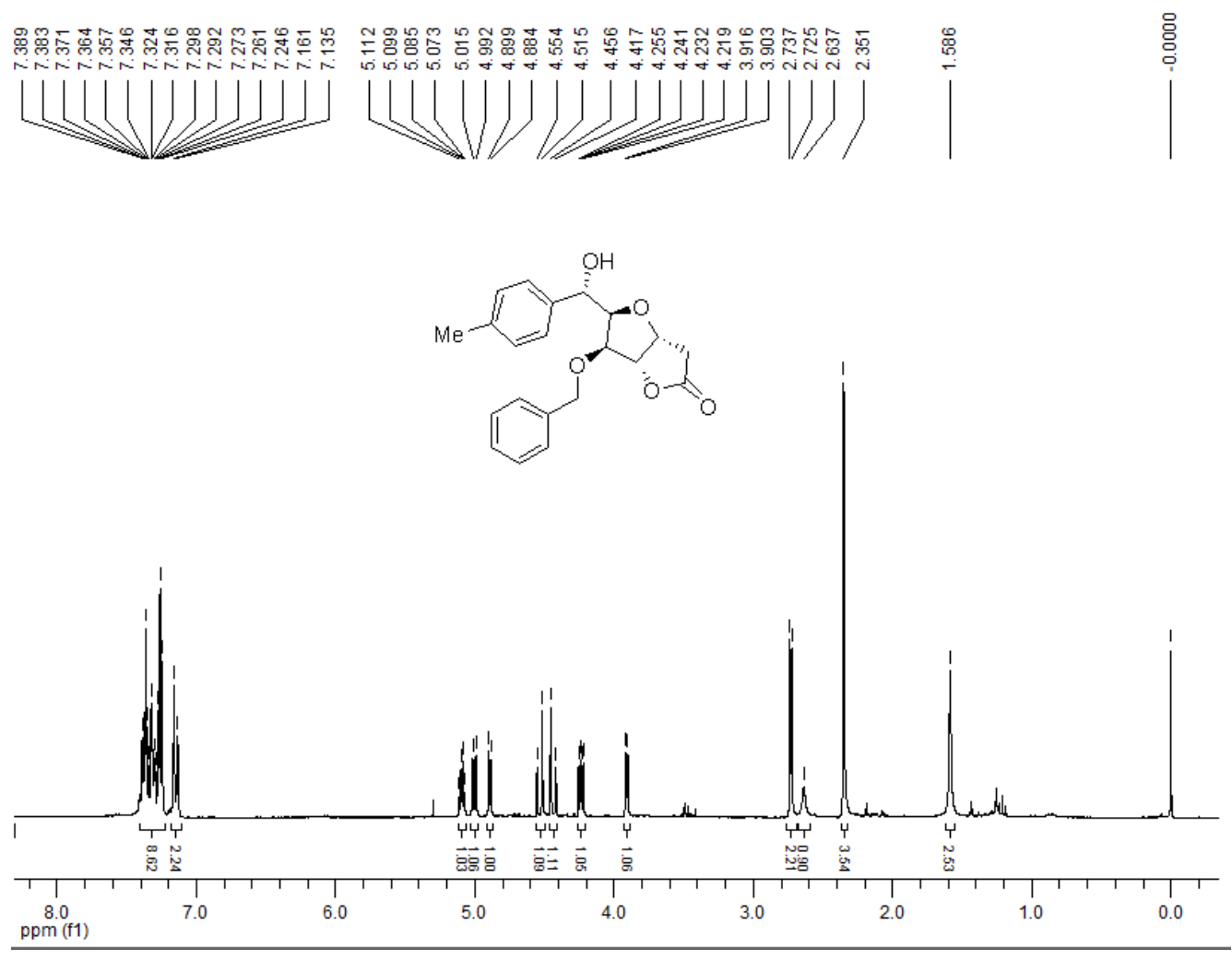

Figura 83. Espectro de $\mathrm{RMN}^{1} \mathrm{H}$ a $300 \mathrm{MHz}$ do composto 36b.

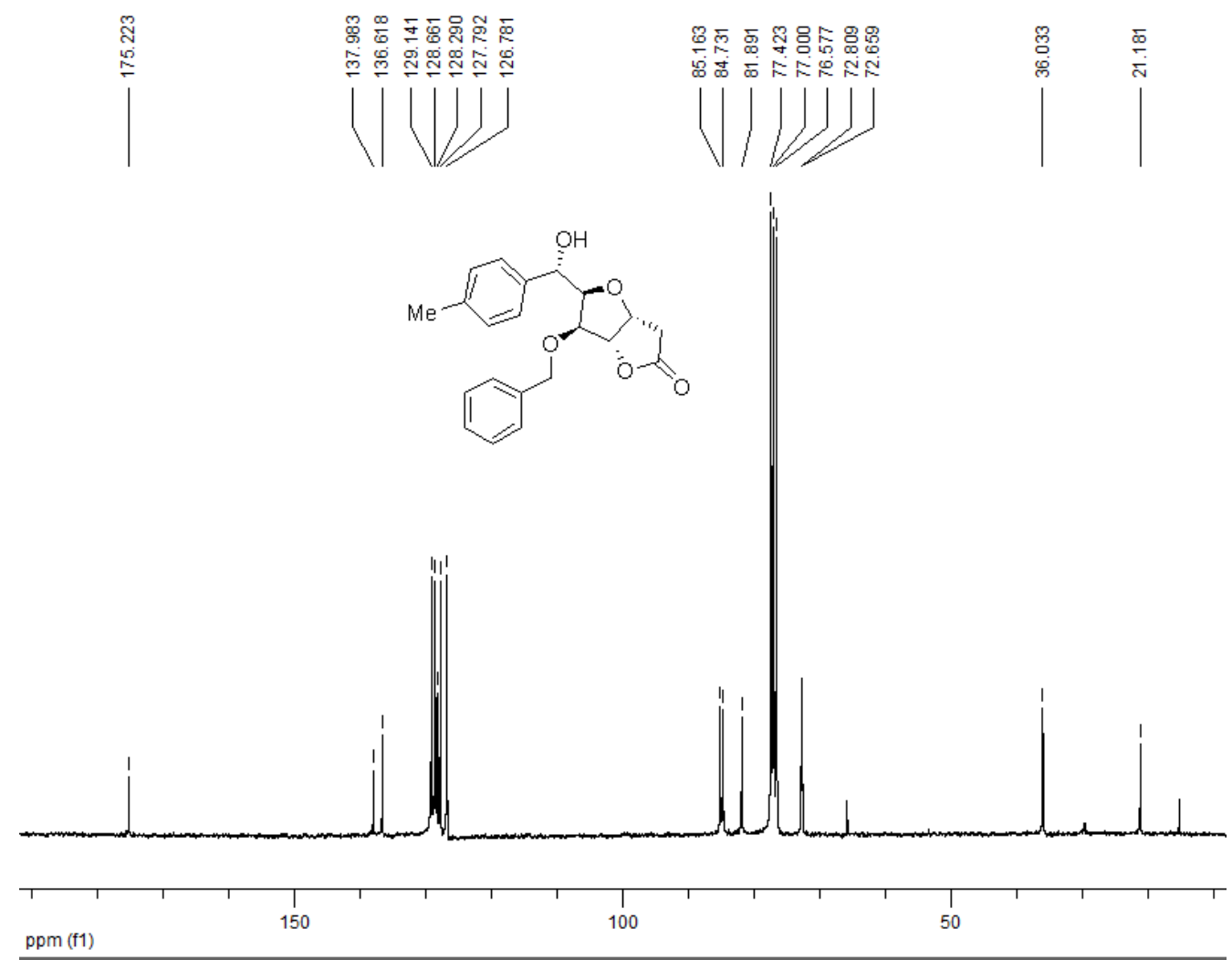

Figura 84. Espectro de $\mathrm{RMN}{ }^{13} \mathrm{C}$ a $75 \mathrm{MHz}$ do composto $36 \mathrm{~b}$. 
윰

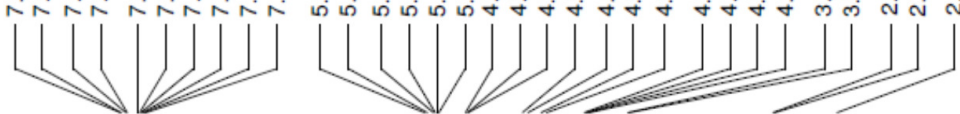

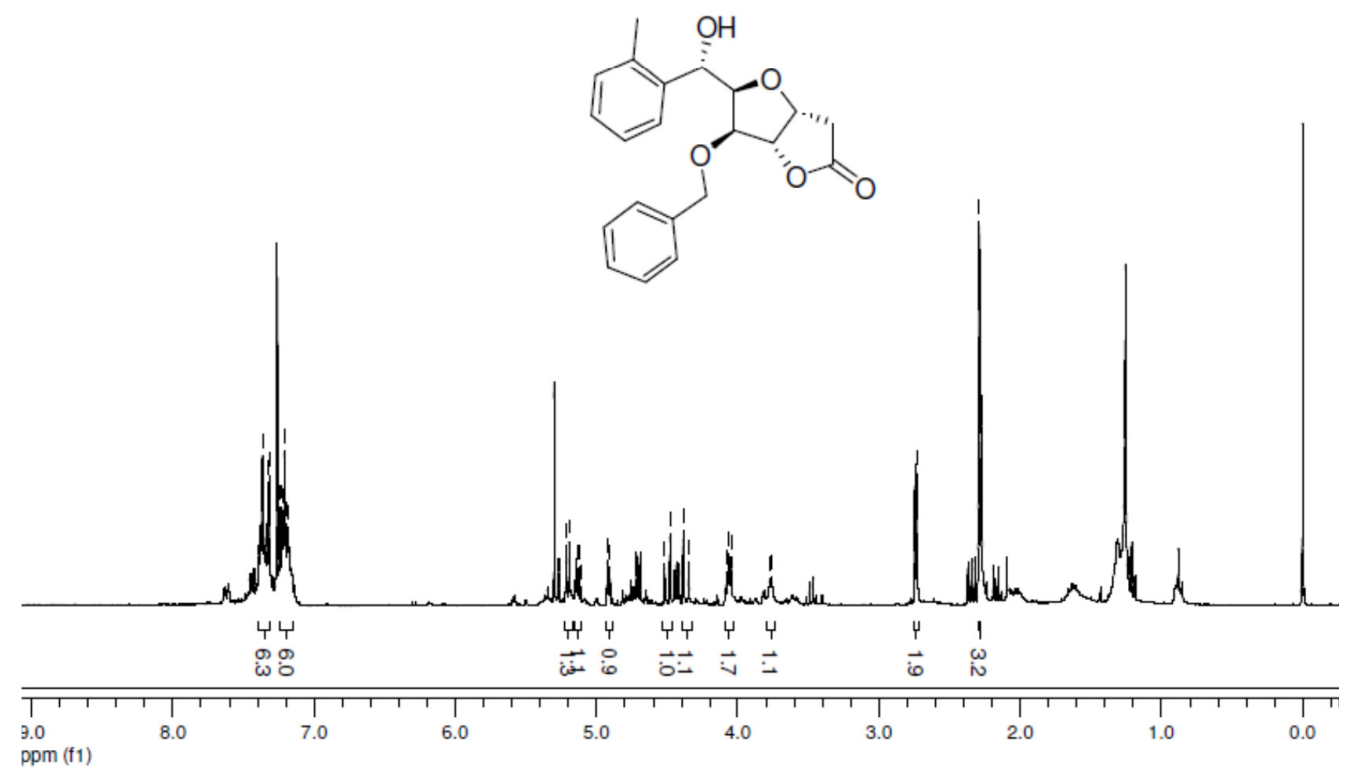

Figura 85. Espectro de RMN ${ }^{1} \mathrm{H}$ a $300 \mathrm{MHz}$ do composto 36c.

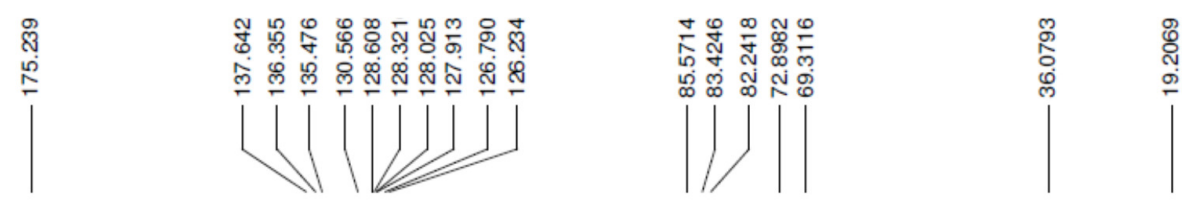<smiles>Cc1ccccc1C(O)C1OC2CC(=O)O[C@H]2[C@H]1OCc1ccccc1</smiles>
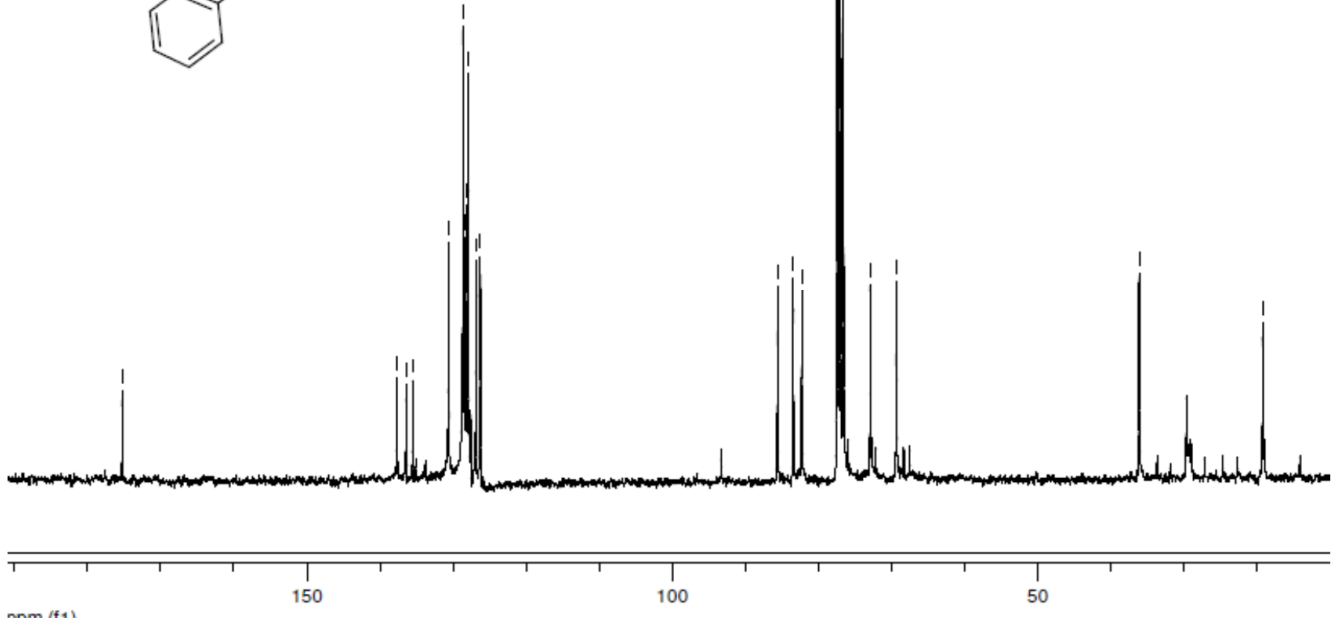

Figura 86. Espectro de $\mathrm{RMN}{ }^{13} \mathrm{C}$ a $75 \mathrm{MHz}$ do composto 36c. 


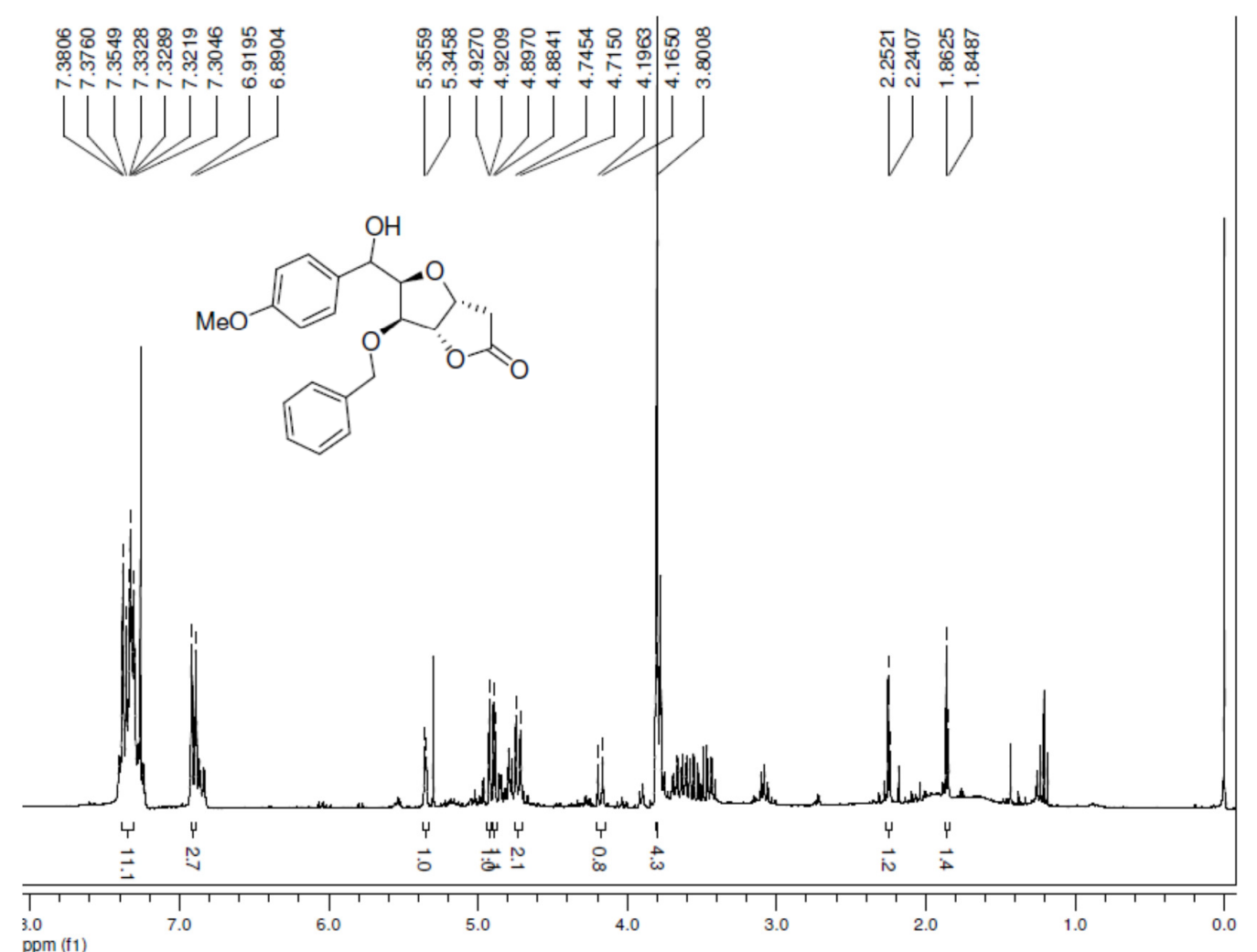

Figura 87. Espectro de RMN ${ }^{1} \mathrm{H}$ a $300 \mathrm{MHz}$ do composto36d
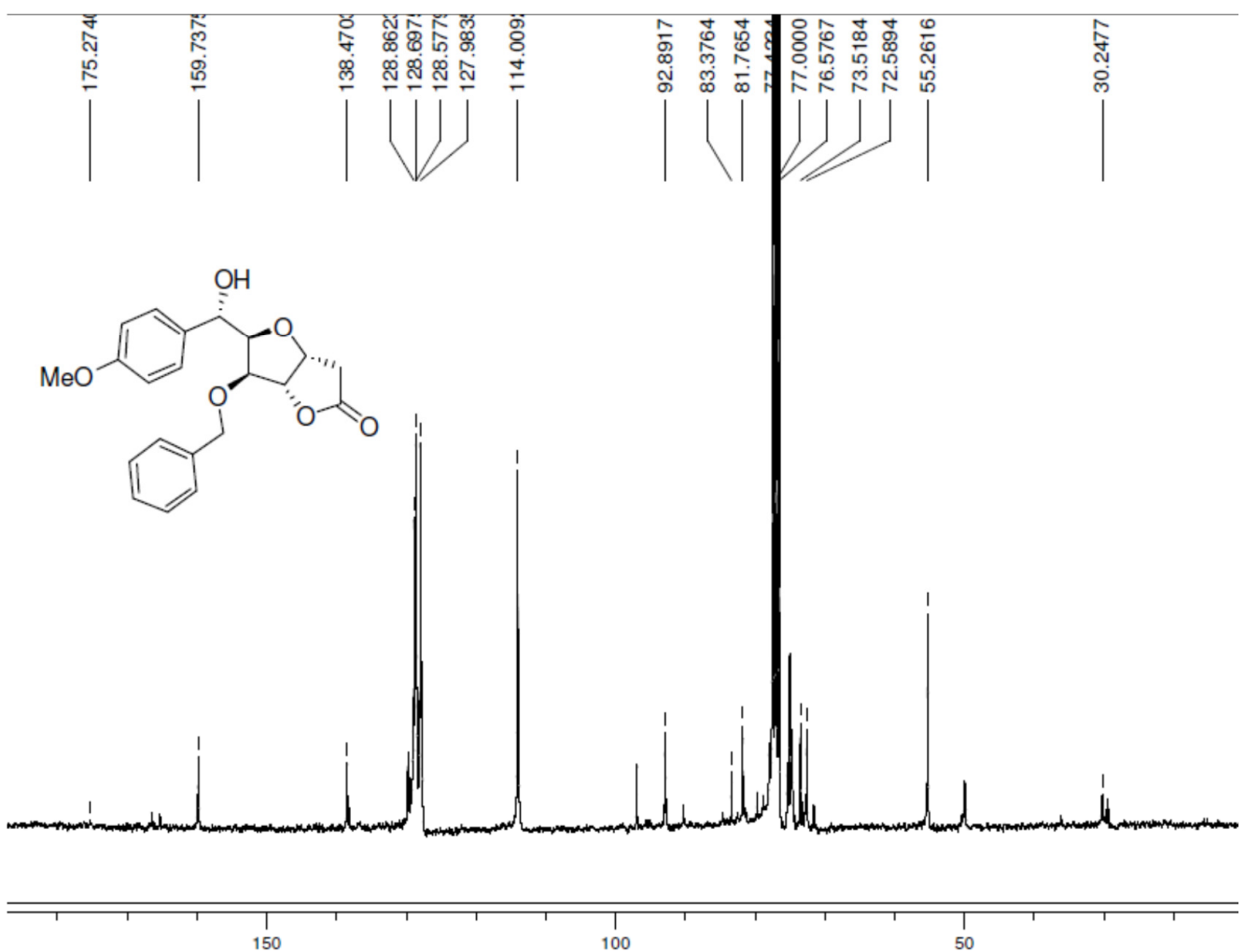

Figura 88. Espectro de $\mathrm{RMN}{ }^{13} \mathrm{C}$ a $75 \mathrm{MHz}$ do composto36d. 


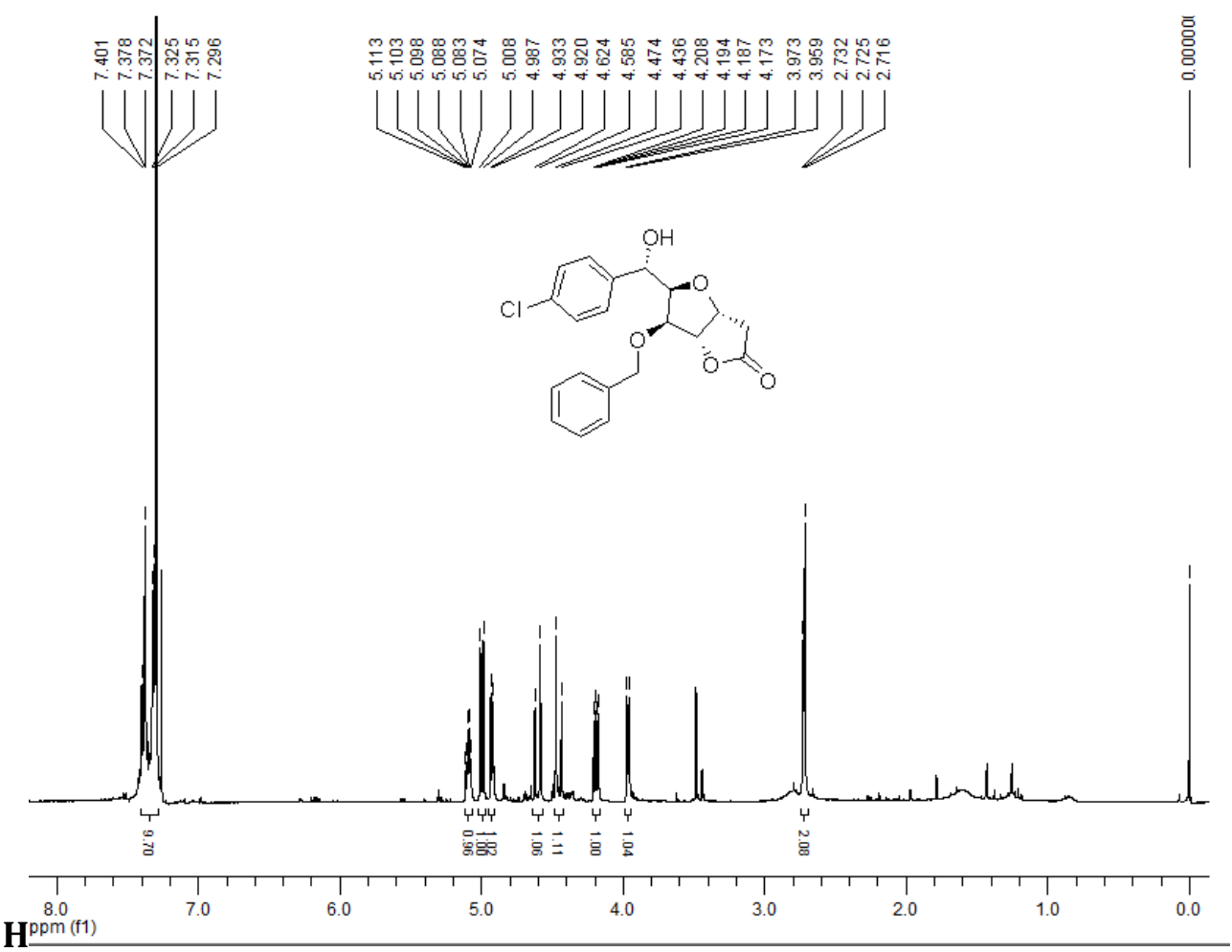

Figura 89. Espectro de $\mathrm{RMN}^{1} \mathrm{H}$ a $300 \mathrm{MHz}$ do composto $\mathbf{3 6 e}$.
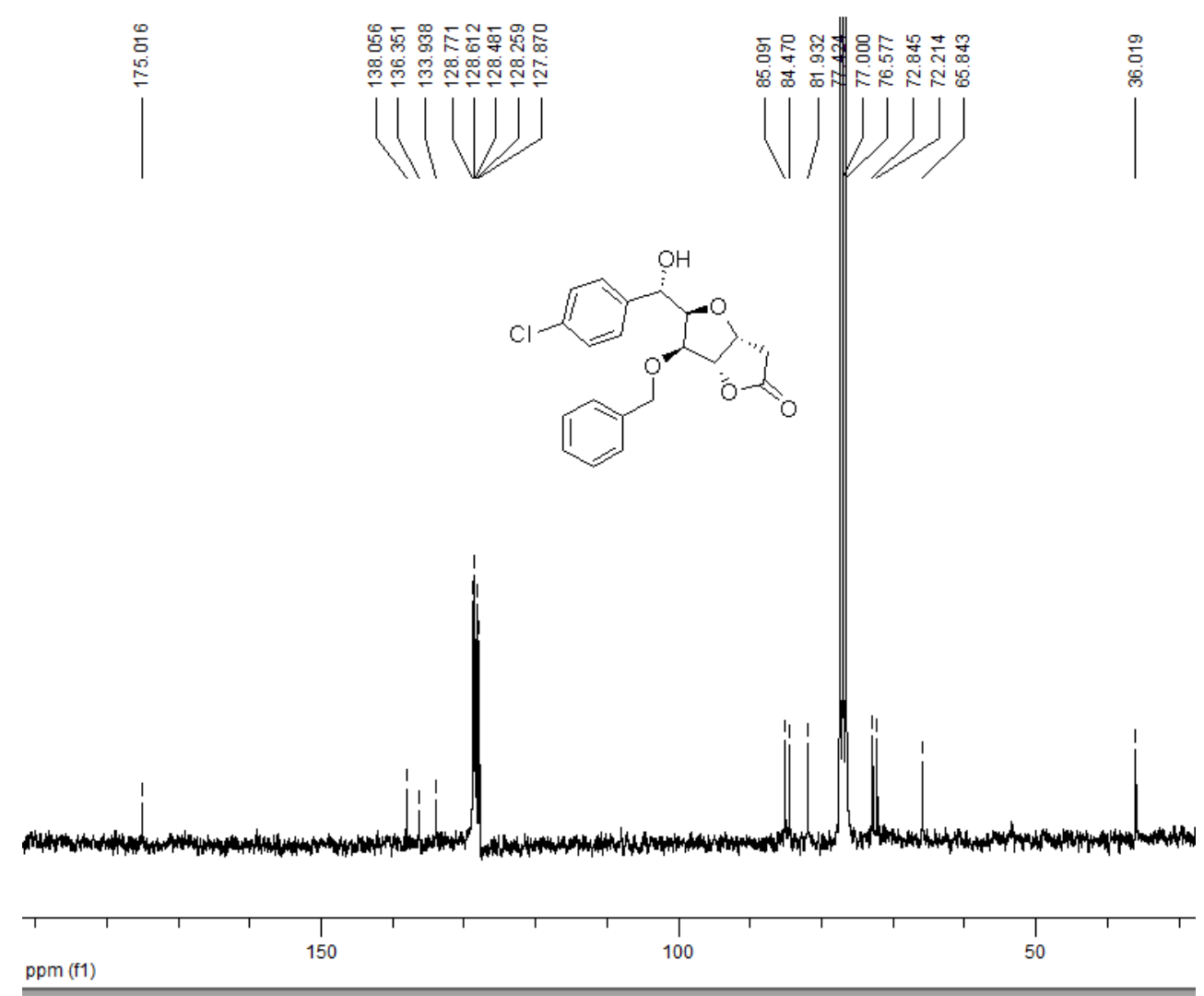

Figura 90. Espectro de $\mathrm{RMN}{ }^{13} \mathrm{C}$ a $75 \mathrm{MHz}$ do composto $36 \mathbf{e}$. 

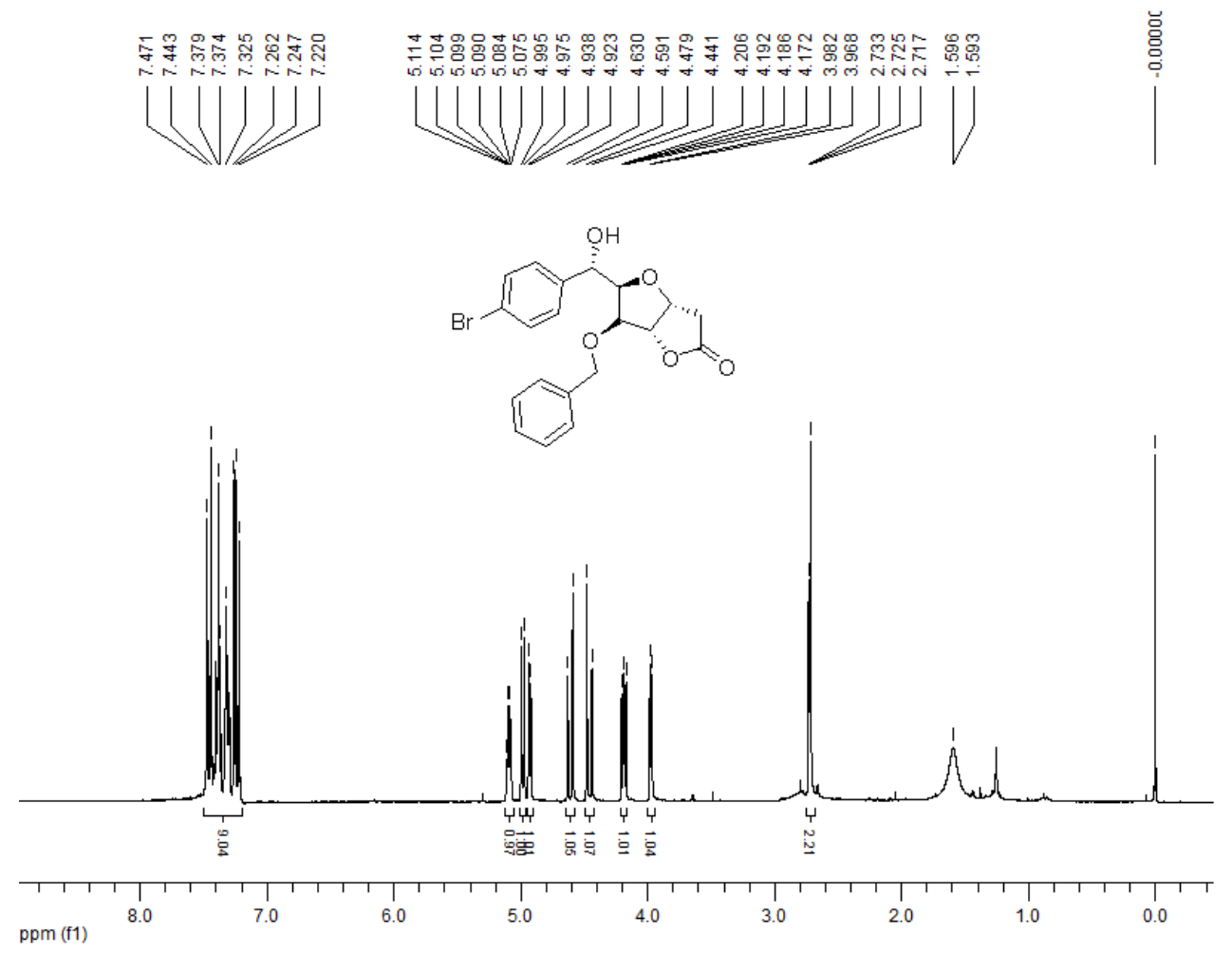

Figura 91. Espectro de $\mathrm{RMN}^{1} \mathrm{H}$ a $300 \mathrm{MHz}$ do composto $36 \mathbf{f}$.
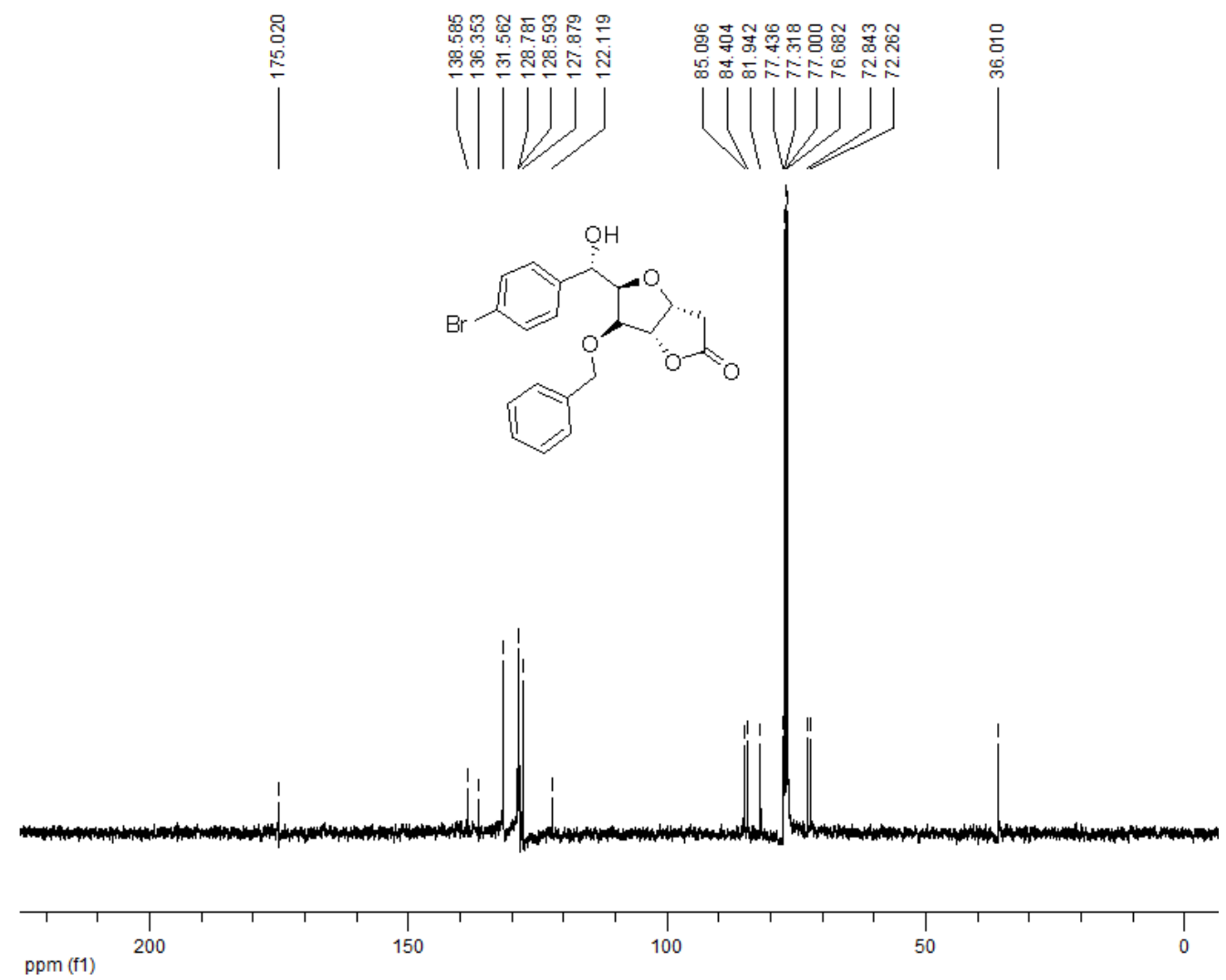

Figura 92. Espectro de $\mathrm{RMN}^{13} \mathrm{C}$ a $75 \mathrm{MHz}$ do composto $\mathbf{3 6 f}$. 

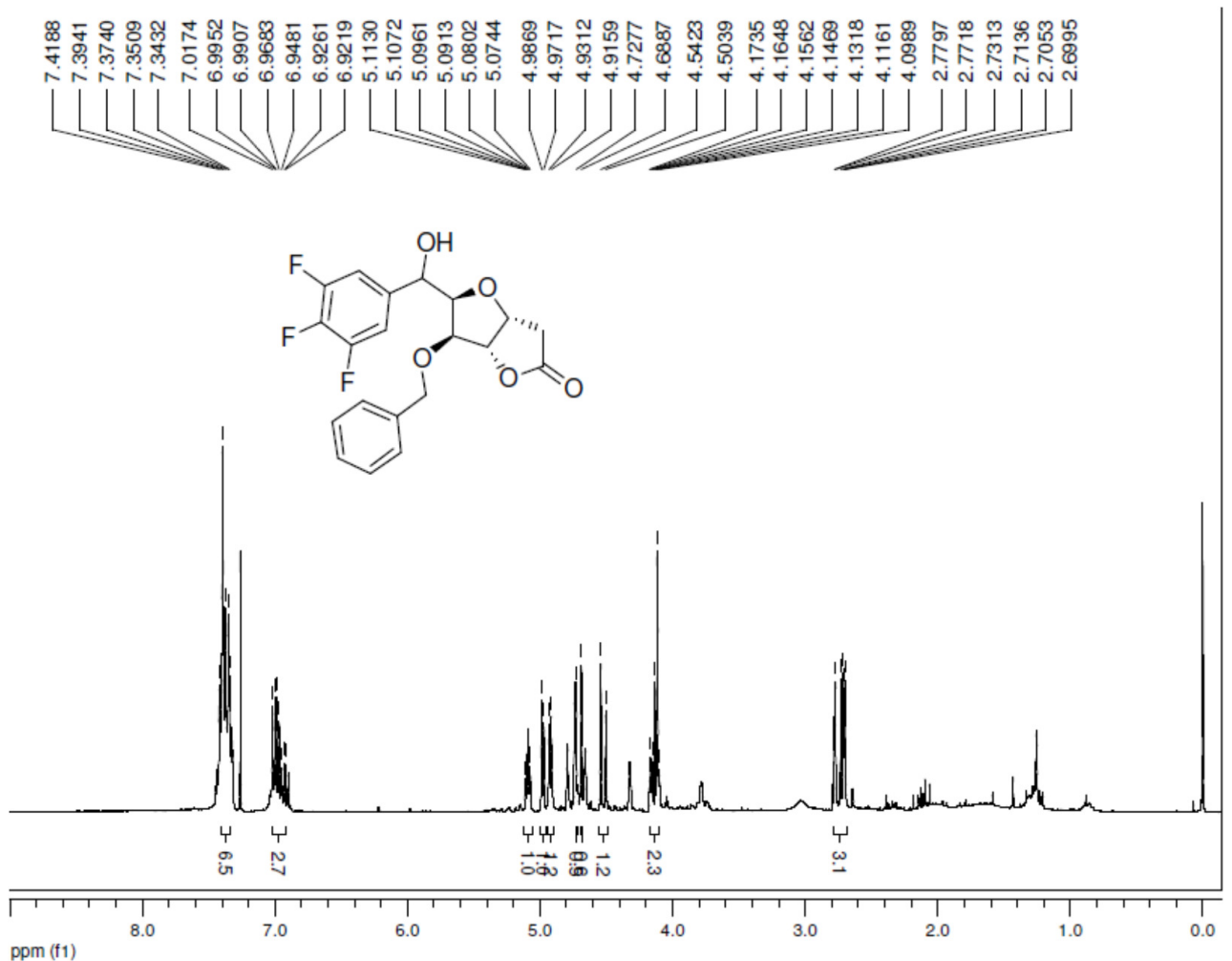

Figura 93. Espectro de $\mathrm{RMN}^{1} \mathrm{H}$ a $300 \mathrm{MHz}$ do composto $\mathbf{3 6 g}$.
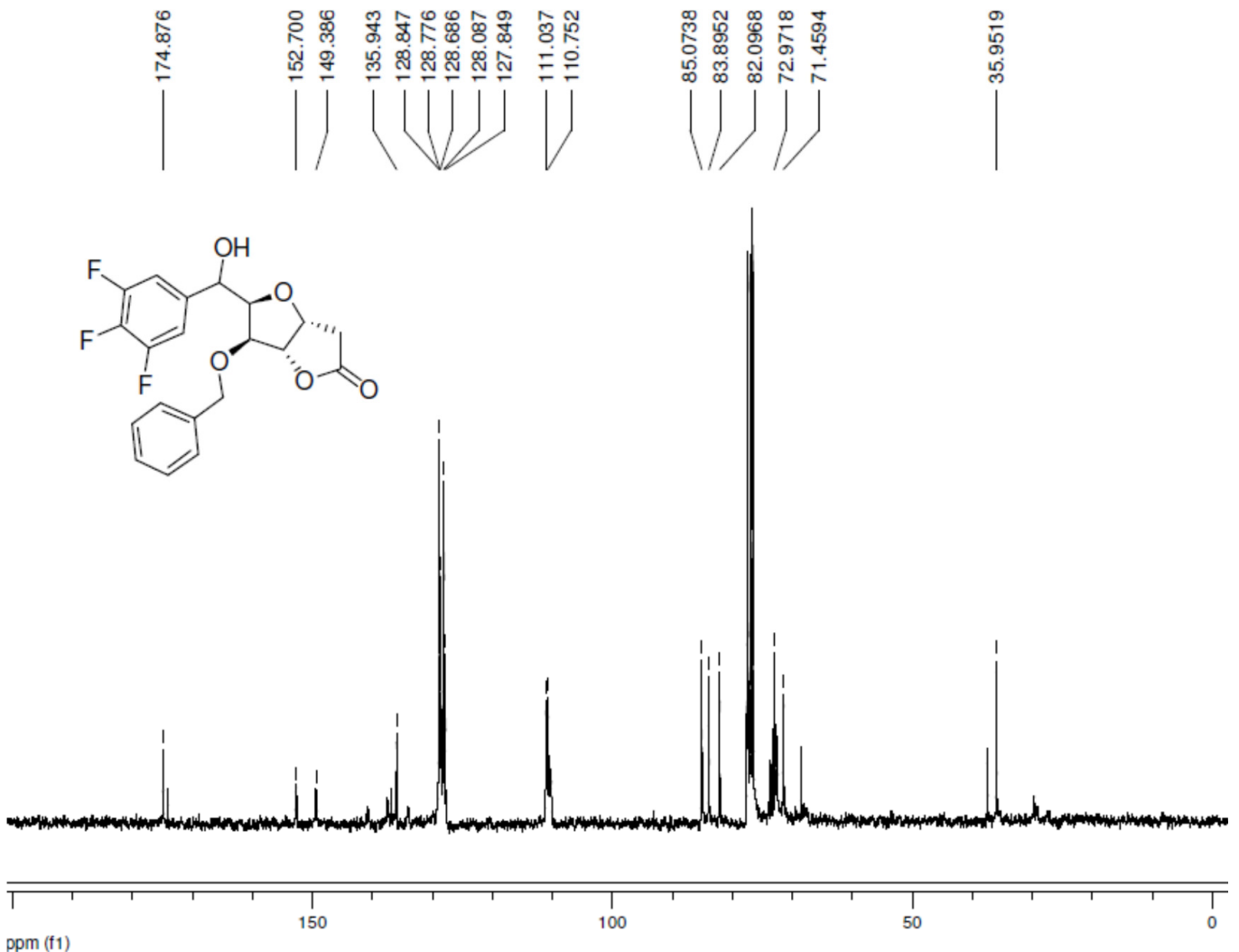

ppm (f1)

Figura 94. Espectro de $\mathrm{RMN}{ }^{13} \mathrm{C}$ a $75 \mathrm{MHz}$ do composto $\mathbf{3 6 g}$. 


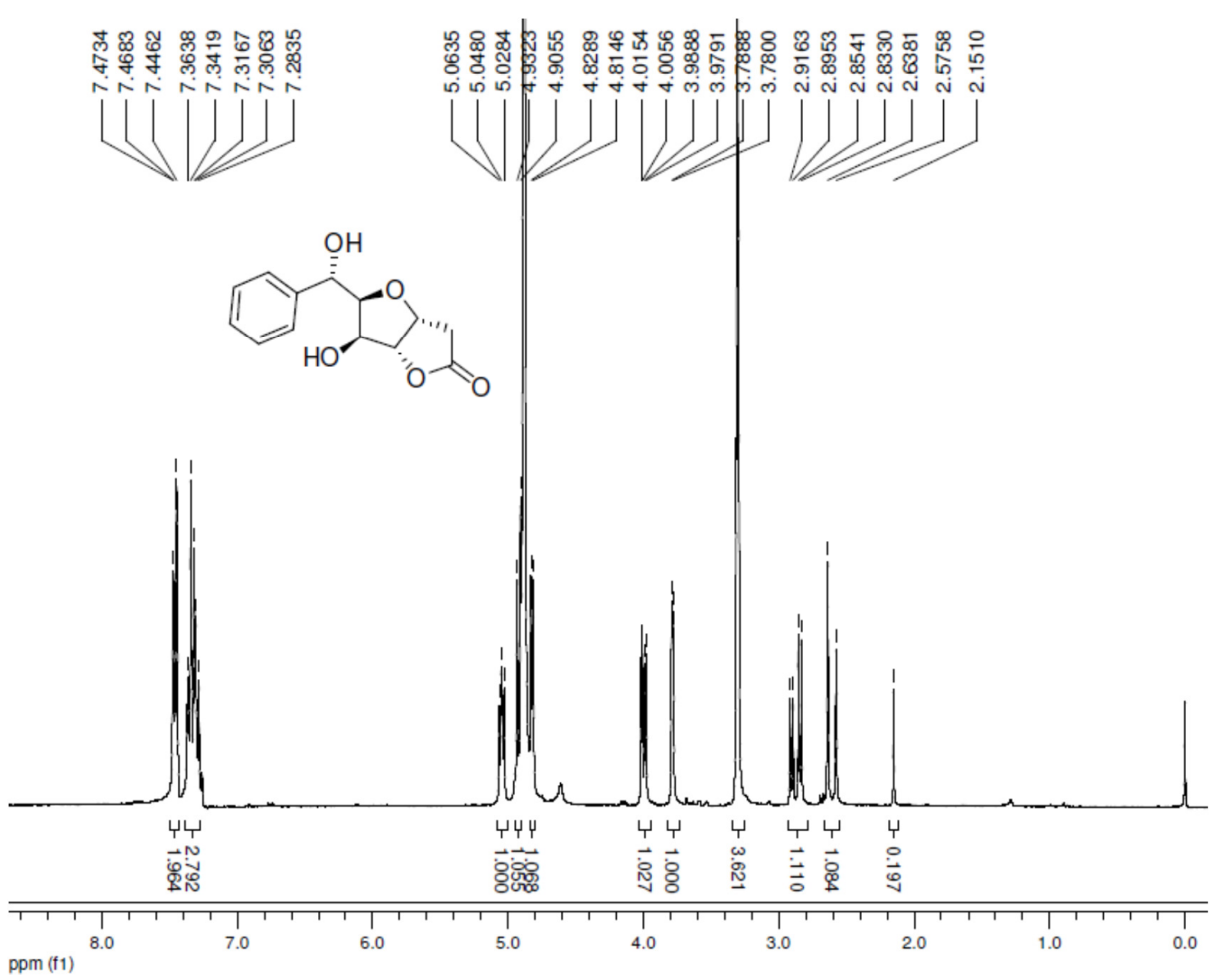

Figura 95. Espectro de $\mathrm{RMN}^{1} \mathrm{H}$ a $300 \mathrm{MHz}$ do composto17a.
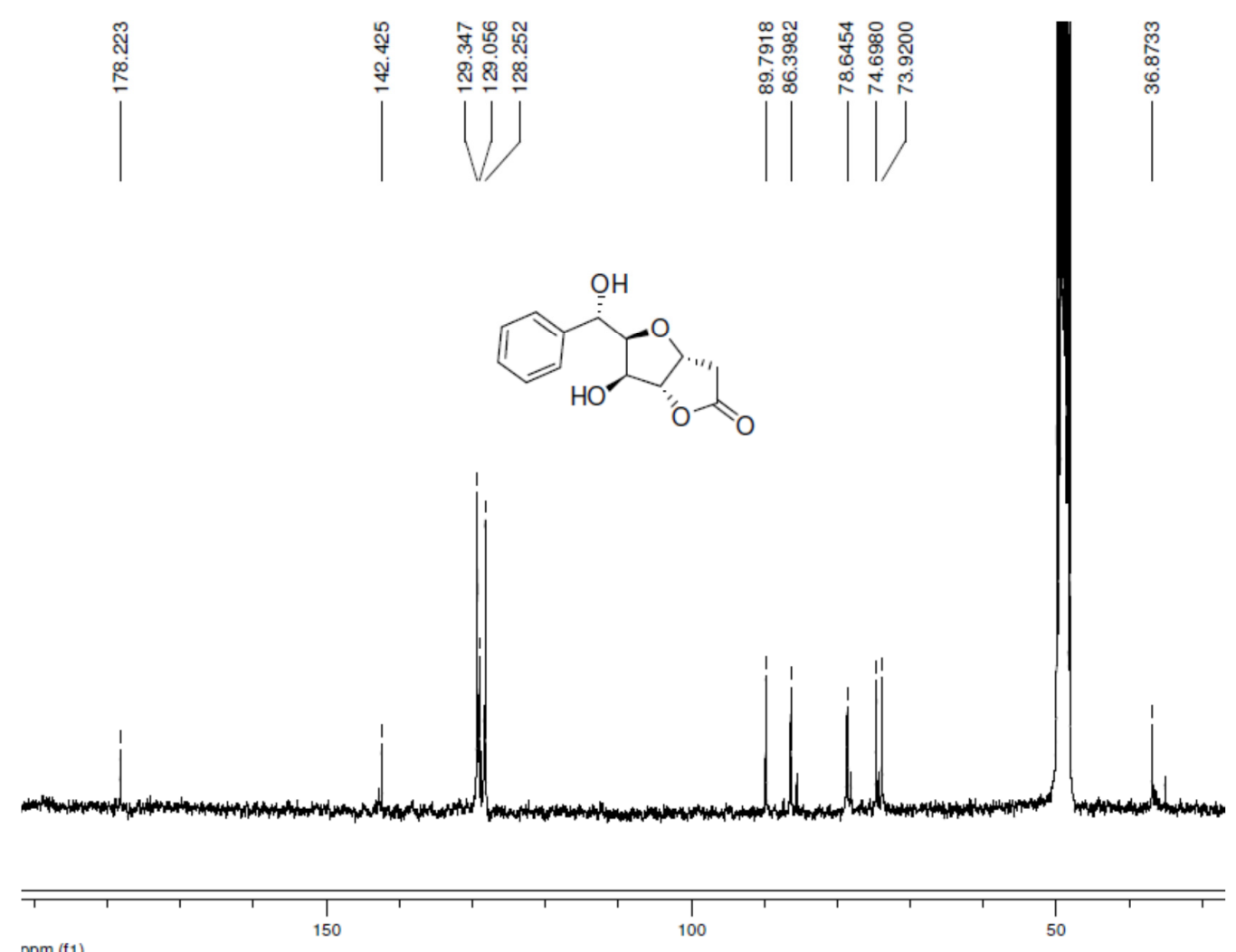

Figura 96. Espectro de $\mathrm{RMN}{ }^{13} \mathrm{C}$ a $75 \mathrm{MHz}$ do composto17a. 


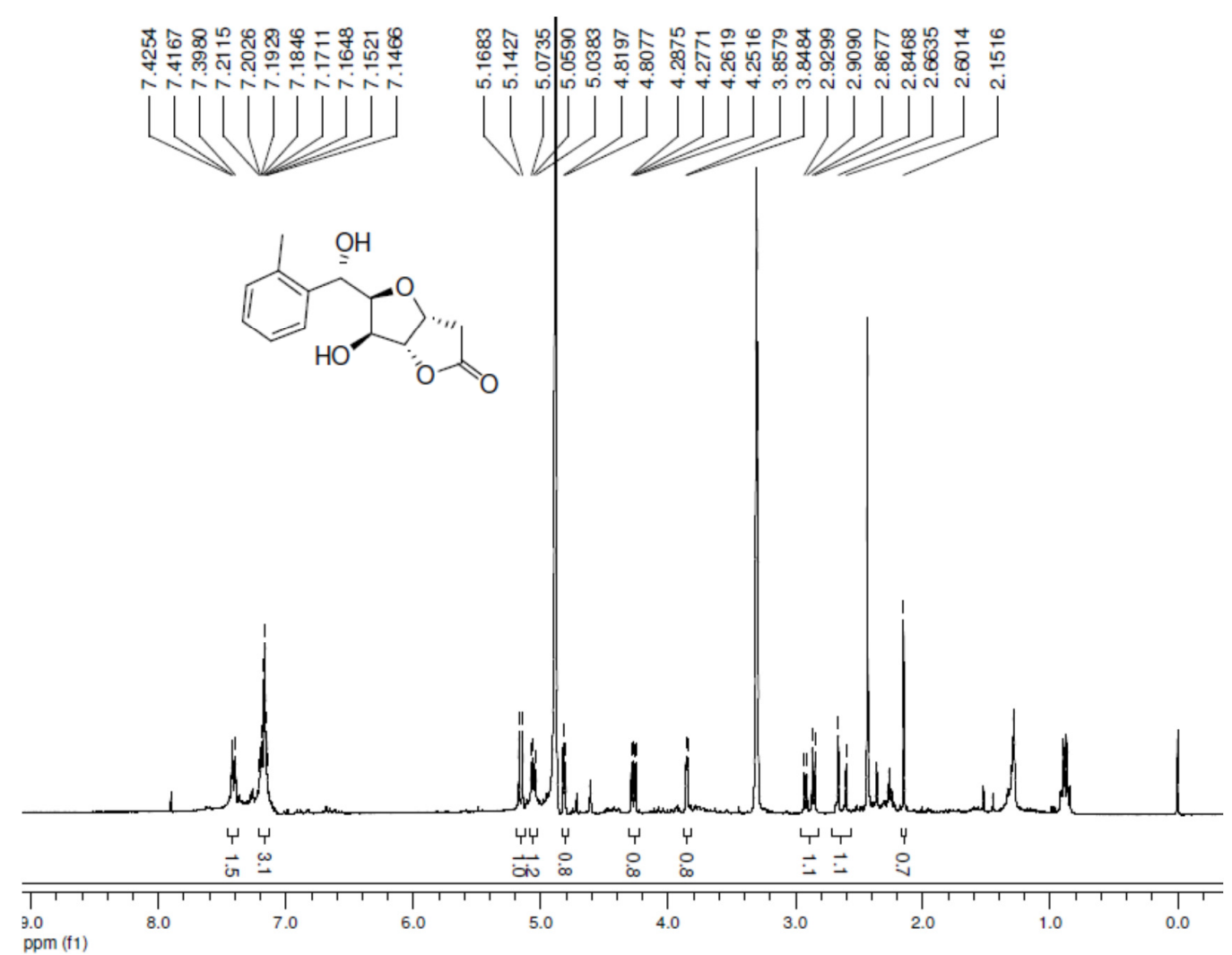

Figura 97. Espectro de $\mathrm{RMN}{ }^{1} \mathrm{H}$ a $300 \mathrm{MHz}$ do composto $\mathbf{1 7 b}$.
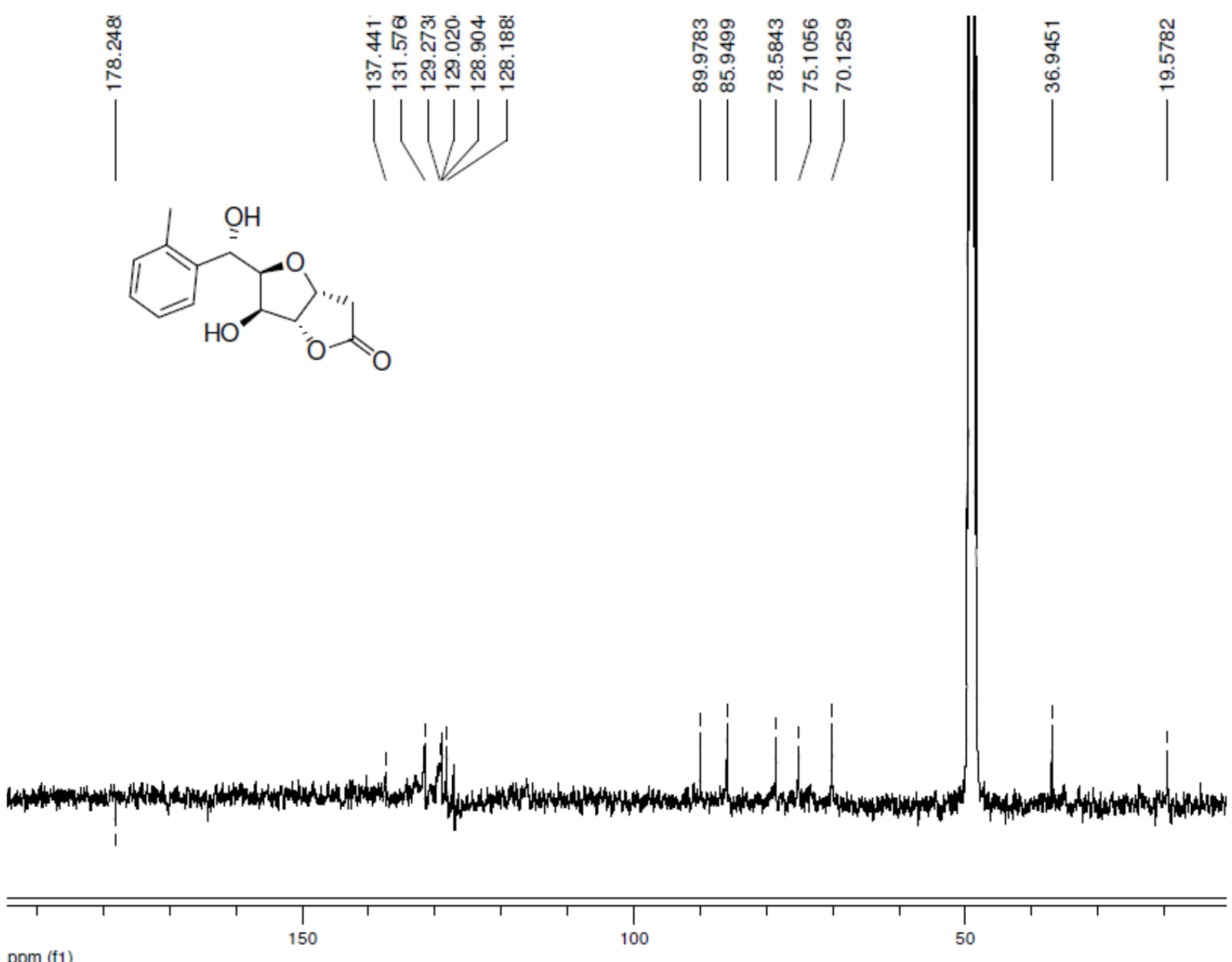

Figura 98. Espectro de $\mathrm{RMN}{ }^{13} \mathrm{C}$ a $75 \mathrm{MHz}$ do composto $\mathbf{1 7 b}$. 

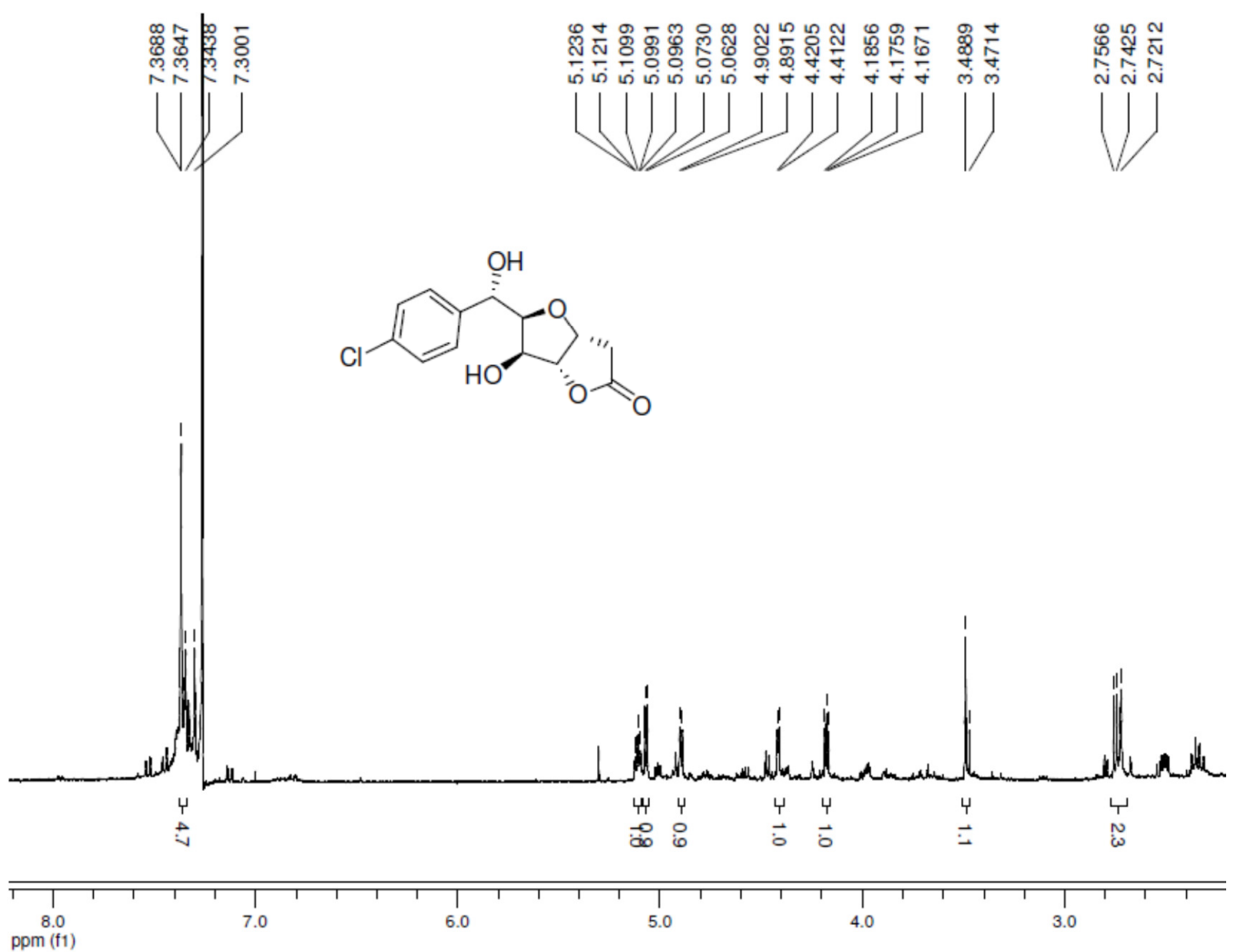

Figura 99. Espectro de RMN ${ }^{1} \mathrm{H}$ a $300 \mathrm{MHz}$ do composto $17 \mathbf{c}$.
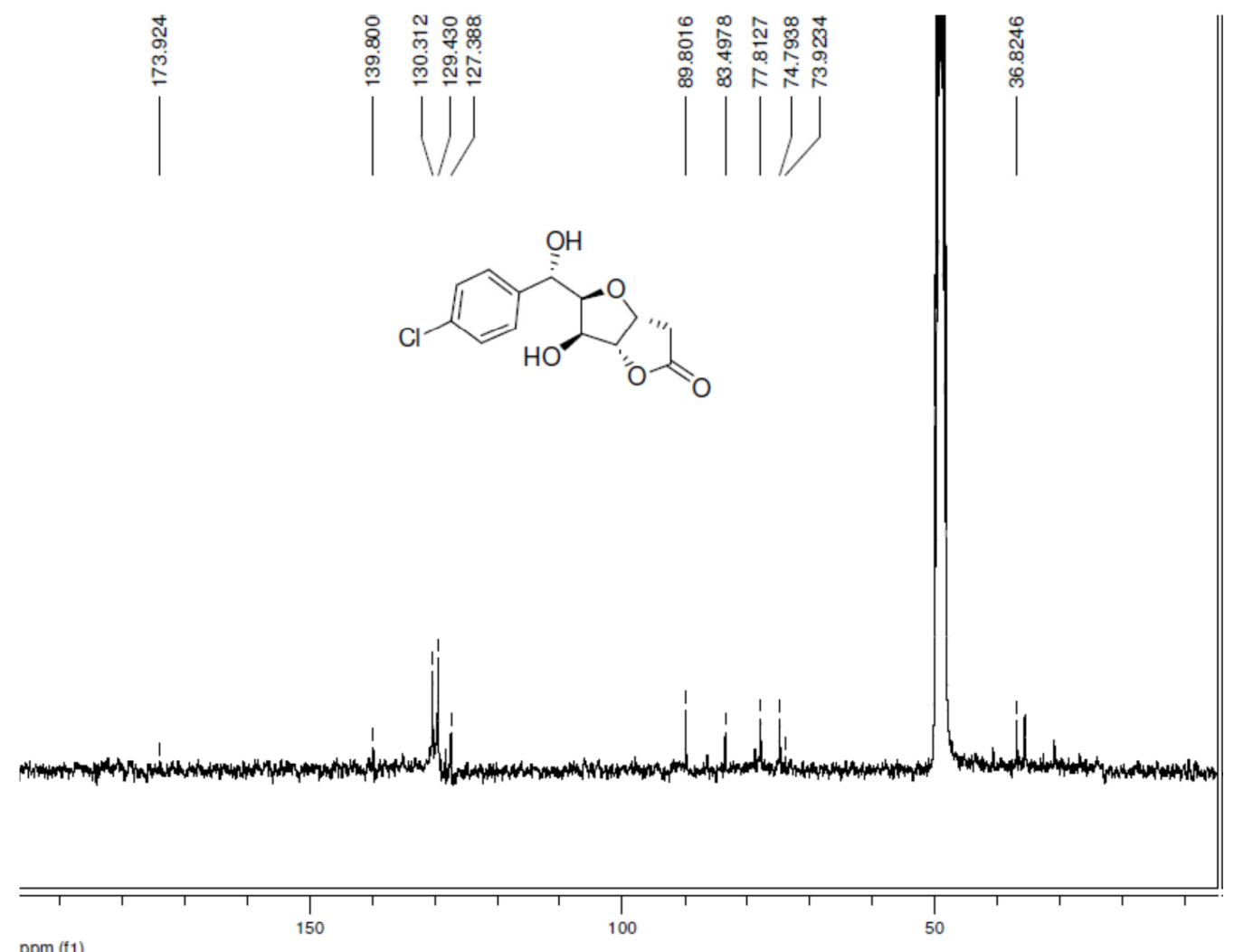

Figura 100. Espectro de $\mathrm{RMN}^{13} \mathrm{C}$ a $75 \mathrm{MHz}$ do composto $17 \mathrm{c}$. 


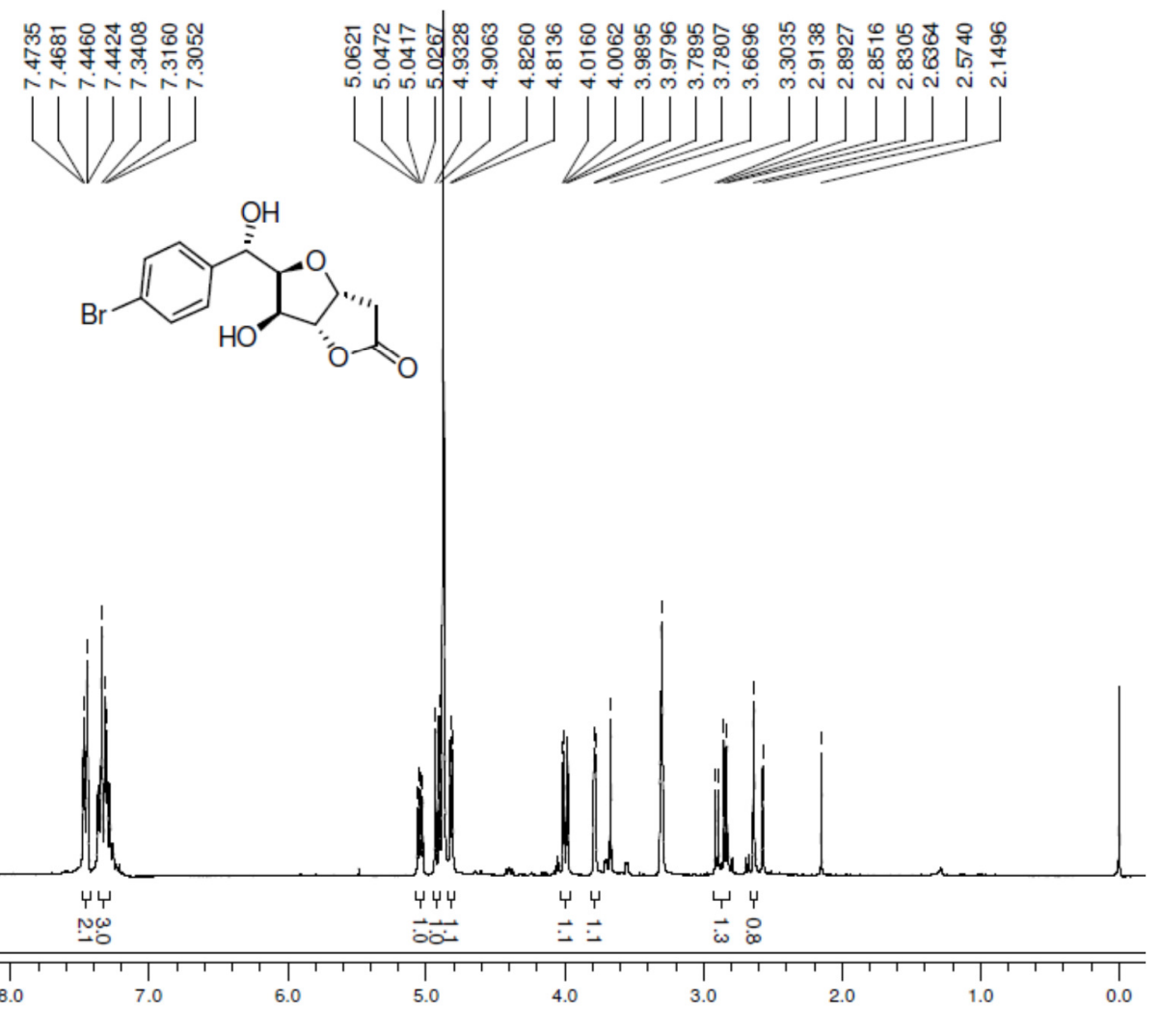

Figura 101. Espectro de $\mathrm{RMN}^{1} \mathrm{H}$ a $300 \mathrm{MHz}$ do composto17d.
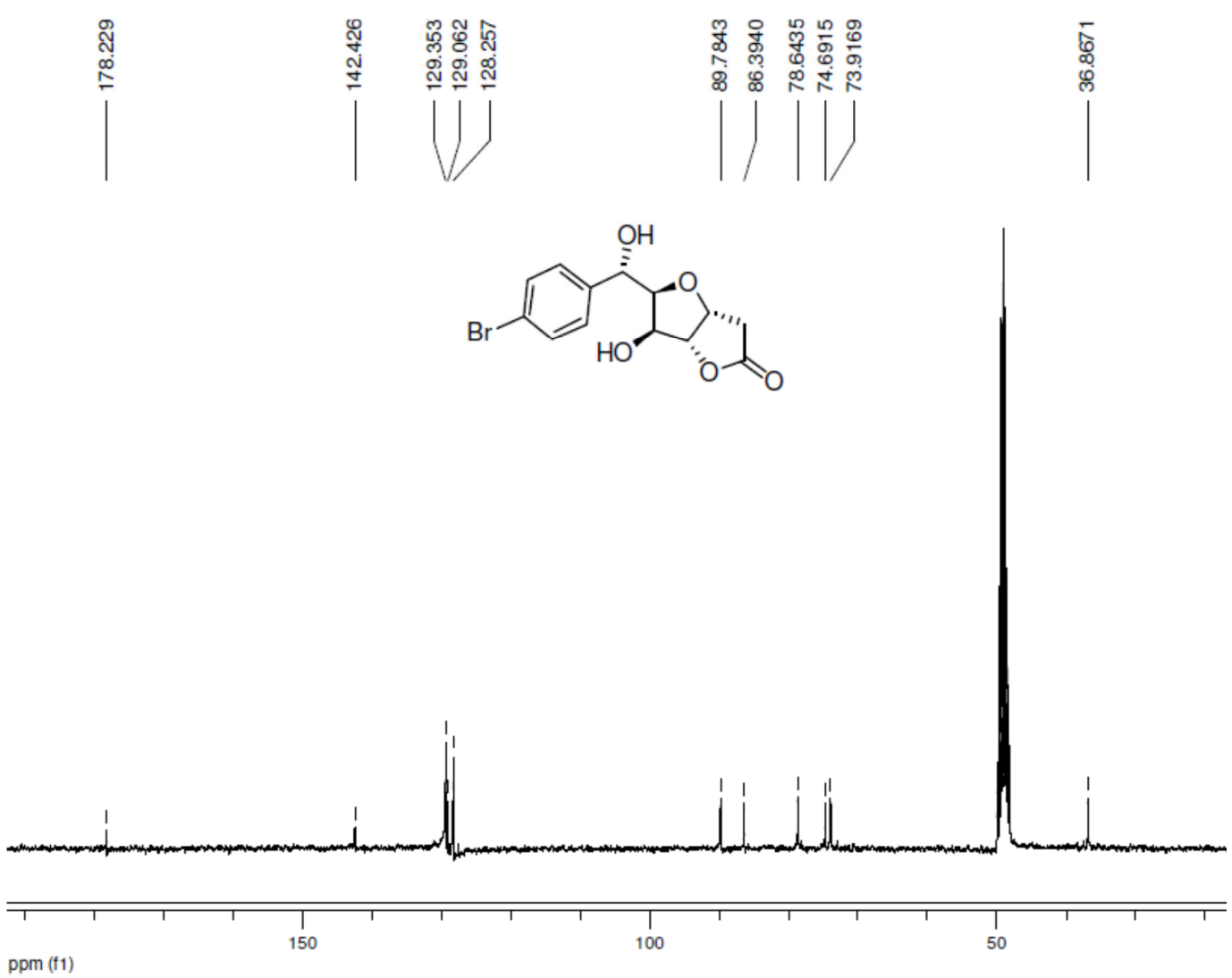

Figura 102. Espectro de $\mathrm{RMN}{ }^{13} \mathrm{C}$ a $75 \mathrm{MHz}$ do composto17d. 


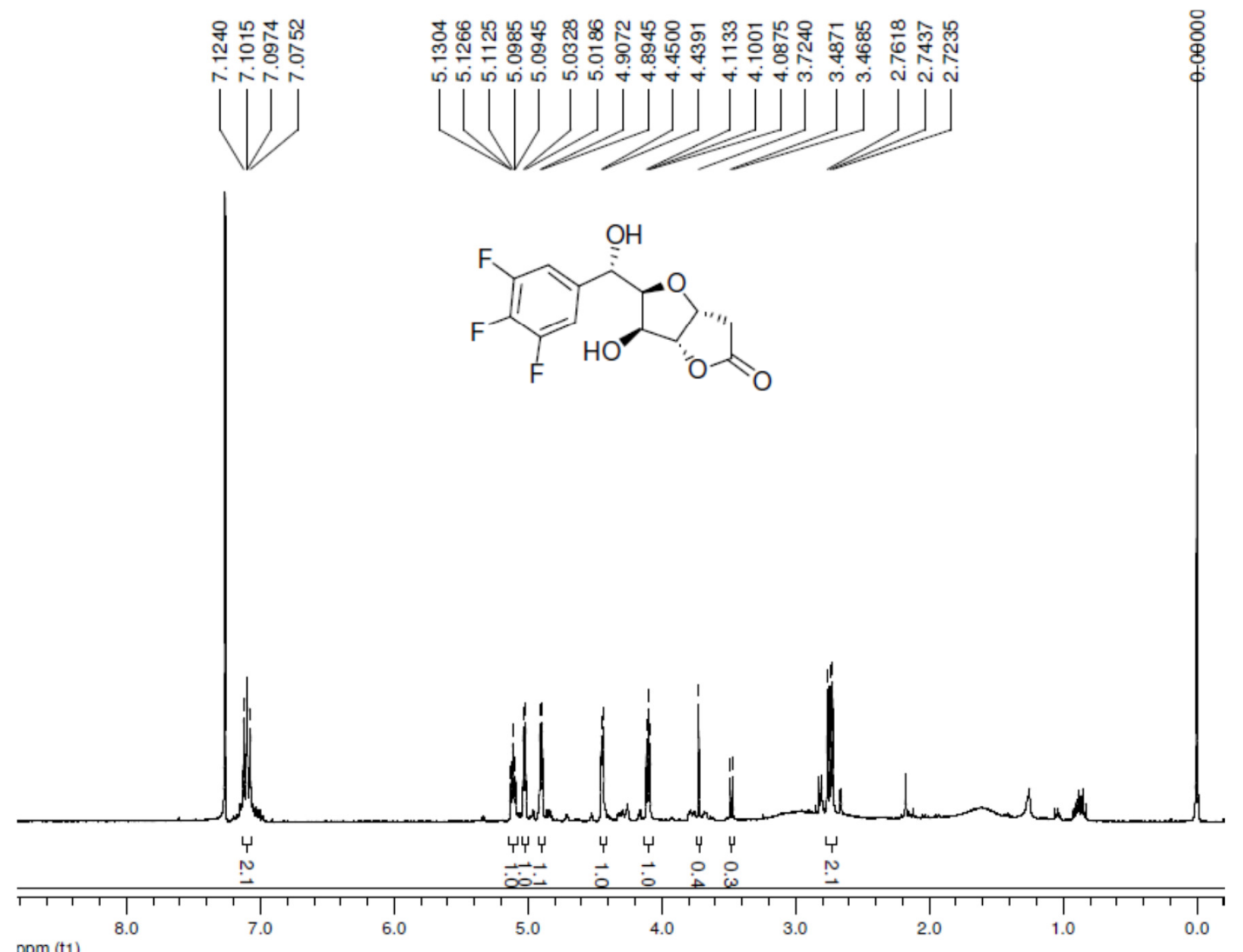

Figura 103. Espectro de $\mathrm{RMN}^{1} \mathrm{H}$ a $300 \mathrm{MHz}$ do composto $17 \mathrm{e}$.
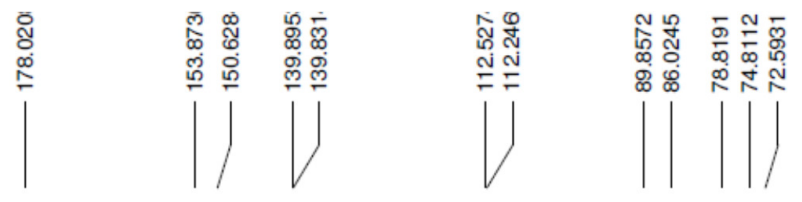

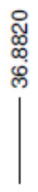<smiles>O=C1C[C@H]2OC([C@H](O)c3cc(F)c(F)c(F)c3)[C@H](O)[C@H]2O1</smiles>

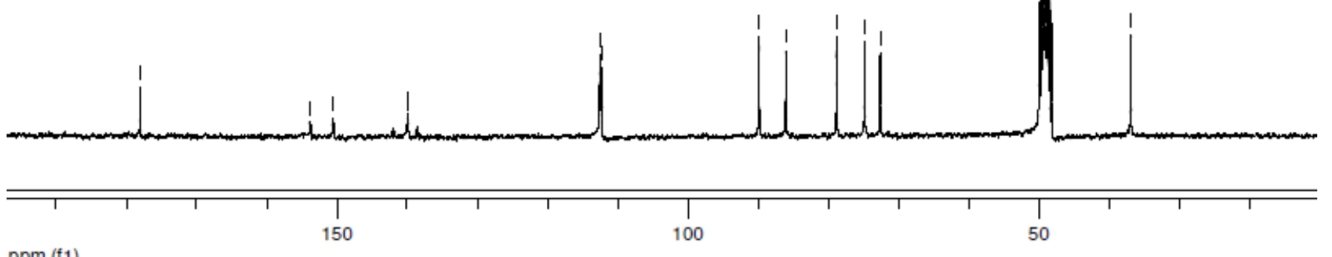

Figura 104. Espectro de $\mathrm{RMN}{ }^{13} \mathrm{C}$ a $75 \mathrm{MHz}$ do composto $\mathbf{1 7 e .}$ 

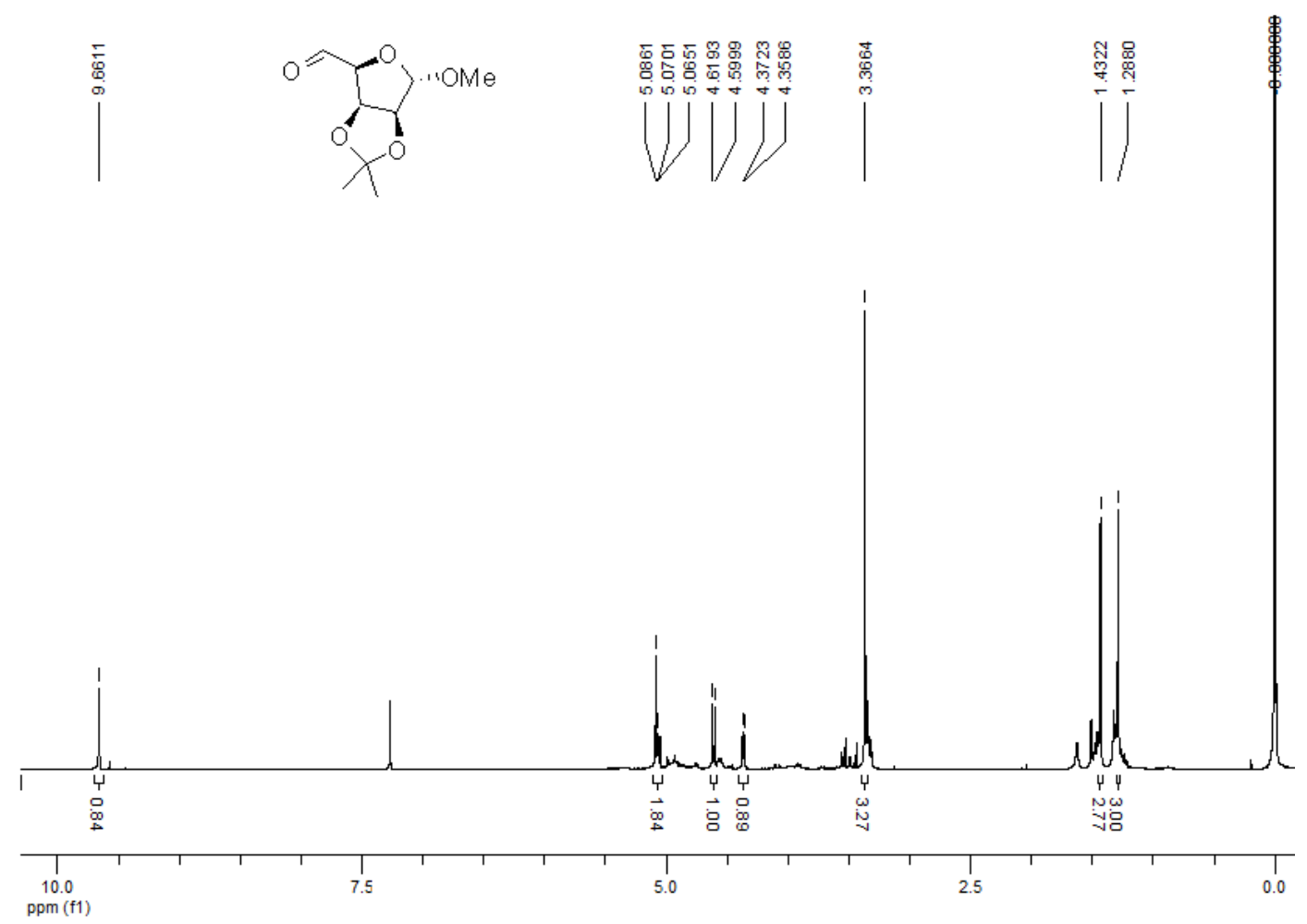

Figura 105. Espectro de $\mathrm{RMN}^{1} \mathrm{H}$ a $300 \mathrm{MHz}$ do composto 53.

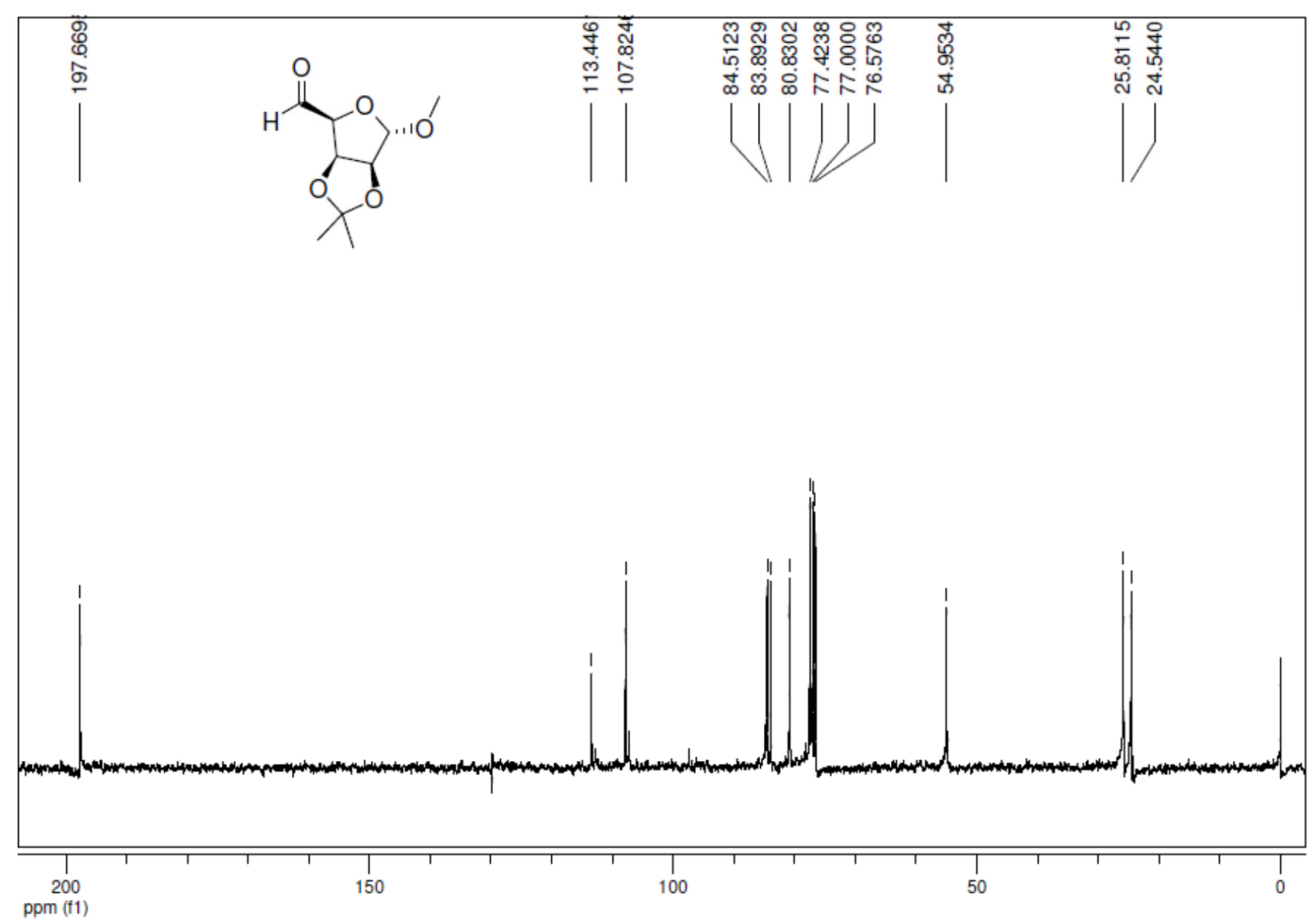

Figura 106. Espectro de $\mathrm{RMN}{ }^{13} \mathrm{C}$ a $75 \mathrm{MHz}$ do composto 53. 


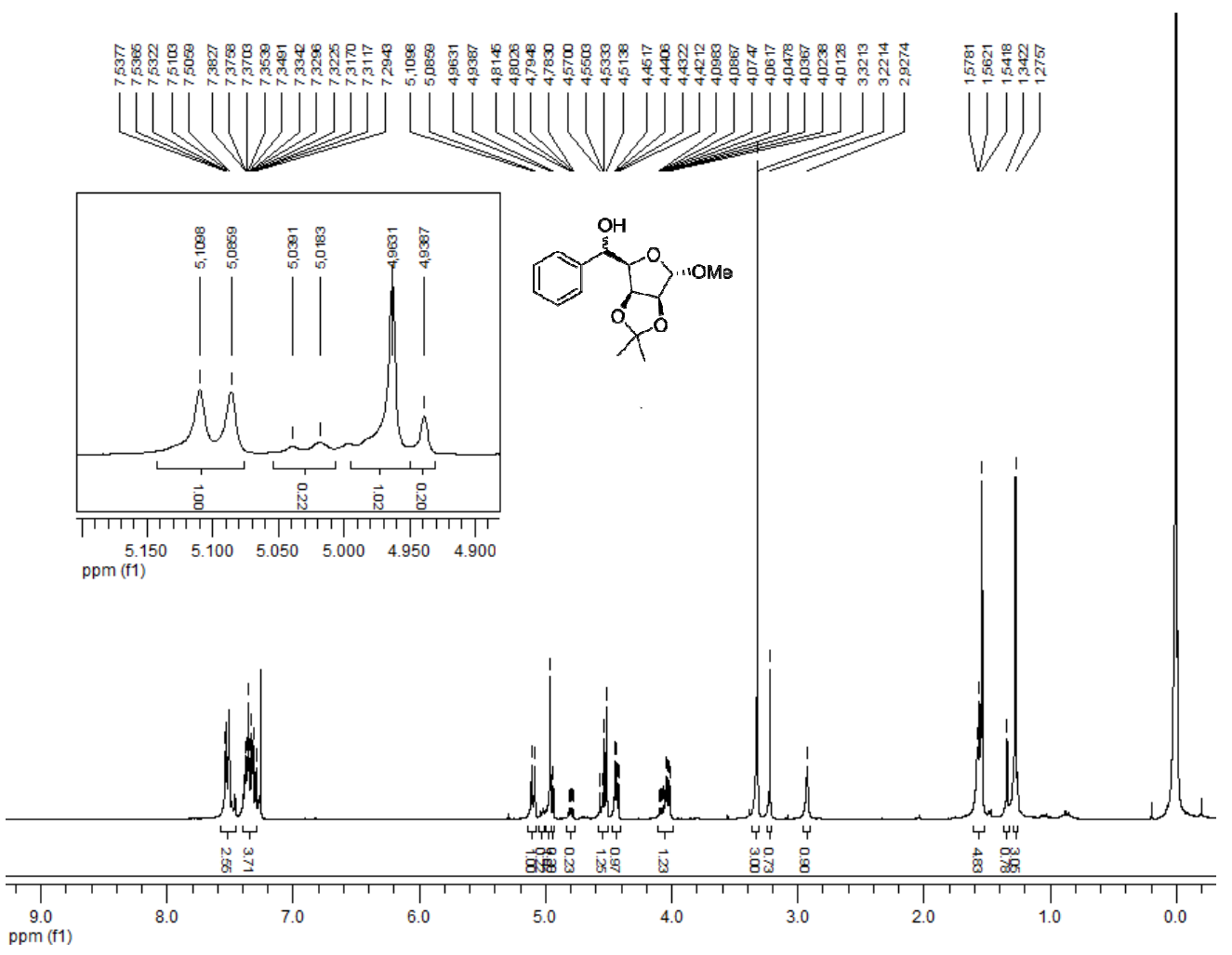

Figura 107. Espectro de $\mathrm{RMN}^{1} \mathrm{Ha} 300 \mathrm{MHz}$ do composto58a.
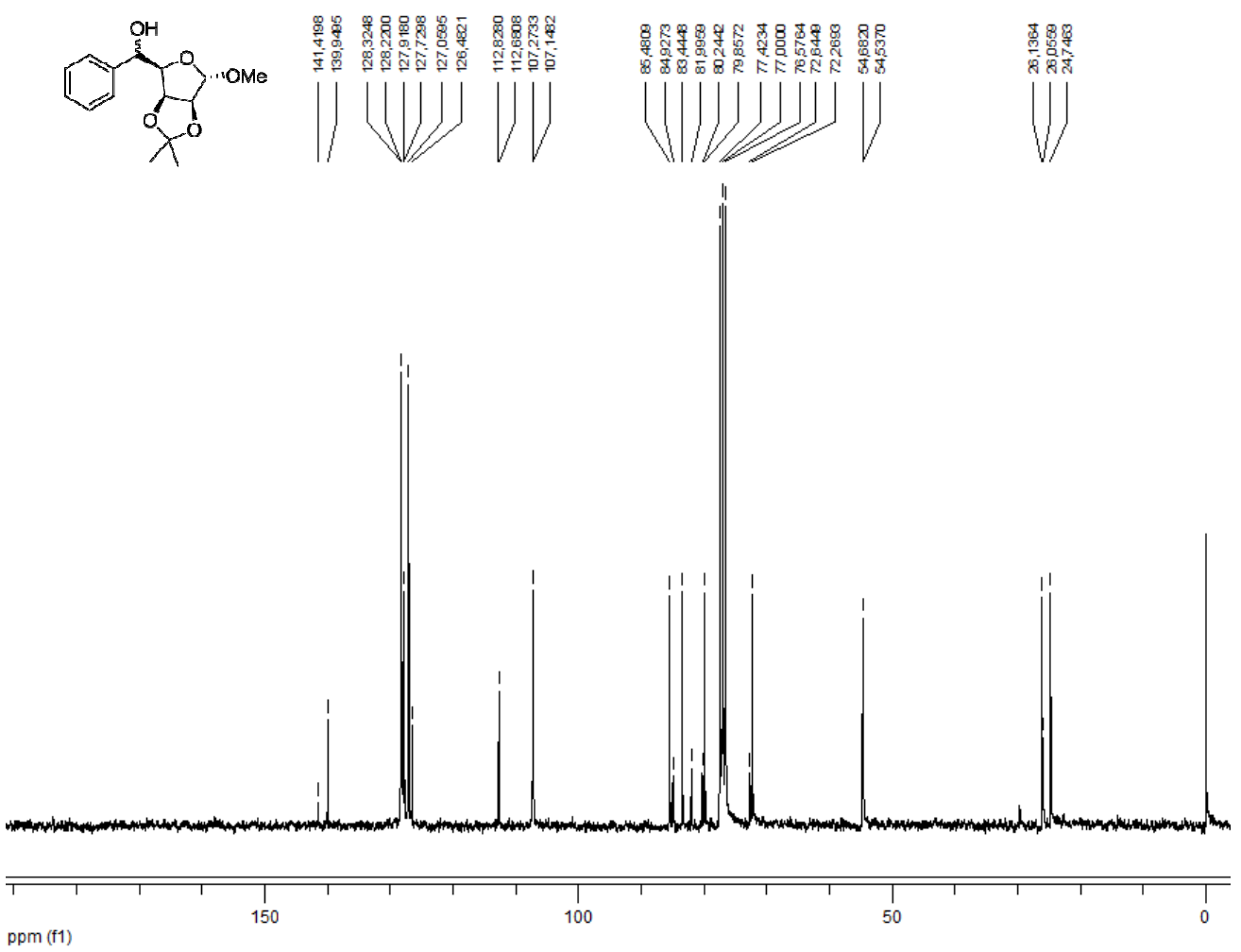

Figura 108. Espectro de $\mathrm{RMN}^{13} \mathrm{C}$ a $75 \mathrm{MHz}$ do composto58a. 


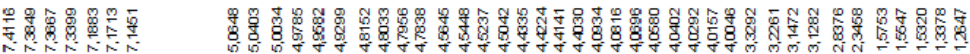

11111
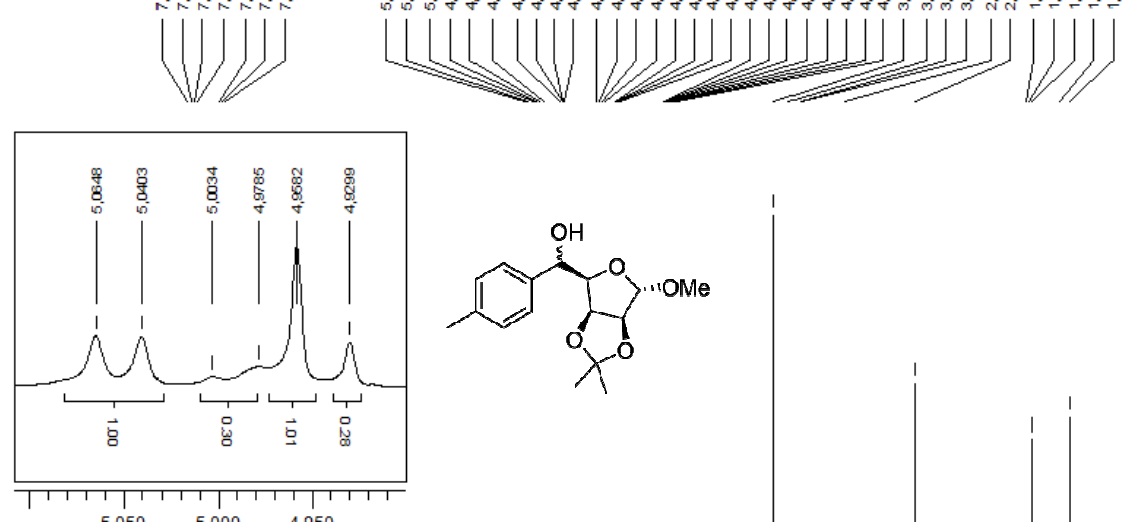

ppm (f1) $5.050 \quad 5.000 \quad 4.95$

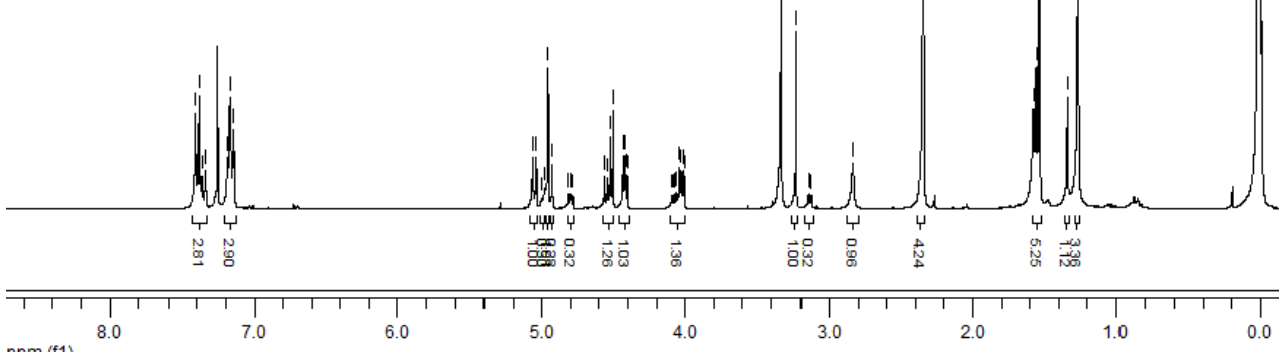

ppm (f1)

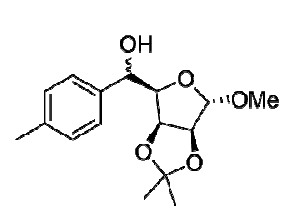

Figura 109. Espectro de $\mathrm{RMN}^{1} \mathrm{H}$ a $300 \mathrm{MHz}$ do composto $\mathbf{5 8 b}$.
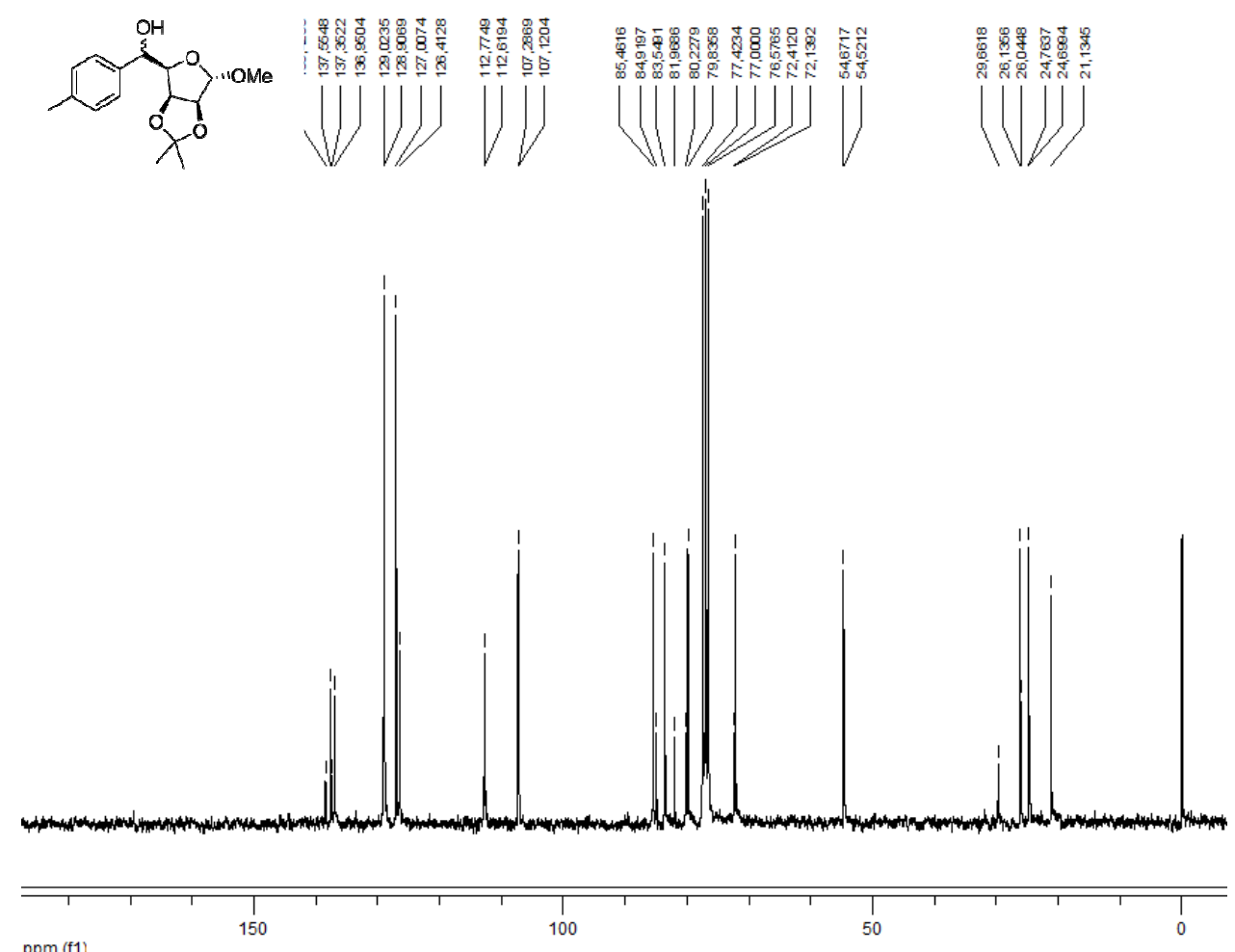

ppm (f1)

Figura 110. Espectro de $\mathrm{RMN}{ }^{13} \mathrm{C}$ a $75 \mathrm{MHz}$ do composto $\mathbf{5 8 b}$. 


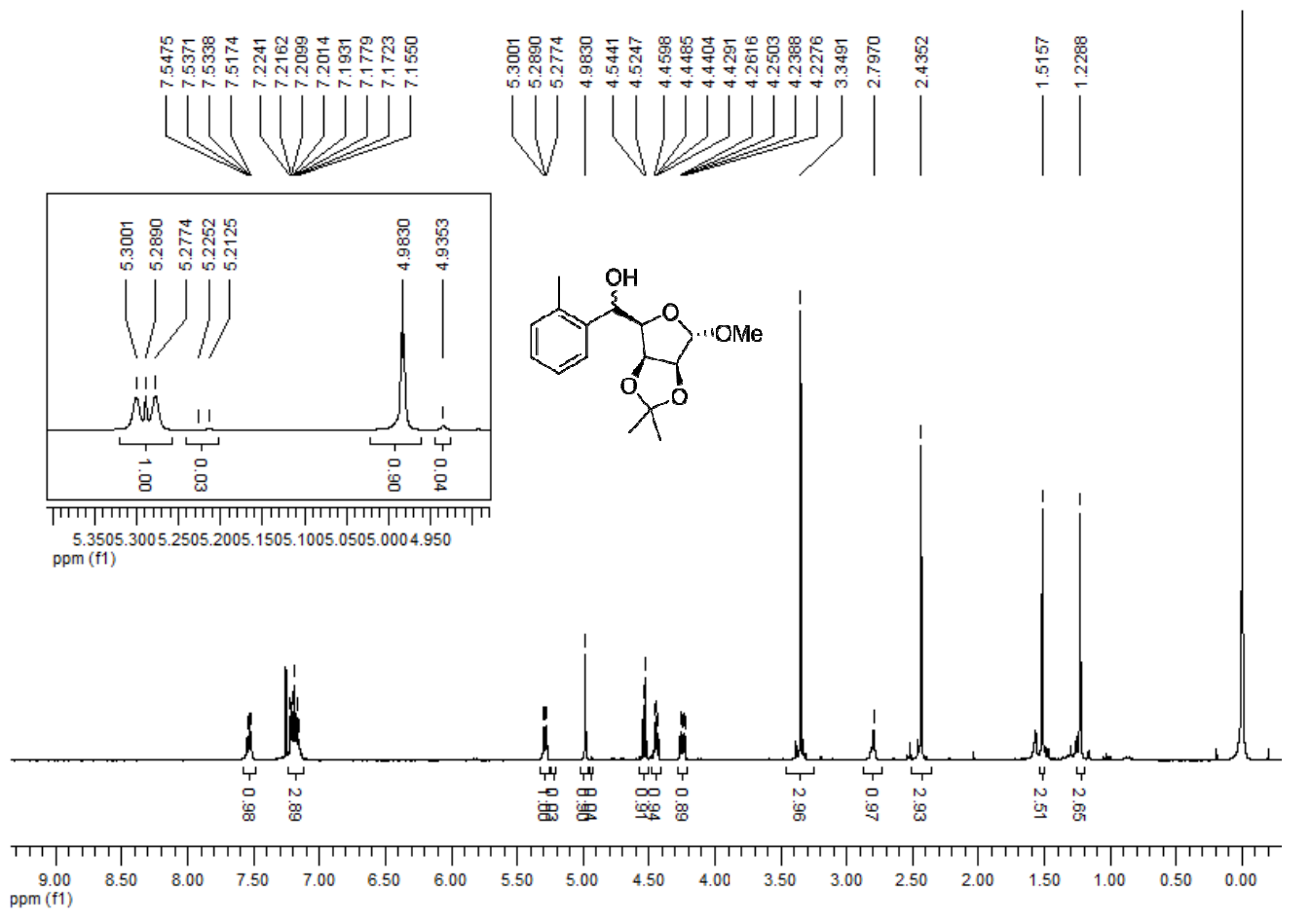

Figura 111. Espectro de $\mathrm{RMN}^{1} \mathrm{H}$ a $300 \mathrm{MHz}$ do composto 58c.
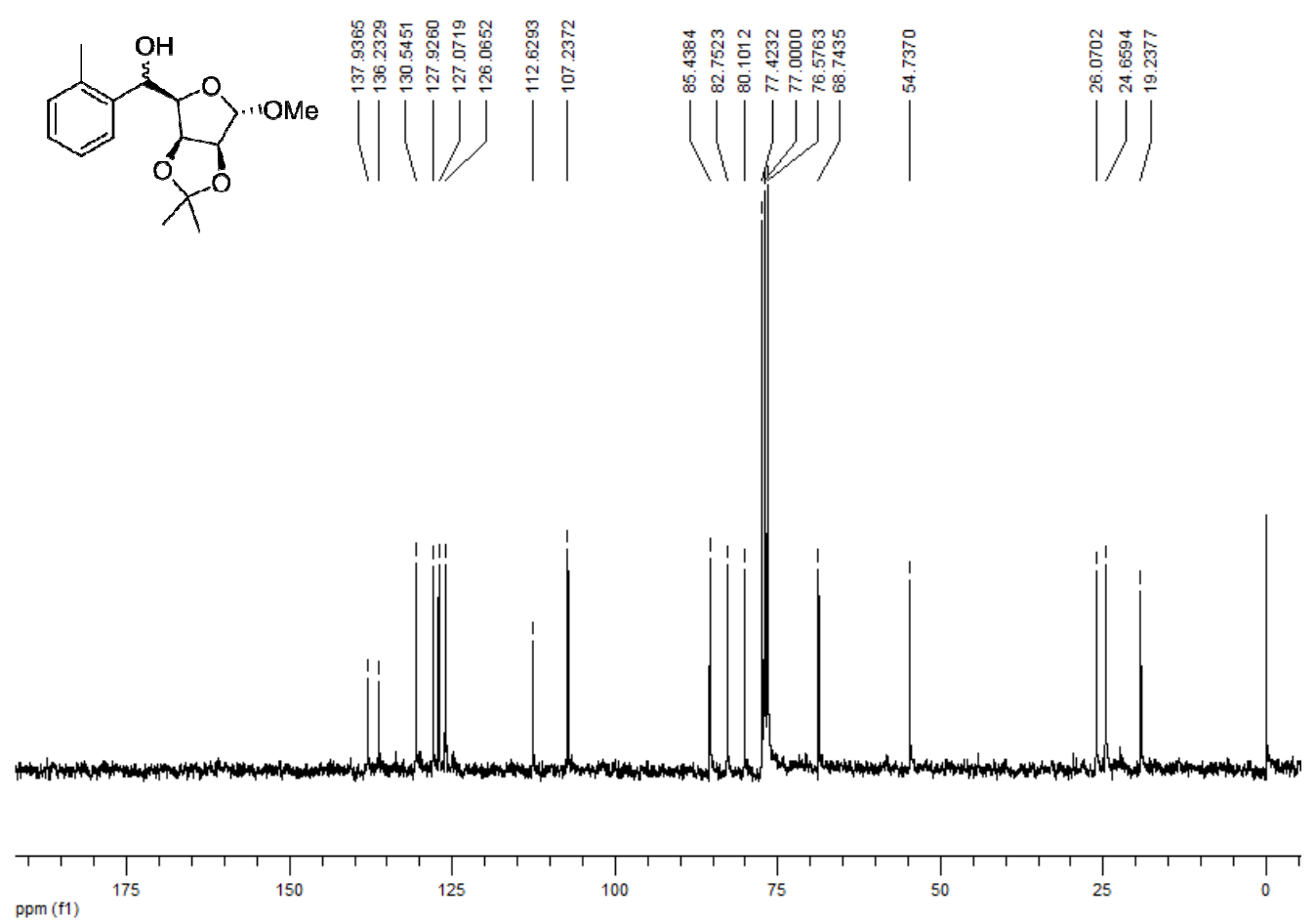

Figura 112. Espectro de $\mathrm{RMN}{ }^{13} \mathrm{C}$ a $75 \mathrm{MHz}$ do composto 58c. 


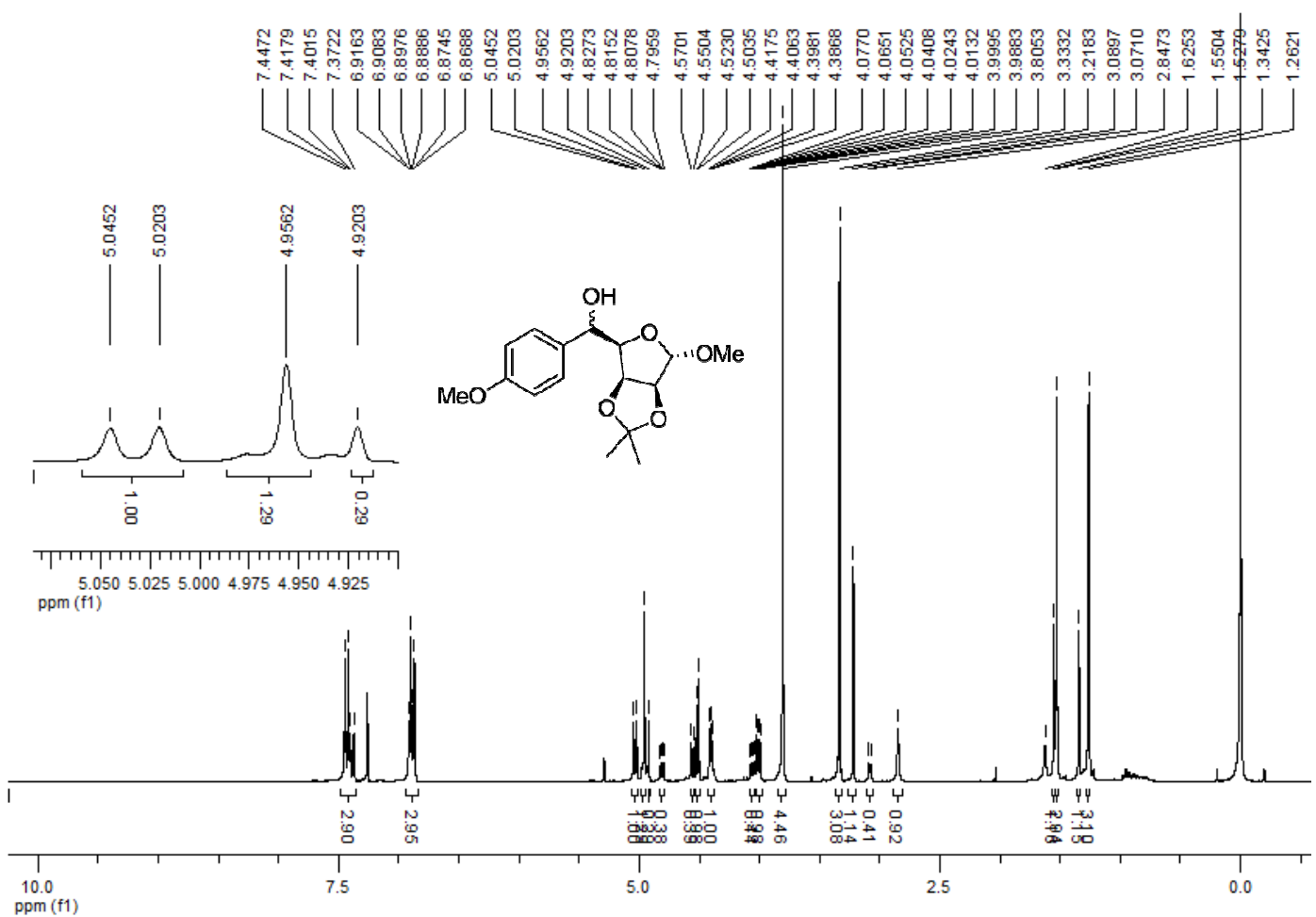

Figura 113. Espectro de $\mathrm{RMN}^{1} \mathrm{H}$ a $300 \mathrm{MHz}$ do composto58d.
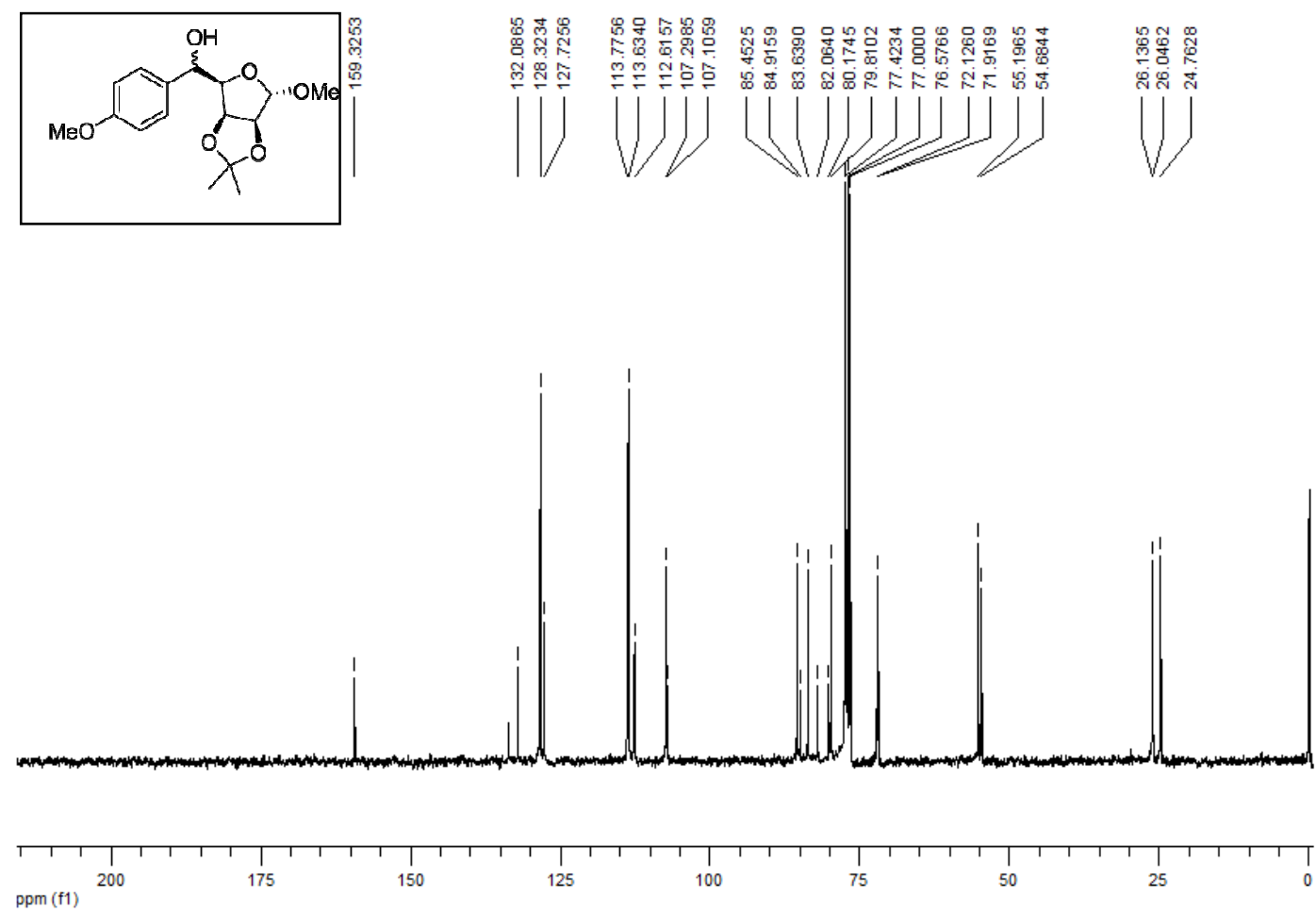

Figura 114. Espectro de $\mathrm{RMN}{ }^{13} \mathrm{C}$ a $75 \mathrm{MHz}$ do composto58d. 


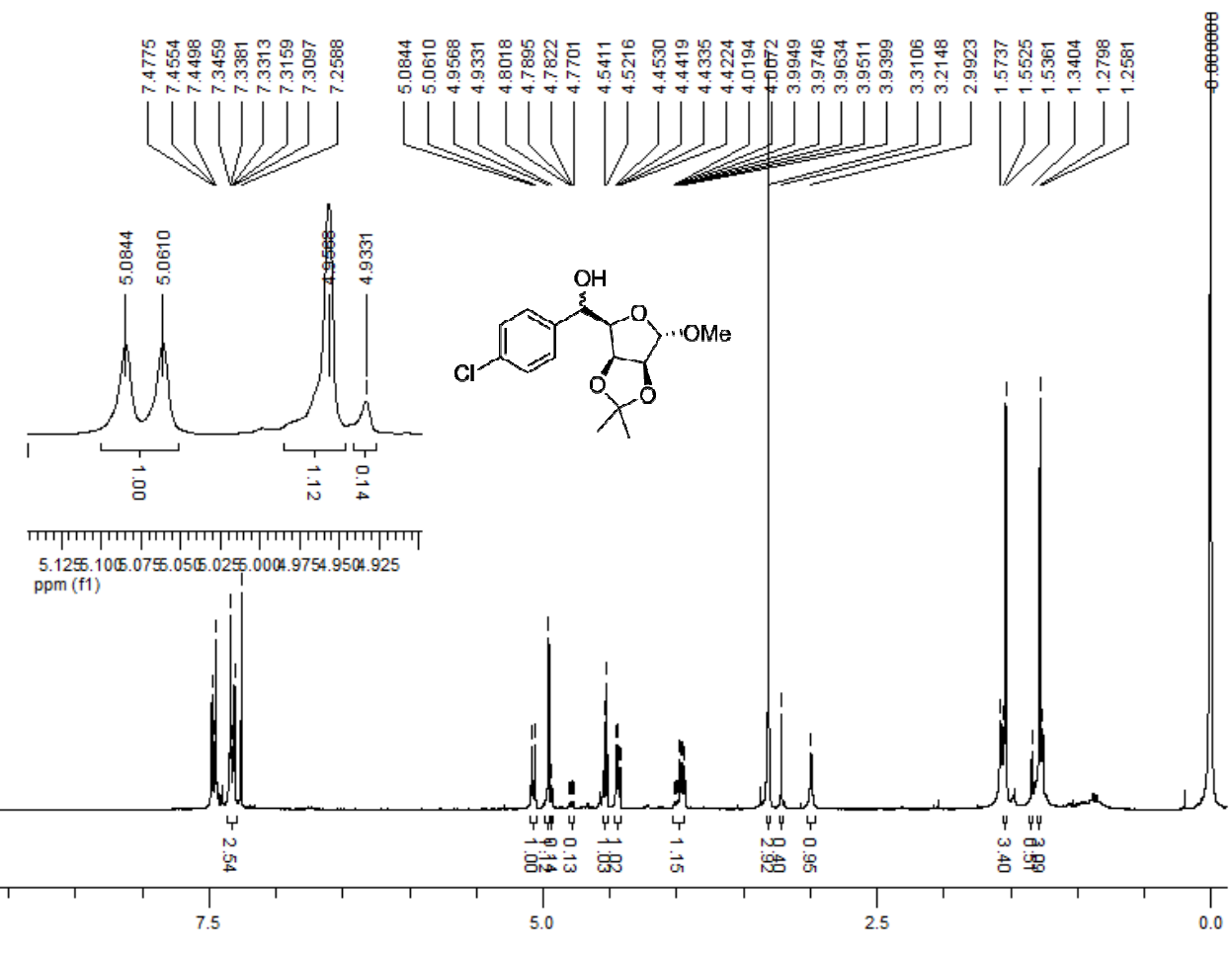

Figura 115. Espectro de RMN ${ }^{1} \mathrm{H}$ a $300 \mathrm{MHz}$ do composto $58 \mathrm{e}$.

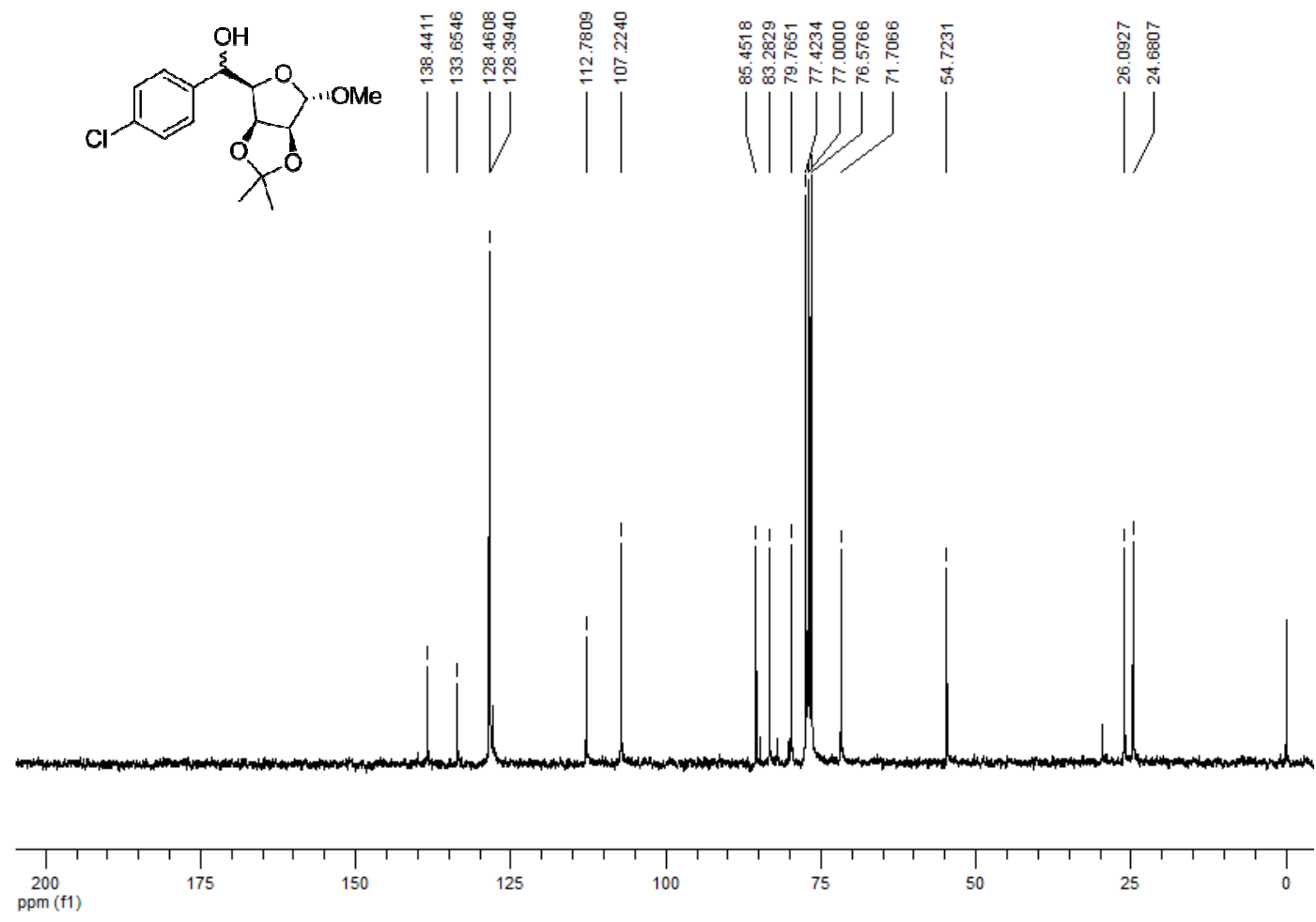

Figura 116. Espectro de $\mathrm{RMN}^{1} \mathrm{H}$ a $75 \mathrm{MHz}$ do composto $58 \mathrm{e}$. 

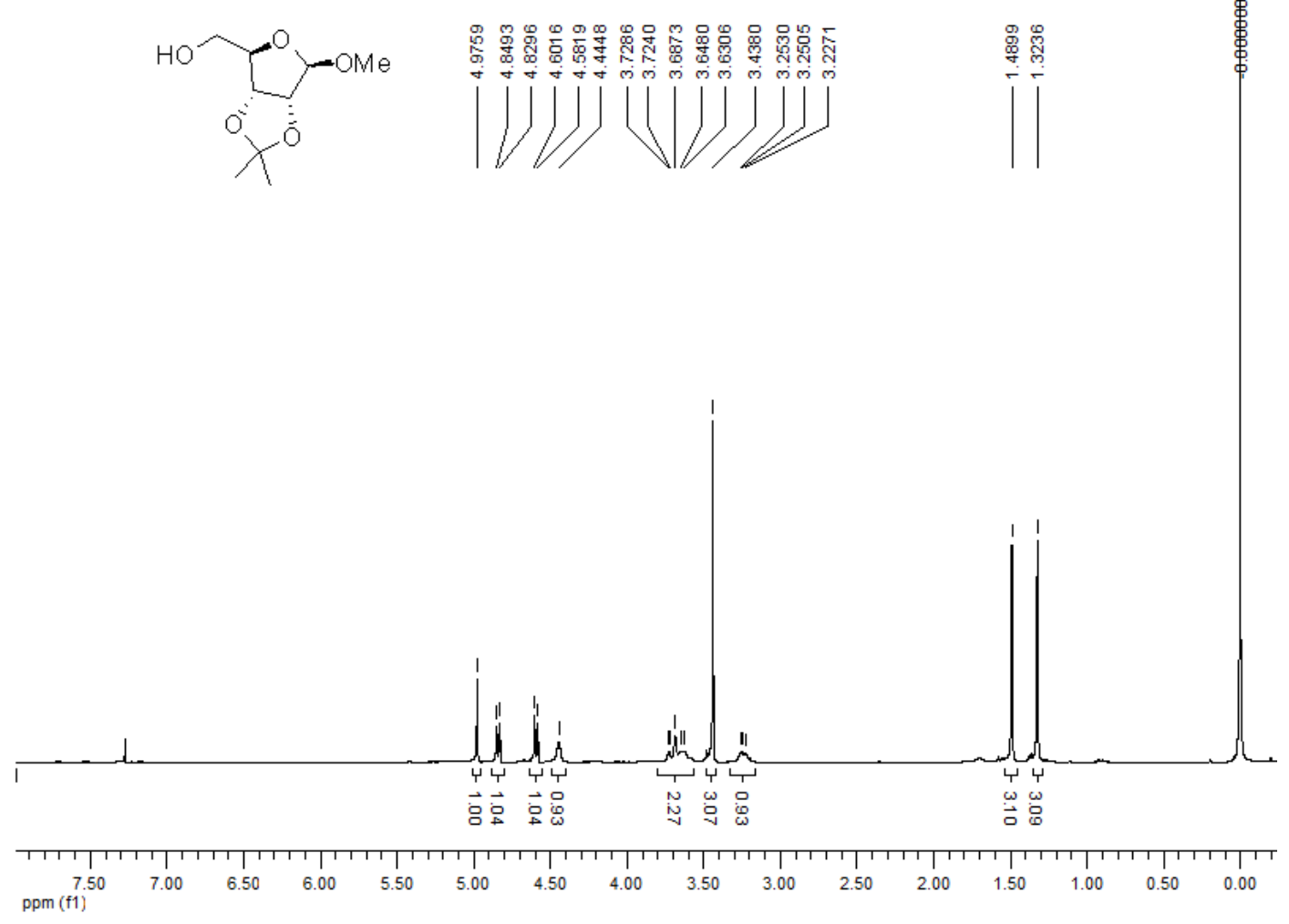

Figura 117. Espectro RMN ${ }^{1} \mathrm{H}$ a $300 \mathrm{MHz}$ do composto54.
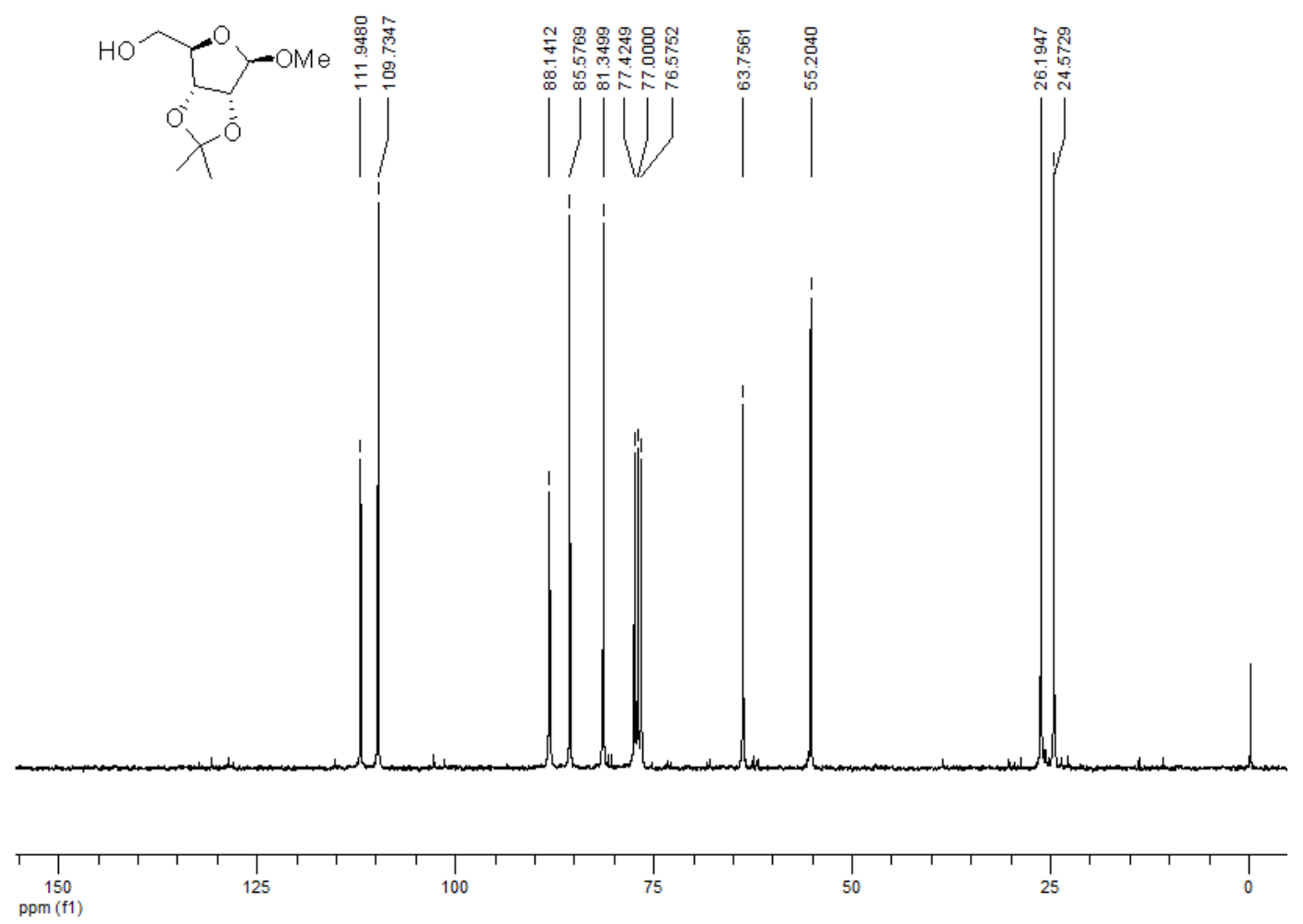

Figura 118. Espectro de $\mathrm{RMN}{ }^{13} \mathrm{C}$ a $75 \mathrm{MHz}$ do composto 54 . 


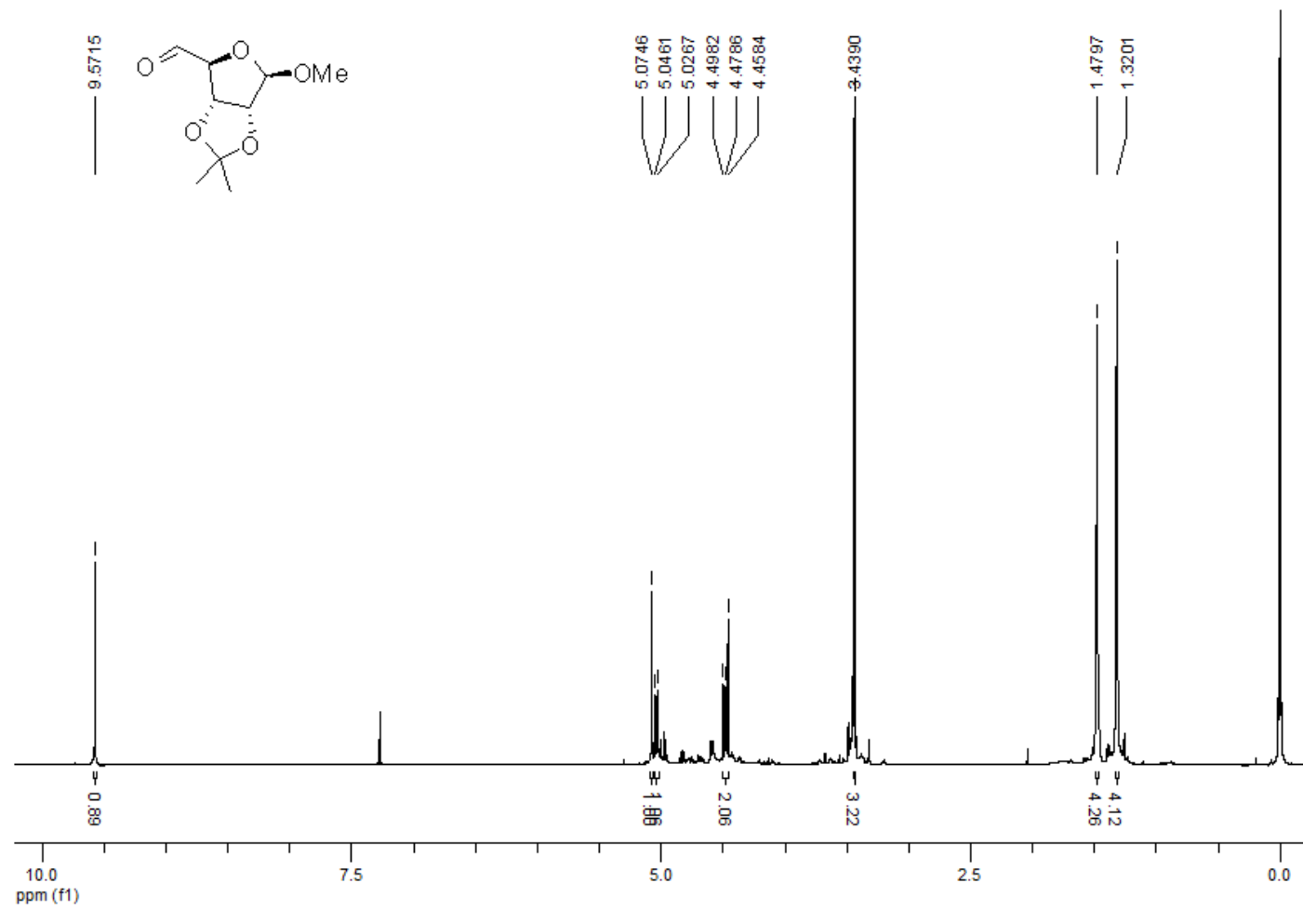

Figura 119. Espectro de $\mathrm{RMN}^{1} \mathrm{Ha} 300 \mathrm{MHz}$ do composto55. 

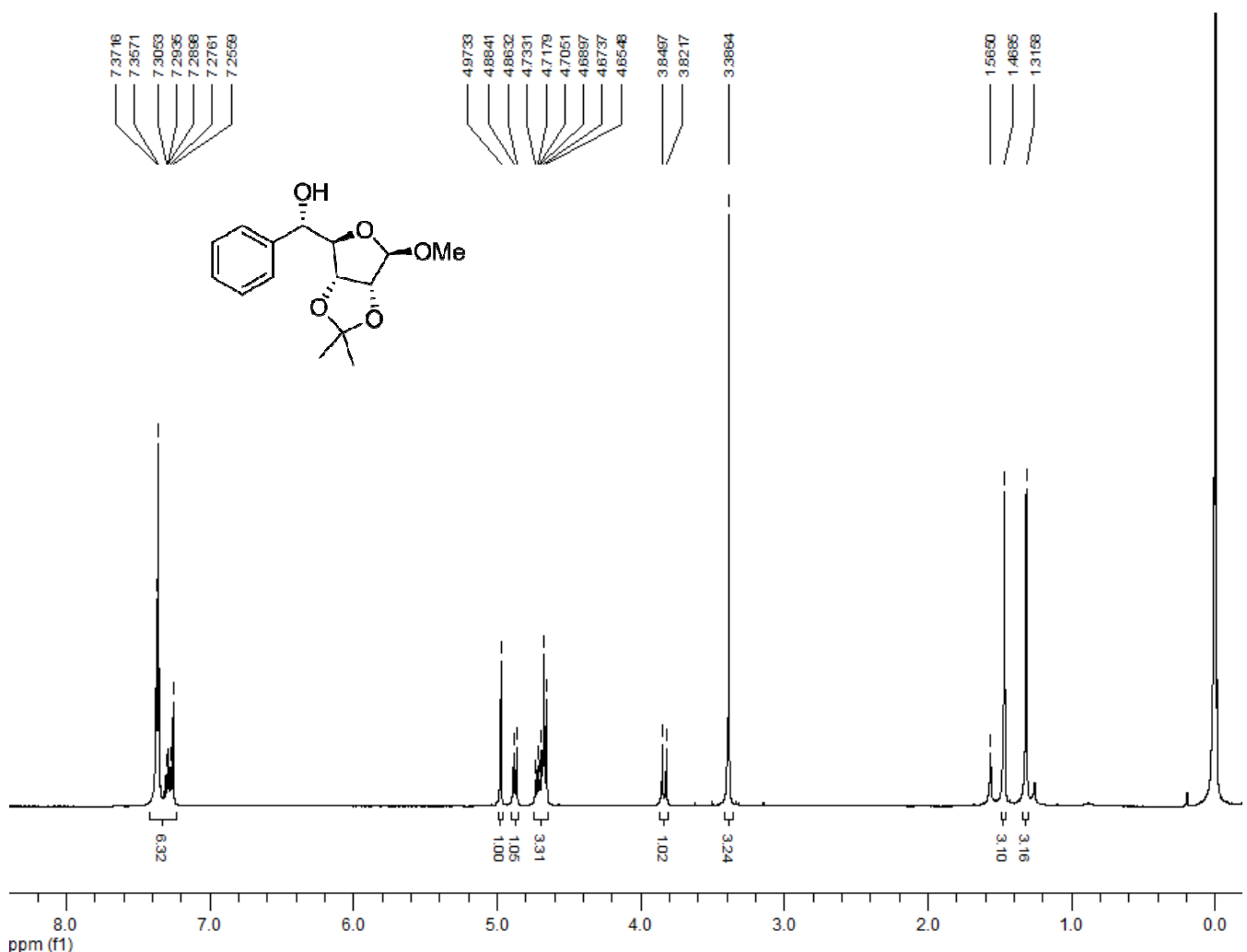

Figura 120. Espectro $\mathrm{RMN}{ }^{1} \mathrm{Ha} 300 \mathrm{MHz}$ do composto59a.
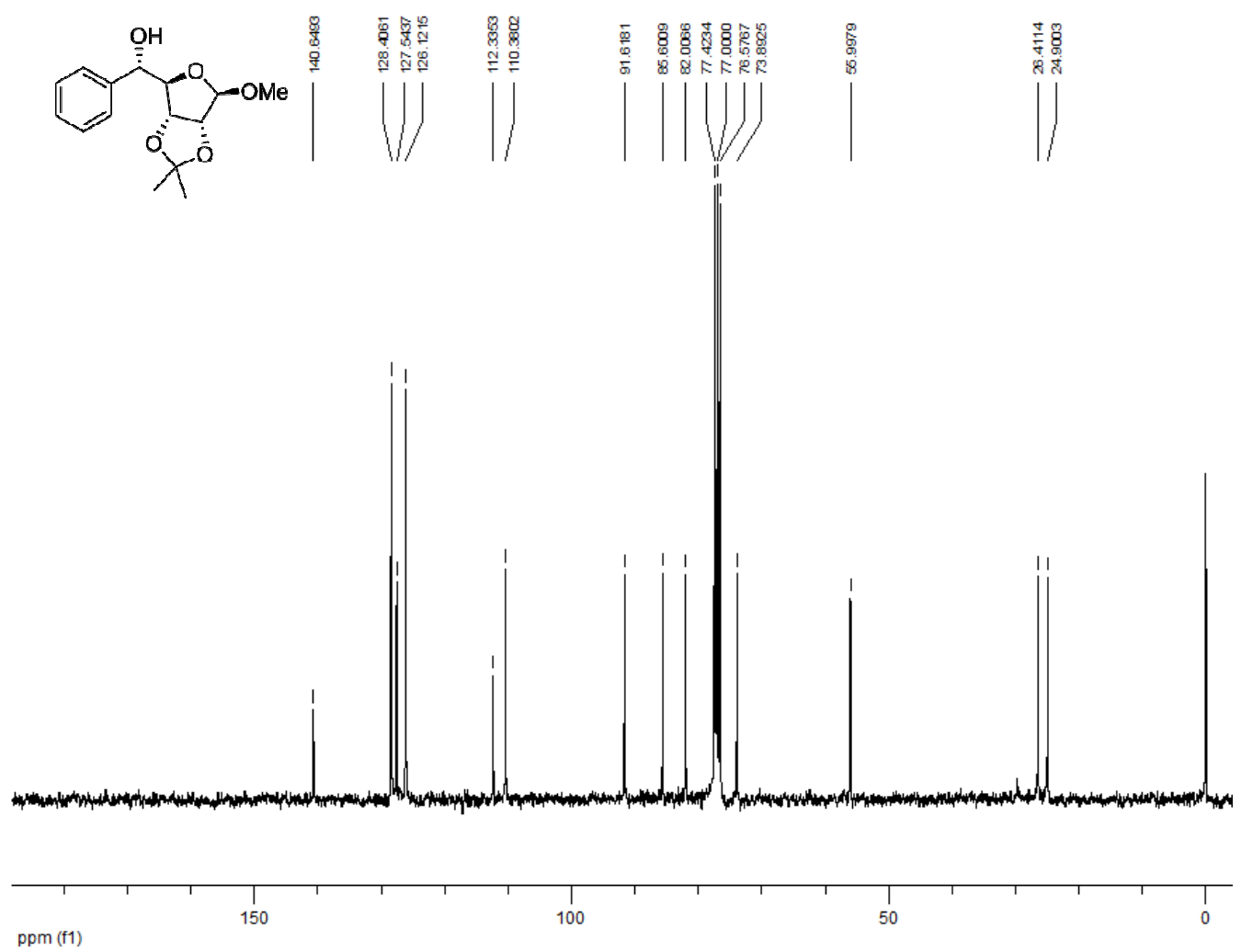

Figura 121. Espectro $\mathrm{RMN}^{13} \mathrm{C}$ a $75 \mathrm{MHz}$ do composto59a. 


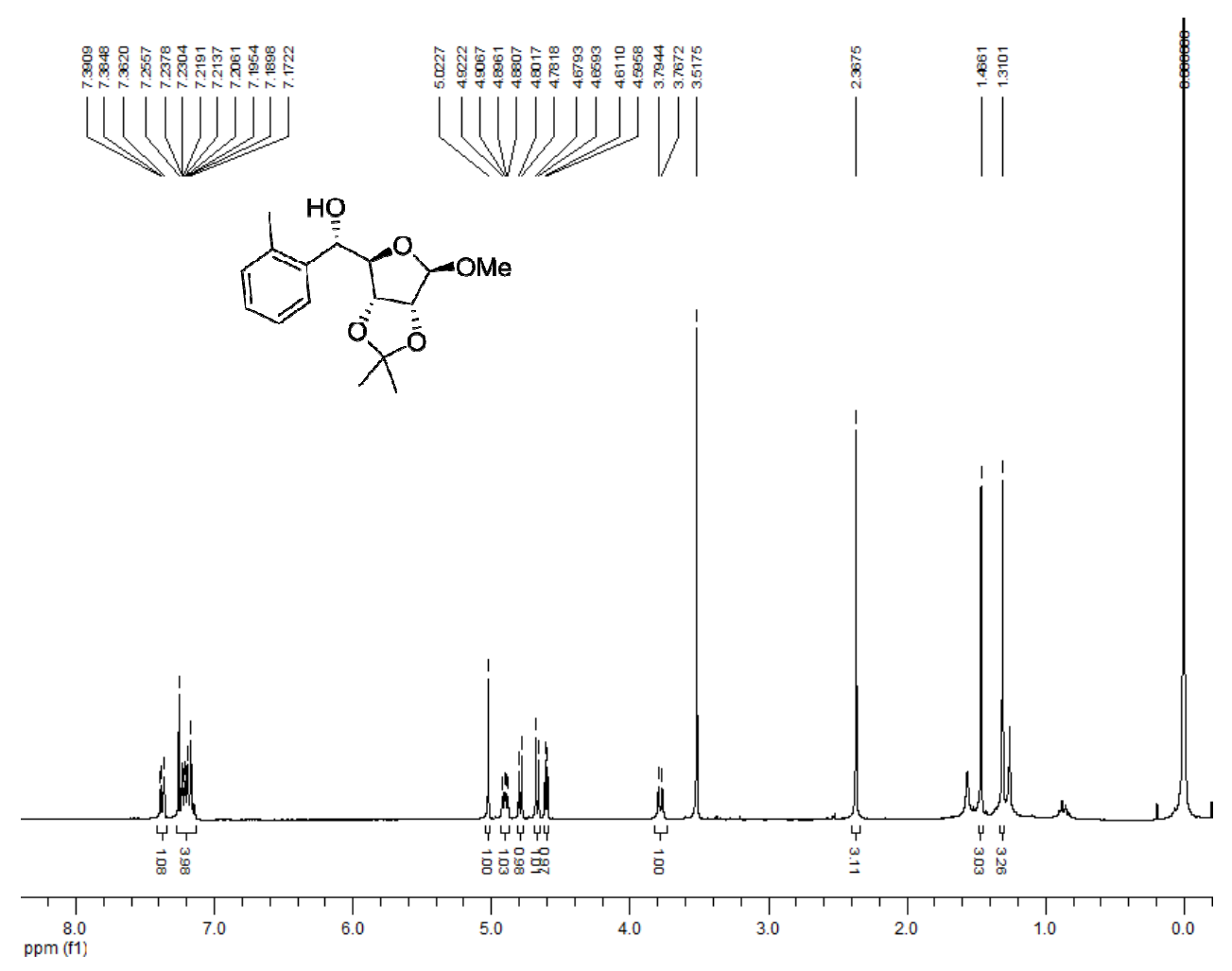

Figura 122. Espectro de RMN ${ }^{1} \mathrm{H}$ a $300 \mathrm{MHz}$ do composto $\mathbf{5 9 b}$.
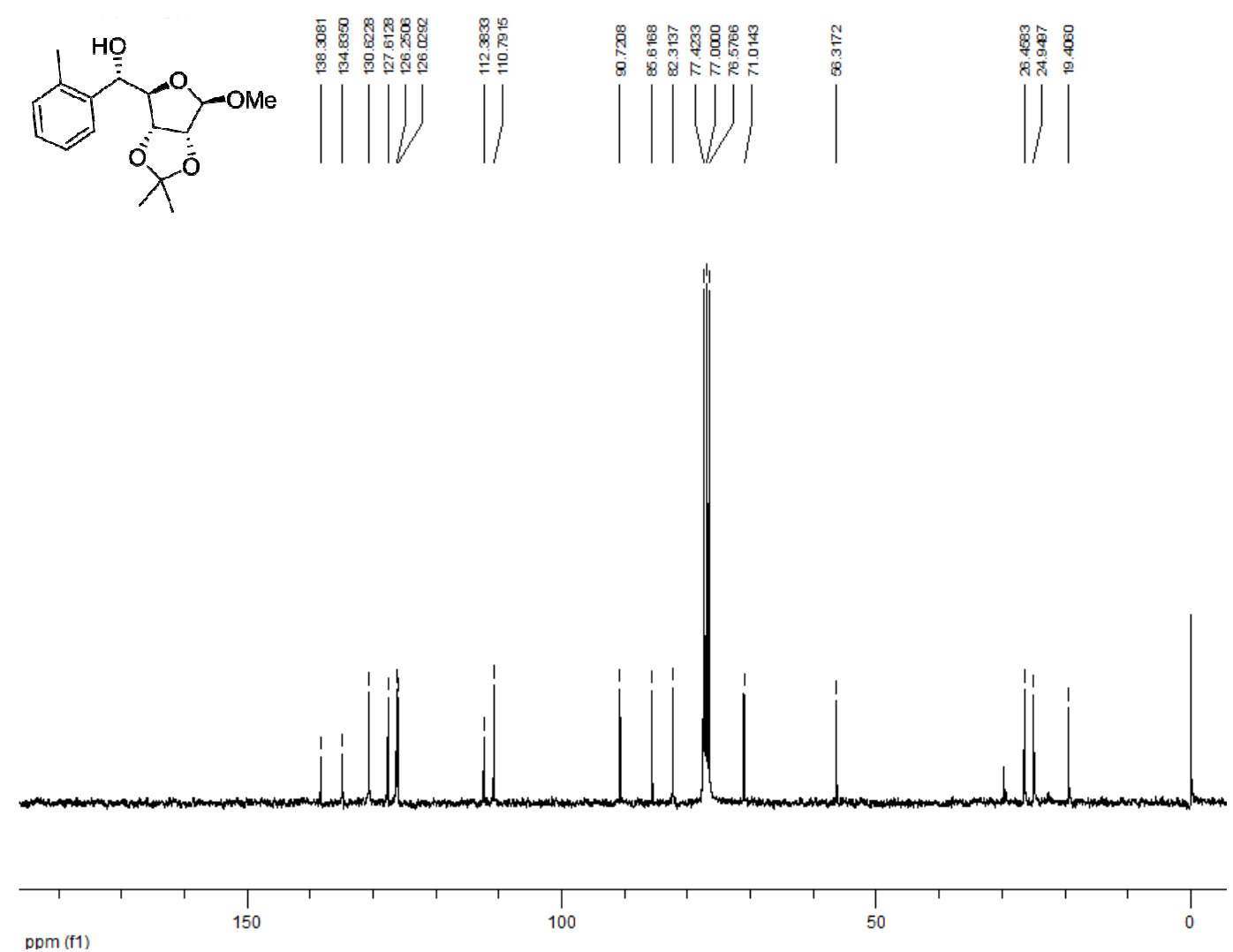

Figura 123. Espectro de $\mathrm{RMN}{ }^{13} \mathrm{C}$ a $75 \mathrm{MHz}$ do composto $\mathbf{5 9 b}$. 


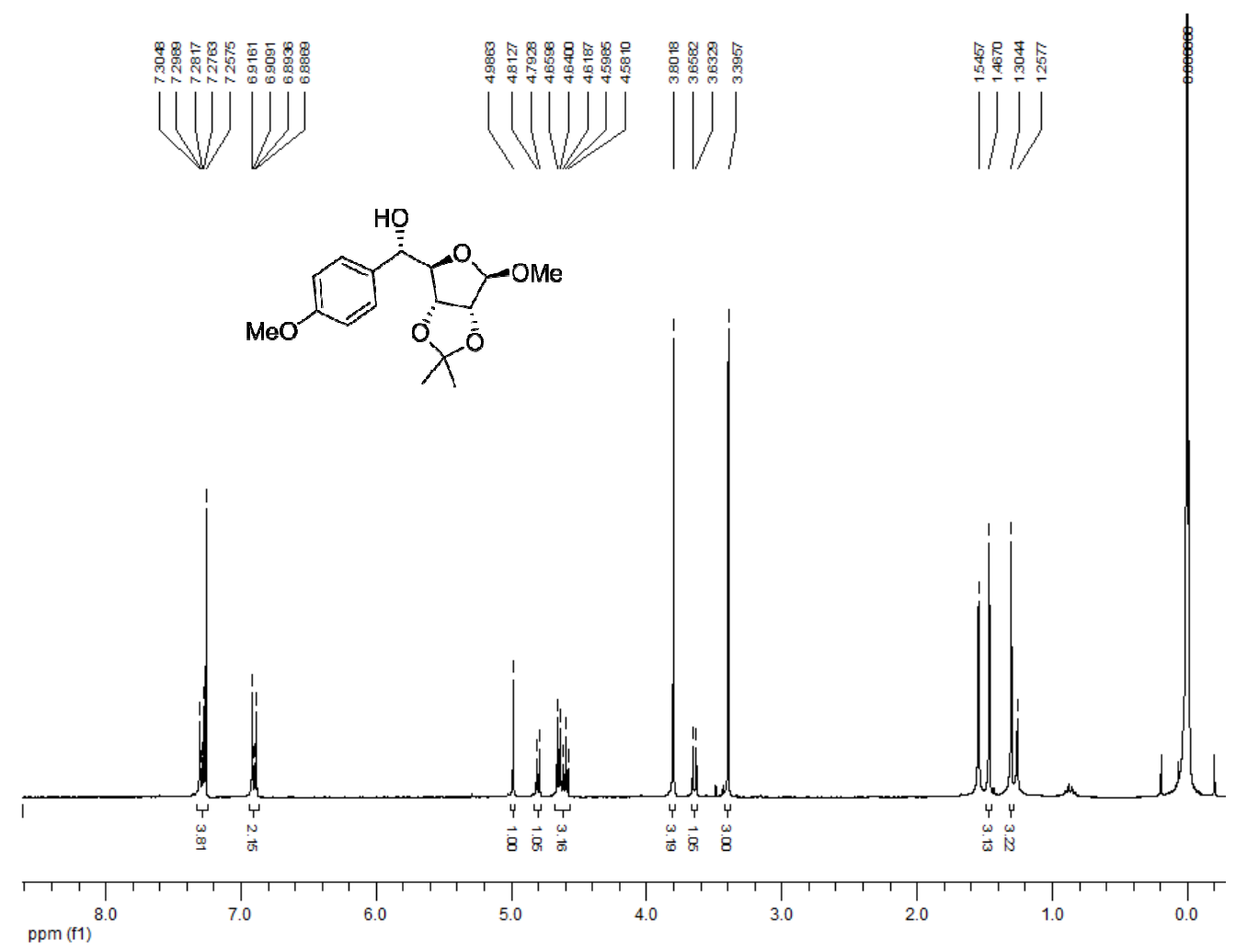

Figura 124. Espectro de $\mathrm{RMN}^{1} \mathrm{H}$ a $300 \mathrm{MHz}$ do composto 59c.
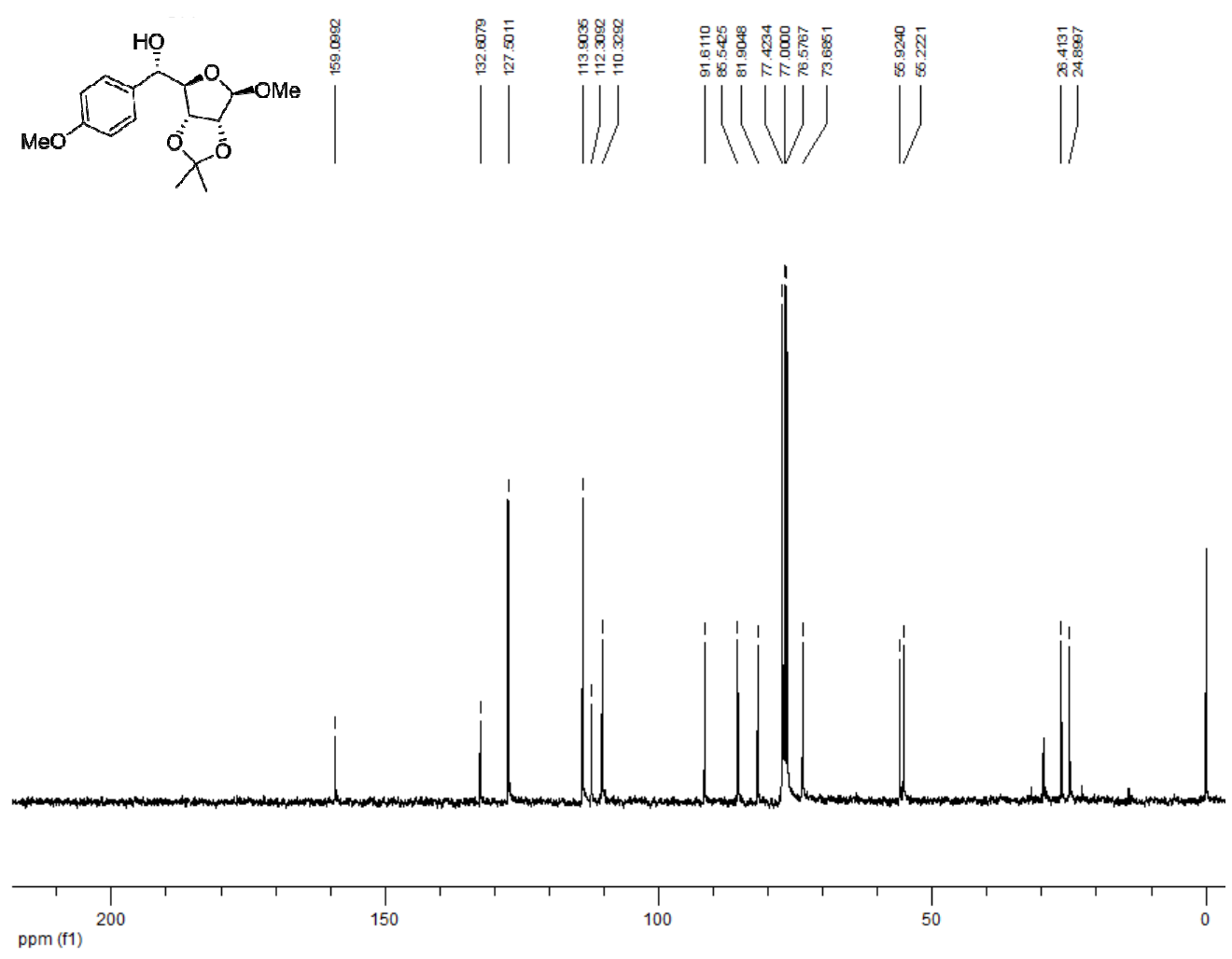

Figura 125. Espectro de $\mathrm{RMN}{ }^{13} \mathrm{C}$ a $75 \mathrm{MHz}$ do composto $59 \mathrm{c}$. 

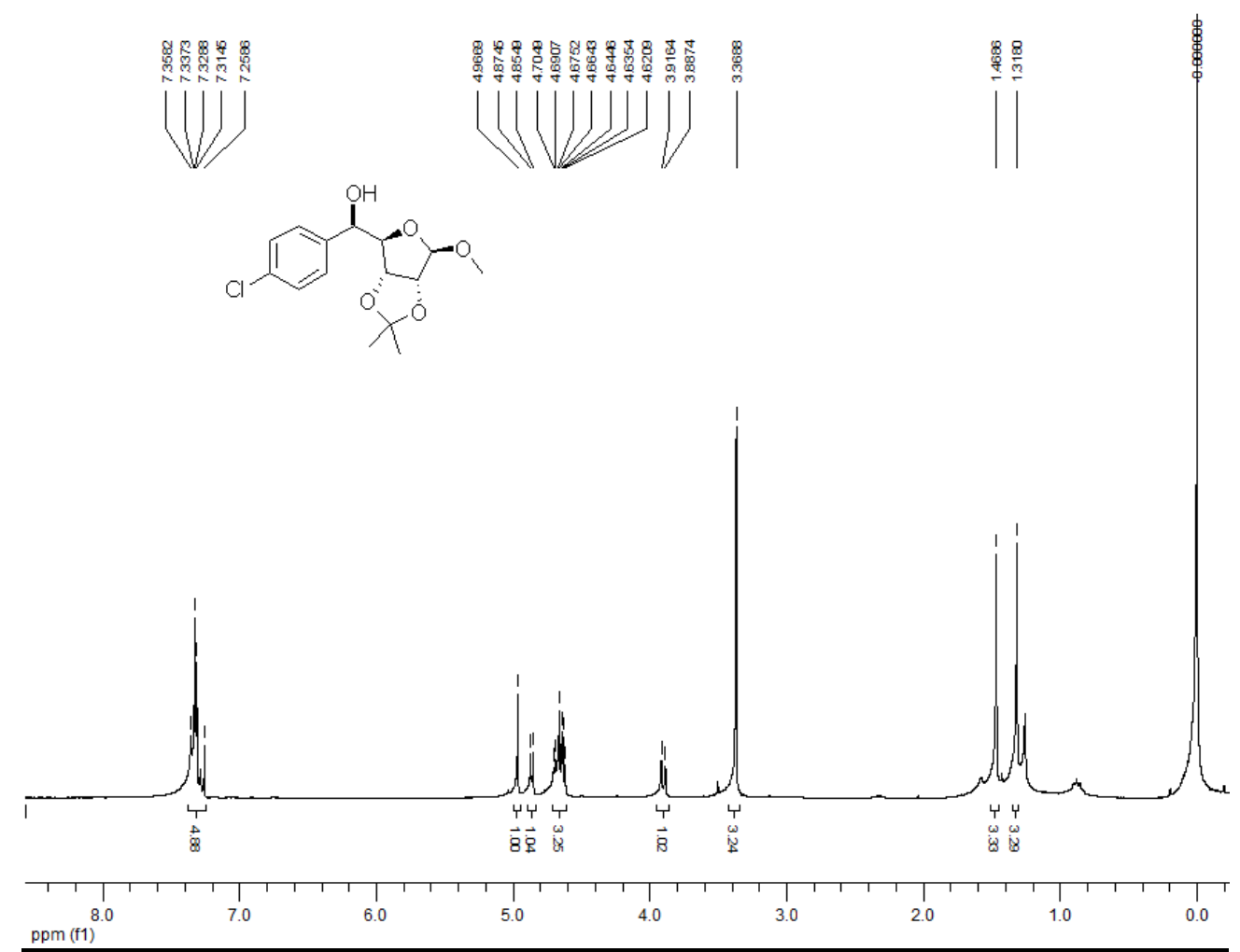

Figura 126. Espectro de $\mathrm{RMN}^{1} \mathrm{H}$ a $300 \mathrm{MHz}$ do composto 59d.

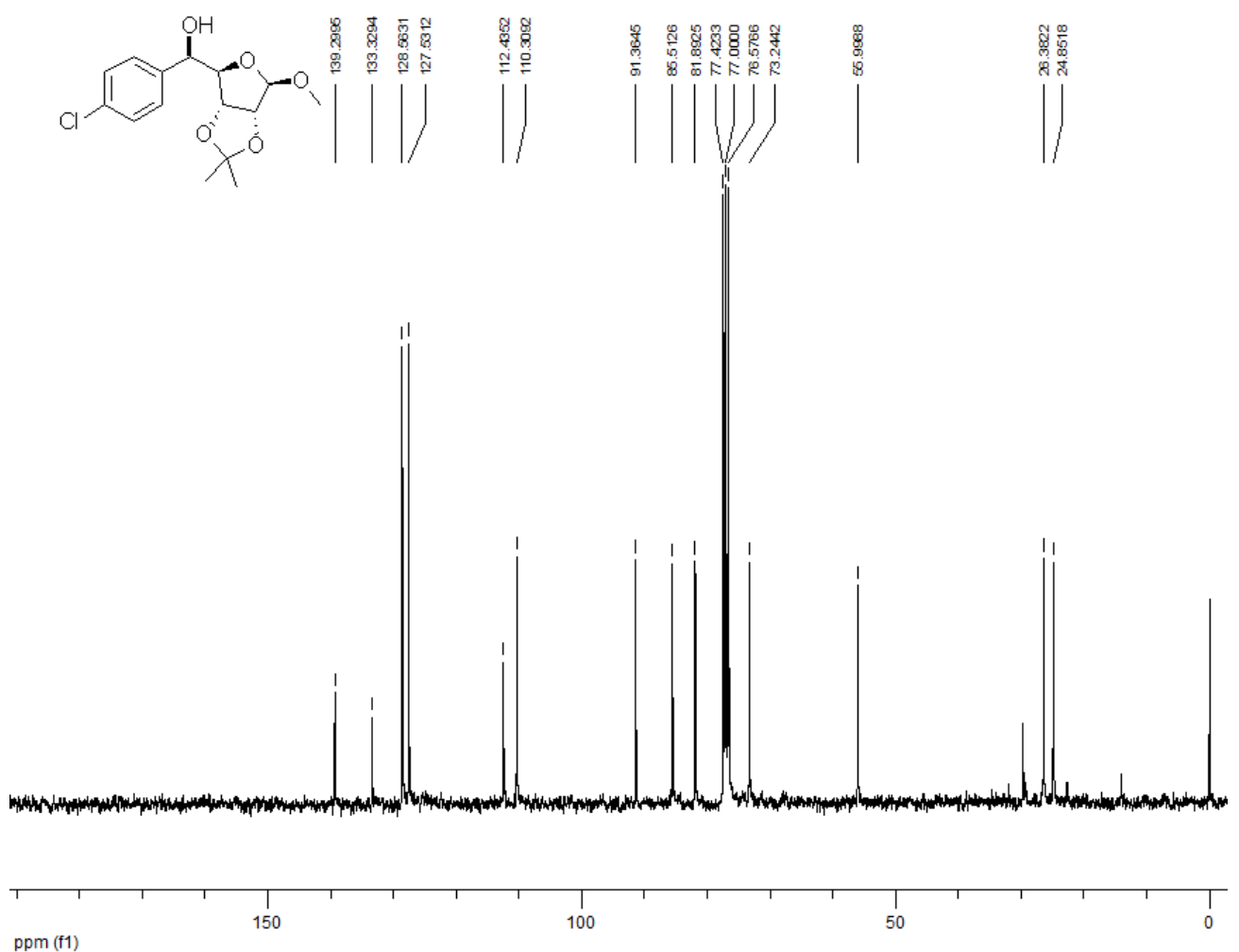

Figura 127. Espectro de $\mathrm{RMN}{ }^{13} \mathrm{C}$ a $75 \mathrm{MHz}$ do composto59d. 


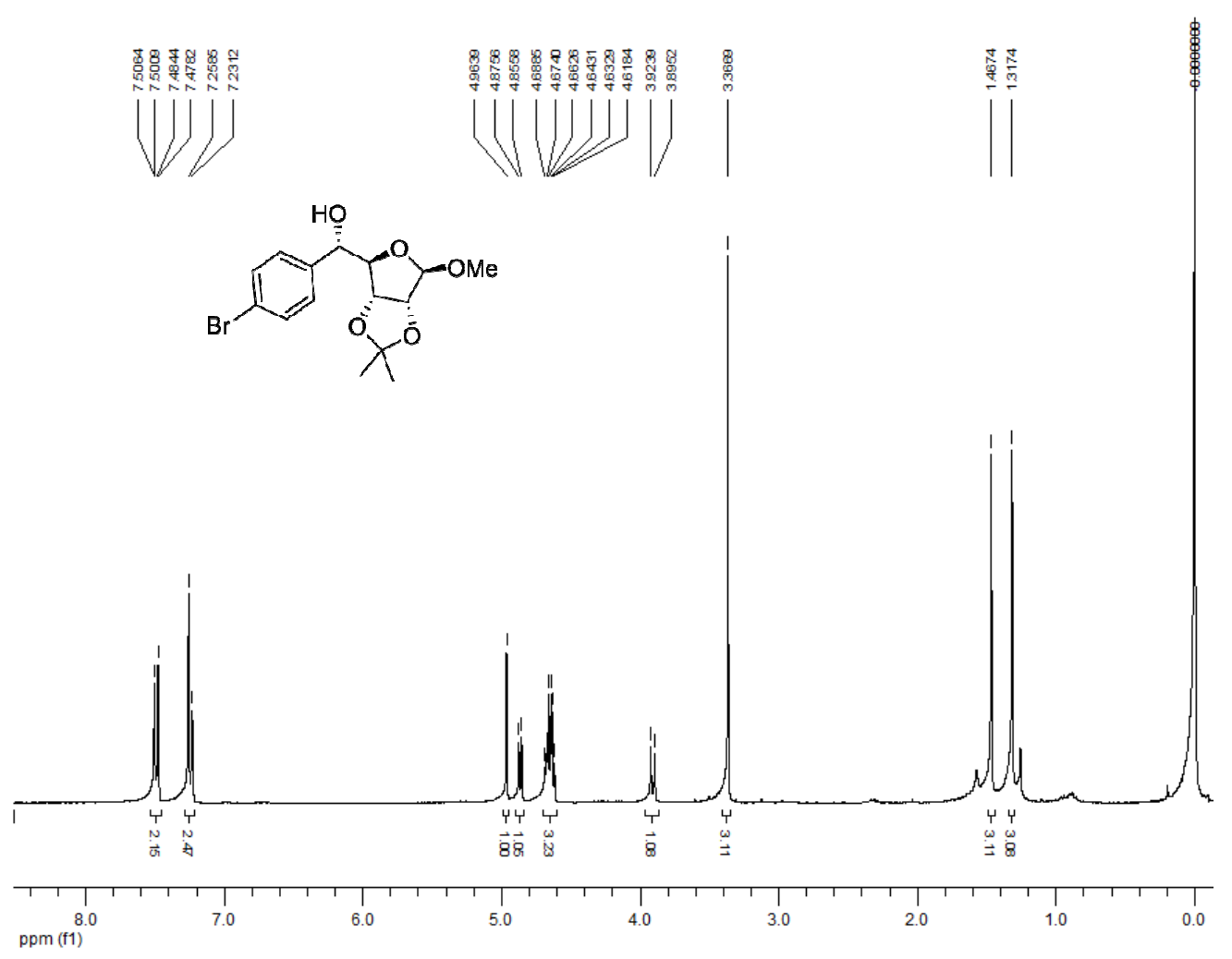

Figura 128. Espectro de $\mathrm{RMN}^{1} \mathrm{H}$ a $300 \mathrm{MHz}$ do composto 59 e.

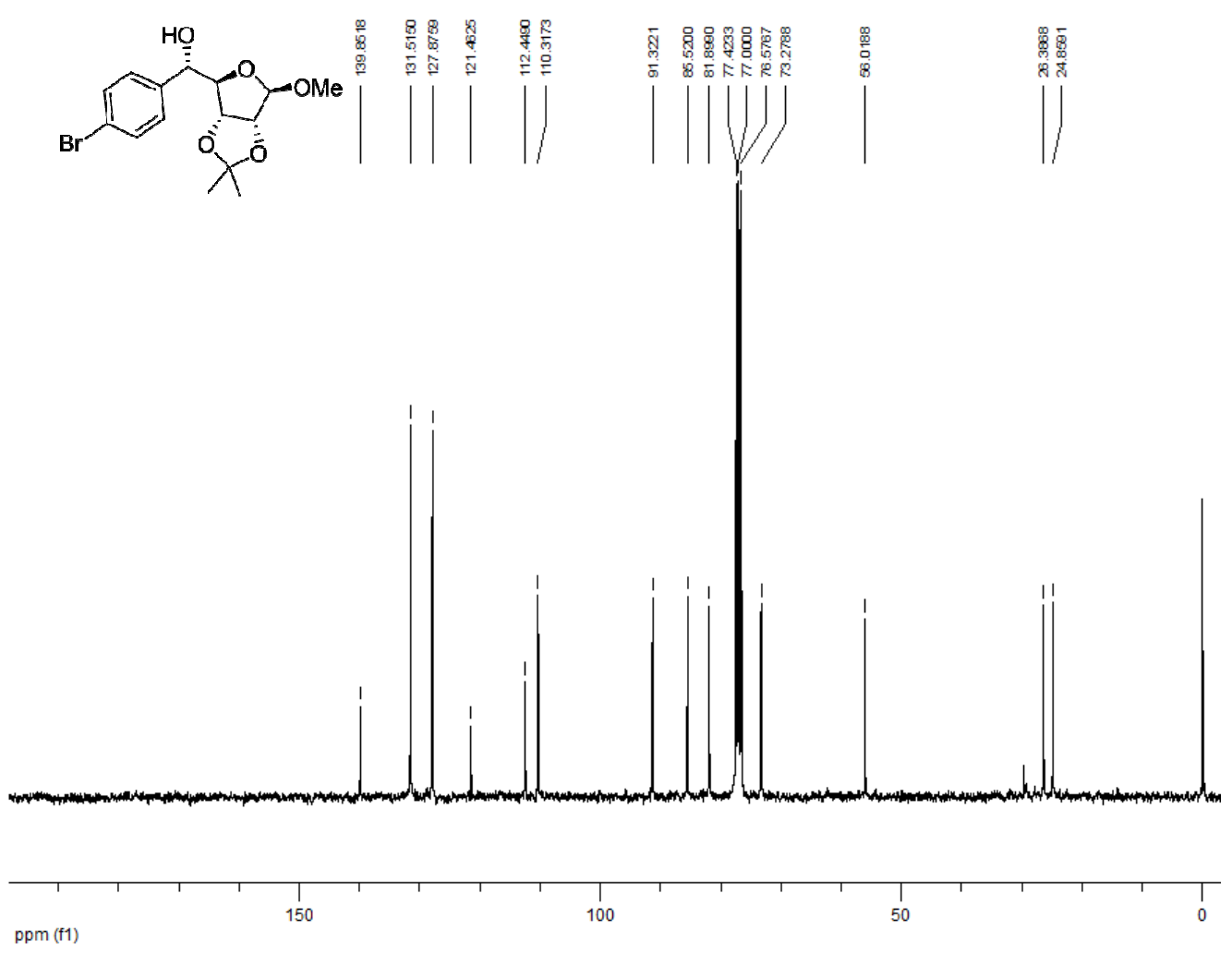

Figura 129. Espectro de $\mathrm{RMN}{ }^{13} \mathrm{C}$ a $75 \mathrm{MHz}$ do composto $59 \mathrm{e}$. 

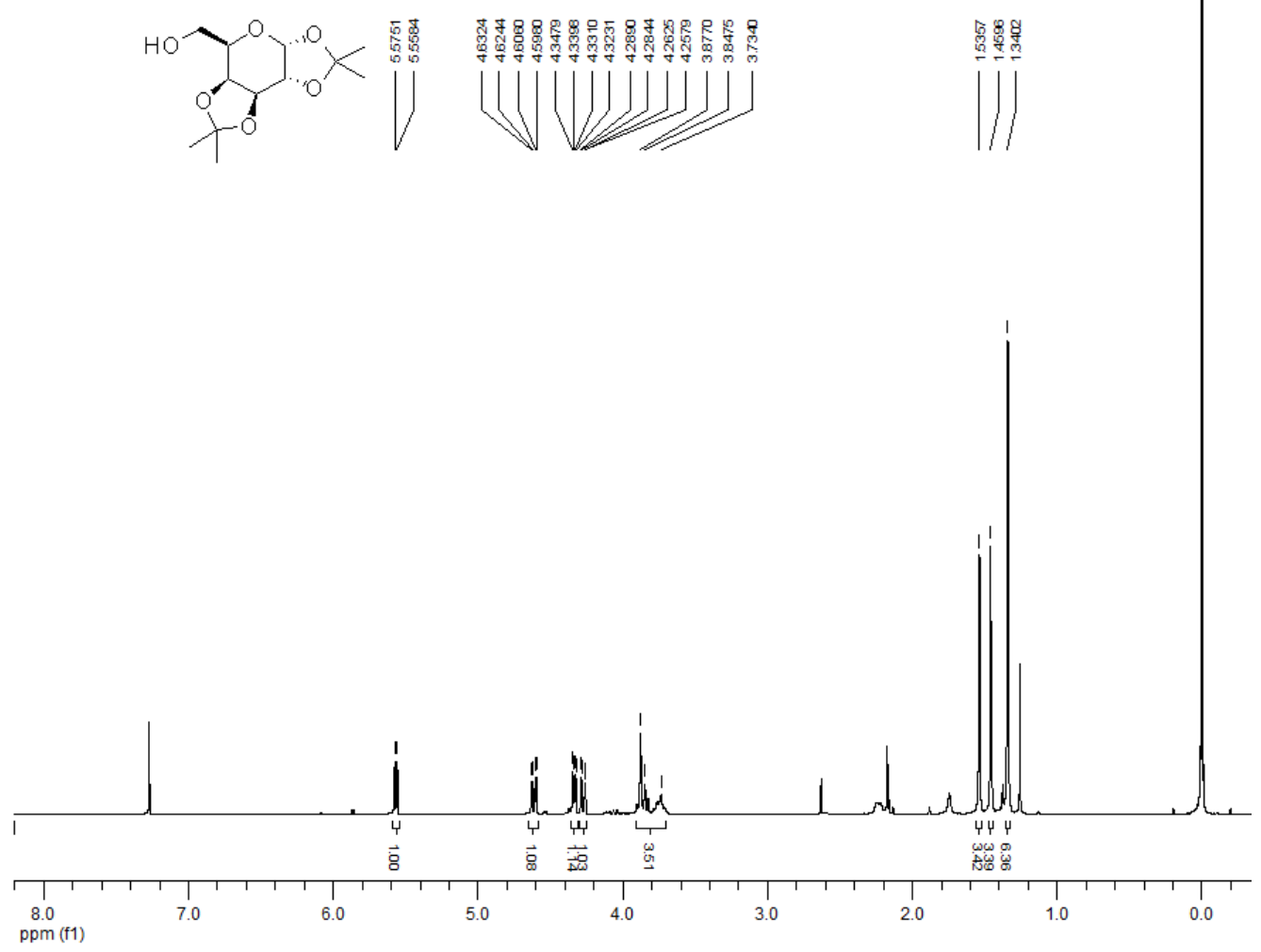

Figura 130. Espectro de $\mathrm{RMN}^{1} \mathrm{H}$ a $300 \mathrm{MHz}$ do composto 56.
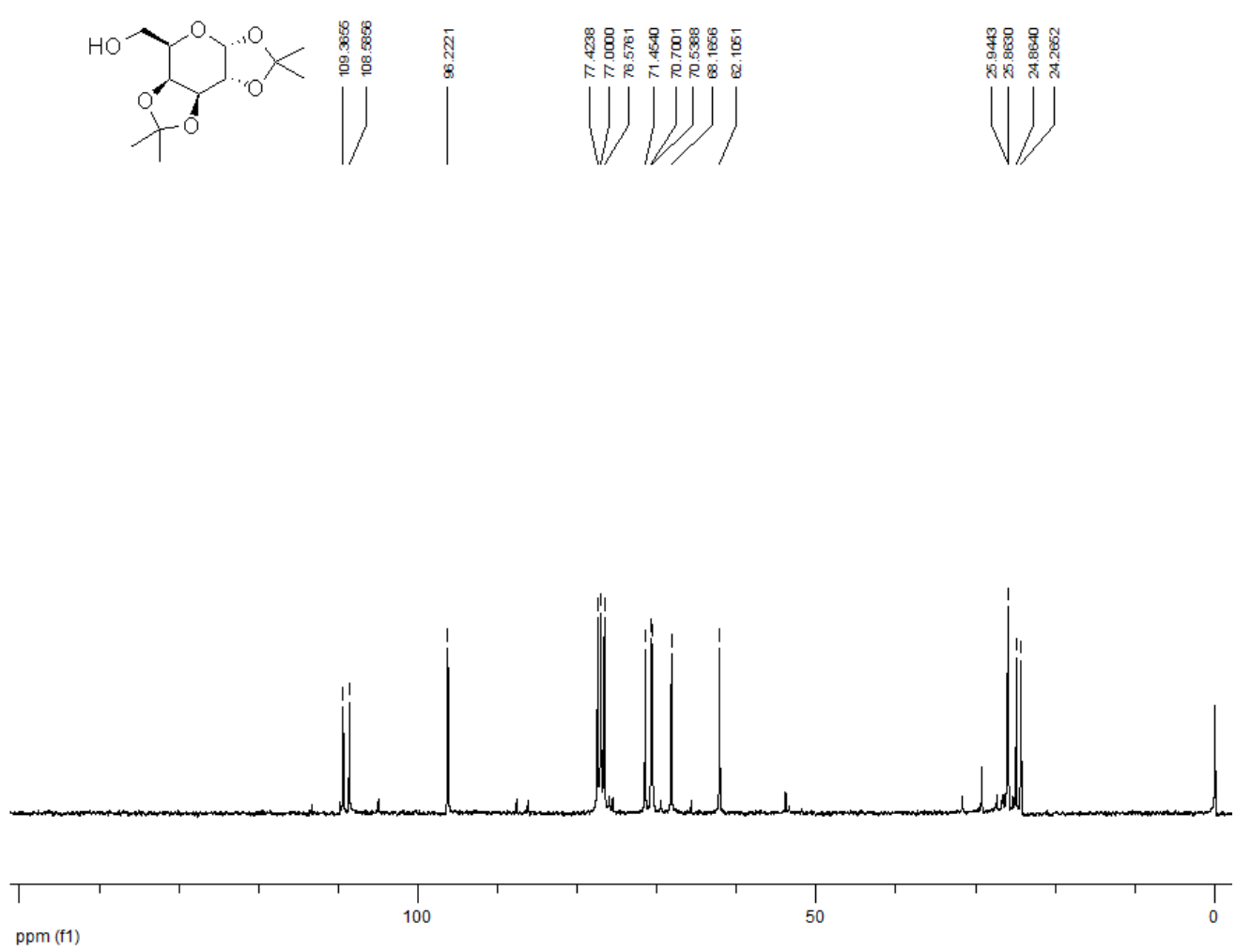

Figura 131. Espectro RMN ${ }^{13} \mathrm{C}$ a $75 \mathrm{MHz}$ do composto 56. 


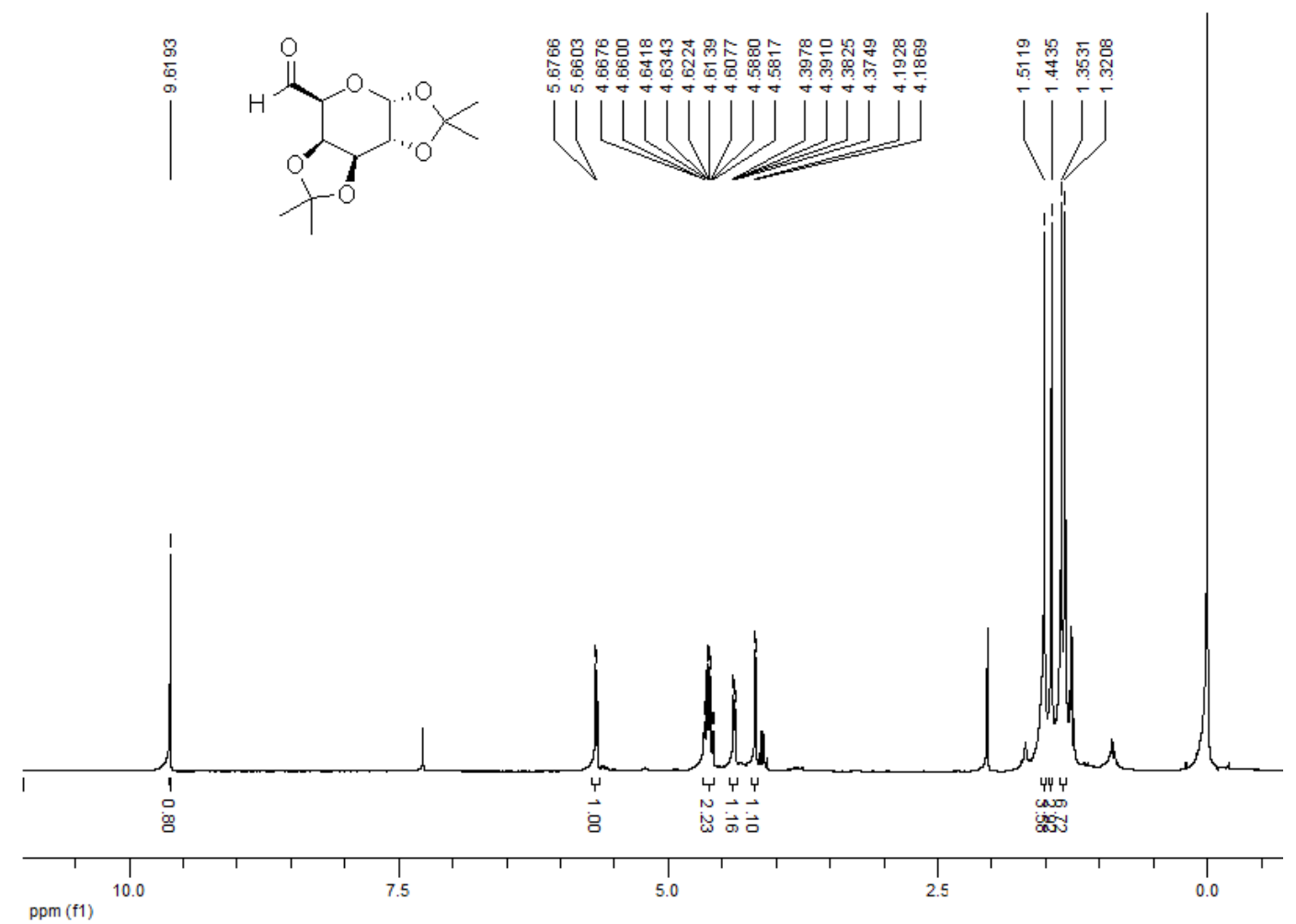

Figura 132. Espectro $\mathrm{RMN}^{1} \mathrm{H}$ a $300 \mathrm{MHz}$ do composto 57.
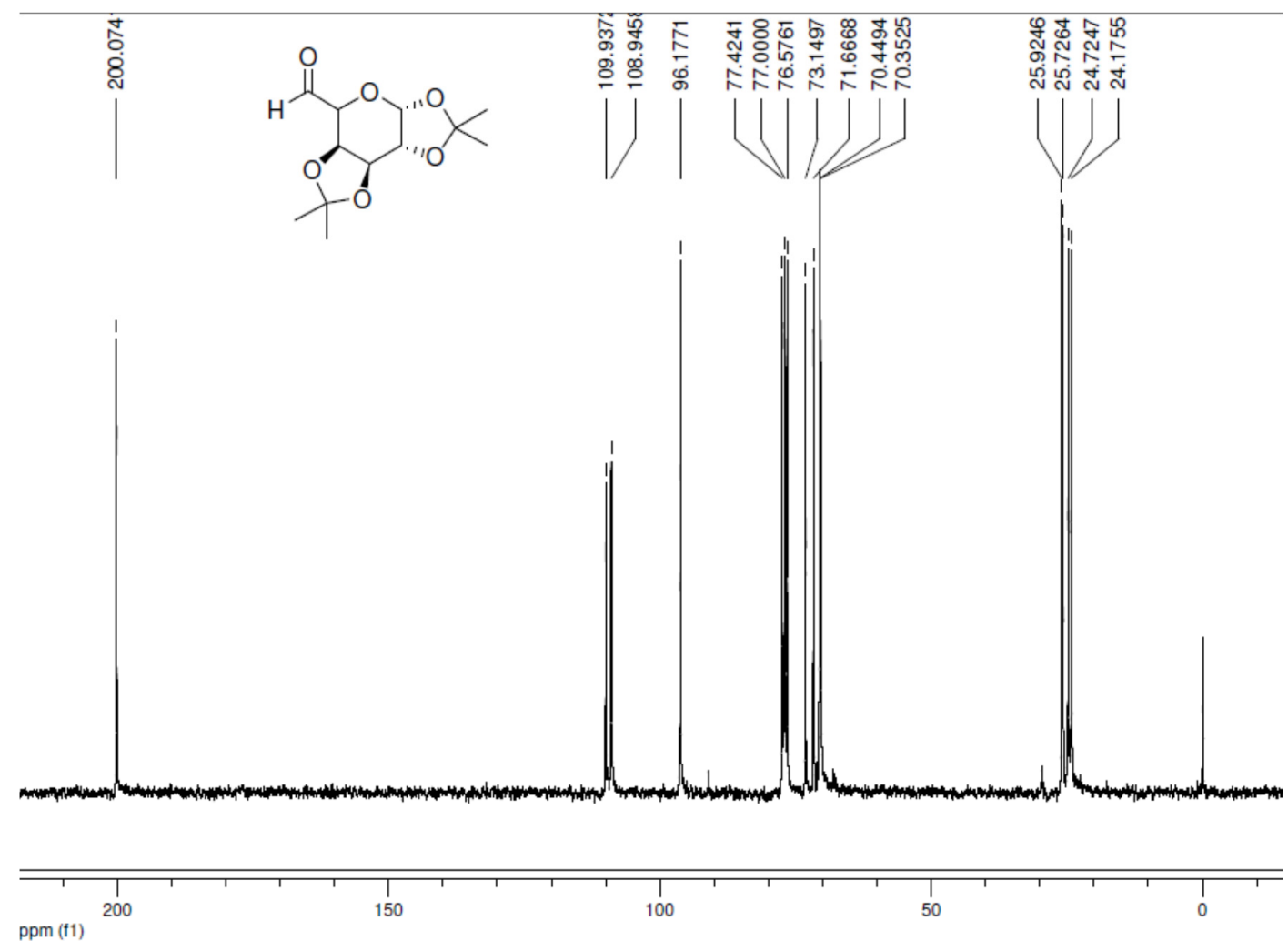

Figura 133. Espectro de $\mathrm{RMN}{ }^{13} \mathrm{C}$ a $75 \mathrm{MHz}$ do composto 57. 

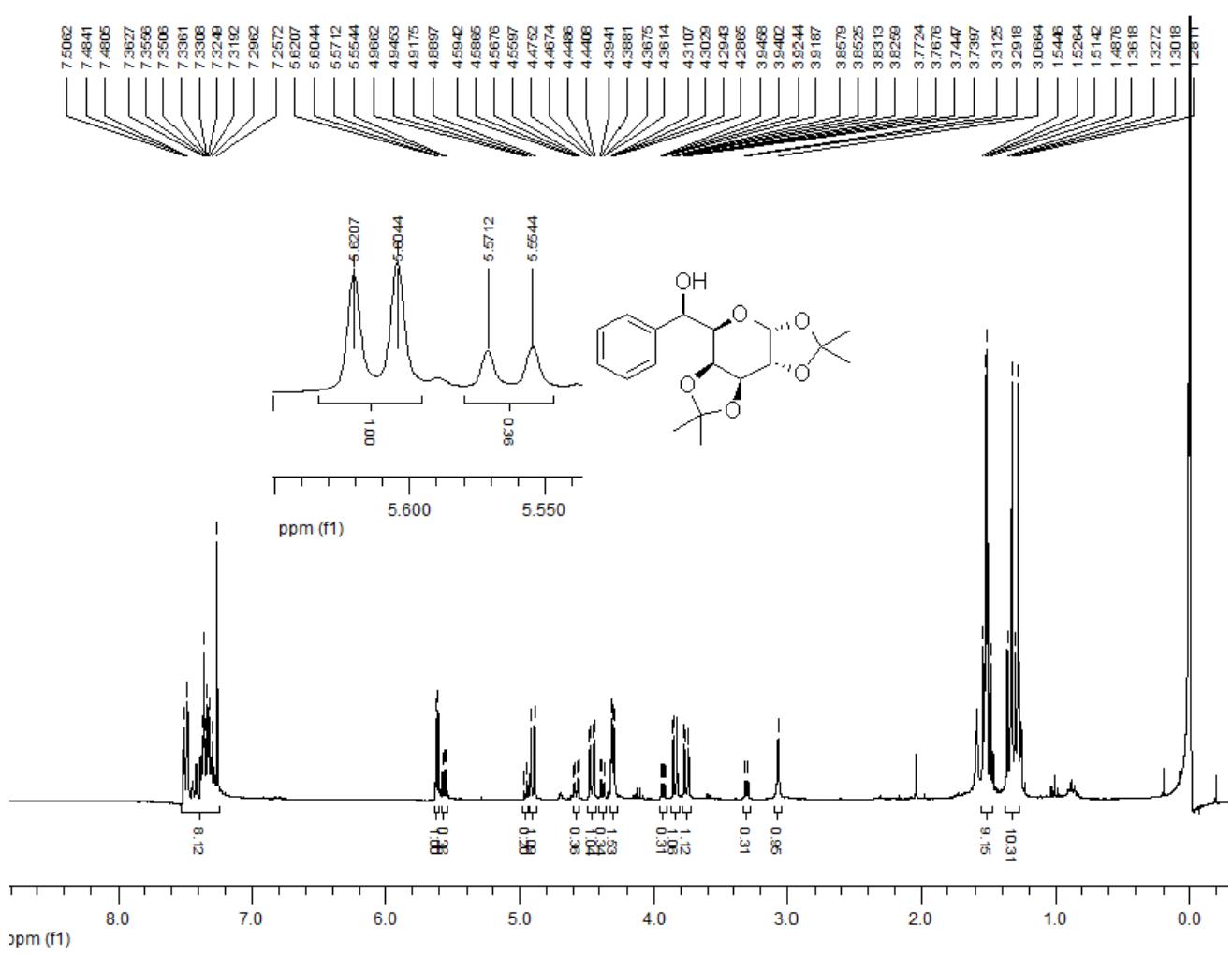

Figura 134. Espectro RMN ${ }^{1} \mathrm{H}$ a $300 \mathrm{MHzdo}$ composto 60a.
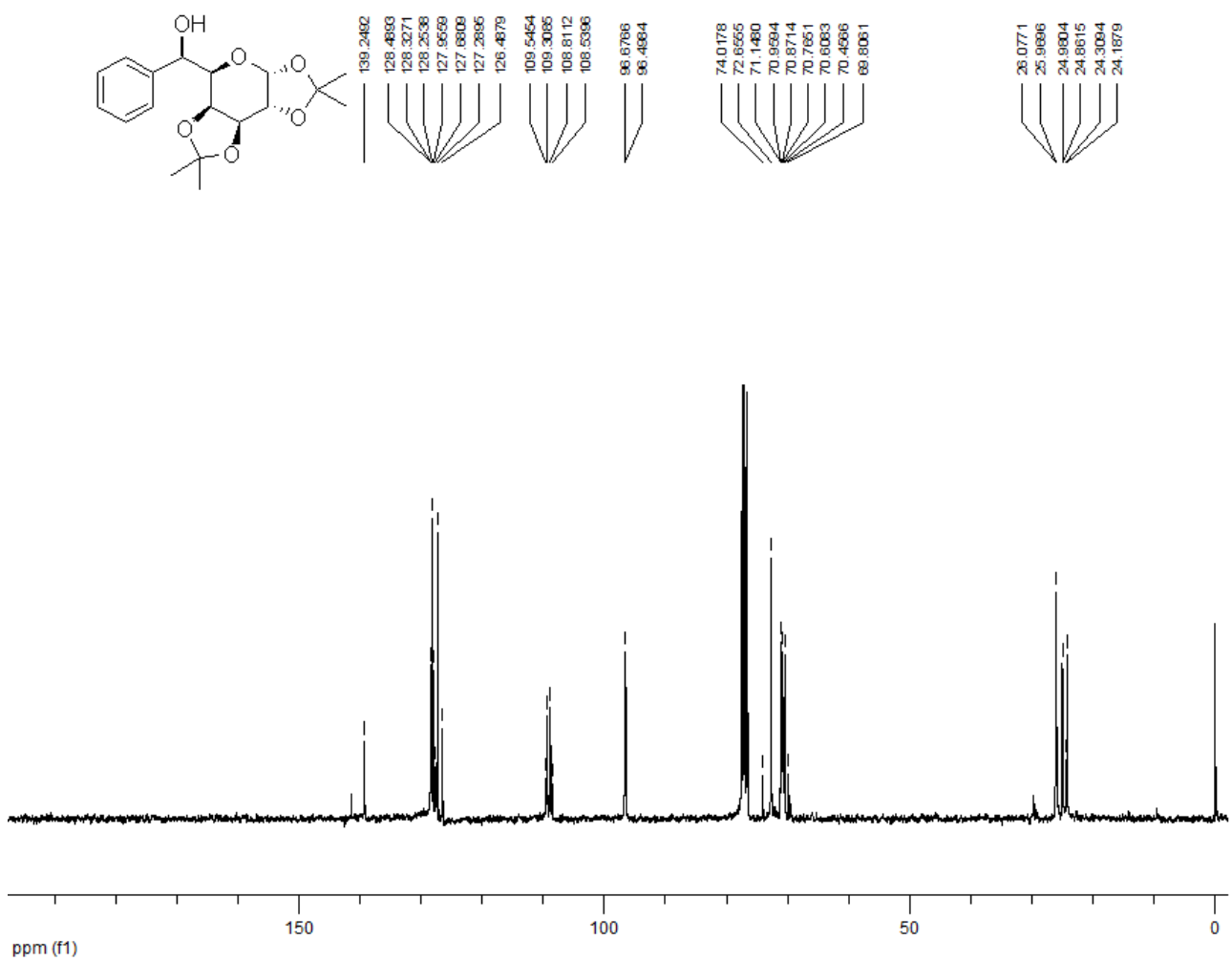

Figura 135. Espectro $\mathrm{RMN}{ }^{13} \mathrm{C}$ a $75 \mathrm{MHz}$ do composto60a. 


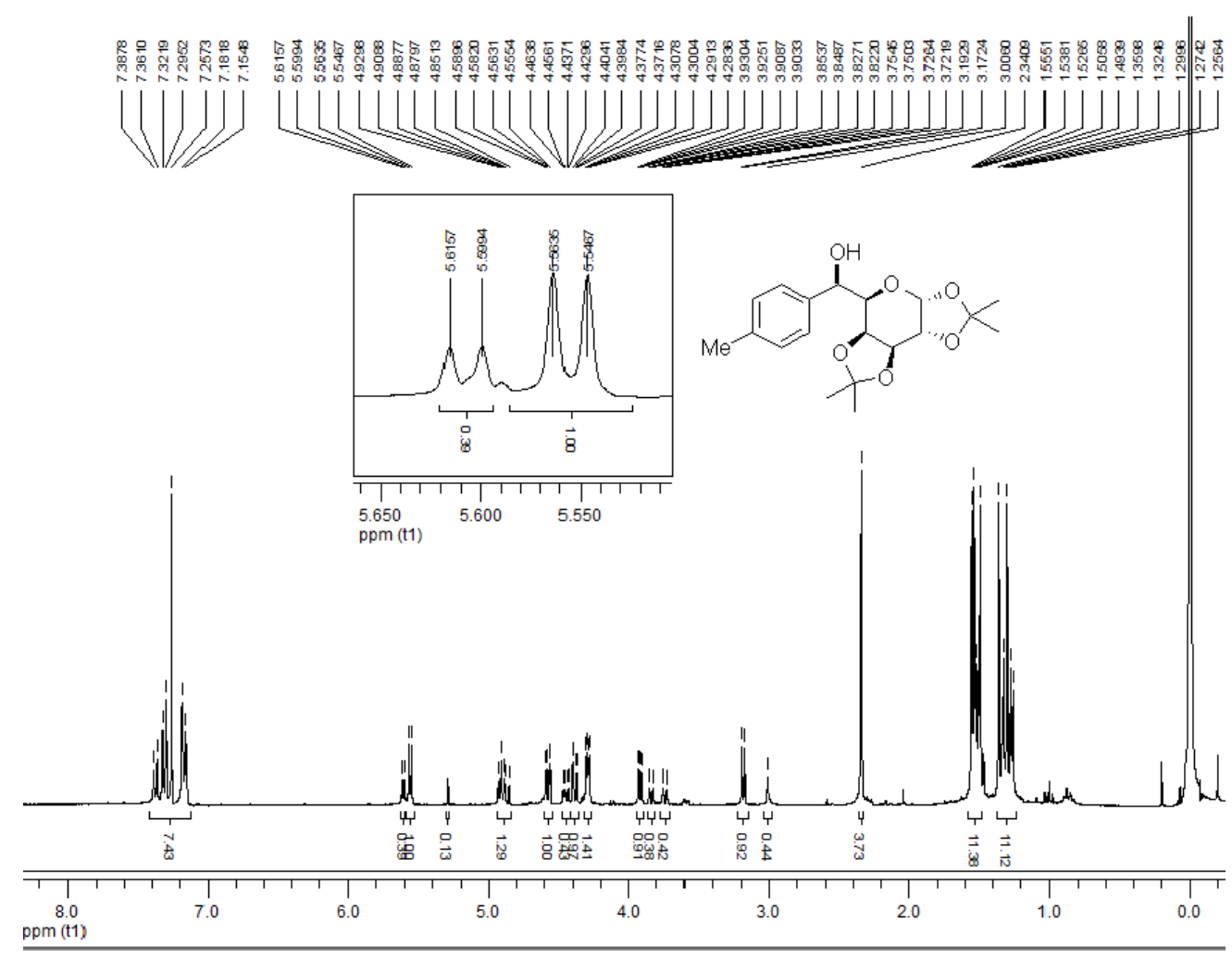

Figura 136. Espectro de $\mathrm{RMN}^{1} \mathrm{H}$ a $300 \mathrm{MHz}$ do composto $60 \mathbf{b}$.
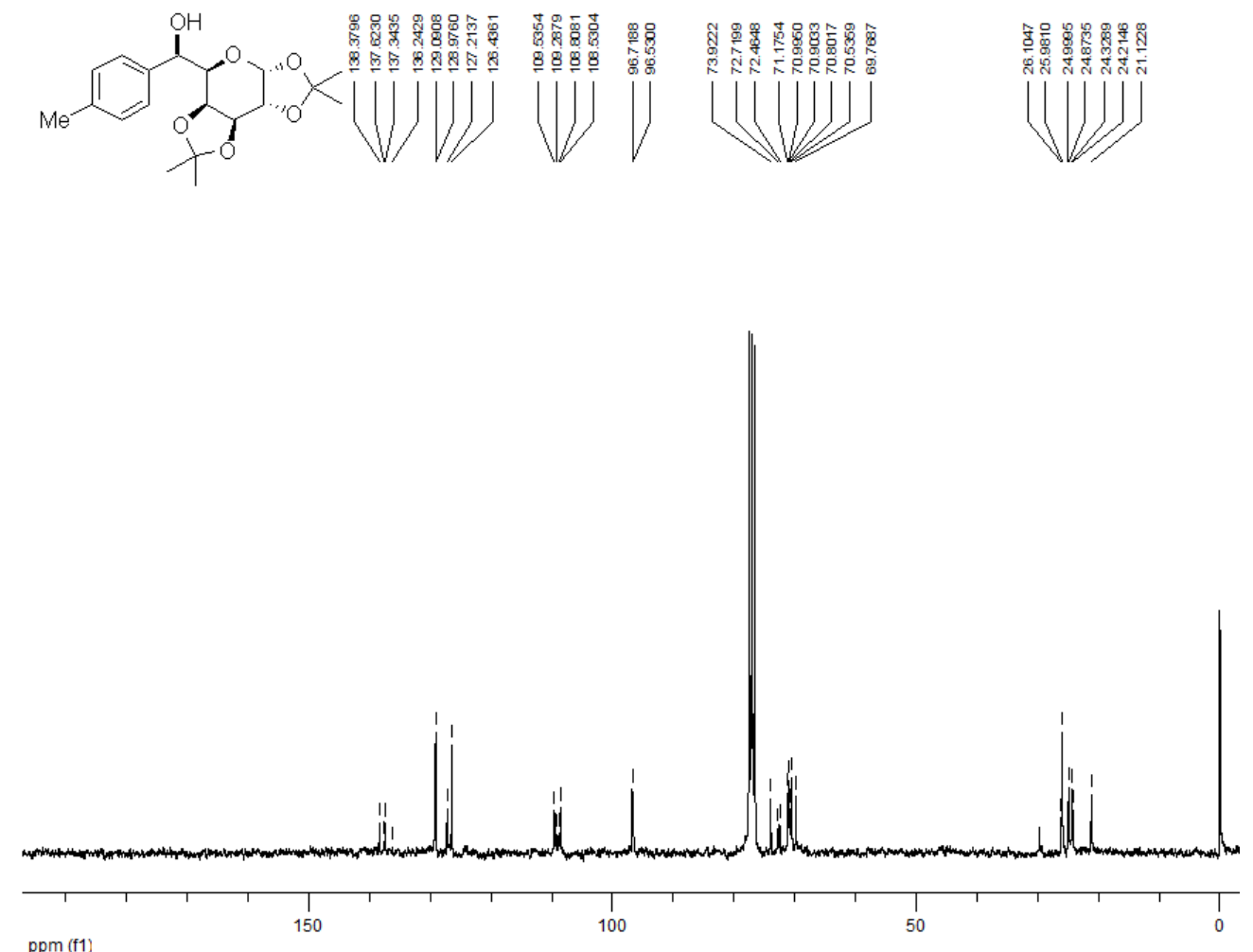

ppm (f1)

Figura 137. Espectro de $\mathrm{RMN}^{13} \mathrm{C}$ a $75 \mathrm{MHz}$ do composto $\mathbf{6 0 b}$. 


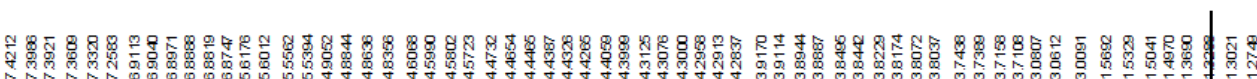
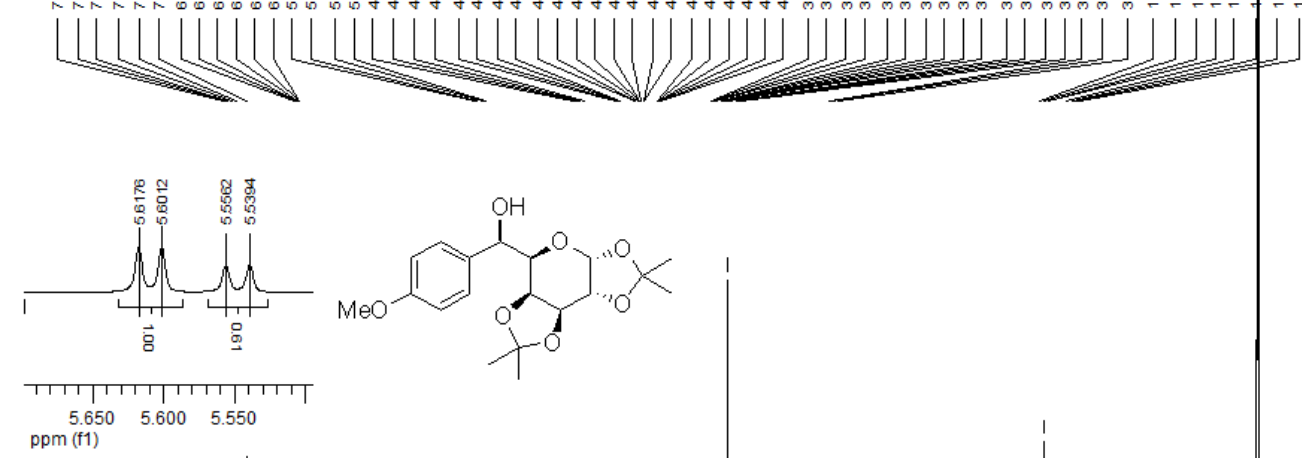

$\mathrm{ppm}(\mathrm{f1})$
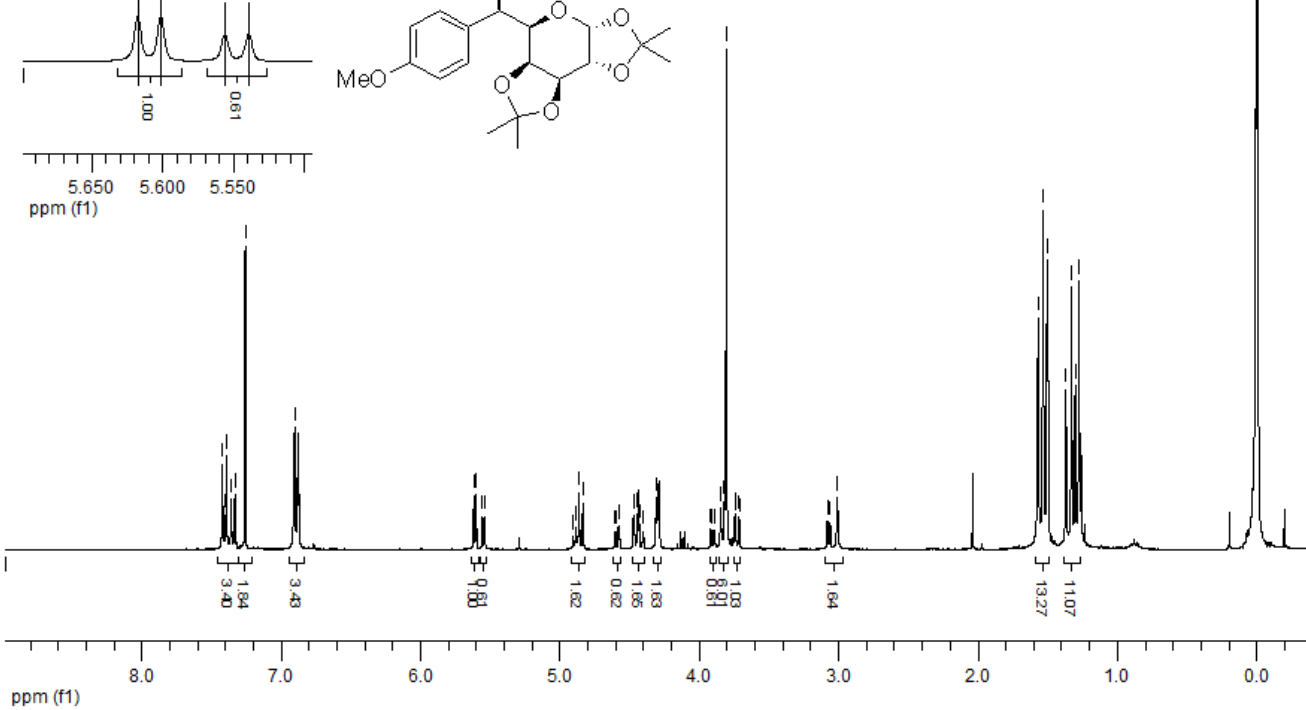

Figura 138. Espectro de $\mathrm{RMN}^{1} \mathrm{H}$ a $300 \mathrm{MHz}$ do composto $60 \mathrm{c}$.

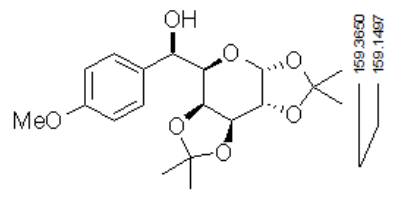
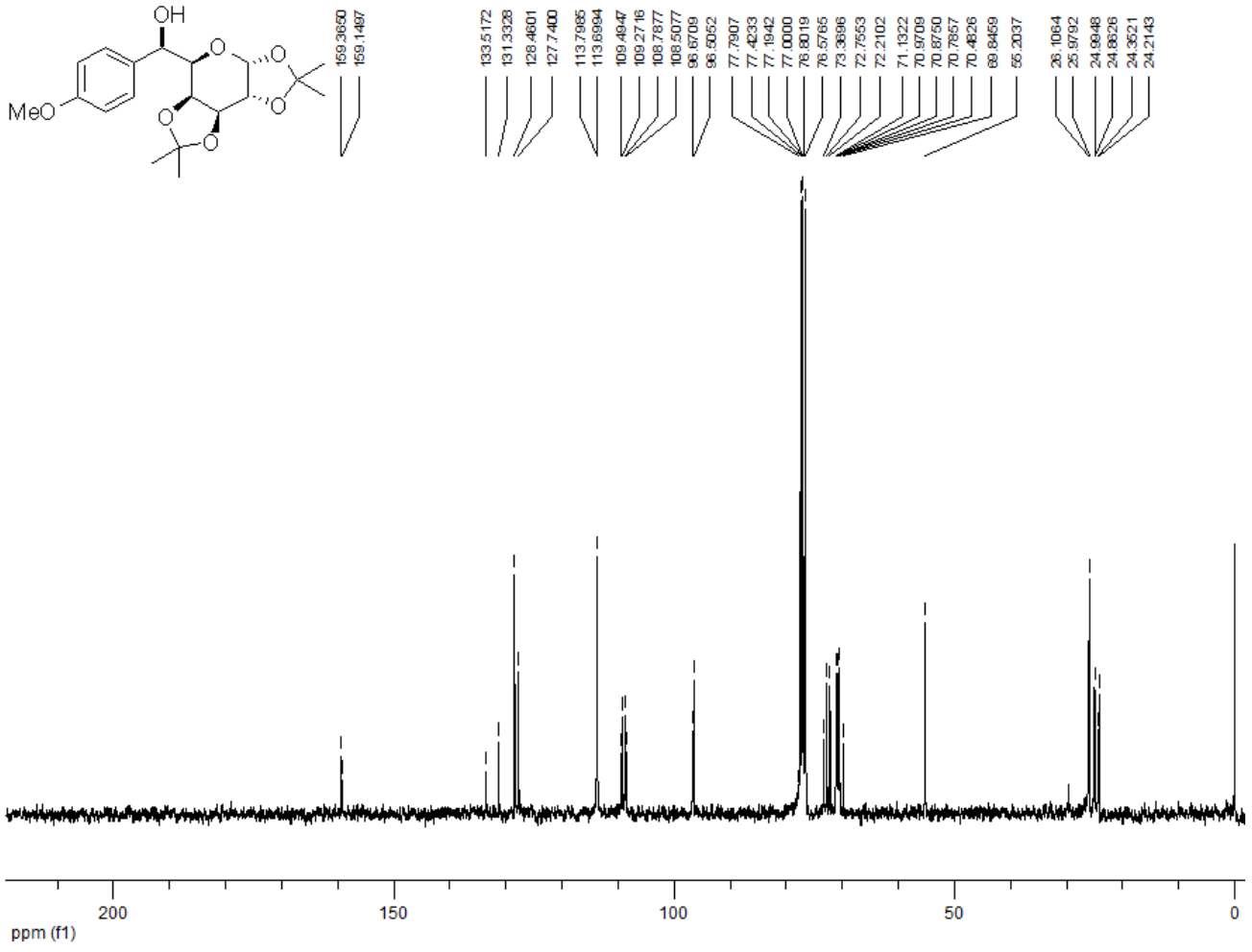

Figura 139. Espectro de $\mathrm{RMN}{ }^{13} \mathrm{C}$ a $75 \mathrm{MHz}$ do composto $60 \mathrm{c}$. 